University of Texas at El Paso

\title{
DigitalCommons@UTEP
}

Open Access Theses \& Dissertations

2013-01-01

\section{A Method to Reduce Plastic Shrinkage Cracking of Concrete Using Re-vibration Technique}

Mustafa Abushaala Aldalinsi

University of Texas at El Paso, maaldalinsi@miners.utep.edu

Follow this and additional works at: https://digitalcommons.utep.edu/open_etd

Part of the Civil Engineering Commons

\section{Recommended Citation}

Aldalinsi, Mustafa Abushaala, "A Method to Reduce Plastic Shrinkage Cracking of Concrete Using Re-vibration Technique" (2013). Open Access Theses \& Dissertations. 1570.

https://digitalcommons.utep.edu/open_etd/1570 


\title{
A METHOD TO REDUCE PLASTIC SHRINKAGE CRACKING OF CONCRETE USING THE RE-VIBRATION TECHNIQUE
}

\author{
MUSTAFA ABUSHAALA ALDALINSI
}

Department of Civil Engineering

\section{APPROVED:}

\author{
Carlos Ferregut, Ph.D., Chair
}

Cesar Carrasco, Ph.D.

Vivek Tandon, Ph.D.

Vinod Kumar, Ph.D.

Benjamin C. Flores, Ph.D.

Dean of the Graduate School 


\section{Copyright (C)}

by

Mustafa A. Aldalinsi

2013 


\section{Dedication}

To my parents

My brothers

My sisters

My wife

My kids

and

My friends 


\title{
A METHOD TO REDUCE PLASTIC SHRINKAGE CRACKING OF CONCRETE USING THE RE-VIBRATION TECHNUQIE
}

\author{
by \\ MUSTAFA ABUSHAALA ALDALINSI, M.Sc.
}

\author{
DISSERTATION \\ Presented to the Faculty of the Graduate School of \\ The University of Texas at El Paso \\ in Partial Fulfillment \\ of the Requirements \\ for the Degree of
}

DOCTOR OF PHILOSOPHY

Department of Civil Engineering THE UNIVERSITY OF TEXAS AT EL PASO

December 2013 


\section{Acknowledgements}

The author wishes to express his gratitude to Dr. Carlos Ferregut, Professor in the Department of Civil Engineering at the University of Texas at El Paso, for his help, patience, and guidance throughout this study. His continuous encouragement brought this study into completion.

Thanks are due to Dr. Cesar Carrasco, Professor and Chairman in the Department of Civil Engineering, Dr. Vivek Tandon, Associate Professor in the Department of Civil Engineering, and Dr. Vinod Kumar, Assistant Professor in the Department of Mechanical Engineering of UTEP, for their help and participating in the committee of the final examination of the author.

Thanks are also due to Jobe Materials, L. P. and Mr. Martin Alderette, Quality Control Manager in Jobe Materials, L. P., for their help and support of the author.

Thanks to all my family and friends for their support, and Libyan Ministry of Higher Education for giving me this opportunity to study in the US. 


\begin{abstract}
One of the problems that reduce durability; thus, performance of concrete is the development of plastic shrinkage cracking (PSC). Traditionally, the development of PSC has been minimized by controlling its exposure to weather conditions or by adding fibers. In this study, concrete re-vibration was used as an alternative technique to control PSC because of the limited availability of fibers in the developing countries. In this study, the wait time after slab casting and before vibration was selected to be 90 minutes while length of re-vibration time was varied from 15 to 45 seconds. Also, the water-cement ratios were selected to be $0.5,0.55$ and 0.6. The slabs were casted based on the form dimensions proposed by ASTM C1579 criteria. Image analysis of cracks was performed to process digital images of the cracks' widths and lengths to estimate crack growth. Cracks widths and lengths were unevenly reduced based on the watercement ratios and the lengths of re-vibration. Re-vibrated and fibered slabs showed similar reduction in cracks dimension. This technique and the fact that re-vibrating is cheaper than adding fibers makes the proposed approach a very suitable alternative for controlling plastic shrinkage cracks, especially in arid regions of the world.
\end{abstract}




\section{Table of Contents}

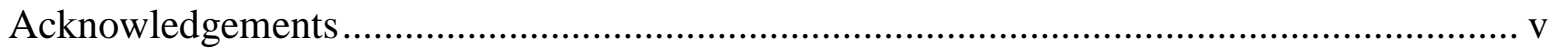

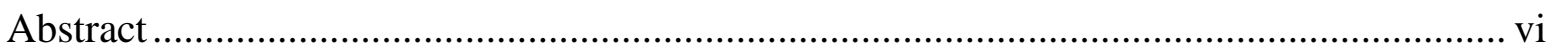

Table of Contents ..................................................................................................... vii

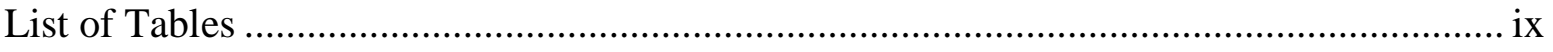

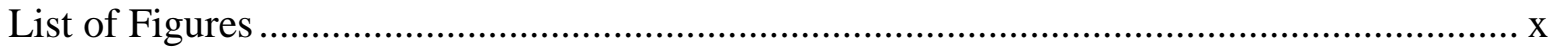

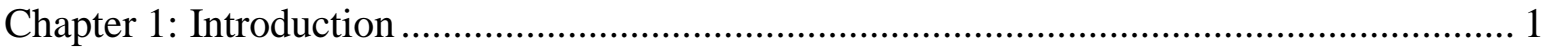

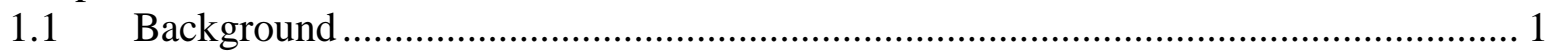

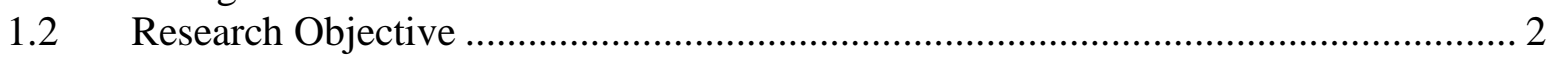

Chapter 2: Review of Literature ........................................................................... 4

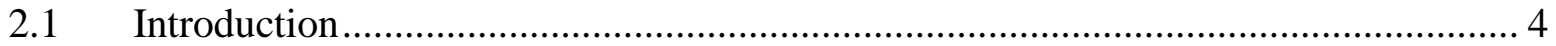

2.2. Mechanisms of Plastic Shrinkage Cracking .......................................................... 4

2.3. ACI Definition of Plastic Shrinkage Cracking ....................................................... 13

2.4. Factors Contributing to Plastic Shrinkage Cracking .......................................... 15

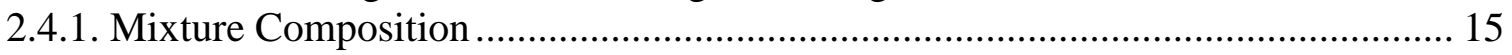

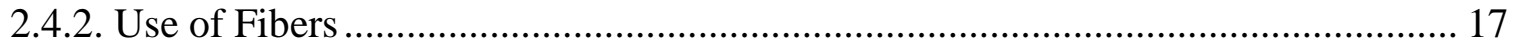

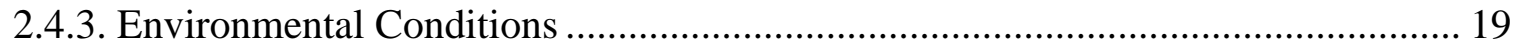

2.4. Test Methods for Evaluating Plastic Shrinkage Cracking ...................................... 23

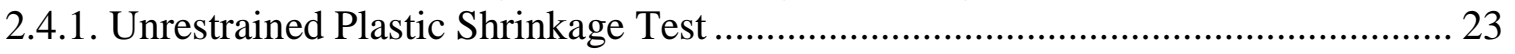

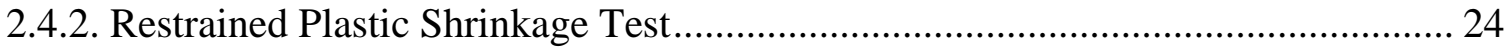

2.4.3 Standard Test Method for Evaluating Plastic Shrinkage Cracking .................... 28

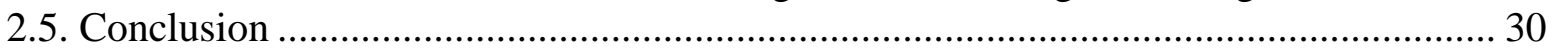

Chapter 3: Mechanisms of Concrete Vibration and Re-vibration .................................... 31

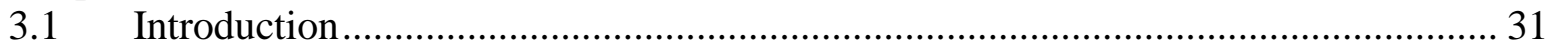

3.2 Mechanism of Concrete Vibration................................................................... 31

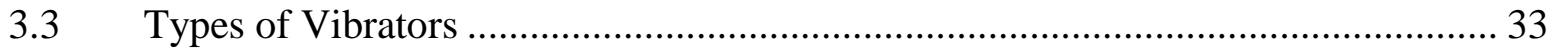

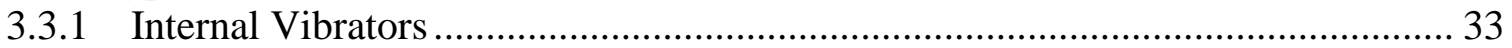

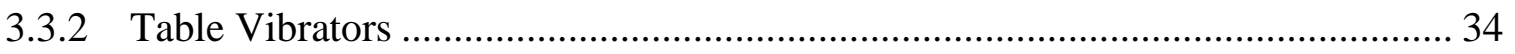

3.3.3 Surface Vibrators ................................................................................... 35

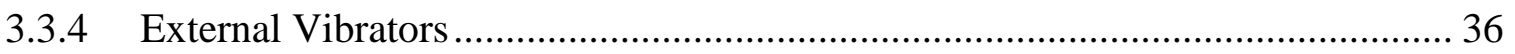

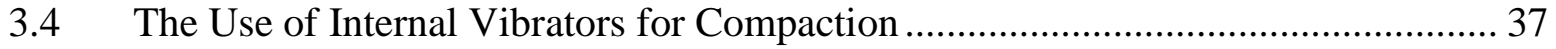

3.4.1 Influence of Compaction on Concrete Hardening ............................................ 38

3.4.2 Guidance for Using a Needle Vibrator ............................................................ 39

3.4.3 Time of Vibration Required for Full Compaction .......................................... 42

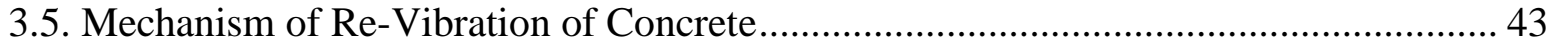

3.5.1. Influence of Re-Vibration on Some Concrete Properties .................................... 44

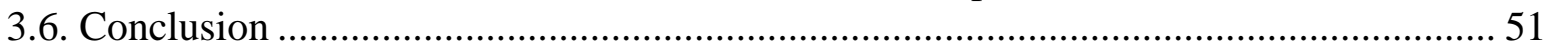

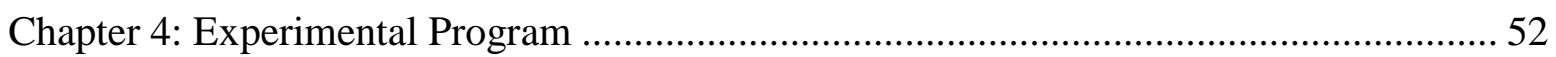

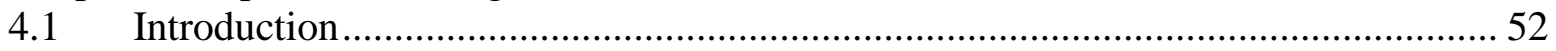

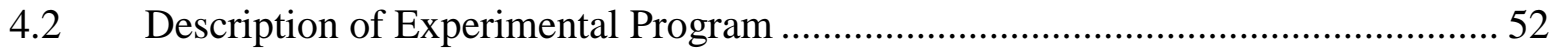

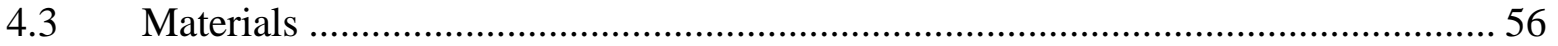

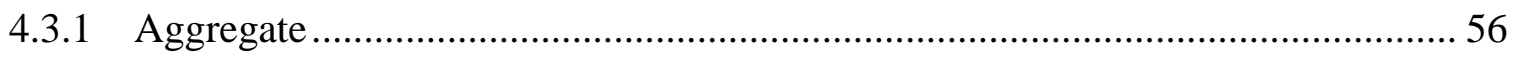




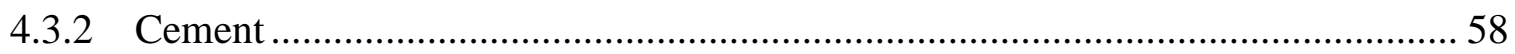

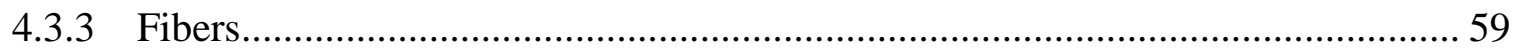

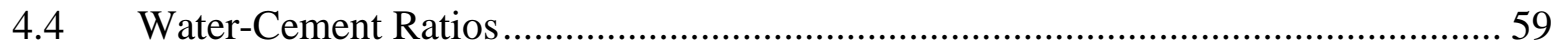

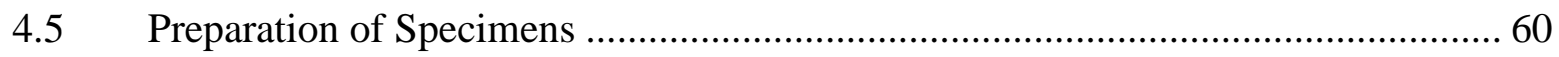

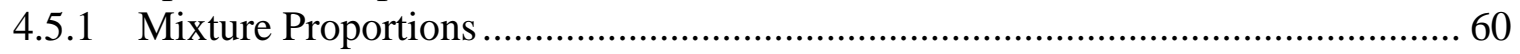

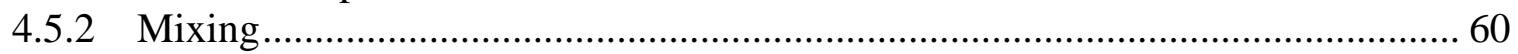

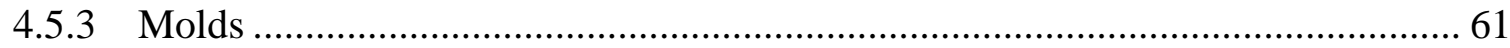

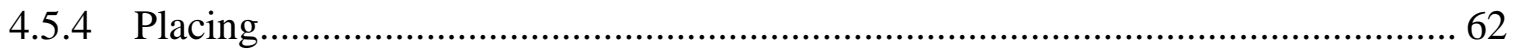

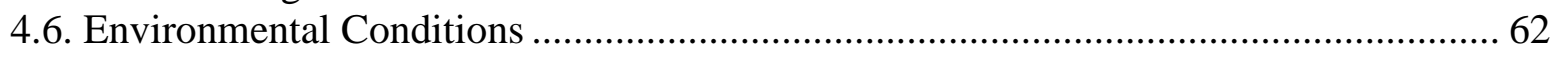

4.7 Re-Vibration Time Lag, Re-vibration Time Length and Re-Vibration Process....... 66

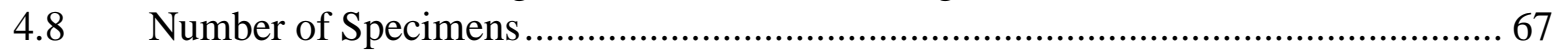

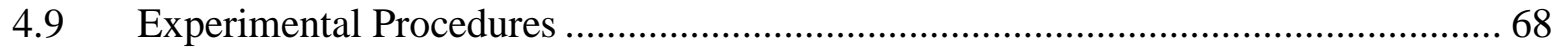

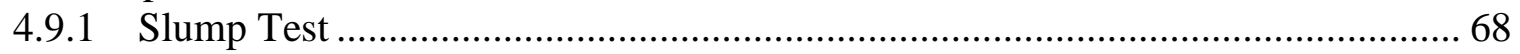

4.9.2 Compressive Strength Test ............................................................................ 70

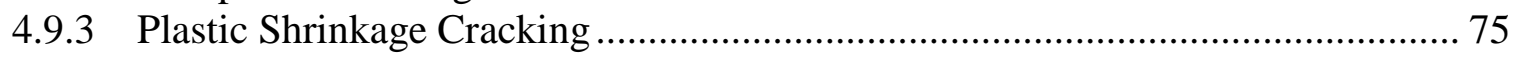

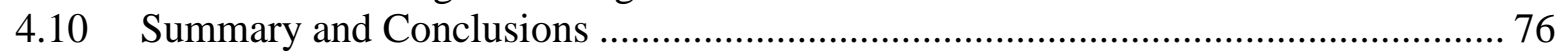

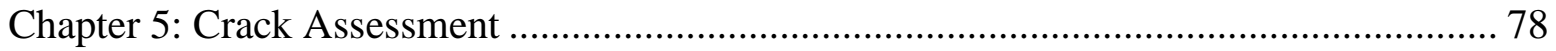

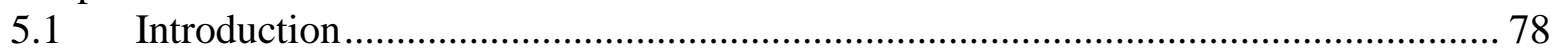

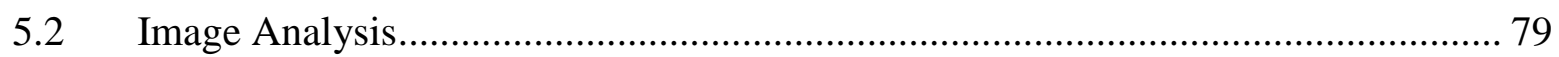

5.2.1 Background ............................................................................................ 79

5.2.2 Image Analysis Approach to Quantify Surface Plastic Shrinkage Cracking........ 80

5.2.3 Image Acquisition ...................................................................................... 83

5.2.4 Image Processing and Crack Measurement ....................................................... 85

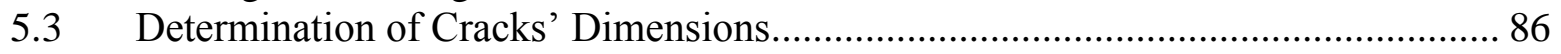

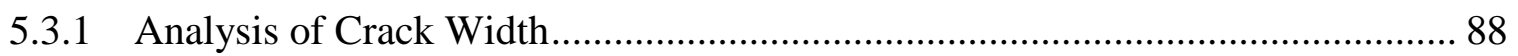

5.3.2 A Model to Predict the Time Length of Re-vibration........................................... 93

5.3.3 Total Crack Length ........................................................................................ 95

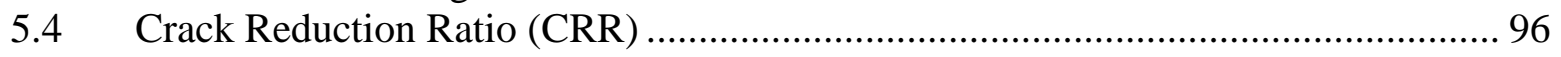

5.4.1 CRR of Average Crack Width .......................................................................... 97

5.4.2 CRR of Total Crack Length ............................................................................ 99

5.5 Growth of Cracks' Width and Length .................................................................. 101

5.5.1 Correlation between the Total Crack Length and Average Crack Width ........... 112

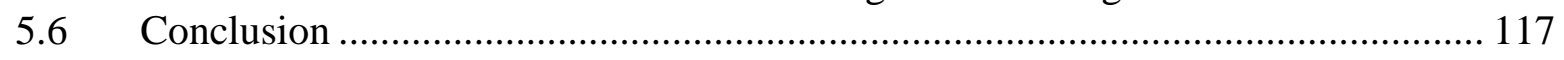

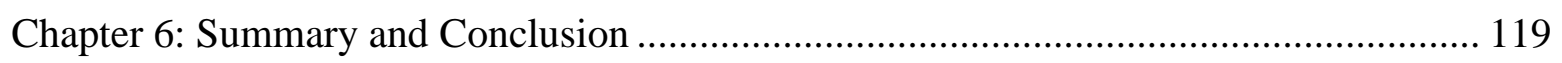

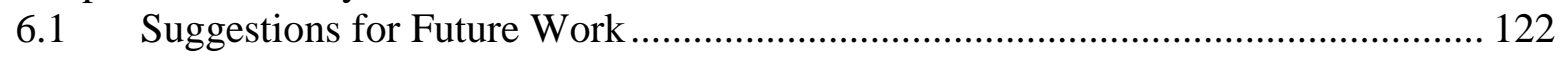

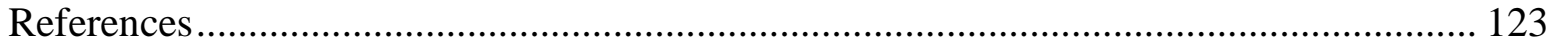

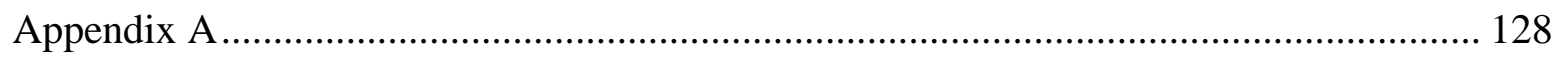

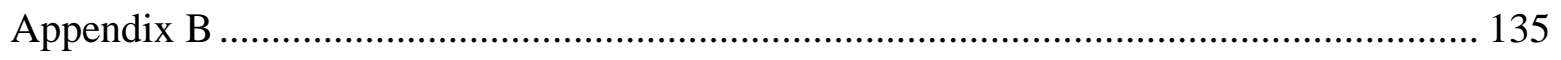

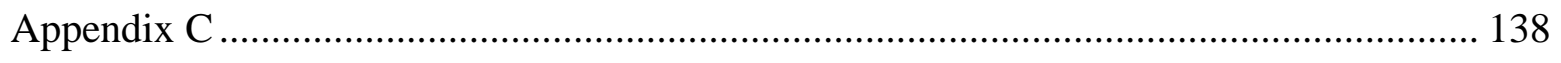

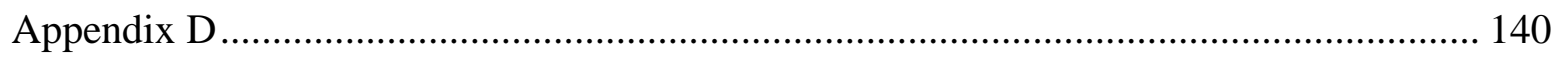

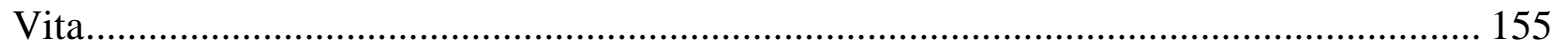




\section{List of Tables}

Table 2.1: Maximum tensile stress when the depth of gelatin cover is constant and spacing factors are varied (Weyers et al. 1982).

Table 2.2: Maximum tensile stress when the depths of gelatin cover are varied and the spacing factor is constant (Weyers et al. 1982)................................................................................... 12

Table 2.3: Experimental results of Pelisser et al. (2010) ............................................................ 19

Table 2.4: Fiber types and volume fractions (after Banthia et al. 1993) ……………................... 26

Table 3.1: Recommended accelerations and frequencies of concrete vibration

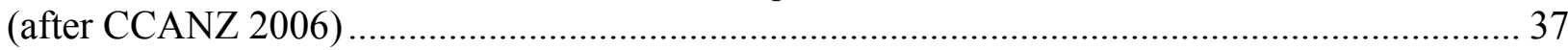

Table 3.2: Selection of internal vibrators (after CVH 2003) .................................................... 42

Table 4.1: ASTM designation numbers and physical properties of coarse and fine aggregates

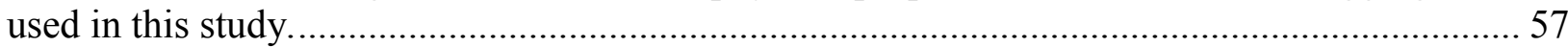

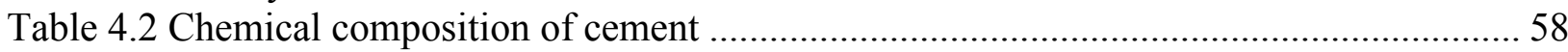

Table 4.3 Potential compound composition of cement............................................................. 58

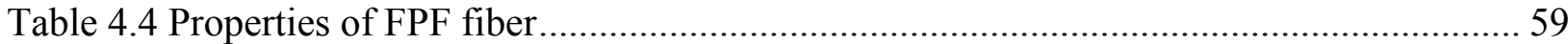

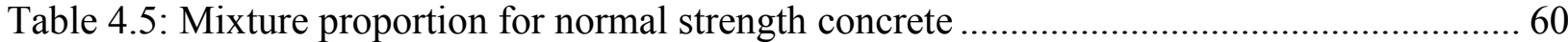

Table 4.6: Designated drying weather conditions and computed evaporation rates......................... 66

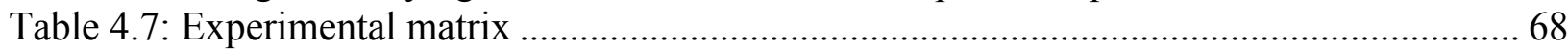

Table 4.8: Slump magnitude and description of workability of the concrete mixtures ................ 70

Table 4.8: Compressive strengths of concrete for initial vibrated, re-vibrated and fibered

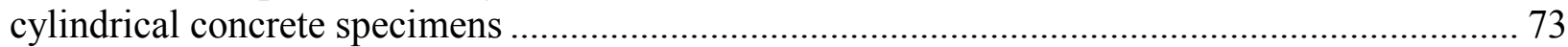

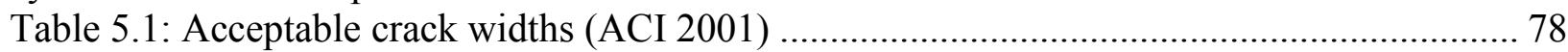

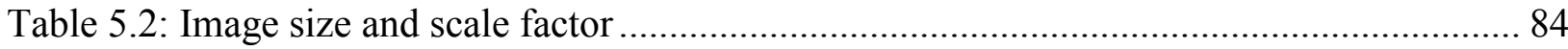

Table 5.3: Crack measurement of the cleaned crack images ....................................................... 86

Table 5.4: The average crack widths measured from the image analysis procedure.................... 92

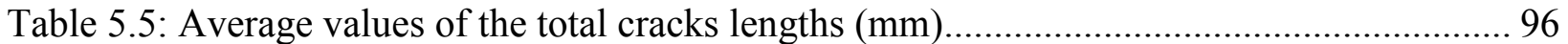

Table 5.6 a: Cracks widths and lengths for non-re-vibrated, fibered and re-vibrated slabs (when water-cement $=0.60$ )

Table $5.6 \mathrm{~b}$ : Cracks widths and lengths for non-re-vibrated, fibered and re-vibrated slabs (when water-cement $=0.55$ )

Table $5.6 \mathrm{c}$ : Cracks widths and lengths for non-re-vibrated, fibered and re-vibrated slabs (when water-cement $=0.5$ ) 


\section{List of Figures}

Figure 2.1: Schematic representation of a liquid filled joint between two spherical particles (after Wittmann 1976).

Figure 2.2: Plastic shrinkage and capillary pressure of concrete as a function of time (after Wittmann 1976) 7

Figure 2.3: Observed plastic shrinkage as a function of capillary pressure (after Wittmann 1976)7 Figure 2.4: Equipment for measurement of water pressure (after Radocea 1992) ......................... 8 Figure 2.5: Three major periods of development of capillary pore pressure (after Lane et al. 1997).....

Figure 2.6: Plastic settlement cracking: a) settlement cracks and b) differential settlement cracks

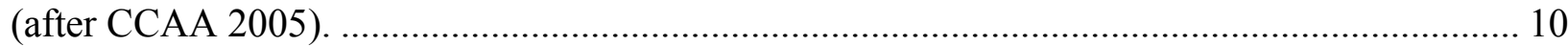

Figure 2.7: Settlement measurement by laser sensor (after Qi et al. 2003) ................................. 13

Figure 2.8: Role of FP and MP fibers in reducing plastic settlement (after Qi et al. 2003) ......... 13

Figure 2.9: How plastic shrinkage cracking develops ................................................................ 15

Figure 2.10: Average crack width measured from optical and automated image analyses for different volumes of fibers (after Qi et al. 2005) .................................................................... 18 Figure 2.11a: Nomograph for estimating the rate of evaporation of water from a concrete surface

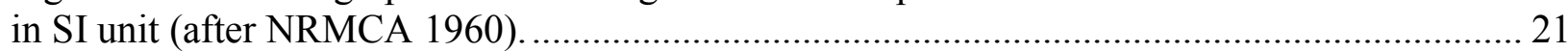
Figure 2.11b: Nomograph for estimating the rate of evaporation of water from a concrete surface

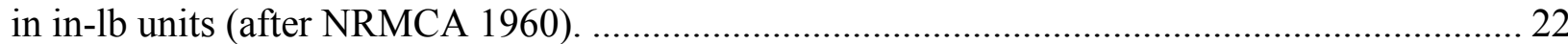

Figure 2.12: Plastic shrinkage apparatus (ASTM C827) ………………………………….... 24

Figure 2.13: Dimensions (mm) of the test set-up (after Banthia et al. 1993) ………................. 25

Figure 2.14-a: Maximum crack widths for macro fibers (after Banthia et al. 1993) ................... 26

Figure 2.14-b: Maximum crack widths for micro fibers (after Banthia et al. 1993) .................... 26

Figure 2.15: Schematic of the shrinkage test set up (after Banthia et al. 1996) ………………... 27

Figure 2.16: Effect of steel fibers on shrinkage cracking (after Banthia et al. 1996) ................... 28

Figure 2.17: Specimen and stress riser geometry (after ASTM C1579- 2013) ………………... 29

Figure 3.1: Significant factors in the rheology of fresh concrete (after Ritchie 1968) ................. 32

Figure 3.2: Principle of internal vibration (after ACI 1993) ................................................... 34

Figure 3.3: Principle of table vibration (after ACI 1993) …………………………………...... 35

Figure 3.4: Principle of surface vibration (after ACI 1993) …………………………............ 35

Figure 3.5: Principle of external vibration (after ACI 1993) ................................................... 36

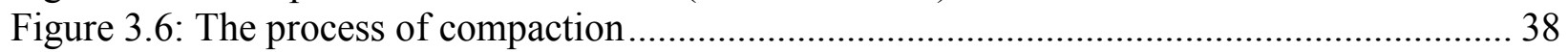

Figure 3.7: Loss of strength through incomplete compaction (after CCAA 2006) ....................... 39

Figure 3.8: Incorrect (a) and correct (b) placing of the needle in concrete

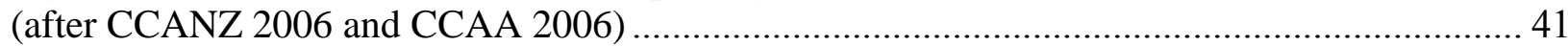

Figure 3.9: Compressive strength versus re-vibration time lag for fixed water-cement ratio

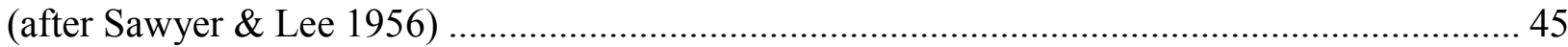

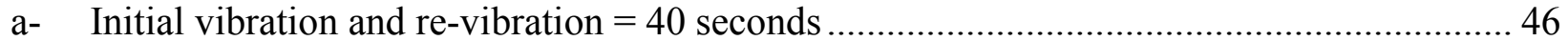

b- Initial vibration and re-vibration $=40$ seconds ........................................................... 46

Figure 3.10: Effect of re-vibration on compressive strength of laboratory-mixed concrete

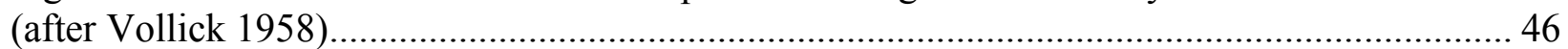
Figure 3.11: Effect of re-vibration on compressive strength (after Maclnnis \& Kosteniuk 1979)47 Figure 3.12: Compressive strength versus water-cement ratio (after Aldalinsi et al. 2003) ........ 48 
Figure 3.13: Compressive strength versus re-vibration time lag for water-cement $=0.53$

(after Aldalinsi et al. 2003)

Figure 3.14: Compressive strength versus re-vibration time lag for different water-cement ratios

(after Krishna et al 2008).... 50

Figure 3.15: Density versus re-vibration time lag for different water-cement ratios

(after Krishna et al 2008) 50

Figure 4.1: Concrete specimens inside the control room......................................................... 53

Figure 4.2: Layout of slab specimens inside the control room ............................................. 54

Figure 4.3: Handheld weather station Kestrel 3000 used in this study.................................... 54

Figure 4.4: Restrained slab mold dimensions (after ASTM C1579-2013)............................. 61

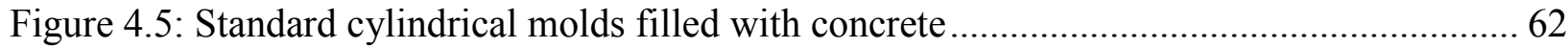

Figure 4.6: Variation of the air temperatures inside the control room.................................... 64

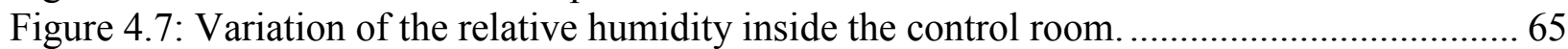

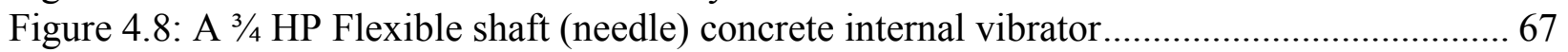

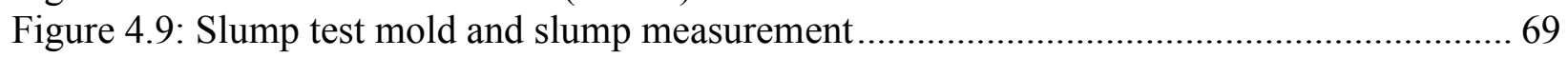

Figure 4.10: Testing compressive strength of concrete (a) cylindrical concrete specimens and (b)

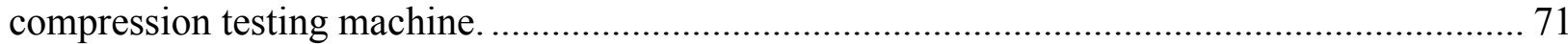

Figure 4.11: 28 day-compressive strengths of concrete for all the cylinders tested versus re-

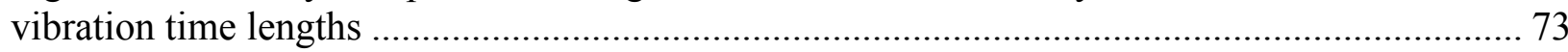

Figure 4.12: Average of 28 day-compressive strength versus re-vibration time lengths ............ 74

Figure 4.13: Air voids due to under-vibration of cylindrical specimens that were not-re-vibrated,

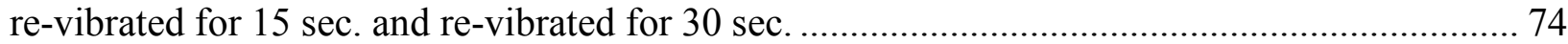

Figure 4.14: Compressive strength versus water-cement ratios ........................................ 75

Figure 4.15: Hairline cracks observed after 30 minutes from casting in some slab specimens ... 76

Figure 5.1: image analysis procedure, (a) image acquisition and (b) image processing ............. 81

Figure 5.2: Image analysis procedure for crack measurement ......................................... 82

Figure 5.3: Extraction of the cleaned crack images from original crack images....................... 84

Figure 5.4: How the average crack width was measured..................................................... 85

Figure 5.4: Different appearances of the developed cracks: a) Short and discontinued crack,

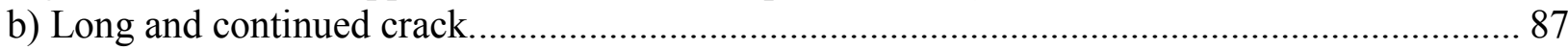

Figure 5.5: Typical crack patterns for concrete specimens made with a water-cement ratio of 0.6: a) non-re-vibrated, b) fibered, c) re-vibrated $15 \mathrm{~s}$, d) re-vibrated $30 \mathrm{~s}$, and e) re-vibrated $45 \mathrm{~s} . . .88$ Figure 5.6: Cleaned crack images for the specimens corresponding to non-re-vibrated concrete

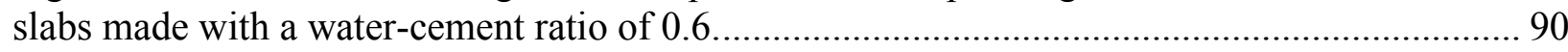
Figure 5.7: Histograms, cumulative distribution, fitting function, and statistical data of cracks widths for non-re-vibrated concrete slabs made with a water-cement ratio of $0.6 \ldots \ldots \ldots \ldots \ldots \ldots . . . . . . .91$ Figure 5.8: Average values of the cracks' width for all slabs versus the water-cement ratios ..... 93 Figure 5.9: Relationship among average cracks widths, water-cement ratios and re-vibration time lengths of tested slab specimens and the best fit model, using 3-D plot. ................................ 95 Figure 5.10: Average values of the total cracks lengths for all slabs versus water-cement ratios 96 Figure 5.11: Crack reduction ratios (CRR) of the average crack widths for fibered and re-

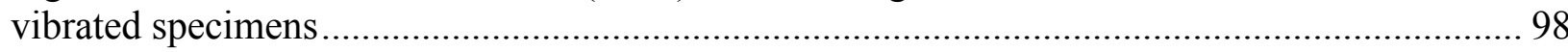
Figure 5.12: Crack reduction ratios (CRR) of the total crack lengths for fibered and re-vibrated

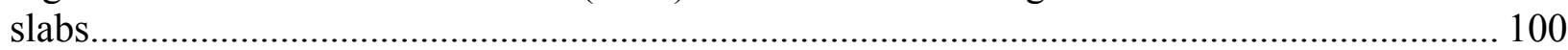

Figure 5.13: Average cracks widths vs. time for a water-cement ratio of 0.60 ...................... 106 Figure 5.14: Average cracks widths vs. time for a water-cement ratio of $0.55 \ldots \ldots \ldots \ldots \ldots \ldots \ldots . . . \ldots 107$ 
Figure 5.15: Average cracks widths vs. time for a water-cement ratio of $0.5 \ldots \ldots \ldots \ldots \ldots \ldots \ldots . . . . . . . . . . .108$

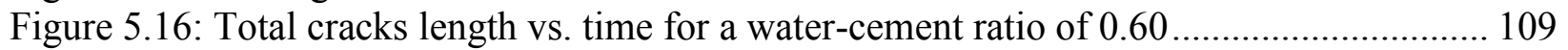

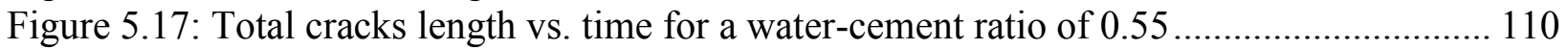

Figure 5.18: Total cracks length vs. time for a water-cement ratio of $0.5 \ldots \ldots \ldots \ldots \ldots \ldots \ldots \ldots \ldots \ldots . . . . . . . . . . .111$

Figure 5.19: Correlation between the total cracks lengths and the average crack widths: a) watercement ratio of $0.6, b)$ water-cement ratio of 0.55 , and c) water-cement ratio of $0.5 \ldots \ldots \ldots \ldots . . . .117$ 


\section{Chapter 1: Introduction}

\subsection{BACKGROUND}

For several decades, the design of concrete has been considered for strength and durability performance. Cracks are clearly a problem that has effects on concrete strength and durability. Although the concrete cracks can occur due to different factors such as weather conditions and concrete settlement, controlling such cracks requires special attention in order to produce reliable and good looking concrete structures.

Early age deterioration of concrete is a continual problem that arises from rapid complex volume changes such as plastic and dry shrinkage. These volume changes cause tensile stresses in the material when strength is still relatively low. The resultant stresses may cause immediate cracking which leads to premature deterioration, affects integrity, durability and long-term service life of a concrete structure (ACI 2000).

One common type of early age deterioration of concrete that frequently occurs is the development of plastic shrinkage cracking, which appears on the surface of fresh concrete within the first few hours after the concrete is cast. Plastic shrinkage cracking can be a problem in concrete structures subjected to a hot, humid and windy environment because a rapid loss of water from the surface of concrete before it has set. These weather conditions are indicators to determine if the plastic shrinkage cracks will develop (NRMCA 1960).

Crack width is traditionally identified as the most important factor that affects the longterm durability of concrete, and it can be quite wide on the upper surface, 2 to $3 \mathrm{~mm}(0.08$ to $0.12 \mathrm{in}$ ), but the width often decreases rapidly below the surface. It is probable that the subsequent events, including drying shrinkage and loading, can cause the plastic shrinkage cracks to propagate (TRC 2006).

Numerous strategies have been proven to reduce the potential for plastic shrinkage cracking and the effectiveness of each strategy has to be adequately quantified to assess the cost and benefit associated with each approach. Controlling the effects of weather conditions has been 
recommended as one solution to prevent an early age cracking (Snell 2008). Also, low volumes of randomly distributed short fibers have been studied as another solution to control plastic shrinkage cracking (Qi at el 2003).

An ASTM test method exists to quantify the plastic shrinkage cracking behaviour of concrete mixture, ASTM C1579 (ASTM 2013). This method was standardized as a test method to evaluate the plastic shrinkage cracking of restrained fiber reinforced concrete. Due to the study of re-vibration technique of concrete as a method to reduce the plastic shrinkage cracking, the consideration of using the same test method is reported as a possible approach to evaluate the plastic shrinkage cracking of restrained reinforced concrete slabs exposed to internal vibration.

\subsection{RESEARCH OBJECTIVE}

The re-vibration technique of fresh concrete is used for durability, improving some concrete properties and cost effectiveness of mixture design. This study addresses the plastic shrinkage cracking phenomena and tests the use of the re-vibration of concrete after one and half hours from concrete placing to reduce the plastic shrinkage cracking.

An experimental program is adopted based on ASTM C1579 criteria (ASTM 2013) to assess plastic shrinkage cracking exposed to re-vibration. Restrained slab specimens similar to the one described in ASTM were used to evaluate the potential for plastic shrinkage cracking for concrete mixtures (containing one type and volume of fiber) exposed to a controlled drying environment.

Water cement ratios are considered to be high ratios $(0.5,0.55$ and 0.6$)$ to give good workable concrete and wet surface recommended in hot and dry weather areas (ACI 1999). Time lag to re-vibrate concrete is chosen to be 1.5 hours because it showed improvement in compressive strengths and densities, as reported in the technical literature. Also, the lengths of re-vibration time are fixed based on the researcher's experience.

The repeatability of adopted test method is considered. This is necessary if the test is to be used as a standard test for assessing plastic shrinkage cracking. Experiments are conducted to 
study the cracks' growth to determine how plastic shrinkage cracking propagates from the time it occurs until the end of the plastic stage ( $24 \pm 2$ hours). Also, the standard compression test of concrete is conducted to show the influence of concrete re-vibration on the 28 days-compressive strengths of concrete. 


\section{Chapter 2: Review of Literature}

\section{$2.1 \quad$ INTRODUCTION}

This chapter provides a summary of current research in the field of early age shrinkage cracking, which is defined in this study as a crack occurring between the time the concrete is placed and the following 24 hours. The previous work oriented to understand the mechanisms responsible for plastic shrinkage cracking and the contributing factors are presented herein. This chapter also reviews, and discusses the efficiency and limitations of the test methods that were developed and used in research conducted over the past 30 years to quantify plastic shrinkage cracking.

\subsection{Mechanisms of Plastic Shrinkage Cracking}

There has been a significant amount of research oriented to understand the mechanisms that lead to plastic shrinkage cracking. Two schools of thought regarding the mechanisms responsible for plastic shrinkage cracking are typically acknowledged. The most commonly recognized mechanism is the development of capillary stress near the surface of concrete, which is characterized by the imbalance between the evaporation rate and the bleeding rate (Powers 1968, Ravina \& Shalon 1968, Wittmann 1976, Radocea 1992, and Lane et al 1997). The other commonly recognized mechanism is plastic settlement (Weyers et al 1982, Qi et al 2003, and CCAA 2005). Both mechanisms are described in detail in the following sections.

According to Ravina \& Shalon (1968), bleeding and evaporation occur in fresh concrete in three stages, which are related to the volume contraction of early-age concrete. In the first stage, the bleeding exceeds evaporation, and the surface of concrete remains wet. During this stage there is no volumetric contraction at the surface of the concrete, and even some expansion may be observed. In the second stage, the rate of evaporation exceeds the bleeding rate, so the amount of volume contraction at the surface is proportional to the water that is removed from the fresh concrete system, and a linear relation is frequently observed between time and shrinkage. During the second stage, water channels may collapse due to the low strength the concrete has 
gained, forming a more dense structure. In the third stage, the volumetric contraction decreases considerably as concrete gains rigidity due to the hydration processes. If the concrete surface has developed sufficient tensile strength, cracks do not form. However, if the surface dries before sufficient tensile strength develops, cracks will occur.

Wittmann (1976) presented a theoretical analysis of capillary pressure to explain the mechanism of plastic shrinkage cracking. He stated that when rapid moisture loss occurs on the surface of fresh concrete, it cannot be substituted by bleeding water rising to the surface. Therefore, water between particles near the surface dries and forms a curved liquid surface, causing a surface meniscus. Figure 2.1 shows a schematic of menisci. In the figure the radii that define the curvature of the surface of the liquid and the attractive force that acts between particles are shown. Continuation of drying changes the radius of capillary meniscus over time. Wittmann used a water filled plastic hose connected to an electrical pressure transducer to monitor and measure changes in capillary pressure in fresh concrete casted in a $15 \times 15 \times 70 \mathrm{~cm}$ prismatic mold. All experiments were carried out with the following conditions: wind speed of 4 $\mathrm{m} / \mathrm{sec}$, air temperature of $20{ }^{\circ} \mathrm{C}$, relative humidity of $50 \%$, and cement content of $350 \mathrm{~kg} / \mathrm{cm} 3 \mathrm{The}$ author's results are shown in Figure 2.2. Figure 2.2 shows the capillary pressure after one hour from concrete casting built up slowly in the mixing water. After about two hours, the increment of capillary pressure was considerably large until, after three to four hours, a maximum value was reached. The capillary pressure suddenly dropped after the maximum value was reached. The arrangement of water in the capillaries of the dispersed system became unstable and as a result, it was redistributed. The maximum pressure was called breakthrough pressure. When breakthrough pressure was reached, the remaining water no longer filled all voids in the dispersed system and the capillaries became smaller and a ring of capillary water formed between two individual particles, as shown in figure 2.1. Therefore, when the breakthrough pressure was reached, no pressure was recorded. Also, the plastic shrinkage was plotted in the figure and the similarity of the two curves was noted in the first few hours. However, stability was observed in the plastic shrinkage after the breakthrough pressure was reached. In addition, 
the author showed the relationship between capillary pressure and plastic shrinkage in Figure 2.3. In the figure, the observed deformation of the plastic shrinkage occurred in the first period, which was directly proportional to the capillary pressure measured at the same time. As the hydration process continued, the fresh concrete became stiffer; therefore, increasing differences of the capillary pressure were needed to cause a certain amount of contraction. The compaction reached by the plastic shrinkage also contributed to the fact that the plot slope gradually decreased. Furthermore, little contraction in the plot occurred after breakthrough pressure was reached. The author concluded that breakthrough pressure exists where a sudden change in capillary pressure can be measured. This breakthrough pressure is reached at a time when the critical conditions that are responsible for plastic shrinkage cracking are established.

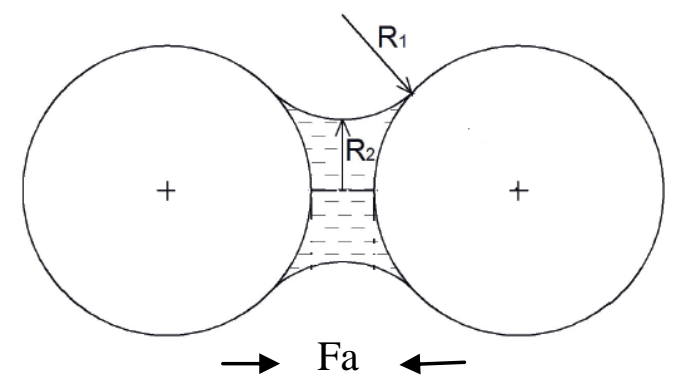

Figure 2.1: Schematic representation of a liquid filled joint between two spherical particles (after Wittmann 1976) 


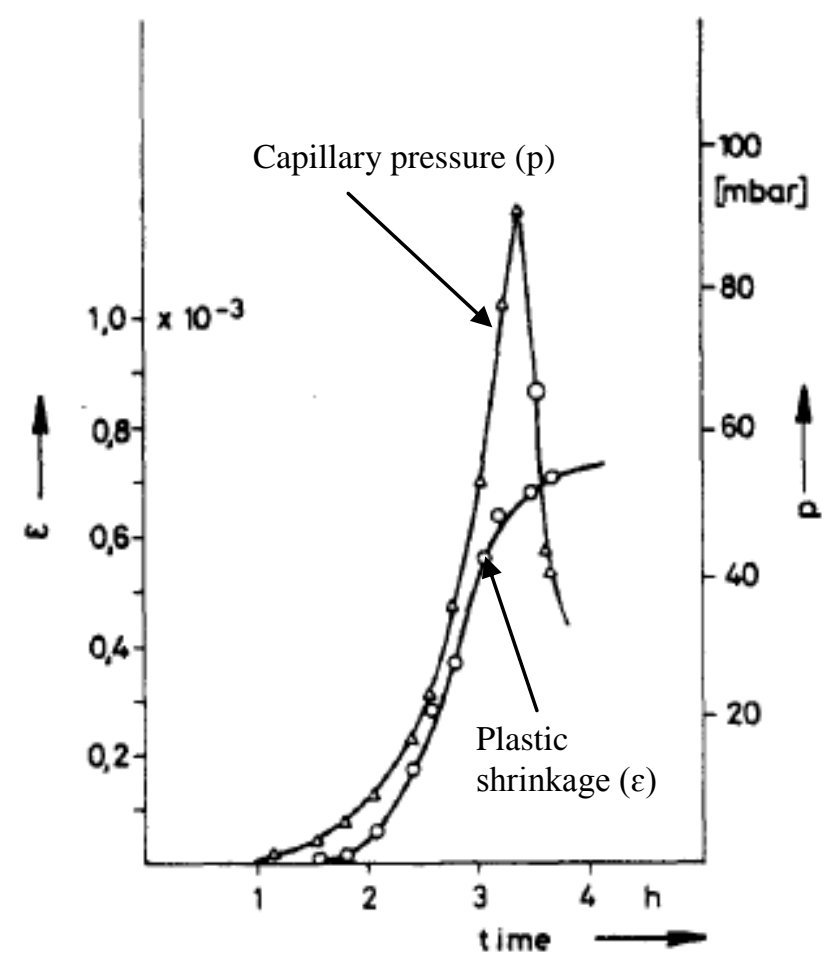

Figure 2.2: Plastic shrinkage and capillary pressure of concrete as a function of time (after Wittmann 1976)

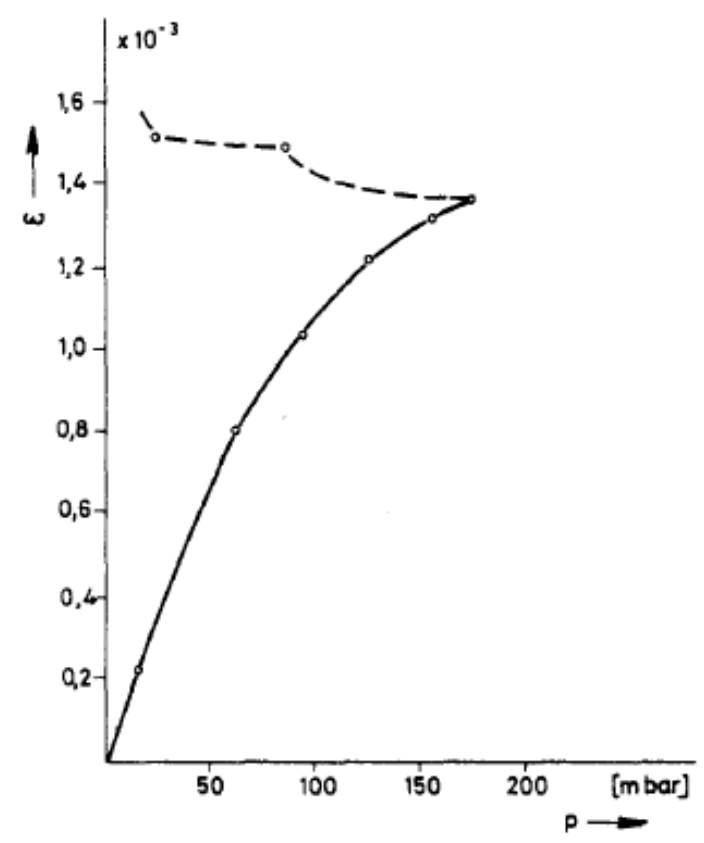

Figure 2.3: Observed plastic shrinkage as a function of capillary pressure (after Wittmann 1976) 
Radocea (1992) used the same measurement system used by Wittmann (1976) with improved accuracy to quantify the capillary pressure developed in cementitious materials as it is shown in Figure 2.4. In this system, water pressures were measured by two sensors at two different depths, 25 and $40 \mathrm{~mm}$, and the depth of the sample container was selected so that the bleeding process would be finished during the dormant period (time period that concrete retains its workability). Radocea's experiment consisted of measuring the changes of water pressure during sedimentation in the mixtures tested. The mixtures had a lower concentration of cement particles than the concentrations of the other materials. The mixtures also had liquid fractions ranging from 0.792 to 0.958 , and cement pastes with water-cement ratios ranging from 0.3 to 1.0. He concluded that for "normal" water-cement ratios (e.g. 0.5 to 1.0), the measurement of changes in water pressure in cement pastes only determined the total time of bleeding. However, he assumed that cement paste is composed of equal layers of particles and this was confirmed by the fact that the relative pressures at different depths are alike.

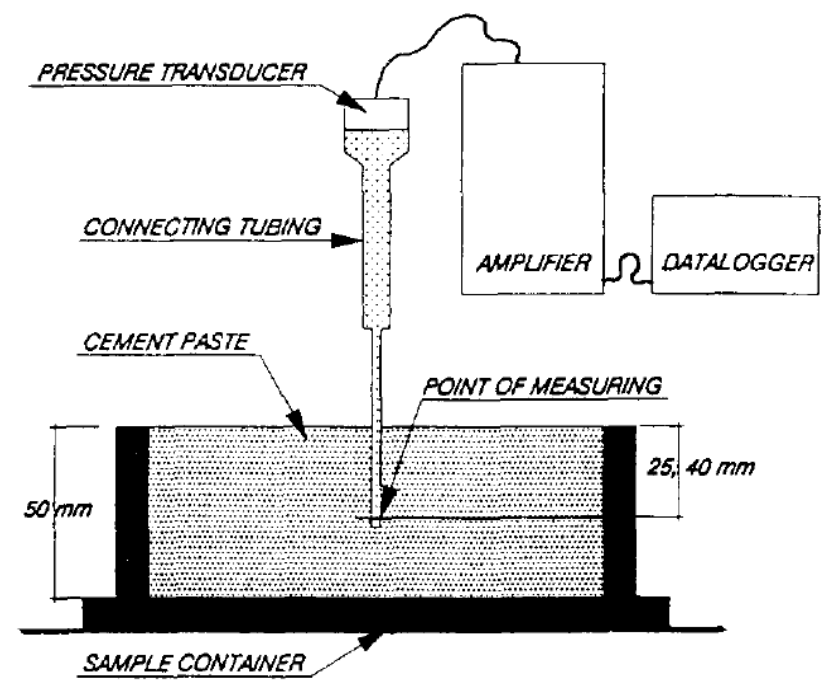

Figure 2.4: Equipment for measurement of water pressure (after Radocea 1992) 
Lane et al. (1997) designed an experimental procedure to investigate the basic physical processes that occur in concrete for periods of several hours to several days after mixing. They concluded that the development of capillary pore pressure at early stages in a concrete mass appears to be a basic physical parameter controlling the occurrence of plastic shrinkage cracking. This was Wittman's conclusion as well. Figure 2.5 shows the development of capillary pressure. In this figure, small vacuum pressures are developed in period 1 because of surface tension forces at the interfaces between the mortar particles and water. These forces increase significantly during period 2 , when the menisci between mortar particles develop very small radii. The capillary pore pressure therefore moves toward a maximum vacuum pressure, also called the breakthrough pressure, during period 2 as the mortar particles are brought closer together. Finally, in period 3, the capillary pore pressure increases quickly, recovering to a value near zero when it reaches equilibrium. The pressure recovery is usually erratic in experimental data because of lodging of solids in the pressure probe. The mortar continues to hydrate and shrink after the pressure recovery, but these changes are not reflected in the capillary pore pressure measurement.
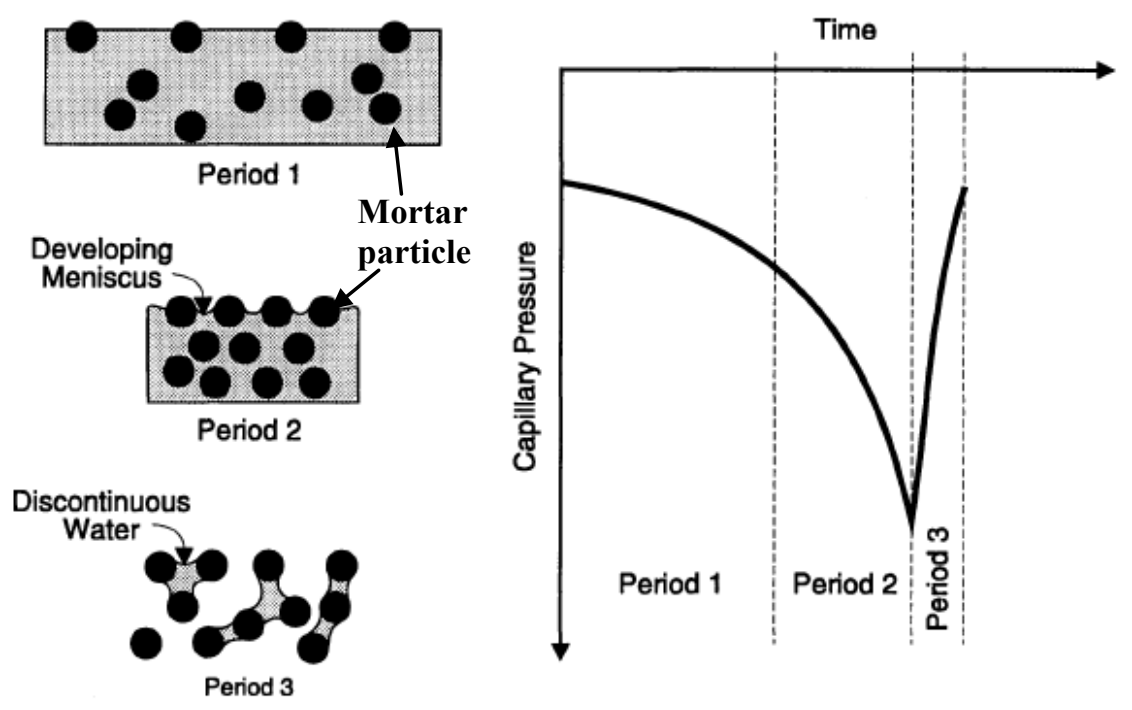

Figure 2.5: Three major periods of development of capillary pore pressure (after Lane et al. 1997) 
The second school of thought considers that plastic settlement cracking, as it is shown in Figure 2.6, can typically be observed to occur over reinforcing bars, over large aggregate particles, which it calls settlement cracking (Figure 2.6 a), or at changes in section depths such as beam/slab junction, which frequently corresponds to the location of cracking (differential settlement cracking, Figure 2.6 b).

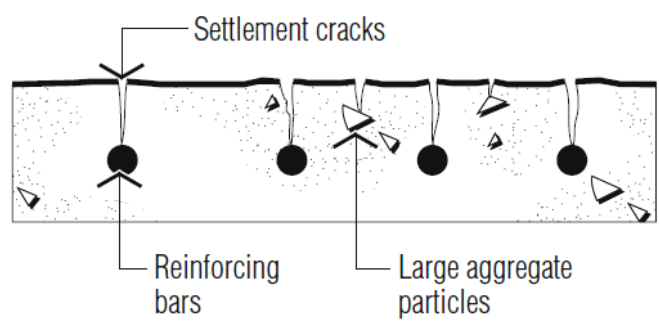

SECTION A-A

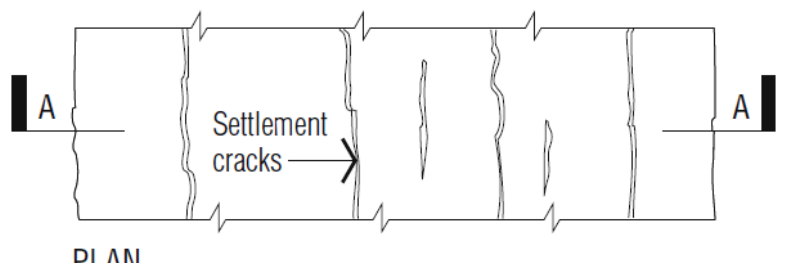

(a)

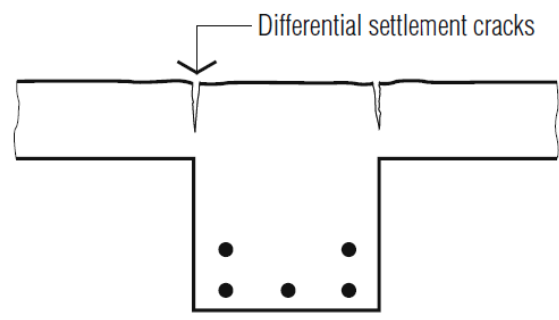

SECTION A-A

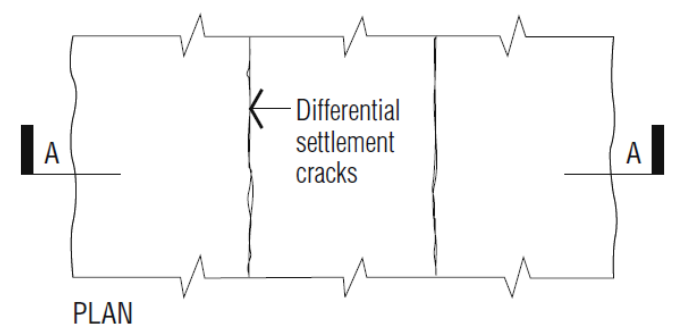

(b)

Figure 2.6: Plastic settlement cracking: a) settlement cracks and b) differential settlement cracks (after CCAA 2005). 
Weyers et al. (1982) used a gelatin model system to simulate the tensile force that was generated over a reinforcing bar when differential settlement occurs. They conducted tests on $15.9 \mathrm{~mm}$ diameter rebars with three spacings typical of bridge decks $(76.2,114.3$, and 152.4 $\mathrm{mm}$ ). The authors used a single slab with bars placed at three different spacings and a constant depth of gelatin cover of $25.4 \mathrm{~mm}$. Also, tests were performed on slabs with gelatin cover depths of $38.8 \mathrm{~mm}, 50.8 \mathrm{~mm}$, and $63.5 \mathrm{~mm}$ using a spacing factor of $152.4 \mathrm{~mm}$ in all of them. Table 2.1 shows the authors' results for the maximum tensile stress levels at the surface directly above the reinforcing bar for the three spacing factors and a $25.4 \mathrm{~mm}$ cover. In this table, the maximum tensile stress level decreases from $1.28 \mathrm{kpa}$ at the $76.2 \mathrm{~mm}$ spacing factor to $1.05 \mathrm{kpa}$ at the $114.3 \mathrm{~mm}$ spacing factor. However, the maximum tensile stress approximately doubled for the $152.4 \mathrm{~mm}$ spacing factor $(1.96 \mathrm{kpa})$. Also, the zone of influence of the reinforcing bar increased from $\pm 25.4 \mathrm{~mm}$ for the $76.2 \mathrm{~mm}$ spacing factor to $\pm 38.1 \mathrm{~mm}$ for the $114.3 \mathrm{~mm}$ and $152.4 \mathrm{~mm}$ spacing factors. The results of the maximum tensile stress levels for the $152.4 \mathrm{~mm}$ spacing factor for concrete cover depths of 25.4, 38.8, 50.8, and $63.5 \mathrm{~mm}$ are shown in Table 2.2. In this table, the maximum tensile stress level decreased with increasing cover depths from $1.96 \mathrm{kpa}$ at 25.4 $\mathrm{mm}$ of concrete cover to $0.24 \mathrm{kpa}$ at $63.5 \mathrm{~mm}$ of concrete cover. Also, the zone of influence of the reinforcing bar increased from $\pm 25.4 \mathrm{~mm}$ for the $\pm 25.4 \mathrm{~mm}$ cover depth to $\pm 38.1 \mathrm{~mm}$ for the $38.8 \mathrm{~mm}$ and $50.8 \mathrm{~mm}$ cover depths and decreased to $\pm 12.7 \mathrm{~mm}$ for the $63.5 \mathrm{~mm}$ cover depth. They concluded that the magnitude of plastic settlement generated tensile force is related to cover thickness, the spacing of the rebars and mixture properties for rebars of a given diameter.

Table 2.1: Maximum tensile stress when the depth of gelatin cover is constant and spacing factors are varied (Weyers et al. 1982).

\begin{tabular}{|c|c|c|c|}
\hline $\begin{array}{c}\text { Spacing factor } \\
(\mathrm{mm})\end{array}$ & $\begin{array}{c}\text { Cover depth } \\
(\mathrm{mm})\end{array}$ & $\begin{array}{c}\text { Zone of influence } \\
(\mathrm{mm})\end{array}$ & $\begin{array}{c}\text { Tensile stress at the surface } \\
(\mathrm{kpa})\end{array}$ \\
\hline 76.2 & 25.4 & \pm 25.4 & 1.28 \\
\hline 114.3 & 25.4 & \pm 38.1 & 1.05 \\
\hline 152.4 & 25.4 & \pm 38.1 & 1.96 \\
\hline
\end{tabular}


Table 2.2: Maximum tensile stress when the depths of gelatin cover are varied and the spacing factor is constant (Weyers et al. 1982).

\begin{tabular}{|c|c|c|c|}
\hline $\begin{array}{c}\text { Cover depth } \\
(\mathrm{mm})\end{array}$ & $\begin{array}{c}\text { Spacing factor } \\
(\mathrm{mm})\end{array}$ & $\begin{array}{c}\text { Zone of influence } \\
(\mathrm{mm})\end{array}$ & $\begin{array}{c}\text { Tensile stress at the surface } \\
(\mathrm{kpa})\end{array}$ \\
\hline 25.4 & 152.4 & \pm 25.4 & 1.96 \\
\hline 38.8 & 152.4 & \pm 38.1 & 1.17 \\
\hline 50.8 & 152.4 & \pm 38.1 & 0.70 \\
\hline 63.5 & 152.4 & \pm 12.7 & 0.24 \\
\hline
\end{tabular}

Qi et al. (2003) studied the characteristic of plastic settlement cracking in fiber reinforced concrete using a non-contact laser held above a cylindrical specimen (diameter of $100 \mathrm{~mm}$ and height of $75 \mathrm{~mm}$ ) to determine the change in height of the concrete surface as it is shown in Figure 2.7. In order to study the effect of two types of fibers: 1) FP-fibrillated polypropylene and 2) MP-monofilament polypropylene on the plastic settlement cracking, the authors produced normal strength concrete (fc' ranges from 17 to $34 \mathrm{Mpa}$ ) using Type I Portland cement, natural sand, pea gravel (maximum size $9 \mathrm{~mm}$ ), and water-cement ratio of 0.50 . The mixture proportions used were 1:0.5:2:2 (cement: water: sand: coarse aggregate by weight). The concrete mixture consisted of $65 \%$ aggregate and fiber by volume, with equal parts of coarse and fine aggregate by weight. The authors showed the role of fiber reinforcement in Figure 2.8. In the figure, it can be seen that the use of fiber reinforcement dramatically reduced settlement. Using a fiber replacement of $0.3 \%$ by volume the FP fiber showed to be more effective at reducing the settlement than the MP fiber. This happened because of the higher surface area of FP fiber than MP fiber. Therefore, the authors used a higher percentage of MP fiber $(0.7 \%)$ to achieve settlement reduction similar to the one occurred when $0.3 \%$ FP fiber was used. 


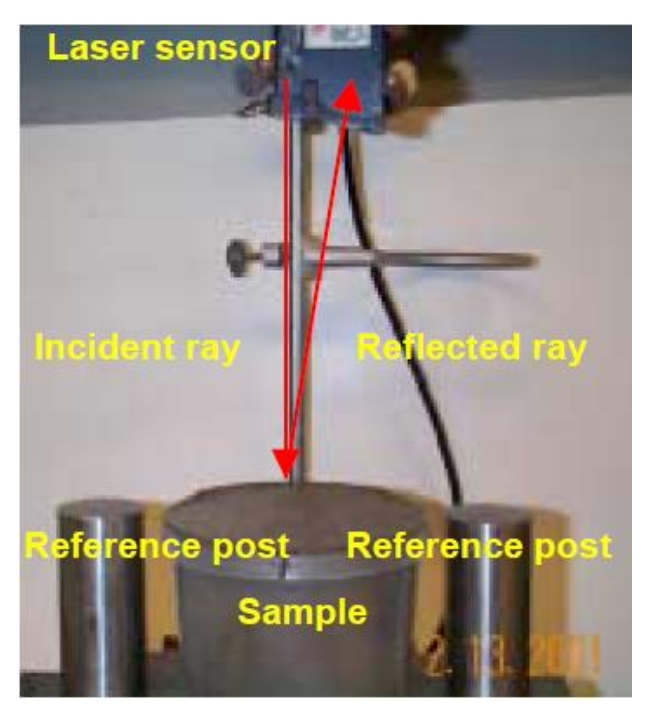

Figure 2.7: Settlement measurement by laser sensor (after Qi et al. 2003)

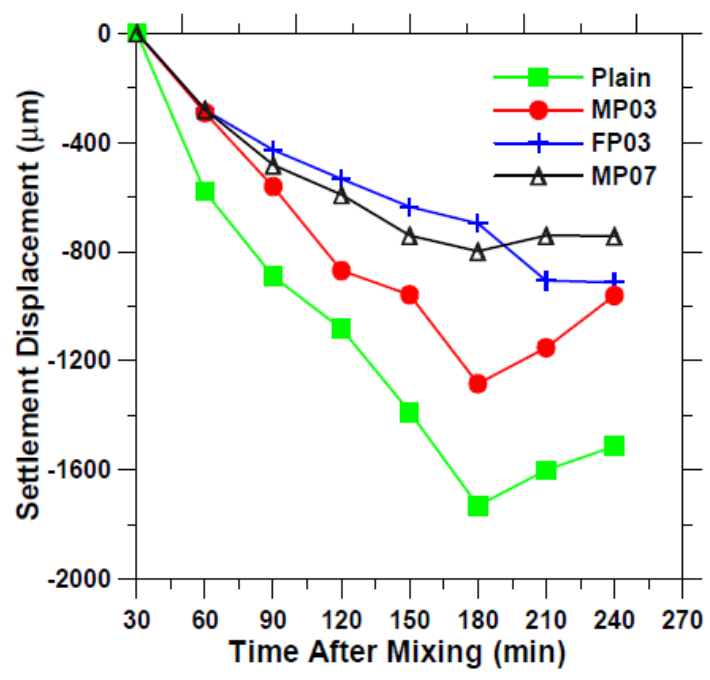

Figure 2.8: Role of FP and MP fibers in reducing plastic settlement (after Qi et al. 2003)

\subsection{ACI Definition of Plastic Shrinkage Cracking}

The American Concrete Institute (ACI), in ACI 116R (2000), defines plastic shrinkage cracking as "cracking that occurs in the surface of fresh concrete soon after it is placed and while it is still plastic." Plastic shrinkage cracks are caused by a rapid loss of water from the surface of concrete before it has set. The critical condition exists when the rate of evaporation of surface moisture exceeds the rate at which rising bleed water can replace it. The water, receding below 
the concrete surface, forms menisci between the fine particles of cement and aggregate causing a tensile force to develop in the surface layers. If the concrete surface has started to set and has developed sufficient tensile strength to resist the tensile forces, cracks do not form. If the surface dries rapidly, the concrete may still be plastic, and cracks do not develop at that time; but plastic cracks will surely form as soon as the concrete stiffens a little more because the tensile strength of the concrete is very low since the concrete has not had time to set. Figure 2.9 illustrates the process of plastic shrinkage cracking. In figure 2.9 (a) the bleeding water moves upward. This immediately starts after the concrete mixture is casted in the formwork. The bleeding water tries to replace the water that evaporates from the concrete surface. If the concrete bleeds excessively, vertical water channels form especially in high water content mixtures. In Figure 2.9 (b) the concrete surface starts drying rapidly due to high rate of evaporation and the bleeding water cannot replace the evaporated water, the concrete tries to shrink. The water hold between fine particles causes tensile forces $\left(\mathrm{F}_{\mathrm{T}}\right)$ in the surface layers. In Figure 2.9 (c) the moist concrete resists the shrinkage before the concrete starts stiffening. The plastic shrinkage cracks will start forming as soon as the concrete stiffens a little more because the tensile strength $\left(\mathrm{S}_{\mathrm{T}}\right)$ of the concrete is very low since the concrete has not had time to set. 


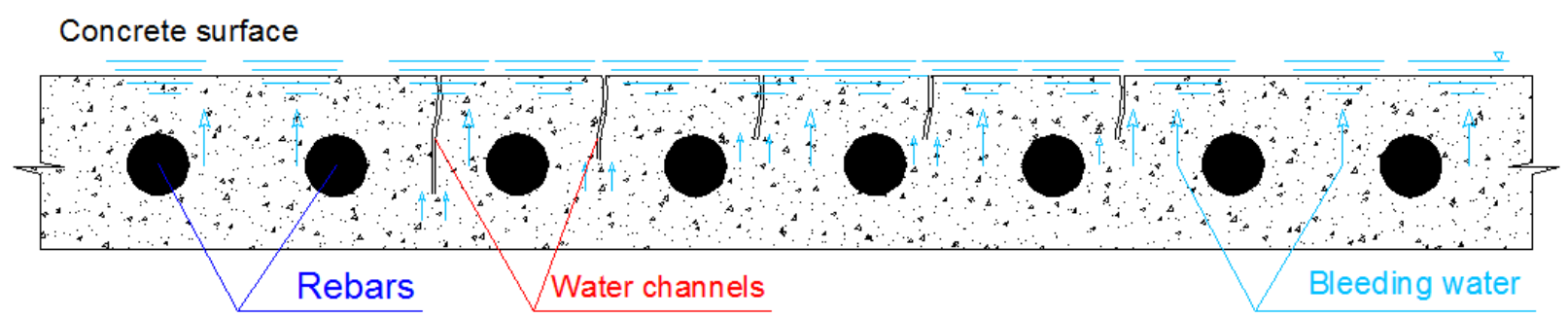

(a)

\section{Evaporation rate $>$ Bleeding water}

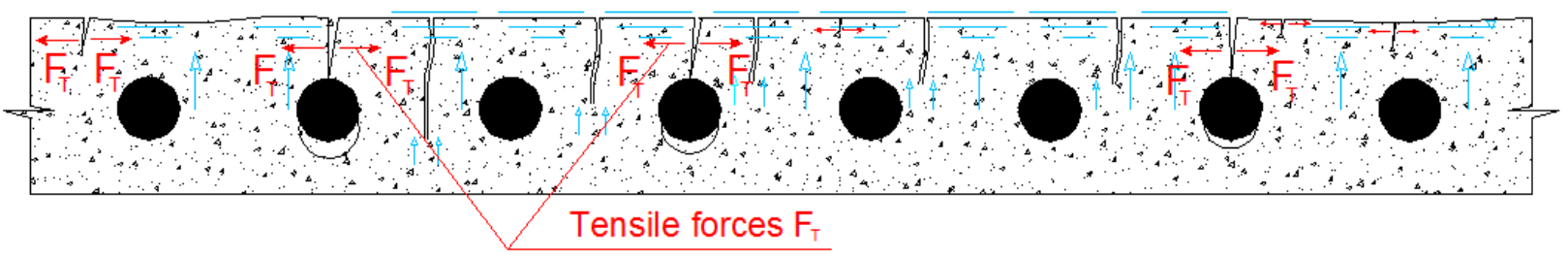

(b)

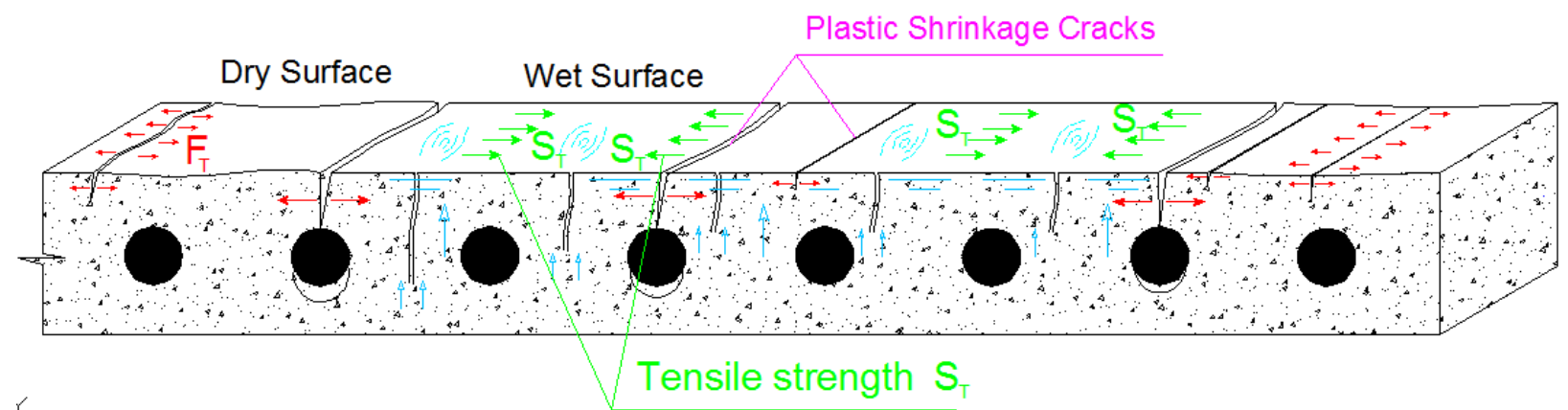

(c)

Figure 2.9: How plastic shrinkage cracking develops

\subsection{Factors Contributing to Plastic Shrinkage Cracking}

Plastic shrinkage cracking is affected by many factors that include: mixture composition, use of fibers, and environmental conditions. In this section the technical literature that describes these factors and how they influence the occurrence of plastic shrinkage cracks is reviewed.

\subsubsection{Mixture Composition}

It is known that increasing cement content, cement fineness, and a low water-cement ratio tend to increase the potential for plastic cracking. Also, very fine pozzolans, such as silica fume, increase the potential for plastic cracking (Cohen et al. 1990, ACI 234-1996, and Abmusallam et al. 1998). In general, the supplementary cementing materials that significantly 
increase set time can increase the risk of plastic shrinkage cracking (PCA 2010). In addition, Soroka and Ravina (1998) discussed that chemical admixtures (type D, ASTM C494) were added to given concrete mixtures in order to accomplish the required performance in both the fresh and hardened states. However, using admixtures (water-reducing and retarding admixtures) that prolong set-delaying provides a longer period of time for water to bleed to the surface, and at the same time admixtures may delay the early age strength development which is required tolerate externally exerted environmental loading. As such, the likelihood for shrinkage cracking is increased.

Cohen et al. (1990) studied the mechanism of plastic shrinkage in Portland cement and Portland cement-silica fume paste and mortar. They studied three forms of silica fume: asreceived powder, densified powder and slurry. The restrained paste (water-cementitious materials ratio of 0.35 ) and mortar specimens (water- cementitious materials ratio of 0.50 ) were prepared using ASTM Type I Portland cement and brass molds with inside dimensions of $50 \mathrm{~mm}$ x $50 \mathrm{~mm}$ and $5 \mathrm{~mm}$ in depth and plexiglass bottoms. Also, unrestrained mortar specimens prepared with a water-cementitious materials ratio of 0.35 were cast in a round, shallow glass dish which was $95 \mathrm{~mm}$ in diameter and $15 \mathrm{~mm}$ deep. The specimens were exposed to drying conditions (wind velocity of $3 \mathrm{~km} / \mathrm{h}$ and air temperature of $40{ }^{\circ} \mathrm{C}$ ) without controlling the relative humidity. All tests were conducted at the same time to avoid the influence of change in relative humidity. Photographs were taken at time intervals $0,15,30,45,60,90$, and 120 minutes to record the surface condition and plastic shrinkage cracking. Also, the samples were weighed at the same time to determine the amount and rate of water evaporation. They concluded that the plastic shrinkage cracking in the as-received and slurry silica fume pastes in contrast to the densified silica fume were most intense and similar to a map-pattern due to the extremely high surface area of the silica fume particles.

Almusallam et al. (1998) studied the effect of mix proportions, i.e. cement content and water-cement ratio, on plastic shrinkage cracking of concrete in hot and dry environments. The concrete specimens were made with ASTM C150 Type V Portland cement, crushed limestone 
(9.5 mm maximum size), dune sand, water-cement ratios varied from 0.40 to 0.65 , and cement contents varied from 300 to $400 \mathrm{~kg} / \mathrm{m} 3$. The effect of these parameters was assessed by measuring the evaporation and bleeding rates. They concluded that both bleeding and evaporation rate were increased with increasing water-cement ratio and cement content which leads to increase the potential for plastic shrinkage. Also, they observed that a combination of low rate of bleeding and evaporation in the concrete mix made with a cement content of 300 $\mathrm{kg} / \mathrm{m} 3$ and water-cement ratio of 0.40 made it less prone to plastic shrinkage cracking. Another important finding of this study was that plastic shrinkage cracking occurred at an evaporation rate ranging from 0.2 to $0.7 \mathrm{~kg} / \mathrm{m} 2 / \mathrm{hr}$ which is lower than the suggested values recommended by the National Ready Mix Concrete Association (NRMCA 1960) and discussed in section 2.4.3.

\subsubsection{Use of Fibers}

One of the solutions proposed to reduce the plastic shrinkage cracking is adding low volumes of randomly distributed short fibers. It has been shown to be an effective solution (Qi et al. 2003 and Qi et al. 2005). Also, there might be other types of fibers that effectively reduce cracking while maintaining workability and limiting the cost, such as poly ethylene-terephthalate (PET) fibers, which are produced from recycled PET bottles (Pelisser et al. 2010). There are some factors that should be considered when using fibers in cracking reduction:

Fiber Type: Using of polypropylene fibers in plastic cracking reduction was recommended by Qi (2003) due to the advantages of low cost and higher strain capacity.

Fiber Geometry: Plastic shrinkage cracking reduction depends on the surface area of the fibers (Banthia \& Yan 2000). Fibers with a small diameter are more efficient. It has been suggested by Soroushian et al. (1995) that the beneficial effects occur when the fiber length is slightly greater than the maximum aggregate size, but if fiber length increases a little more, it leads to a less homogeneous distribution of fibers. 
Fiber Volumes: Crack reduction depends not only on fiber type and geometry but also depends on fiber volume. Increasing the volume of fiber leads to dramatic reduction of cracks area as it is shown in following sections (Qi et al. 2005 and Pelisser et al. 2010).

Qi et al. (2005) studied the use of fibrillated polypropylene fibers with a length of $19 \mathrm{~mm}$ in six mixtures. The mixtures were produced using ASTM Type I Portland cement, water-cement ratios of 0.50 , siliceous sand, and pea gravel (1:0.5:2:2). The mixtures contained fiber volumes of $0.0 \%, 0.05 \%, 0.10 \%, 0.15 \%, 0.20 \%$, and $0.25 \%$. Visible cracking was observed in all the specimens (560 $\mathrm{mm} \times 355 \mathrm{~mm} \times 100 \mathrm{~mm}$ depth) except for the concrete containing $0.25 \%$ fiber by volume. Six plain specimens were tested. Also, for each of the mixes containing fiber volumes of $0.05 \%, 0.10 \%$, and $0.15 \%$ four specimens were tested. For mixes with fiber volumes of $0.20 \%$ and $0.25 \%$, two specimens were prepared. Automated image and optical image analyses were conducted by the authors to evaluate the change in crack pattern along with different volumes of fiber. Reduction in crack width with increasing volume of fiber can be observed in Figure 2.10.

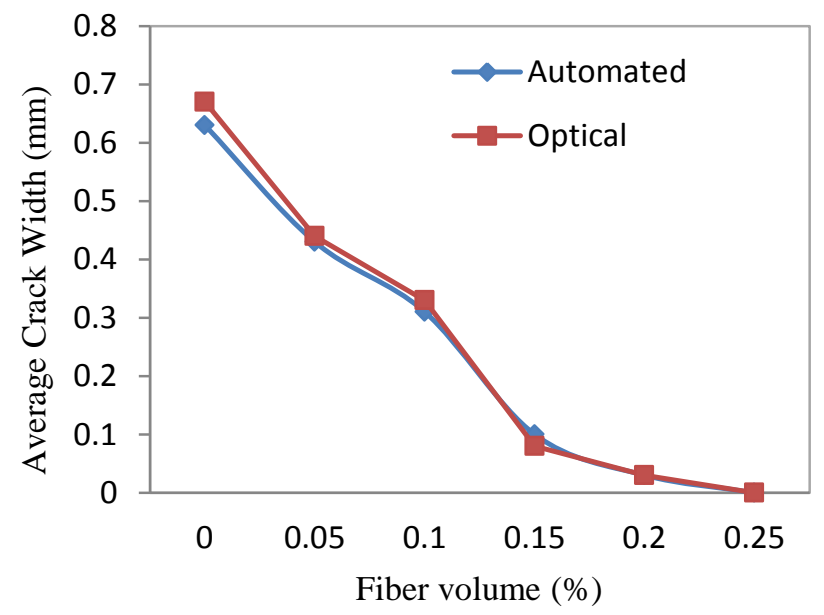

Figure 2.10: Average crack width measured from optical and automated image analyses for different volumes of fibers (after Qi et al. 2005)

Pelisser et al. 2010 studied the influence of the addition of polypropylene, glass, nylon, and poly-ethylene-terephthalate (PET) fibers on plastic shrinkage cracking of thin slabs $(910 \mathrm{~mm}$ 
x $610 \mathrm{~mm}$ x $20 \mathrm{~mm}$ of thickness). The mixtures were produced using ASTM Type II Portland cement, natural sand, and water-cement ratio of 0.60 (1:2.7:0.60). The fibers were added to the mixtures at three different volume fractions $(0 \%, 0.05 \%$, and $0.10 \%)$. Three specimens $(\mathrm{a}, \mathrm{b}$, and c) were cast for each fiber volume fraction. Two specimens ( $a$ and $b$ ) were cast for each fiber volume fraction of PET. The environmental conditions, mass loss, average rate of evaporation, and the average resulting cracks length are shown in Table 2.3. The experimental cracking results in table 2.3 showed that the addition of short polypropylene fibers to the mortar mixture was more efficient at restraining considerably crack formation due to plastic shrinkage. Glass and PET fibers showed similar results, while the nylon fibers showed the worse results.

Table 2.3: Experimental results of Pelisser et al. (2010)

\begin{tabular}{|c|c|c|c|c|c|c|c|c|c|}
\hline & \multicolumn{9}{|c|}{ Fiber volumes (\%) } \\
\hline & \multirow{2}{*}{$\begin{array}{l}\text { Ref. } \\
0.00\end{array}$} & \multicolumn{2}{|c|}{ Polypropylene } & \multicolumn{2}{|c|}{ Glass } & \multicolumn{2}{|c|}{ PET } & \multicolumn{2}{|c|}{ Nylon } \\
\hline & & 0.05 & 0.10 & 0.05 & 0.10 & 0.05 & 0.10 & 0.05 & 0.10 \\
\hline \multicolumn{10}{|c|}{ Cracking } \\
\hline Cracking length (mm) & 460 & 115.2 & 52 & 146.3 & 105.3 & 169.8 & 93 & 226 & 171.9 \\
\hline Number of cracks & 35 & 18 & 9 & 17 & 12 & 12 & 5 & 13 & 10 \\
\hline \multicolumn{10}{|c|}{ Environmental conditions } \\
\hline Wind speed $(\mathrm{km} / \mathrm{h})$ & 14.6 & 13.9 & 13.7 & 16.1 & 15 & 15.8 & 15.5 & 14.8 & 15.3 \\
\hline Air temperature $\left({ }^{\circ} \mathrm{C}\right)$ & 35.5 & 31.1 & 32.4 & 35.4 & 35.7 & 27.7 & 30 & 31.6 & 30 \\
\hline Relative humidity (\%) & 48.5 & 48.1 & 36.7 & 55.3 & 57.6 & 57.5 & 69.8 & 63.2 & 69.8 \\
\hline \multicolumn{10}{|c|}{ Mixture conditions and mass loss } \\
\hline Mortar temperature $\left({ }^{\circ} \mathrm{C}\right)$ & 35.2 & 30.5 & 31.3 & 35.9 & 36.4 & - & - & 31.4 & 23.3 \\
\hline Mass loss $(\%)$ & 6.87 & 6.2 & 6.6 & 5.86 & 2.44 & 6.82 & 3.82 & 5.86 & 3.82 \\
\hline $\begin{array}{l}\text { Average rate of evaporation } \\
\qquad\left(\mathrm{kg} / \mathrm{m}^{2} / \mathrm{h}\right)\end{array}$ & 1 & 0.8 & 0.9 & 0.8 & 0.8 & - & - & 0.7 & - \\
\hline
\end{tabular}

\subsubsection{Environmental Conditions}

Plastic shrinkage cracking occurs at high ambient temperature, high wind velocity and low relative humidity, which all act to accelerate the water evaporation, resulting in a higher shrinkage rate. The research on the parameters that affect evaporation rates of the bleed water 
goes back to the 1800s. The research developed the formula for evaporation rate from water surfaces (ponds, reservoirs, lakes, etc). Menzel (1954) of the Portland Cement Association simplified the formulae and established the evaporation rates that would result in the formation of plastic shrinkage cracks in fresh concrete. Bloem (1960) of the National Ready Mixed Concrete Association (NRMCA) developed the frequently used nomograph, shown in Figure 2.11 , that relates the air temperature, relative humidity, concrete temperature and wind velocity parameters, which are relatively easy to measure using a handheld weather station, to predict the evaporation rates for a concrete surface with bleed water. Also, Uno (1998) developed the following equation to make it easier to calculate the evaporation rates for concrete surfaces.

$$
\begin{aligned}
& \mathrm{E}=5\left(\left[\mathrm{~T}_{\mathrm{C}}+18\right]^{2.5}-\mathrm{r}\left[\mathrm{T}_{\mathrm{a}}+18\right]^{2.5}\right)(\mathrm{V}+4) * 10^{-6} \ldots \ldots \ldots \ldots \mid \text { Metric Units } \mid \\
& \mathrm{E}=\left(\mathrm{T}_{\mathrm{C}}^{2.5}-\mathrm{rT}_{\mathrm{a}}^{2.5}\right)(1+0.4 \mathrm{~V}) * 10^{-6} \ldots \ldots \ldots \ldots \ldots \ldots \ldots \ldots \ldots \ldots \ldots \ldots \ldots \ldots
\end{aligned}
$$

Where: $\mathrm{E}$ is the evaporation Rate, $\mathrm{Kg} / \mathrm{m}^{2} / \mathrm{hr}\left(\mathrm{lb} / \mathrm{ft}^{2} / \mathrm{hr}\right), \mathrm{T}_{\mathrm{c}}$ is the concrete (water surface) temperature, ${ }^{\circ} \mathrm{C}\left({ }^{\circ} \mathrm{F}\right)$, Ta is the air temperature, ${ }^{\circ} \mathrm{C}\left({ }^{\circ} \mathrm{F}\right), \mathrm{r}$ is the relative humidity (percent)/100, and $\mathrm{V}$ is wind velocity, $\mathrm{kph}(\mathrm{mph})$. 


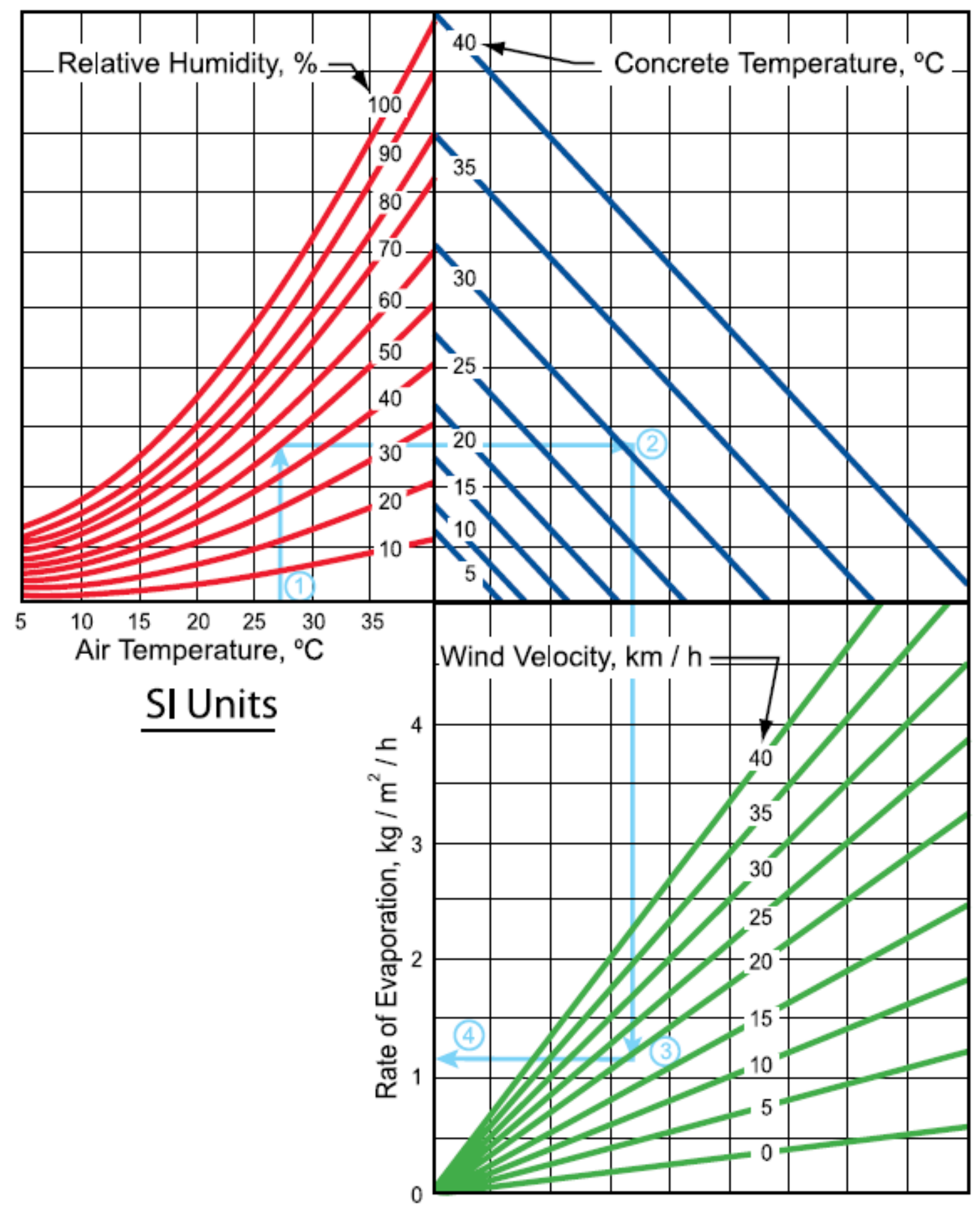

Figure 2.11a: Nomograph for estimating the rate of evaporation of water from a concrete surface in SI unit (after NRMCA 1960). 


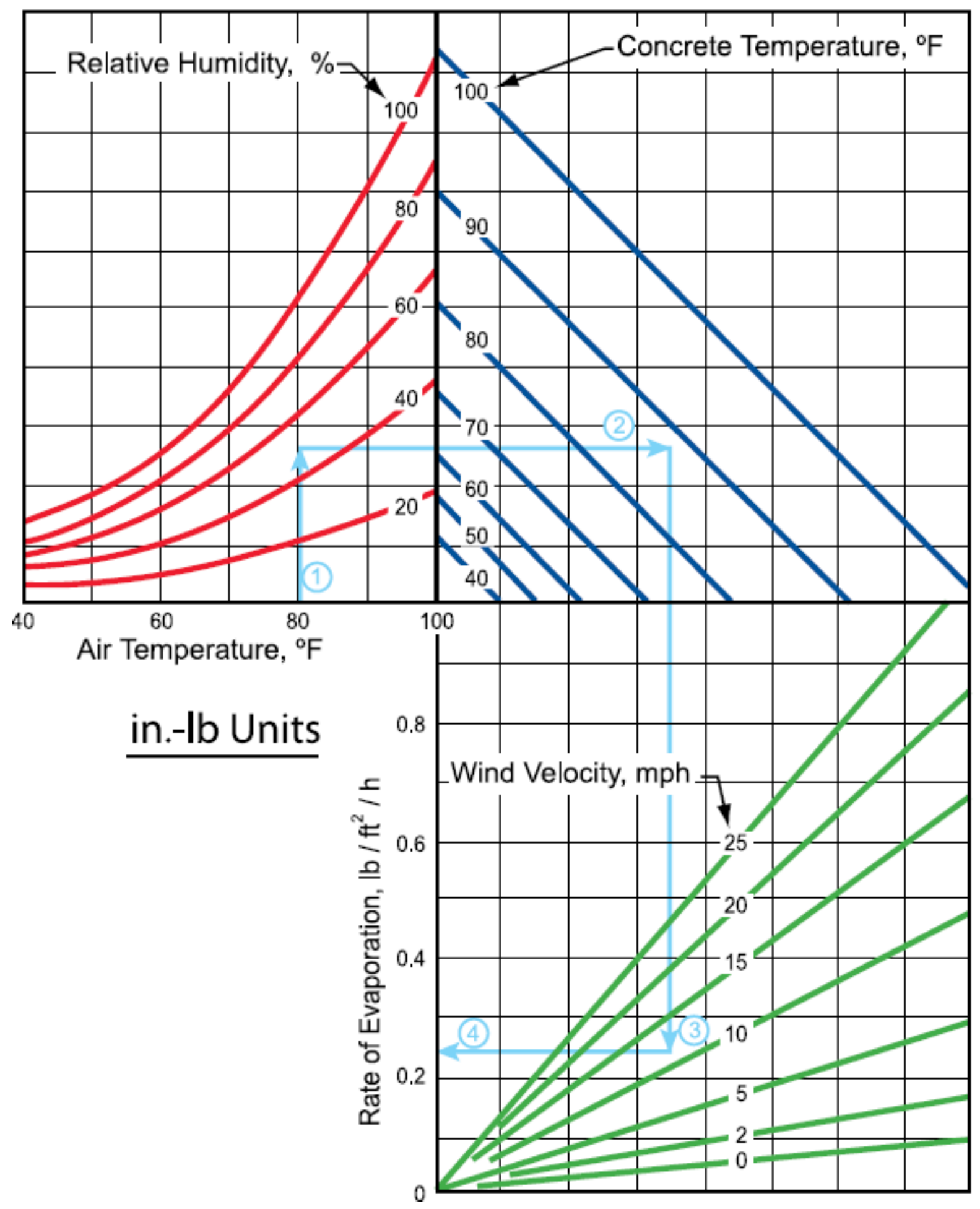

Figure 2.11b: Nomograph for estimating the rate of evaporation of water from a concrete surface in in-lb units (after NRMCA 1960). 
By using the nomograph or equation 2.1, evaporation rates are estimated to provide guidance to researchers as to when plastic shrinkage cracks may develop. The National Ready Mixed Concrete Association (NRMCA 1960) stated that when the evaporation rates exceed 1.0 $\mathrm{kg} / \mathrm{m}^{2} / \mathrm{hr}\left(0.2 \mathrm{lb} / \mathrm{ft}^{2} / \mathrm{hr}\right)$, plastic shrinkage cracks are expected. In such a case, measures have to be taken to reduce the possibility of crack development. Some of these include: erecting a wind screen, cooling the concrete, using a fogging system, and placing concrete at night. When the evaporation rate is between 0.5 and $1.0 \mathrm{~kg} / \mathrm{m} 2 / \mathrm{hr}(0.1$ and $0.2 \mathrm{lb} / \mathrm{ft} 2 / \mathrm{hr})$ plastic shrinkage cracking may or may not occur. Therefore, action has to be taken to reduce the possibility of crack formation. When the evaporation rates are $0.5 \mathrm{~kg} / \mathrm{m}^{2} / \mathrm{hr}\left(0.1 \mathrm{lb} / \mathrm{ft}^{2} / \mathrm{hr}\right)$ or less, plastic shrinkage cracks are not expected (ACI 308R-2001 and Snell 2008).

\subsection{Test Methods for Evaluating Plastic Shrinkage Cracking}

In the past several decades, many experimental techniques have been proposed for studying plastic shrinkage cracking of cement-based materials. Most test methods focus on parameters that describe crack width, length, and area. Evaporation and bleeding capacity of fresh concrete mixture are also commonly utilized. Since adding fiber is considered as a solution to reduce concrete plastic shrinkage cracking, most test methods have been used to test fiber reinforced concrete.

\subsubsection{Unrestrained Plastic Shrinkage Test}

Magnat \& Azari (1990) conducted an experimental investigation on the plastic shrinkage of steel fiber reinforced concrete (SFRC). They tested several concrete mixtures according to ASTM C827 criteria (ASTM 1982), which measured the vertical displacement of plastic concrete over time by optically monitoring the movement of a spherical ball (diameter $15 \mathrm{~mm}$ ) resting on the top surface of fresh cylindrical specimens of diameter $100 \mathrm{~mm}$ and height $200 \mathrm{~mm}$ as it is shown in Figure 2.12. In the test, three different cement contents C1, C2, and C3 (370, 433, and $468 \mathrm{~kg} / \mathrm{m} 3$ ) were investigated. Also, four types of steel fibers (melt extract, hooked, crimped, and Harex) were used and the volume of the fibers ranged between 0 and $4.47 \%$ of the mix volume. The authors showed the influence of fiber reinforcement on the plastic shrinkage in 
the mixes having $\mathrm{C} 1$ cement. The results showed a significant reduction in plastic shrinkage with increasing fiber volume. The rate of shrinkage was maximum in the first $40 \mathrm{~min}$ after the beginning of the test. This was followed by a gradual rate of shrinkage up to $140 \mathrm{~min}$, after which no further shrinkage occurs until the completion of the test after $280 \mathrm{~min}$. Tests showed that crimped and Harex fibers were more effective in restraining plastic shrinkage compared with melt extract and hooked fibers, due to their better anchorage characteristics. Also, the authors showed the influence of mix proportion on the plastic shrinkage in the mixes having C2 and C3 cement. Unlike mixes made with $\mathrm{C} 1$ cement, $\mathrm{C} 2$ and $\mathrm{C} 3$ mixes contained pulverized fuel ash (PFA), superplasticizer, and an air-entraining agent. At 280min after beginning plastic shrinkage tests, the shrinkage of mixes C1, C2 and C 3 was 7600, 4210 and 3340 micro-strain, respectively. These differences are likely to be due to an interaction of a number of factors such as water-cement ratio, workability, and the presence of admixtures.

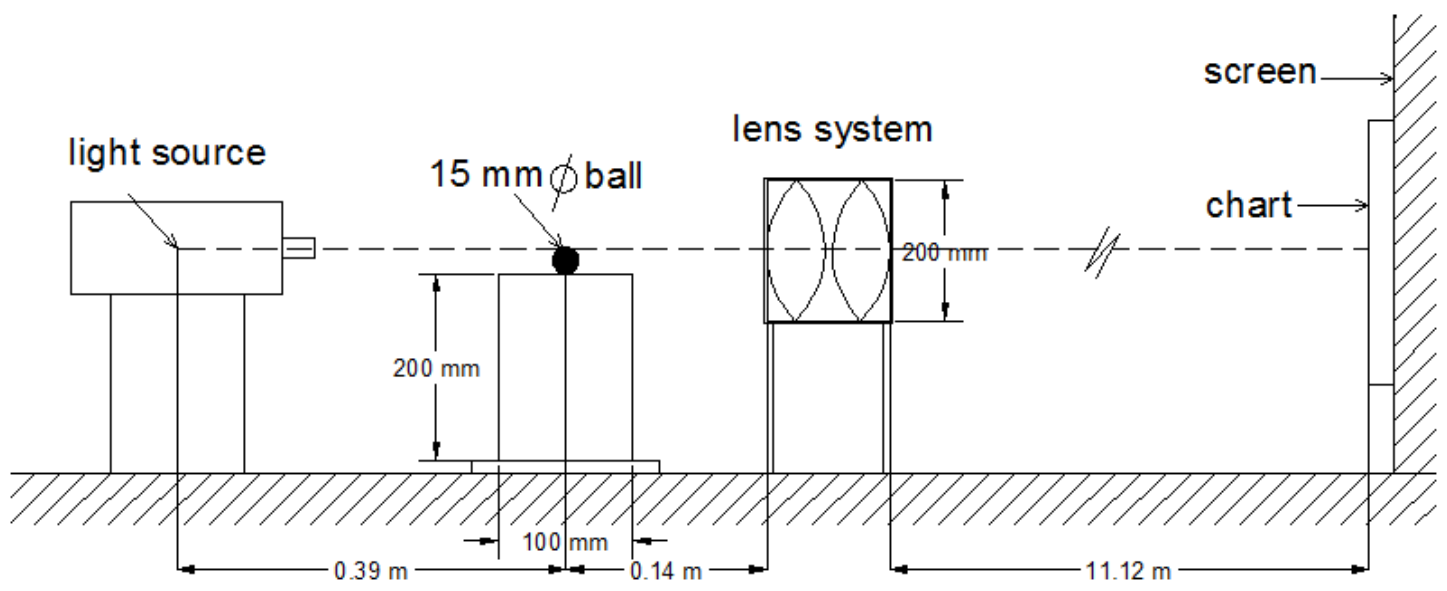

Figure 2.12: Plastic shrinkage apparatus (ASTM C827)

\subsubsection{Restrained Plastic Shrinkage Test}

Restrained plastic shrinkage cracking tests can be classified by specimen geometry as linear beam specimens (Banthia et al. 1993 and 1996) and slab type specimens (Kraai 1985, Cohen et al. 1990, Balaguru 1994, and Wang et al. 2001). The differences among these specimens are the specimen geometry, type and magnitude of restraint. 
Kraai (1985) used slab specimens of various sizes and restraint magnitudes. He tested the influences of mixture proportion (1: 4: 0.7, cement: sand: water-cement) and environmental conditions using slabs with restraint supplied by wire mesh from the wall perimeter. Modifications to Kraai's slab test method in term of slab dimensions and restraint magnitudes have been used by many researchers such as Cohen et al. (1990), whose work was reviewed earlier in this chapter, Balagurn (1994), and Wang et al. (2001).

Banthia et al. (1993) studied the influence of seven types of fibers at different fiber volume fractions, as they are shown in Table 2.4, on restrained shrinkage cracking in Portland cement pastes (1:0.2:0.4, cement: silica fume: water) and mortars (1:0.2:0.6:2, cement: silica fume: water: sand). The authors proposed a liner beam specimen $(40 \times 40 \times 500 \mathrm{~mm})$ with restraint supplied by triple-bar anchors at ends of the beam as shown in Figure 2.13. The study was aimed at studying cracking of concrete specimens under one-dimensional restrain when they were subjected to sever drying environment (air temperature of $50 \mathrm{oC}$ and relative humidity of $50 \%$ ). The results of crack observations are shown in Figure 2.14. The authors concluded that the fibers were effective in improving the behavior of cementitious materials under restrained shrinkage conditions. However, sufficient and constant end restraint in the proposed specimen is often difficult to achieve while concrete is still in plastic state (Qi 2003).
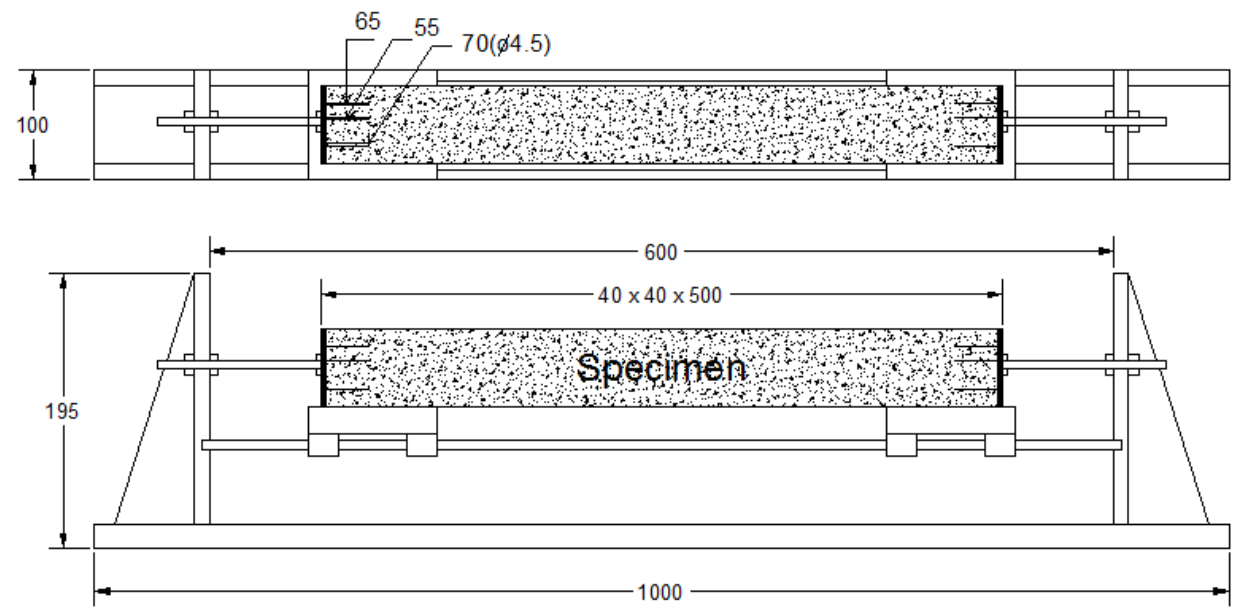

Figure 2.13: Dimensions (mm) of the test set-up (after Banthia et al. 1993) 
Table 2.4: Fiber types and volume fractions (after Banthia et al. 1993)

\begin{tabular}{|c|c|c|c|c|}
\hline Fiber type & \multicolumn{4}{|c|}{ Fiber volume fraction, (Vf \%) } \\
\hline \multicolumn{5}{|c|}{ Macro (large) fibers with different deformed geometry } \\
\hline Steel (F1) & 0.50 & 0.75 & 1.0 & 2.0 \\
\hline Steel (F2) & 0.50 & 0.75 & 1.0 & - \\
\hline Steel (F3) & 0.50 & 0.75 & 1.0 & - \\
\hline \multicolumn{7}{|c|}{ Micro (fine) fibers with different geometry } \\
\hline Carbon (C1) & 0.25 & 0.50 & 0.75 & - \\
\hline Carbon (C2) & 0.15 & 0.25 & 0.50 & 1.0 \\
\hline Polypropylene (P) & 0.25 & 0.50 & 1.0 & 3.50 \\
\hline Steel (S) & 1.0 & 2.0 & 3.0 & - \\
\hline
\end{tabular}
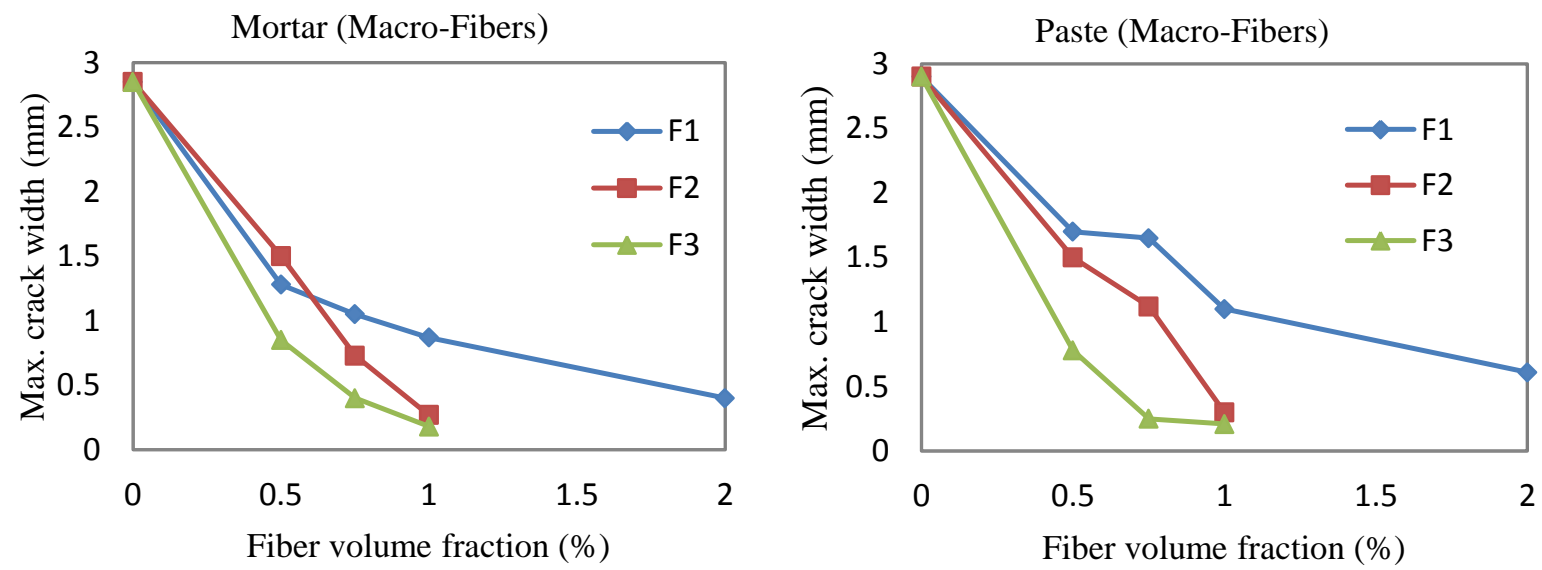

Figure 2.14-a: Maximum crack widths for macro fibers (after Banthia et al. 1993)
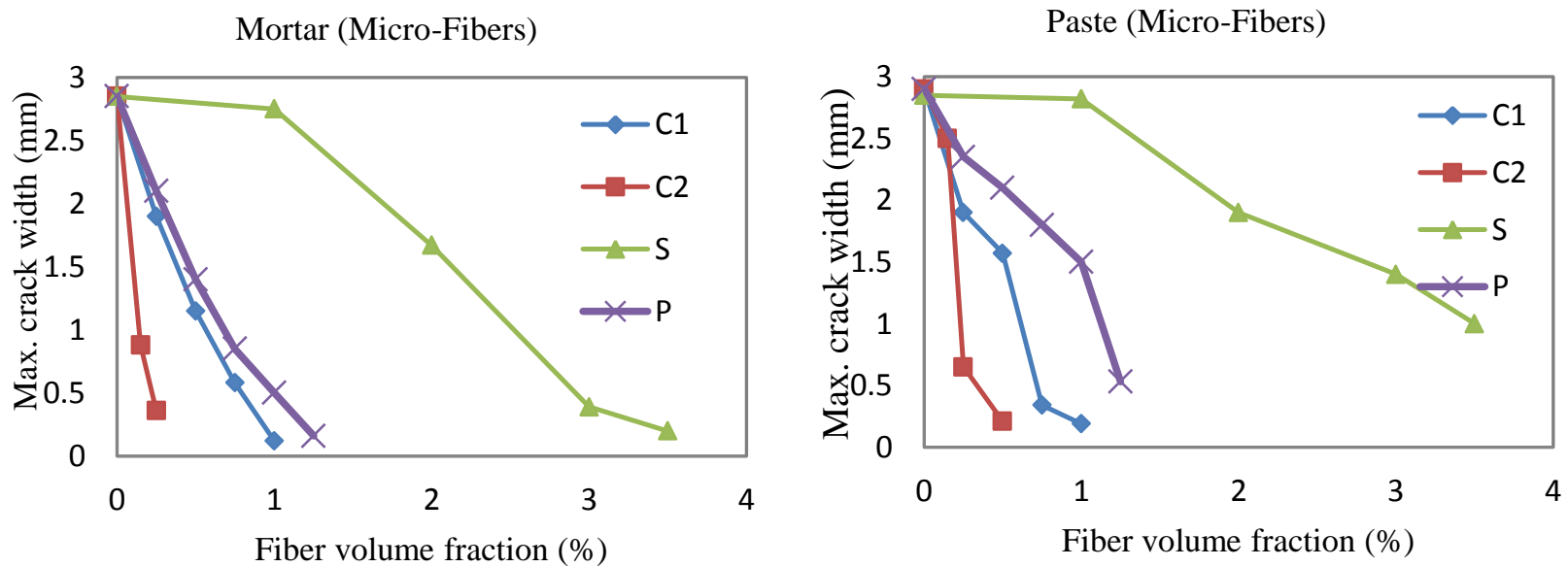

Figure 2.14-b: Maximum crack widths for micro fibers (after Banthia et al. 1993) 
Banthia et al. (1996) developed a test procedure to evaluate the early-age shrinkage cracking of a concrete mixture (1:0.55:1:1, cement: water-cement ratio: sand: rock). The volumes of steel fiber reinforced concrete (SFRC) investigated were $0.1,0.5$, and $1.0 \%$. Specimens with dimensions $1010 \times 100 \times 100 \mathrm{~mm}$ were cast directly on a rough concrete subbase with exposed aggregate to simulate restraint in real concrete structures. The whole assembly, as it is shown in Figure 2.15, was subjected to a drying environment (air temperature of $38^{\circ} \mathrm{C}$ and relative humidity of $5 \%$ to induce cracking. The final values of the total crack area are plotted in Figure 2.16 as a function of fiber volume fractions. The authors concluded that the use of fibers was found to be very effective not only in reducing the widths of the shrinkage cracks but also in preventing multiple cracking from occurring. However, while this test method may represent the actual condition of restraint in construction practice, the complex stress field and randomly distributed crack pattern makes quantitative analysis difficult.

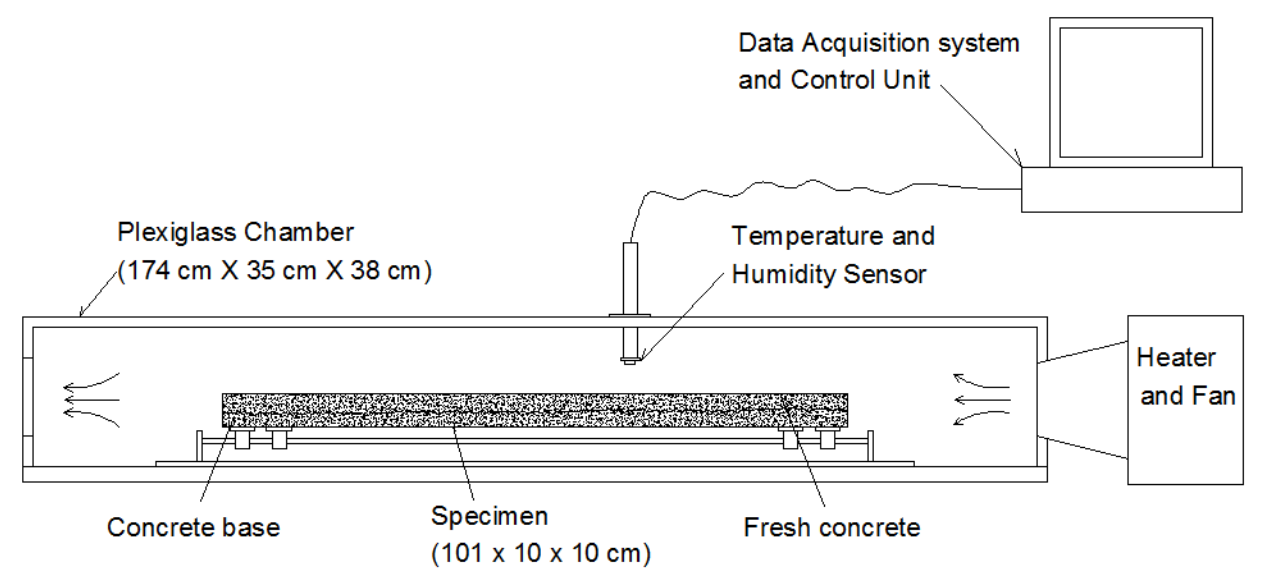

Figure 2.15: Schematic of the shrinkage test set up (after Banthia et al. 1996) 


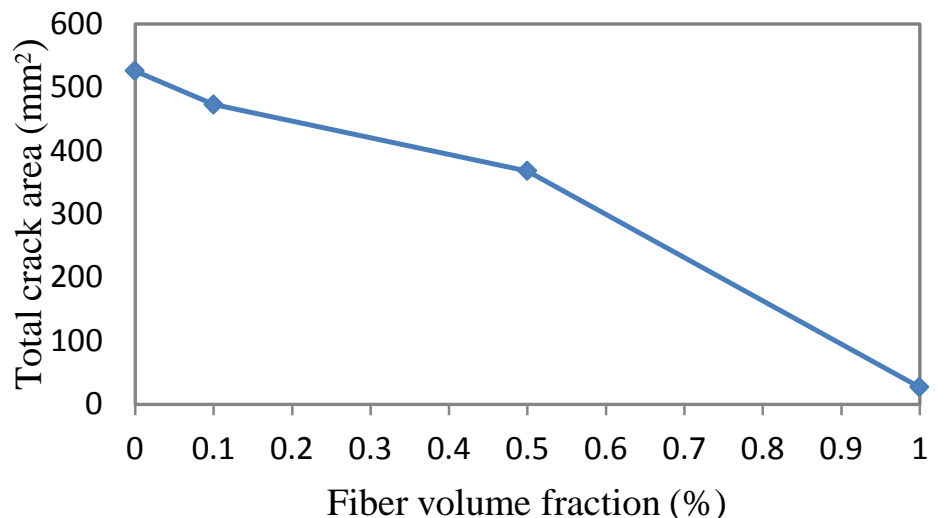

Figure 2.16: Effect of steel fibers on shrinkage cracking (after Banthia et al. 1996)

While these test methods can give an approximate rating to crack sensitivity of different mixtures, the results vary widely, and no consensus exists regarding how the data should be properly interpreted. To enable different fiber compositions and volumes to be compared and specified, there is a critical need for a standard test method. It should effectively evaluate the efficiency of fiber reinforcement in plastic cracking reduction and determine the optimized fiber volumes and fiber properties (Naani et al. 1993, Balagurn 1994, Berke \& Dallaire 1994, Banthia et al. 1996, Qi, et al. 2003)

\subsubsection{Standard Test Method for Evaluating Plastic Shrinkage Cracking}

ASTM C1579 (ASTM 2013) is currently used as a standard test method for evaluating plastic shrinkage cracking of restrained fiber reinforced concrete. This test method is intended to evaluate the effects of evaporation, settlement, and early autogenous shrinkage on the plastic shrinkage cracking performance of fiber reinforced concrete up to and for some hours beyond the time of final setting. The measured values obtained from this test may be used to compare the performance of concretes with different mixture proportions, concretes with and without fibers, concretes containing various amounts of different types of fibers, and concretes containing various amounts and types of admixtures. For meaningful comparisons, the evaporative conditions during test shall be sufficient to produce an average crack width of at least $0.5 \mathrm{~mm}$ in 
the control specimens. In addition, the evaporation rate from a surface free of water shall be within $\pm 5 \%$ for each test. The dimensions of the specimen for a maximum coarse aggregate size equal to or less than $19 \mathrm{~mm}(3 / 4 \mathrm{in})$ are illustrated in Figure 2.17. The mold can be fabricated from metal, plastic, or plywood. This test was used to evaluate the influence of re-vibration of the concrete mixes on the plastic shrinkage cracking. More details about this test are given in chapter 4 .
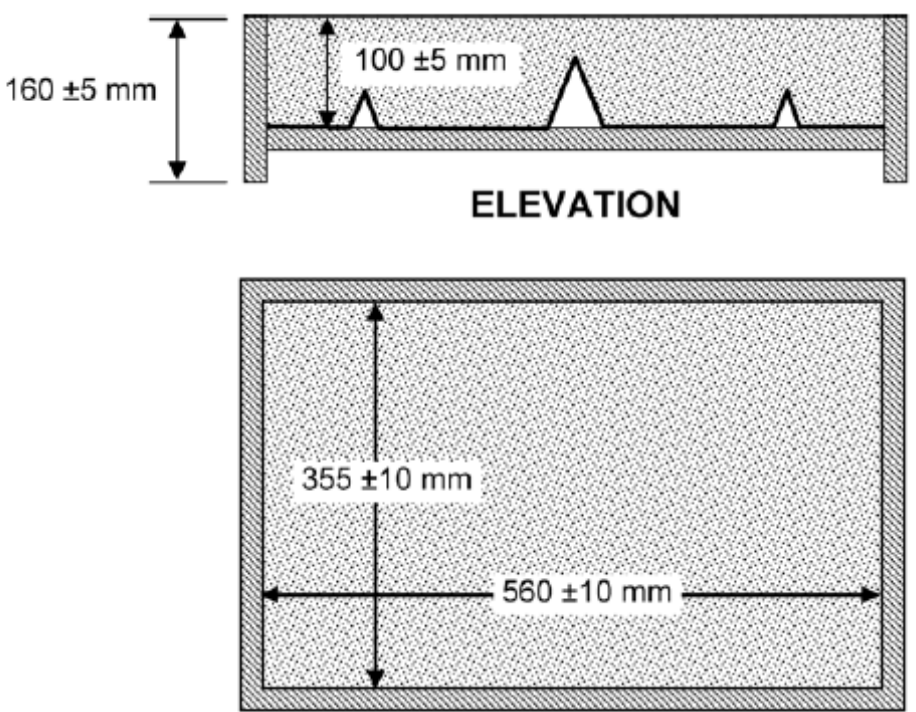

PLAN

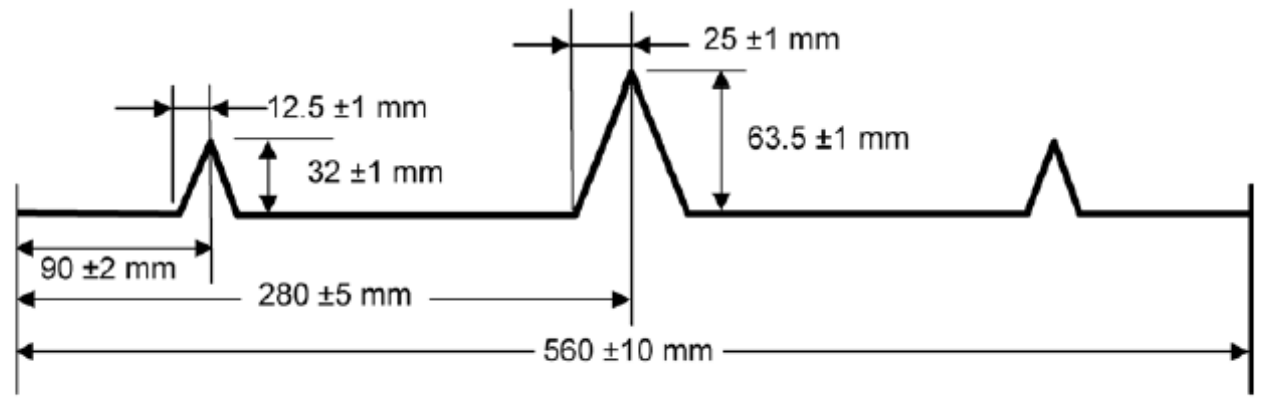

Stress Riser Geometry

Figure 2.17: Specimen and stress riser geometry (after ASTM C1579- 2013) 


\subsection{ConClusion}

This chapter has outlined current research in the area of plastic shrinkage cracking. Controlling of such cracking has been done either by adding fibers to concrete mixtures or by controlling the effects of weather conditions that surround concrete constructions. However, no one has considered that the re-vibration of concrete is an alternate solution to control the plastic shrinkage cracking. In this thesis the re-vibration technique is proposed as an alternative and economic approach to controlling plastic cracks. The standard restrained test method adopted by ASTM C1579, which is typically used to evaluate the plastic shrinkage cracking of fibered concrete, was adopted to assess the efficiency of the re-vibration technique in reducing plastic shrinkage cracking. 


\section{Chapter 3: Mechanisms of Concrete Vibration and Re-vibration}

\subsection{INTRODUCTION}

This chapter is a continuation of the literature review and provides an introduction to vibration and re-vibration techniques of fresh concrete. This chapter also provides a summary of current research in the field of concrete re-vibration, which is defined in this study as a second vibration that is applied sometime after the concrete is placed and exposed to initial vibration. Vibrators used for concrete compaction and consolidation are presented. Internal vibrators are presented in detail. Studies that report the effects of vibration on concrete strength are reviewed and discussed. This chapter further provides guidance and specification for the use of a needle vibrator and the time needed for full compaction of the concrete. Publications that report the influence of the re-vibration technique on some concrete properties are also reviewed and discussed.

\subsection{MECHANISM OF CONCRETE VibRATION}

Vibration of concrete is a technique that helps fresh concrete to settle by subjecting the individual particles to a rapid succession of impulses, causing differential motion (each particle moving independently of the others). The particles are forced to move toward the surface, around rebar and flush against the form face. This eliminates voids and brings paste to the surface, which makes finishing easier. The vibration technique provides better flowing and workability for fresh Concrete (CVH 2003).

Ritchie (1968) subdivided the workability (rheology) of fresh concrete that may affect the behaviour of a concrete mix during vibration, into three main sections: stability, compactability and mobility. An explanation of these sections follow and are depicted as a diagram in Figure 3.1:

Stability is "the flow of fresh concrete without applied force and is measured by bleeding and segregation characteristics." (ACI1993). Stability can also be seen as the ability of a fresh concrete mix to resist the segregation effects during transportation, handling, placing, and compacting. Bleeding occurs when the mortar is unstable and releases the water upward. 
Segregation is the separation of the constituent parts of a concrete mix so that it is no longer in a homogeneous state.

Compactability (relative density) measures the ease with which fresh concrete can be compacted properly with efficient removal of entrapped air and repositioning of the aggregate particles in a dense state without causing segregation.

Mobility is related to characteristics of viscosity, cohesion, and the internal resistance of the concrete to shear. Viscosity depends on the resistance developed between adjacent layers of the matrix when they are displaced. Cohesion is that property of concrete which resists the segregation of the aggregate particles by direct tensile strength. Internal resistance occurs when a mix is displaced and the aggregate particles tend to translate and rotate. This resistance of flow can be recorded as the angle of internal resistance of the mix. Therefore, the angle of internal resistance of concrete mixes is considered as the most important part of the mobility characteristic.

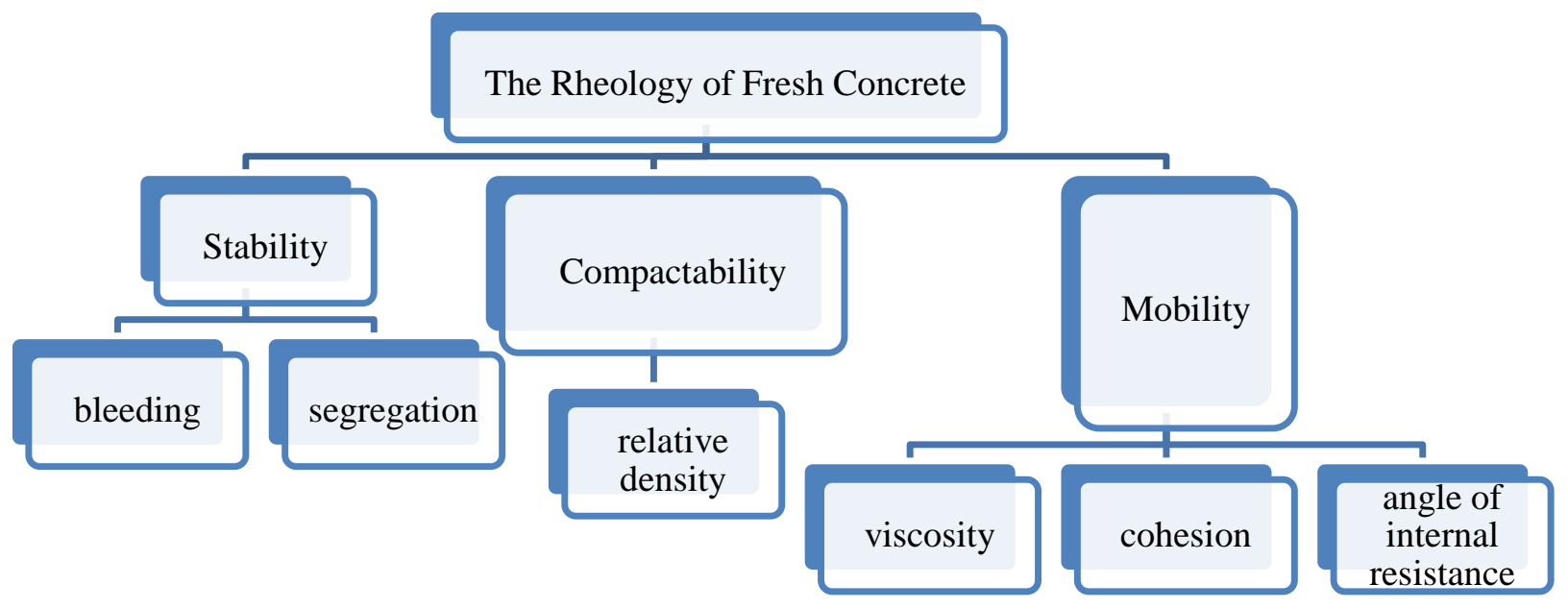

Figure 3.1: Significant factors in the rheology of fresh concrete (after Ritchie 1968)

As a conclusion from the study of the flow properties of fresh concrete, the parameters of stability, compactability, and mobility are important to determine the suitability of any concrete mix. Also, if a range of mixes is found to be suitably stable, the incomplete compaction should be based on the compactability and mobility characteristics. In this thesis, the assumption that the 
full compaction of concrete can be completed by re-vibration sometime after the concrete was cast to fulfil the compactability and mobility requirements.

Vibration of fresh concrete is done with vibrators which impart a vibratory force into the concrete through a combination of frequency, amplitude and acceleration. Frequency is the number of vibration cycles per minute, and is expressed as rotation per minute (rpm) or vibration per minute (vpm). Frequency moves the sand and slurry around the rocks, and governs liquefaction. Amplitude is a deviation from point of rest and is more effective with a heavier mass of concrete. It moves the rocks and determines the radius of action. It may be simpler to think of frequency as the number of times that the vibratory forces occur, while amplitude is the distance that the force is "thrown." A light, thin section, for example, would be vibrated at high frequency and low amplitude, because high amplitude would throw the concrete out of the form. Heavier, thicker sections, on the other hand, are more effectively vibrated with higher amplitude and lower frequency. Acceleration is the rate at which the velocity is changing at any time in the cycle (ACI 1993 and CCANZ 2006).

\subsection{TYPES OF VIBRATORS}

The most commonly used systems for vibrating concrete are internal vibration, table vibration, surface vibration, and external vibration. With each of these, the mechanism of vibration and the effect of the formwork on the concrete mix are different. (ACI 1993, ACI 1996, Bhattacharjee 2005 and CCANZ 2006).

\subsubsection{Internal Vibrators}

The principle of internal vibration, shown in Figure 3.2, reveals that the rotating member in the vibrator head produces an eccentric motion that generates the vibrations. Circular compression waves are then produced in rapid succession. The waves travel away from their source and through the concrete. They rapidly decrease with increasing distance from the vibrator, due not only to the damping effect at the vibrator itself and in the concrete, but also to the increased length around the circular wave. Accelerations of internal vibrators are ranged from 
100 to $200 \mathrm{~g}$ for concrete with maximum aggregate sizes of 38,19 and $10 \mathrm{~mm}\left(1 \frac{1}{2}, 3 / 4\right.$ and $3 / 8$ in). The optimum frequency of internal vibrators is about 12,000 vpm. According to ACI 309 (ACI 1993), the factors that should be considered with respect to mechanisms of internal vibration are the following:

1. Reduction of the amplitude of the vibrator head in fresh concrete.

2. Transmission of vibrations from the vibrator to the fresh concrete.

3. Geometric reduction in energy-density during circular propagation of the compression waves.

4. Damping effect on wave propagation through the fresh concrete.

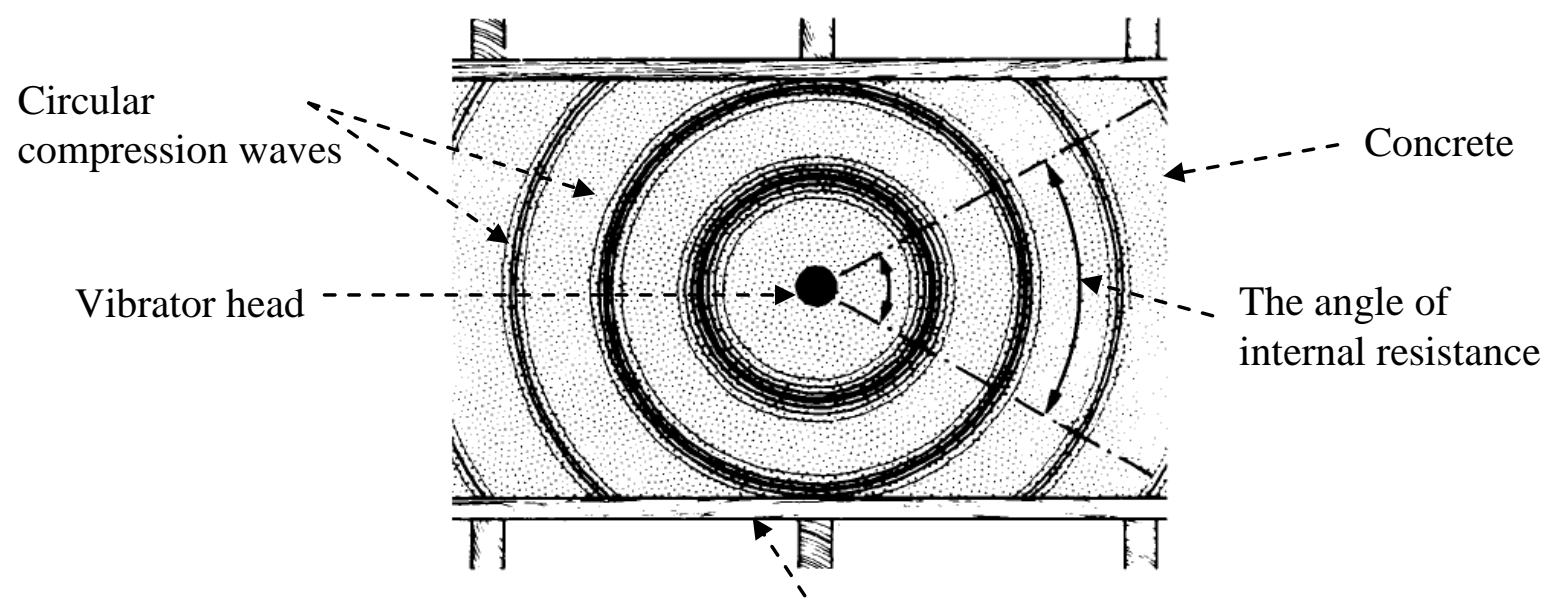

Formwork

Figure 3.2: Principle of internal vibration (after ACI 1993)

\subsubsection{Table Vibrators}

Vibrating table techniques are usually restricted to pre-casting operations. On a vibrating table, the forms as well as the concrete can move during vibration and resonance may occur. Also, reflection of the pressure waves against the concrete surface will influence the amplitude distribution. Figure 3.3 shows the principle of table vibration. Table vibrators can give less consistent results even with careful operation. The compaction effect is determined by the acceleration of the table. Accelerations of about 5-10 g before the forms are placed on the table, 
and 2-4 g during vibration, are required. The optimum frequency range is low, 3,000-6,000 vpm. Relatively large amplitudes are generally needed for efficient and rapid consolidation.

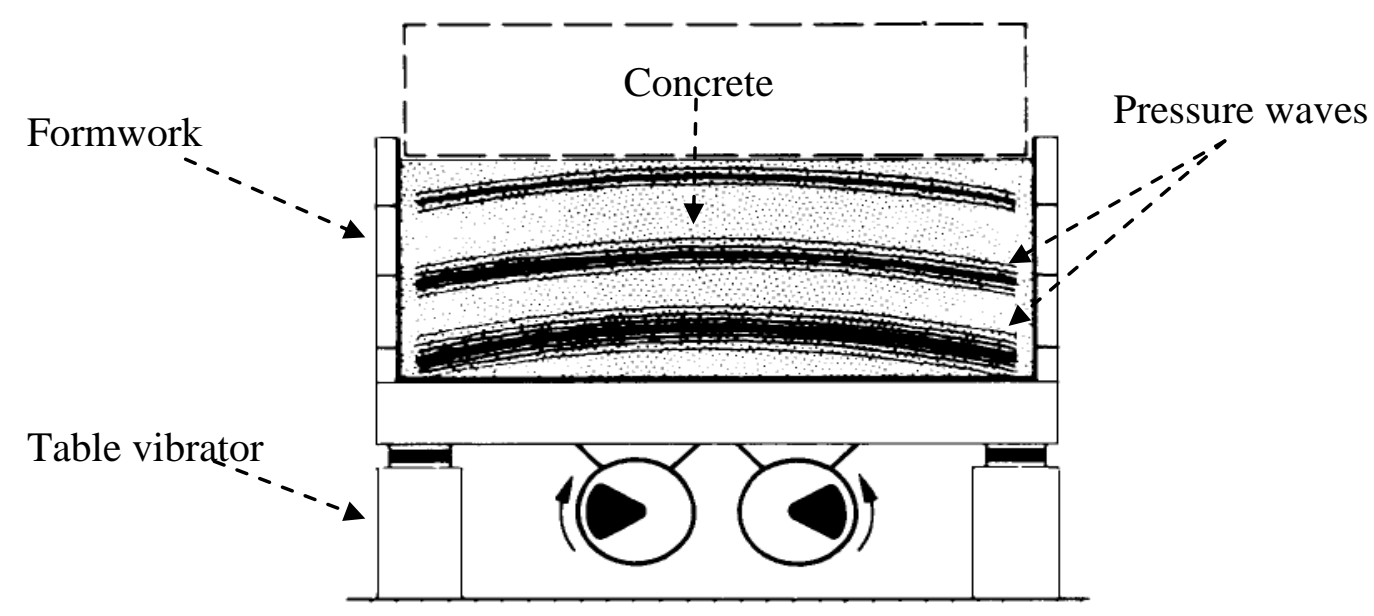

Figure 3.3: Principle of table vibration (after ACI 1993)

\subsubsection{Surface Vibrators}

Surface vibration, as shown in Figure 3.4, is usually accomplished by comparatively light single or double vibrating screeds, which can compact up to $200 \mathrm{~mm}$ thick layers of flowing to plastic concrete mixtures. For such screeds, a frequency range of 3,000 to $6,000 \mathrm{vpm}$ and accelerations to 5-10 g are customary. The amplitude distribution along the screed should be reasonably uniform.

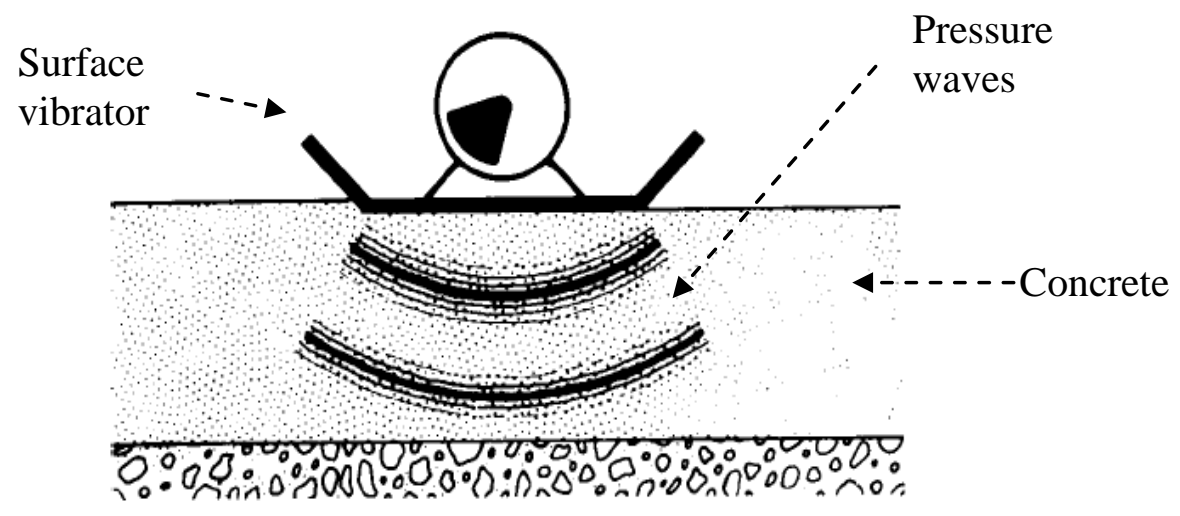

Figure 3.4: Principle of surface vibration (after ACI 1993) 


\subsubsection{External Vibrators}

The external vibrator, as shown in Figure 3.5, consists of an electric motor with an unbalanced member to create the vibration. In external vibration, the distribution of vibrations should be uniformly over as large a form surface as possible, normally the maximum distance between vibrators ranges from 5 to $8 \mathrm{ft}(1.5$ to $2.5 \mathrm{~m})$. The amplitude should be fairly uniform over the entire surface. The suitable frequency depends to a great extent on the size and design of the forms. Large forms need high frequency vibrators to obtain the required even distribution of the vibrations over the entire form. In general, the frequencies that range between 3,000 and $12,000 \mathrm{vpm}$ are the best ones that provide a better surface appearance.

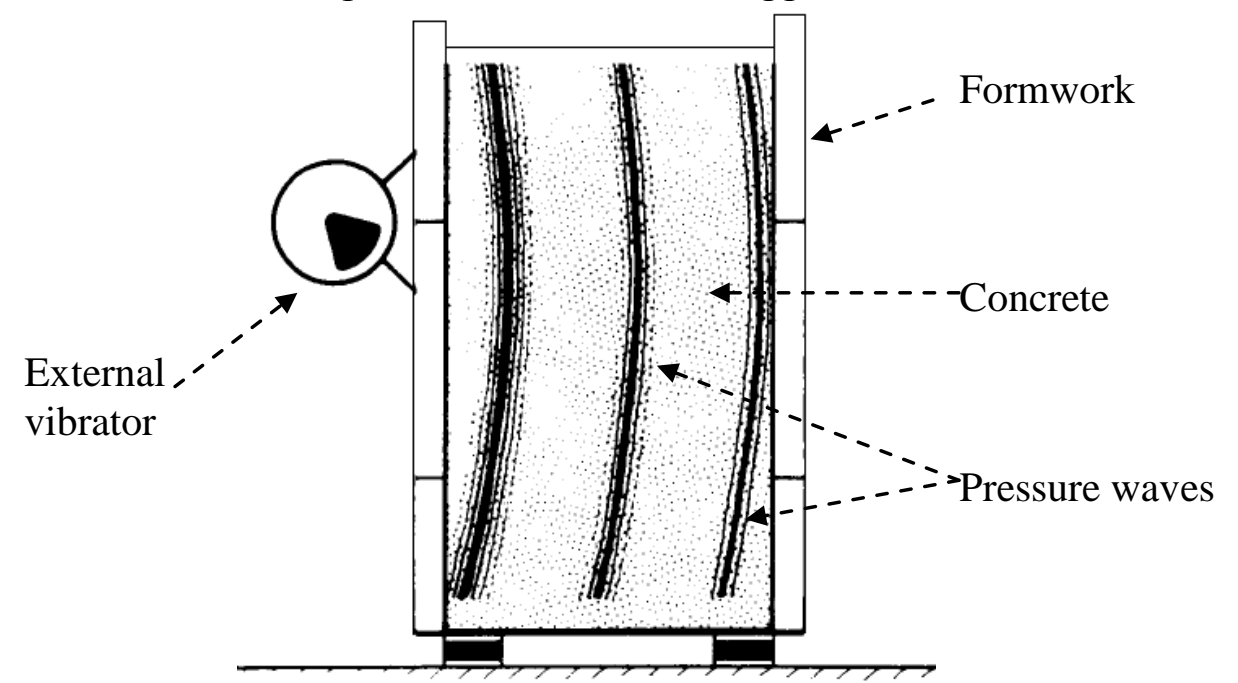

Figure 3.5: Principle of external vibration (after ACI 1993)

Table 3.1 summarizes the frequency and acceleration used to describe the performance characteristics of each vibrating system. 
Table 3.1: Recommended accelerations and frequencies of concrete vibration (after CCANZ 2006)

\begin{tabular}{|c|c|c|c|}
\hline \multirow{2}{*}{ Type of Vibrator } & $\begin{array}{c}\text { Recommended acceleration } \\
\text { (without concrete load) }\end{array}$ & \multicolumn{2}{|c|}{ Recommended frequency } \\
\cline { 2 - 4 } & $\mathrm{g}$ & $\mathrm{Hz}$ & vpm \\
\hline Internal & $100-200$ & $150-250$ & $9000-15000$ \\
\hline Table & $5-10$ & $50-100$ & $3000-6000$ \\
\hline Surface & $5-10$ & $50-100$ & $3000-6000$ \\
\hline External & $5-10$ & $50-200$ & $3000-12000$ \\
\hline
\end{tabular}

\subsection{THE USE OF INTERNAL VIBRATORS FOR COMPACTION}

Compaction is the process that expels entrapped air from freshly placed concrete and packs the aggregate particles together so as to increase the density of the concrete. It increases significantly the ultimate strength of concrete and enhances the bond with reinforcement. It also increases the abrasion resistance and general durability of the concrete, decreases the permeability and helps to minimize the concrete's shrinkage-and-creep characteristics. Proper compaction also ensures that the formwork is completely filled (i.e. there are no pockets of honeycombed material) and that the required finish is obtained on vertical surfaces. When first placed in the form, normal concretes, excluding those with very low or very high slumps will contain between $5 \%$ and $20 \%$ by volume of entrapped air. The aggregate particles, although coated with mortar, tend to arch against one another and are prevented from slumping or consolidating by internal friction (CCAA 2006).

Compaction of concrete using internal vibrators is a two-stage process (see Figure 3.6). The first stage is when the aggregate particles are set in motion and slump to fill the form, giving a level top surface. In the second stage, entrapped air is expelled. It is important to recognize the two stages in the compaction process because, with vibration, the initial consolidation of the concrete can often be achieved relatively quickly. The concrete liquefies and the surface levels 
give the impression that the concrete is compacted. Entrapped air takes a little longer to rise to the surface. Compaction must therefore be prolonged until this is accomplished, i.e. until air bubbles no longer appear on the surface (CVH 2003).

Most concrete is compacted by means of immersion or poker (needle) vibrators. This method is considered the most satisfactory because the poker works directly on the concrete and can be moved from one position to another easily and quickly. For most reinforced concrete work, pokers of diameters from $25 \mathrm{~mm}$ up to $75 \mathrm{~mm}$ are used. Diameters up to 100 and $150 \mathrm{~mm}$ are available, but their use is mainly restricted to mass concrete in heavy civil engineering works like dam construction. Due to their weight, these large pokers usually need two people to handle and operate them. For efficient compaction, the largest diameter that the complexity of formwork and reinforcement will allow should be used (CCANZ 2006).

Stage 1: From 3 to 5 seconds

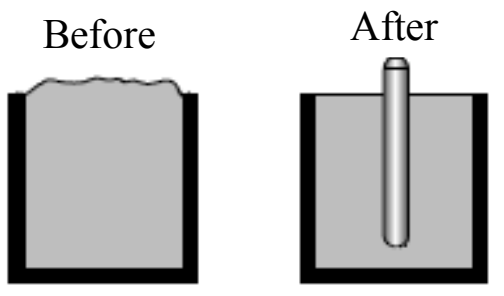

Stage 2: From 7 to 15 seconds

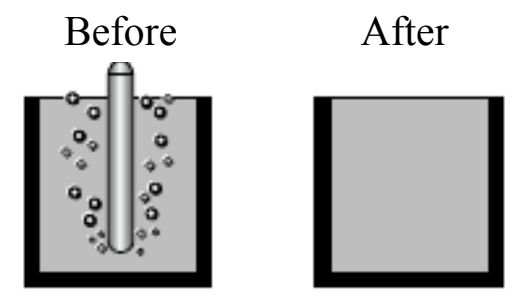

Figure 3.6: The process of compaction

\subsubsection{Influence of Compaction on Concrete Hardening}

The influence of compaction on compressive strength is considerable, as is illustrated in Figure 3.7. For example, the strength of concrete containing 10\% of entrapped air (air voids) may be as little as $50 \%$ that of the concrete when fully compacted. Permeability may be similarly 
affected since compaction, in addition to expelling entrapped air, promotes a more even distribution of pores within the concrete, causing them to become discontinuous. This reduces the permeability of the concrete and hence improves its durability. The abrasion resistance of concrete surfaces is normally improved by adequate compaction. However, excessive vibration, or excessive working of the surface, can cause an excessive amount of mortar (and moisture) to collect at the surface, thereby reducing its potential abrasion resistance. In flatwork a careful balance is required to expel entrapped air without bringing excessive amounts of mortar to the surface of the concrete (CCAA 2006).

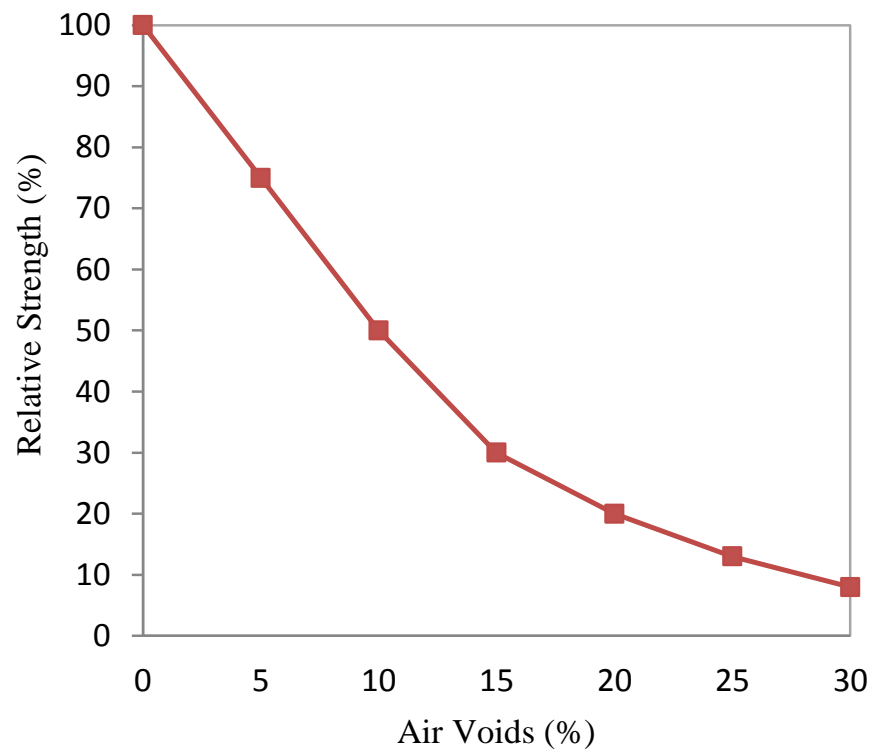

Figure 3.7: Loss of strength through incomplete compaction (after CCAA 2006)

\subsubsection{Guidance for Using a Needle Vibrator}

CCANZ (2006) and CCAA (2006) provide guidelines for producing a proper compacted mix through the use of a needle vibrator:

1. Make sure that the operator can see the concrete surface.

2. When inserting the needle, allow it to penetrate to the bottom of the layer as quickly as possible under its own weight. If done slowly, the top part of the layer will be compacted first, making it more difficult for the entrapped air in the lower part to escape the surface. 
3. Leave the needle in the concrete for about 10 seconds and withdraw it slowly ensuring that the hole made by the needle is closed up. If a hole is left (this is often difficult to prevent if the concrete is very stiff), replace the needle near enough to the hole for the next spell of vibration to close it up. For the final insertion, withdraw the needle even more slowly and wiggle it about to ensure that the hole closes up properly.

4. Replace the needle in the concrete to correct spacing.

5. Avoid touching the formwork face with the needle as this will leave a 'needle burn' on the formwork and a resulting mark will be left on the finished concrete surface. To be on the safe side, keep the vibrator about 75-100 mm away from the formwork.

6. Avoid touching the reinforcement with the needle, although, provided that all the concrete is still fresh, vibrating the reinforcement should not do any harm and could improve the bond. The danger lies in the vibrations in the reinforcement being transmitted into parts of the section where the concrete may have stiffened, in which case the bond may be affected.

7. Avoid using the needle to make the concrete flow and never use it to flatten a heap. Instead, insert the needle carefully around the perimeter, which will avoid segregation, remembering that compaction starts only after the heap has been flattened.

8. Make sure that the needle extends about $150 \mathrm{~mm}$ into any previous layer of concrete and put the whole length of the poker head into the concrete. This is essential to keep the bearings cool. Avoid leaving the needle running when it is not in the concrete, otherwise there is a risk of the bearings overheating.

9. Avoid sharp bends in flexible drives and do not move the vibrator by pulling on the flexible drive.

10. Remember that where finish is important, a little extra vibration can reduce the number of blowholes.

11. Make sure the driver motor will not vibrate itself off the staging's, and when finished clean all the equipment thoroughly. 
Figure 3.8 shows the incorrect and correct placement of a needle vibrator in concrete. The Selection of a proper needle vibrator, based on its application, is given in Table 3.2 (CVH 2003).

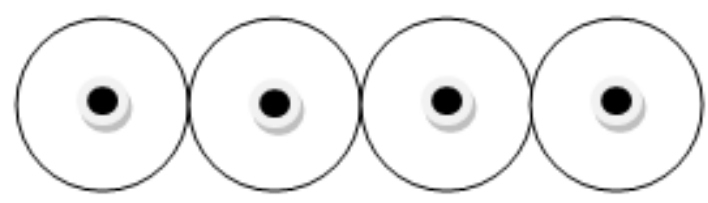

Centrally placed and widely spaced

(a) Insertion positions leave un-compacted areas

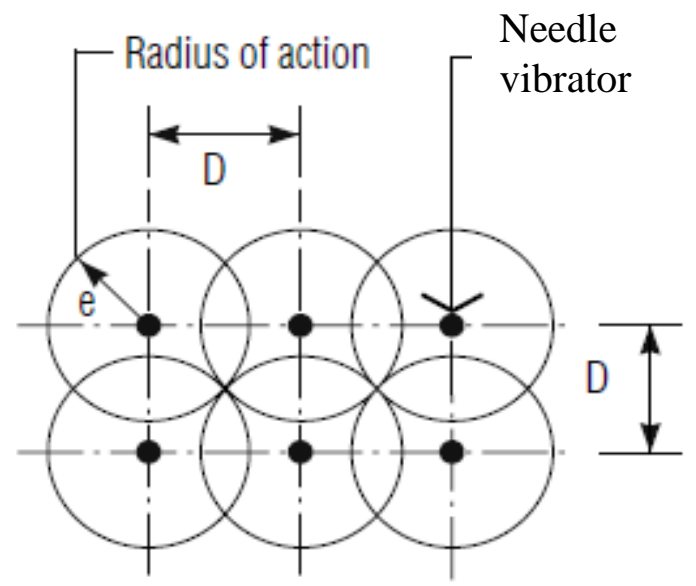

(b) Overlapping radii of action

Ensure complete compaction

Figure 3.8: Incorrect (a) and correct (b) placing of the needle in concrete (after CCANZ 2006 and CCAA 2006) 
Table 3.2: Selection of internal vibrators (after CVH 2003)

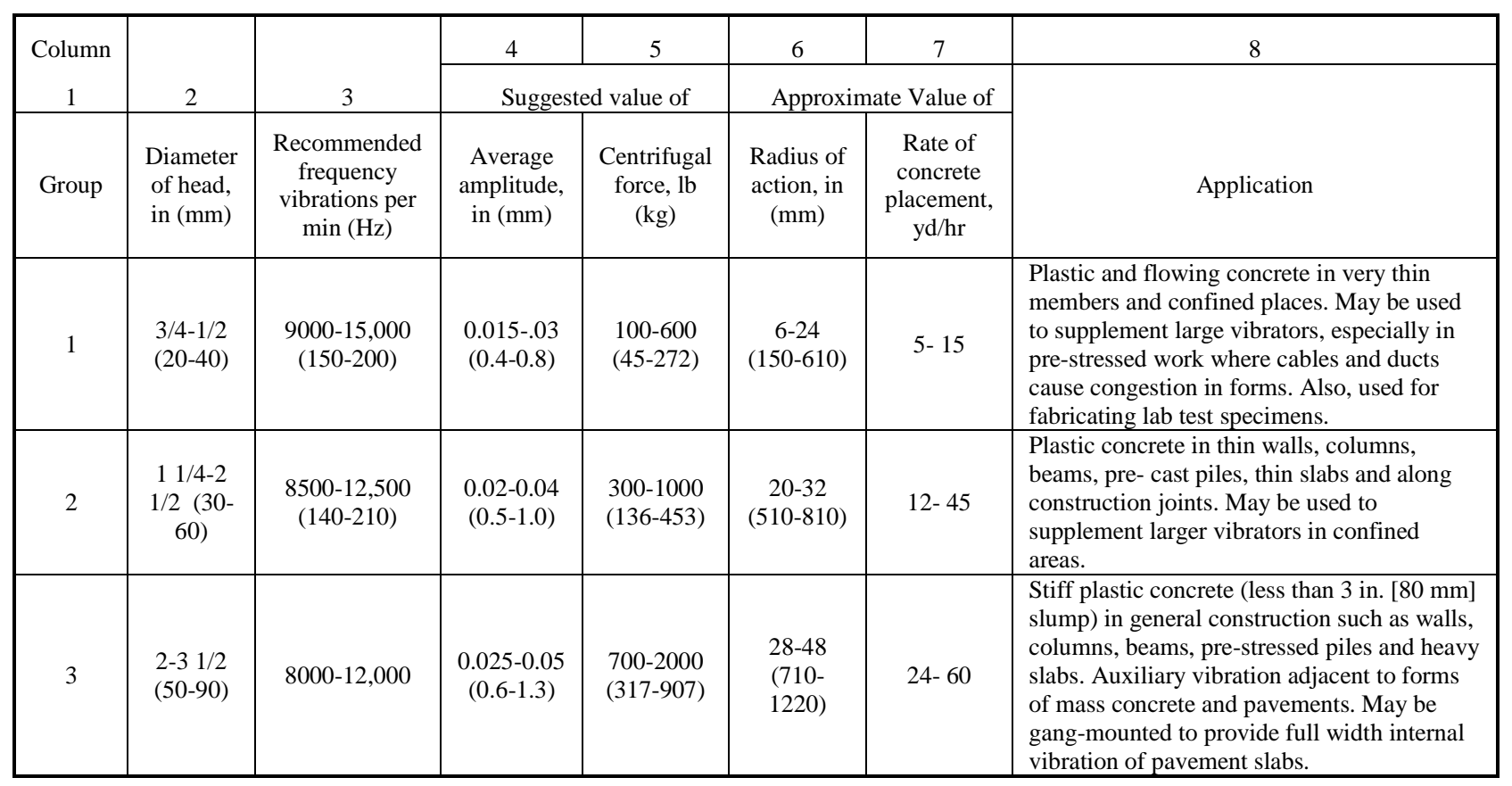

\subsubsection{Time of Vibration Required for Full Compaction}

The length of time that a needle has to be in the concrete at any one position, in order to fully compact the surrounding concrete, cannot be precisely stated since it depends on the workability of the mix, on the size of the needle itself and the volume of concrete. The vibration time for fresh concrete right after casting will vary between 5 and 15 seconds for concrete with a slump of $25-75 \mathrm{~mm}$. practically, a time of around 10 seconds in the fresh concrete should be satisfactory (Vollick 1958, Maclnnis \& Kosteniuk 1979, Aldalinsi et al. 2003, Bhattacharjee 2005, CCANZ 2006 and CCAA 2006).

CCANZ 2006 provides the following steps, based on engineers' experience, to judge if the concrete mix has the right amount of vibration (fully compacted):

1. Initial consolidation is rapid and the level of the concrete drops quickly but the entrapped air has still to be removed.

2. As the concrete is vibrated, air bubbles come to the surface. When the bubbles stop, it can be taken as a sign that not much more useful work can be done on the concrete. The distance of the bubbles from the needle is also a useful guide to its radius of action. 
3. Sometimes the sound can be a helpful guide. When the needle is inserted there is usually a dropping off in frequency, and when the pitch (whine) becomes constant the concrete is free from entrapped air.

4. The surface appearance also gives an indication of whether or not compaction is complete. A thin film of shining mortar on the surface is a sign that the concrete is compacted, as is cement paste showing at the junction of the concrete and formwork.

In general, the dangers from under-vibration are far greater than those from overvibration. Therefore, in cases where there is any doubt of over-vibration, don't be in a hurry to stop vibrating. In fact, over-vibration is better than under-vibration, since it is impossible to overvibrate a properly designed mix (CCANZ 2006 and CCAA 2006).

Bhattacharjee (2005) proposed an equation to calculate the time needed to vibrate the reinforced concrete, in order to have a fully compacted mix, based on volume of the concrete, concrete slump, diameter of the needle, coefficient of aggregate shapes, and coefficient of steel density.

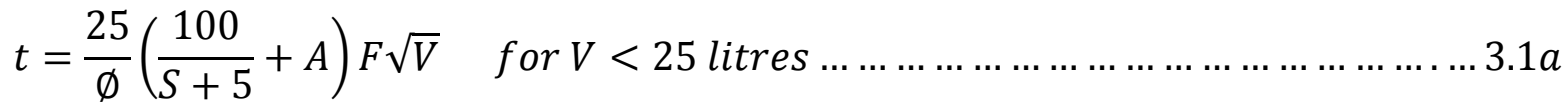

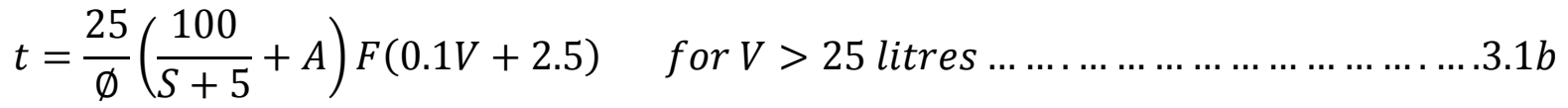

Where: $\mathrm{t}$ is the total needed vibration duration (sec) for $\mathrm{V}$ liters of concrete, $\emptyset$ is the diameter of the needle vibrator $(\mathrm{mm}), \mathrm{S}$ is the slump of the concrete $(\mathrm{cm}), \mathrm{A}$ is the coefficient of aggregate shape $A=1$ for rounded and $A=5$ for crushed, and $F$ is the coefficient of steel density $F=1.5$ for very dense $\mathrm{F}=1$ for no reinforcement.

\subsection{MECHANISM OF RE-VIBRATION OF CONCRETE}

Re-vibration of concrete is the process of vibrating again the placed concrete, intentionally and systematically, sometime after its consolidation is completed. It is well known that the vibration of concrete after placement improves the concrete's properties. However, the 
technique of disturbing the concrete mix during the hardening process, which is known as revibration, is not widely used. The technique was developed in order to release the water which is generally trapped beneath horizontal reinforcing bars not only was this achieved by the disturbance of the hydration process, but also many of the properties of the concrete appear to be actually improved by the re-vibration. The earliest report about the benefit of re-vibration of fresh concrete was written by Tuthill and Davis (1938). Research that shows the advantages of re-vibration of concrete has been conducted by Sawyer \& Lee (1956), Vollick (1958), Tuthill (1977), Maclnnis \& Kosteniuk (1979), ACI (1996), Aldalinsi et al. (2003), Bhattacharjee (2005), CCANZ (2006), CCAA (2006), Krishna et al. (2008), and Ismail (2009). These works are summarized and discussed in the following section.

\subsubsection{Influence of Re-Vibration on Some Concrete Properties}

Sawyer \& Lee (1956) studied the relationship between the compressive strength of concrete and the re-vibration time lag (the time elapsed from the time concrete is cast and vibrated and the time when the second vibration is applied) for concrete mixtures with and without air entrainment. They concluded that in case of the non-air-entrained mix, re-vibration could start up after 6 hours have passed from the first vibration. The maximum allowable revibration time lag for the air-entrained mix was found to be $51 / 4$ hours. In addition, the compressive strength was increased about $36 \%$ for 7 day-specimens without air entrainment. The increment of compressive strength occurred after a vibration time lag of 4 hours. For the 28 and 90 day-specimens, the increments in the compressive strengths were $24 \%$ and $15 \%$, respectively. The air-entrained specimens had about $6 \%$ less strength than their non-air-entrained counterparts. The air-entrained specimens showed the maximum increase in strength when revibration was applied about 3 hours after casting. Figure 3.9 shows the experimental results done by the authors for different re-vibration time lag intervals ranging from 1 hour to 6 hours and a fixed water-cement ratio. 


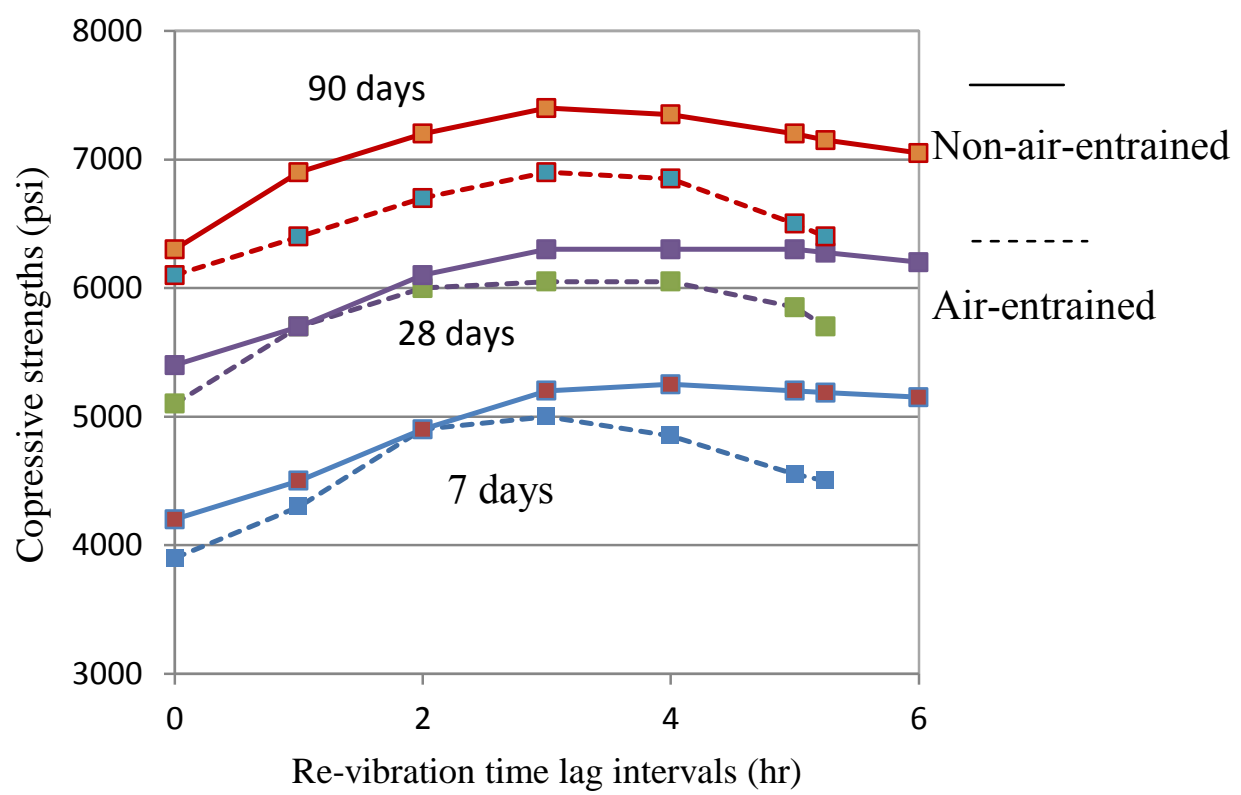

Figure 3.9: Compressive strength versus re-vibration time lag for fixed water-cement ratio (after Sawyer \& Lee 1956)

Vollick (1958) studied the effect of re-vibration at re-vibration time lags of 1, 2, 3, and 4 hours on the 28 day-compressive strength of concretes designed with varying cement contents and different admixtures. Also, effects on bleeding and hardening time were investigated. He concluded that the compressive strength increased due to re-vibration. His results, which were based on the standard compressive strength test of $6 \times 12$ in. cylinders, show that the mixes containing $4 \frac{1}{2}$ sacks of cement per cubic yard increased their strength from $8.5 \%$ to $17.1 \%$, and the mixes containing $5 \frac{1}{2}$ sacks increased their strength from $6.9 \%$ to $18.7 \%$. The plots in Figure 3.10 show the effect of re-vibration on the 28 day-compressive strength of laboratory tested concrete mixtures. 


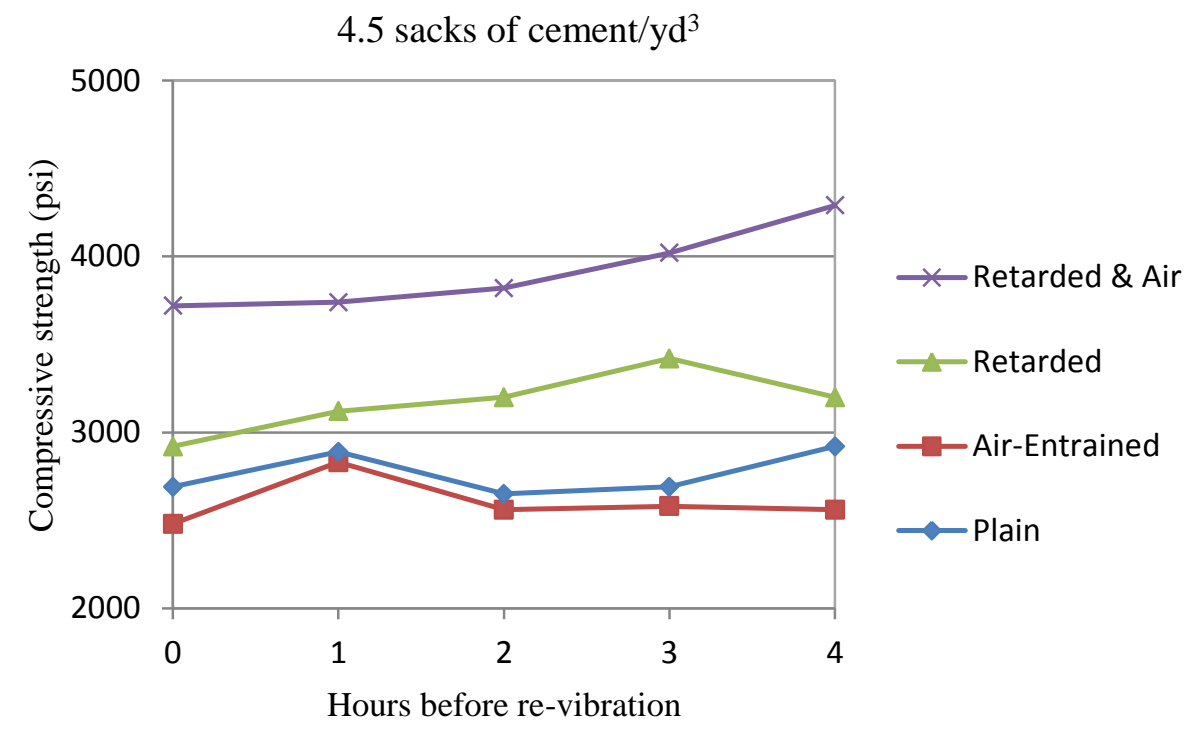

a- Initial vibration and re-vibration $=40$ seconds

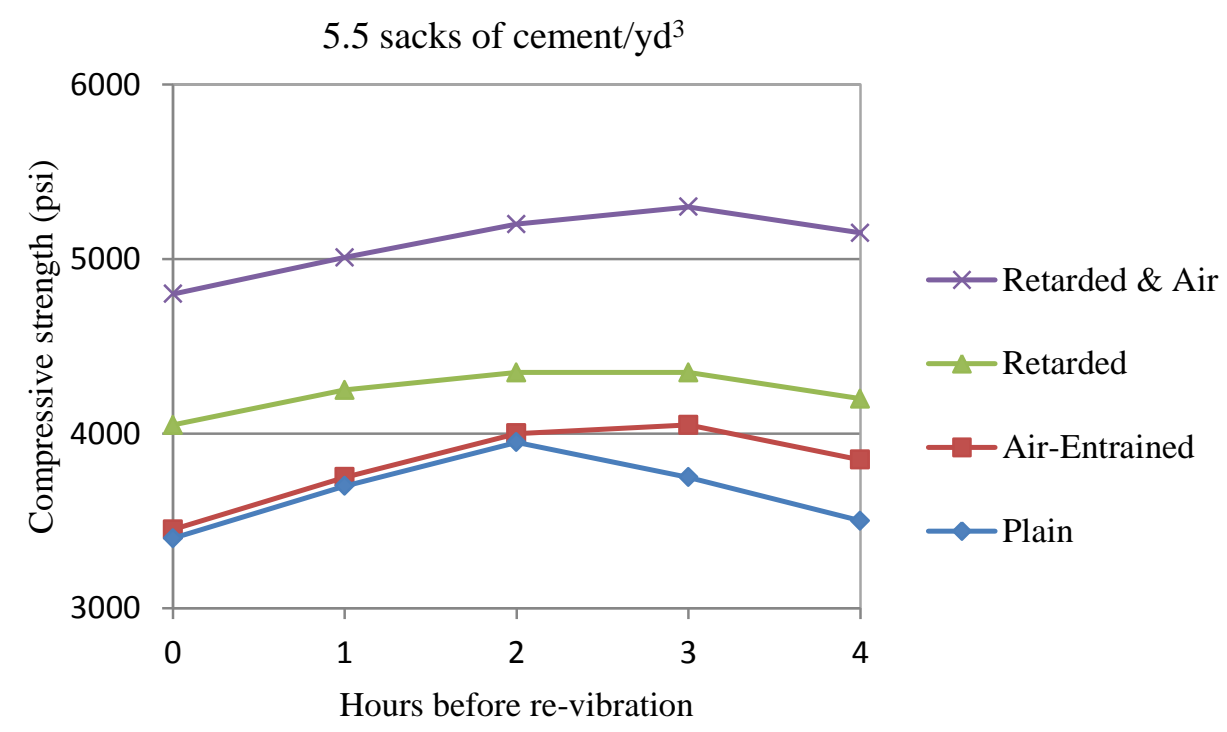

b- Initial vibration and re-vibration $=40$ seconds

Figure 3.10: Effect of re-vibration on compressive strength of laboratory-mixed concrete (after Vollick 1958) 
Maclnnis \& Kosteniuk (1979) studied the effect of re-vibration and high-speed slurry mixing on the compressive strength of high-strength concretes, in the range of 70 to $84 \mathrm{Mpa}$ compressive strengths and water-cement ratios of $0.3,0.35$ and 0.40 . Re-vibration after $21 / 2$ hours from casting was found to produce significant strength increases at all water-cement ratios tested at all ages, as is shown in Figure 3.11. The figure shows that increases in strength ranged from $3 \%$ to $9 \%$ and were the largest for the water-cement ratio of 0.35 . The high-speed slurry mixing, used in the study, did not produce strength increases.

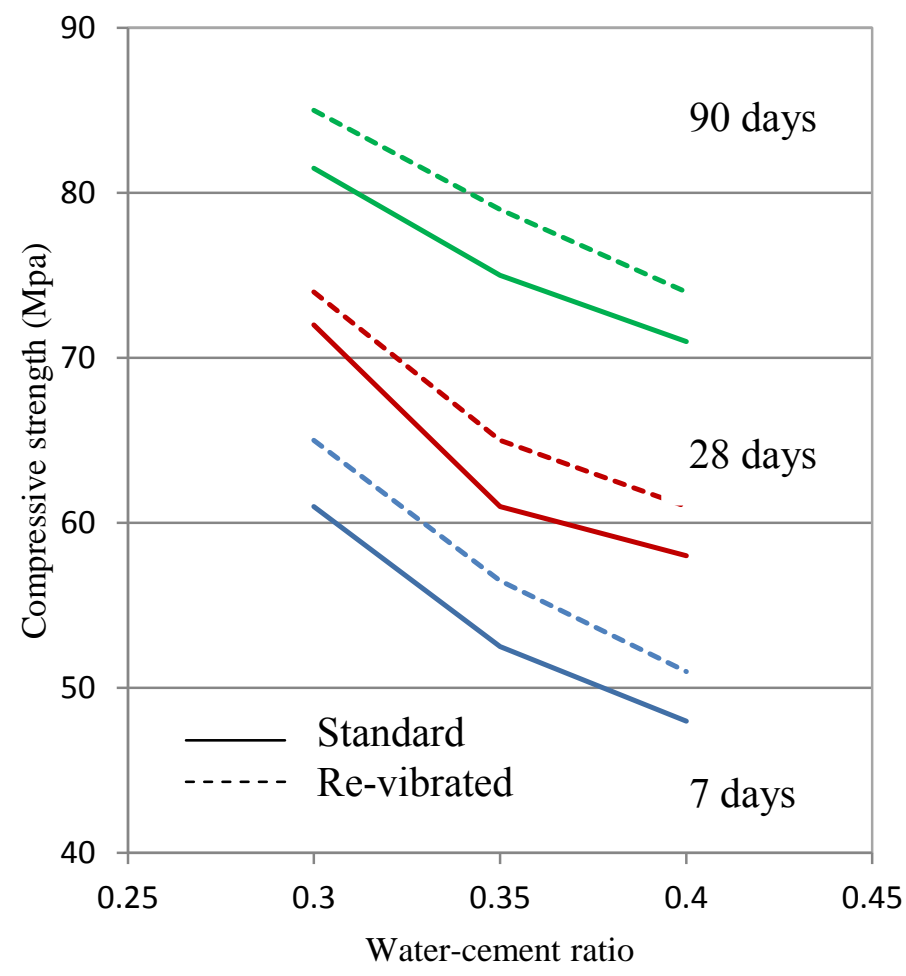

Figure 3.11: Effect of re-vibration on compressive strength (after Maclnnis \& Kosteniuk 1979)

Aldalinsi et al. (2003) studied the effect of re-vibration on 28 day-compressive strength of concrete in dry climates. In this study, the re-vibration time lag was varied from $1 / 2$ hour to 3 hours while the length of re-vibration was varied from 45 to 75 seconds. They tested 40 cubic concrete samples $(15 \times 15 \times 15 \mathrm{~cm})$ made with concrete mixtures with water-cement ratios of 0.50 , $0.53,0.57$, and 0.61 . Ten samples for each water-cement ratio were casted. They concluded that the compressive strength was increased when re-vibration time lag was $1 / 2$ hour, 1 hour and 2 
hours and decreased after a re-vibration time lag of 3 hours from casting. Also, they found that the best length of re-vibration was 75 seconds for all concrete mixtures, as is shown in Figure 3.12. The figure shows the relationship between water-cement ratio and compressive strength for different initial vibration times. The figure also shows small differences in the compressive strength for a given water-cement ratio. The exception is the concrete mix with a water-cement ratio of 0.57 , for which the longer the mix was vibrated the higher the compressive strength of the sample. Figure 3.13 shows the 28 -day compressive strength of concrete versus the revibration time lags for water-cement ratio of 0.53 , which was selected by the authors to be the best water-cement ratio among the tested ones based on the workability tests.

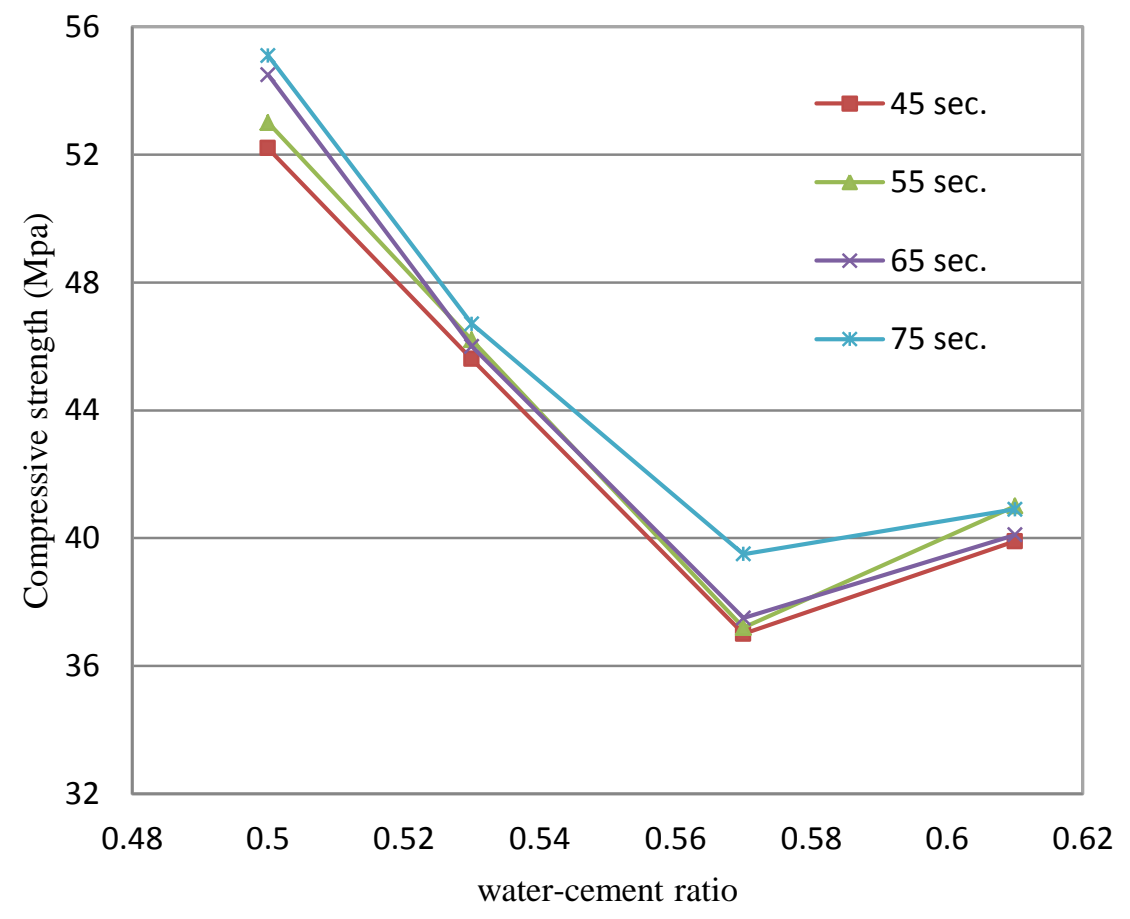

Figure 3.12: Compressive strength versus water-cement ratio (after Aldalinsi et al. 2003) 


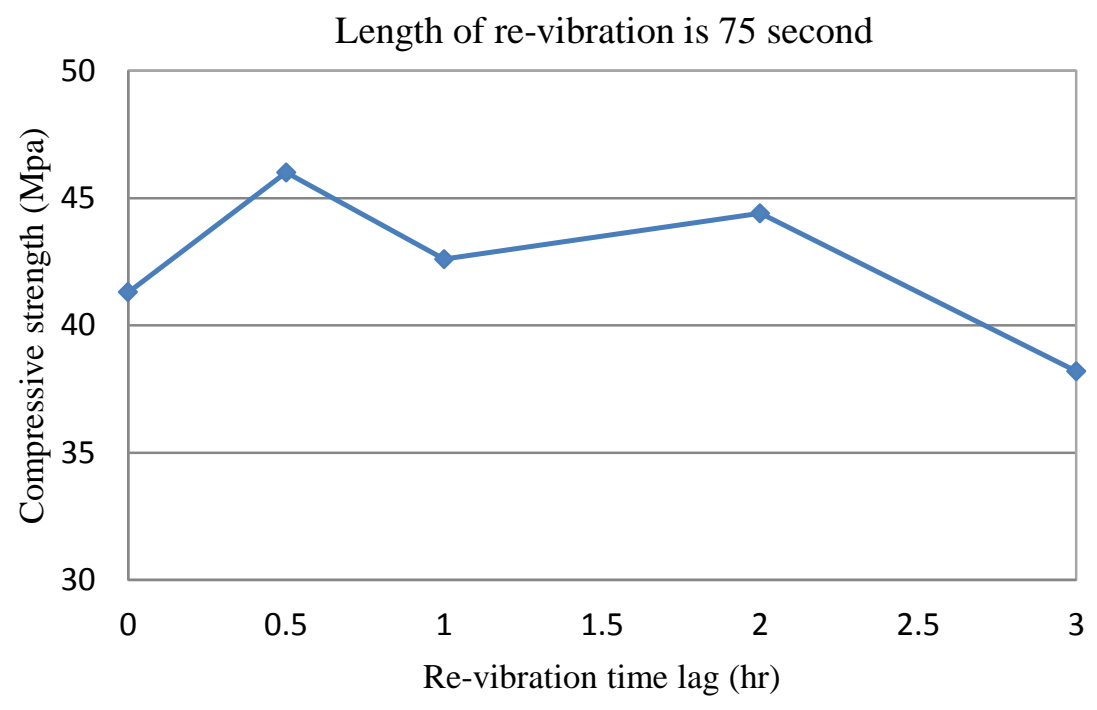

Figure 3.13: Compressive strength versus re-vibration time lag for water-cement $=0.53$ (after Aldalinsi et al. 2003)

Krishna et al. (2008) studied the effect of re-vibration of concrete on the compressive strength of concrete and concrete density. They used a wide range of water-cement ratios varying from 0.35 to 0.70 and with different re-vibration time lag intervals ranging from $1 / 2$ hour to four hours. The plots in Figure 3.14 show the change in compressive strength for different revibration time lags and water-cement ratios. It can be observed that the compressive strengths increase with time lag up to a point in which it reaches a maximum value. Re-vibration time lags longest that the one corresponding to the maximum values result in lower compressive strengths. Also, by comparing Figures 3.14 and 3.15 it can be concluded that changes in compressive strength at a given time lag are positively correlated to changes in concrete density. 


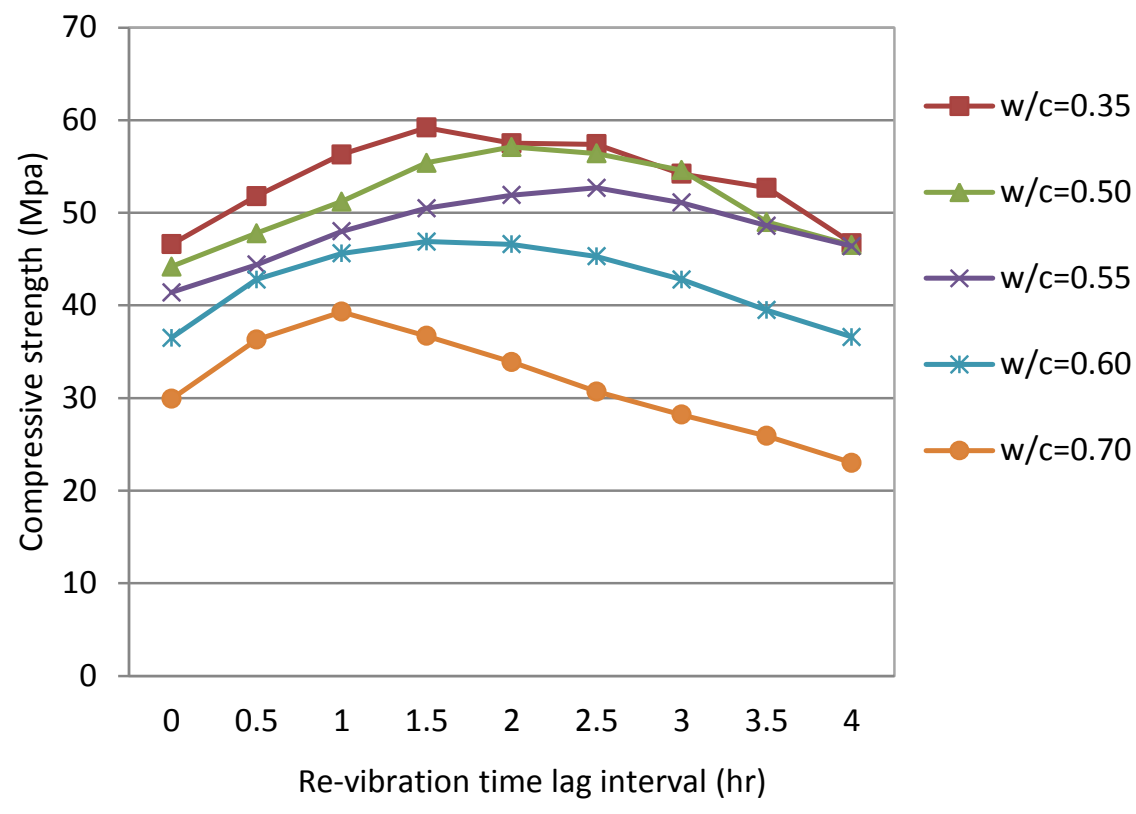

Figure 3.14: Compressive strength versus re-vibration time lag for different water-cement ratios (after Krishna et al 2008)

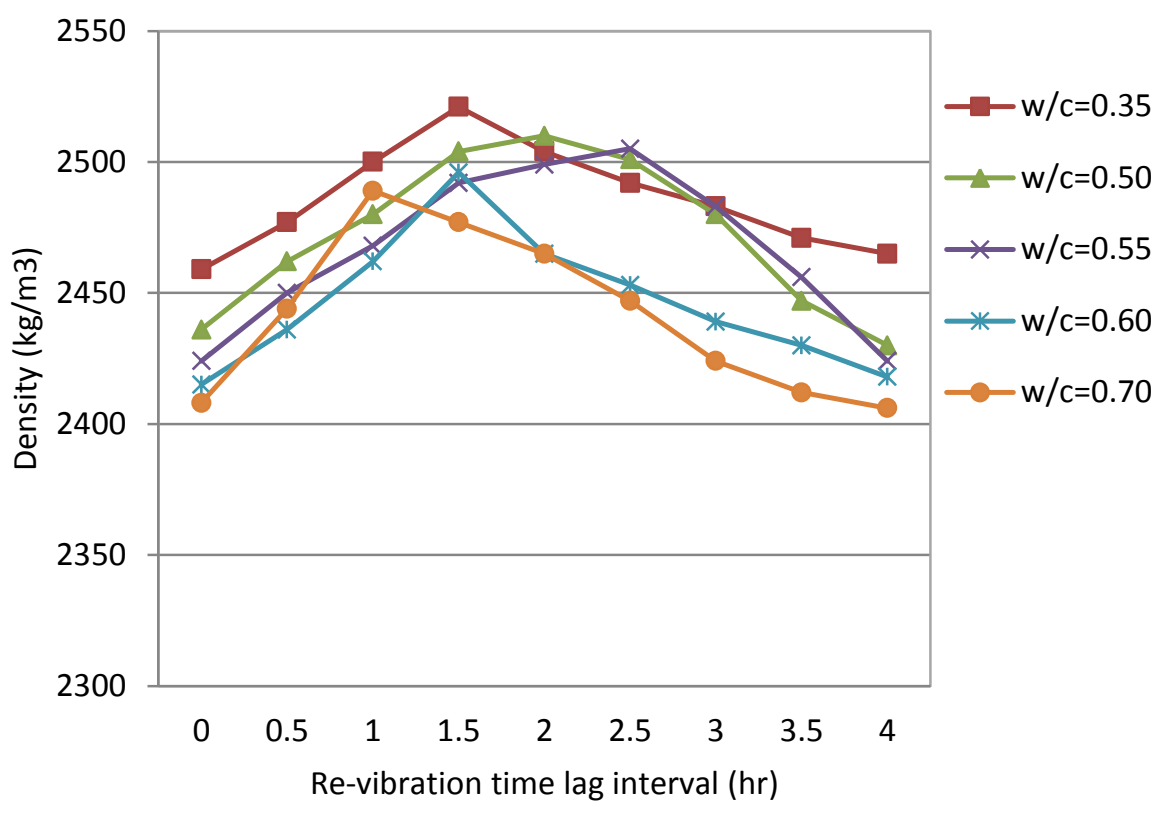

Figure 3.15: Density versus re-vibration time lag for different water-cement ratios (after Krishna et al 2008) 


\subsection{ConCLuSION}

This chapter has reviewed the mechanisms of concrete vibration and re-vibration. The current research in the area of concrete re-vibration has shown successful application of concrete re-vibration. Therefore, the question now arises as to whether concrete re-vibration can be generally used to control the damage that may occur due to plastic shrinkage of concrete. Based on the experimental results, it appears that concrete can be successfully re-vibrated up to 6 hours from the time of mixing. However, re-vibration between 1 to 2 hours after placing was at all times found to result in an increase in the 28-day compressive strength, as shown in Figures 3.10, 3.13, and 3.14. In general, the improvement of the compressive strength would depend on the workability (rheology) of the concrete mix. The mixes liable to high bleeding show better improvement in the compressive strength and the bond between concrete and reinforcement due to the concrete re-vibration expels the trapped water. It is also possible that some of the improvement in the compressive strength is due to a relief of the plastic shrinkage stresses around aggregate particles (Neville 2011). Therefore, the impact of re-vibration technique on controlling plastic shrinkage cracking will be investigated in the next two chapters. 


\section{Chapter 4: Experimental Program}

\subsection{INTRODUCTION}

This chapter describes, in detail, the experimental program that was followed to assess the influence of applying re-vibration to concrete in the development of plastic shrinkage cracking. The experimental program was based on ASTM's standard experimental procedure for evaluating plastic shrinkage cracking of fibered concrete. In addition, a workability test was conducted on the concrete mixes. The chapter describes the experimental design, equipment used for conducting the tests, and properties of the materials used. Several tests to confirm the influence of the re-vibration technique in the compressive strength of concrete were also done. The results of the experimental program integrated the data-base which was used to determine the factors that influence the development of plastic shrinkage cracking after the casted concrete is re-vibrated. These results were compared with those of mixes that contained fiber and were not applied a second vibration.

\subsection{Description of Experimental Program}

The literature review did not identify a standard test procedure to evaluate the influence of re-vibration on the development of PSC. The only standard procedure available is ASTM's method for evaluating PSC of fibered concrete. The experimental program followed in this research used ASTM's C1579 Standard Test Method for Evaluating Plastic Shrinkage Cracking for Restrained Fiber Reinforced Concrete (shown in Appendix A) as the basis for the test method employed in this research. Several modifications were made and will be described later. The main modification was that non-fibered concrete mixes were disturbed by a second vibration sometime after casting. The mold used in this test has stress raisers and provides a sufficient surface area that exposes the concrete to a designated drying weather condition, guaranteeing the formation of plastic shrinkage cracks. In addition, the specimen has a volume that facilitates the application of vibration using an internal vibrator. It was assumed that the introduction of a second vibration would not modify the basic information that the method provides regarding 
plastic shrinkage cracking. Modifications made to ASTM C1579 Test method included the following:

1. The environmental conditions were controlled in a control room instead of the environmental chamber that is described in ASTM C1579. The control room, as shown in Figure 4.1, was used in this study to control the air temperature, wind velocity, and relative humidity which generates sufficient drying conditions that prompt evaporation rates ranging from 0.5 to $1.0 \mathrm{~kg} / \mathrm{m}^{2} / \mathrm{hr}(0.1$ to $0.2 \mathrm{lb} / \mathrm{ft}^{2} / \mathrm{hr}$ ). The layout of the specimens inside the control room is shown in Figure 4.2. Concrete that is subject to these rates, as described in section 2, may develop plastic shrinkage cracking. The weather conditions were recorded by using a handheld weather station, as shown in Figure 4.3. The size of the control room facilitated the application of vibration using an internal vibrator. Variations of evaporation rates from specimen to specimen were minimized because all specimens were under the same weather conditions at the same time.

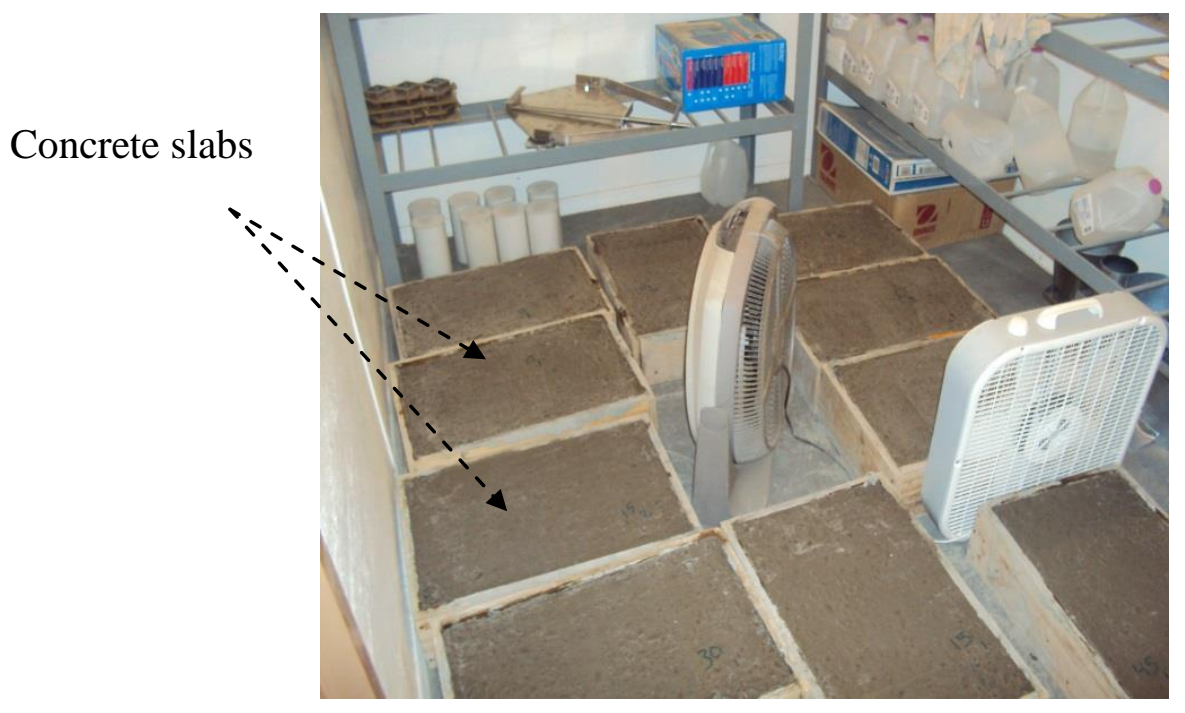

Figure 4.1: Concrete specimens inside the control room. 


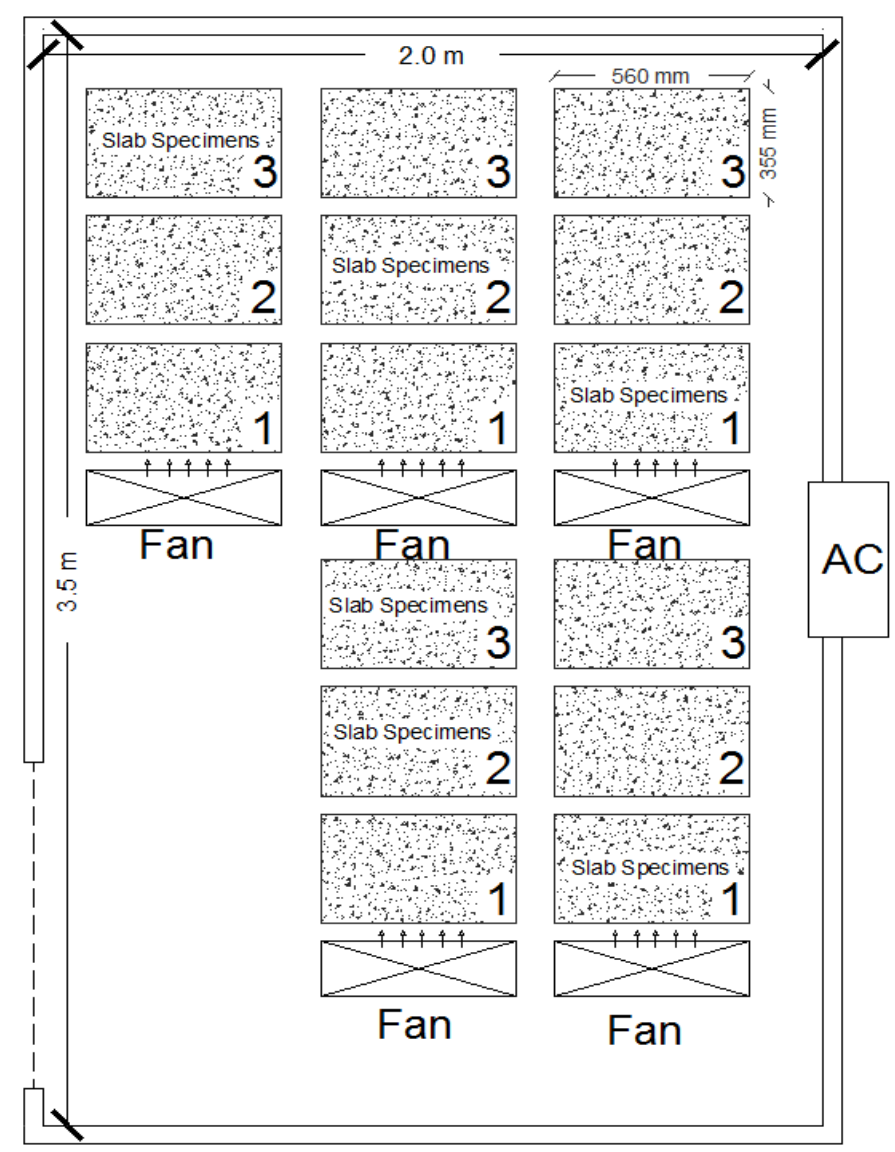

Figure 4.2: Layout of slab specimens inside the control room

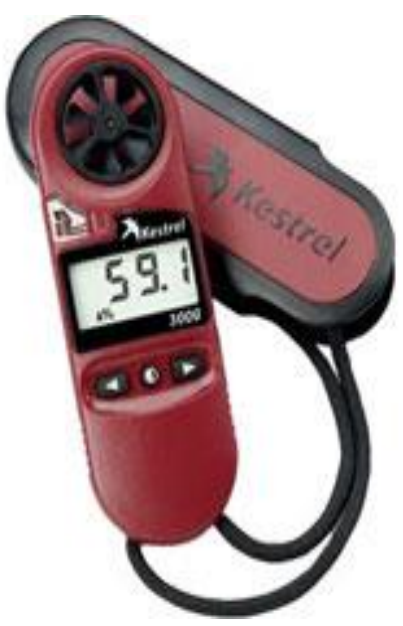

Figure 4.3: Handheld weather station Kestrel 3000 used in this study. 
2. The influences of settlement and autogenous shrinkage on the plastic shrinkage cracking were not considered due to unavailability of laboratory equipment to measure settlement displacement and volume change of concrete. Only the influence of evaporation rates was considered.

3. An internal vibrator that meets minimum frequency requirements in ASTM C192 was used instead of the vibrating platform specified in ASTM C1579. More details about the selection of the internal vibrator are presented later on.

4. The specimens were monitored for up to six hours. Re-vibration was introduced $1.5 \mathrm{~h}$ after casting. Therefore, the author did not attempt to determine the final setting times of the concrete, which are commonly considered to be up to 6 hours after casting for normal concretes (PCA 2003, Qi et al. 2003 \&2005, and Transportation Research Circular 2006).

After six hours, the concrete specimens were stored in the control room under uncontrolled weather conditions for the next 18 hours. Mixing of the concrete ingredients was done in accordance with ASTM C192 specification. Before placing the concrete in cylindrical and slab molds, the slump test was conducted to measure the workability of the used concrete mixtures. After placing the concrete in both cylindrical and slab molds, initial vibration was applied to compact the concrete uniformly. After being initially vibrated, the specimens were placed inside a control room that allows researchers to control and monitor the environmental variables (relative humidity, air speed, and air temperature). The specimens were re-vibrated after having spent 90 minutes inside the control room. Three re-vibration times were used: 15 , 30 , and 45 seconds.

After 24 hours from casting, the final readings for crack widths and lengths were made. Also, after 24 hours from casting concrete in the cylindrical molds, the cylindrical concrete specimens were removed from the mold and cured in a water tank at $21 \pm 2{ }^{\circ} \mathrm{C}\left(70 \pm 3.5{ }^{\circ} \mathrm{F}\right)$, as specified by ASTM, for 28 days. Finally, the cylindrical specimens were tested to determine their compressive strength. Results were used to evaluate the impacts of concrete re-vibration on the compressive strength of concrete. 


\subsection{MATERIALS}

Concrete used in this research was made using a mixture of only three materials: aggregate, Portland cement, and potable water. In addition, fibers were used to prepare the concrete mixes for the specimens that were used to compare the effectiveness of utilizing the revibration technique vs. adding fibers to the concrete mix in the control PSCs. The following section describes in more detail each of the materials used.

\subsubsection{Aggregate}

Locally available sand (C-33), called siliceous sand, and gravel (maximum size $19 \mathrm{~mm}$, $3 / 4$ in), called limestone-dolomite, were used in this study. The physical properties of coarse and fine aggregates used in this study are shown in Table 4.1. All aggregates were conditioned in a laboratory environment for at least 24 hours before their use. In preparing the mixtures, the moisture content was adjusted to substitute for the absorption capacity of the aggregates. The fine and coarse aggregates met the standard gradation requirements, as specified in ASTM C33/C33M (ASTM 2013), and shown in Appendix B. 
Table 4.1: ASTM designation numbers and physical properties of coarse and fine aggregates used in this study.

\begin{tabular}{|c|c|c|c|}
\hline ASTM & Test Procedures & $\begin{array}{l}\text { Coarse Aggregate } \\
(19 \mathrm{~mm}, 3 / 4 \mathrm{in})\end{array}$ & $\begin{array}{l}\text { Fine Aggregate } \\
\qquad(\mathrm{C}-33)\end{array}$ \\
\hline $\mathrm{C} 127 / \mathrm{C} 128$ & Specific Gravity (SSD) & 2.701 & 2.602 \\
\hline $\mathrm{C} 127 / \mathrm{C} 128$ & Absorption Capacity, \% & 0.5 & 1.1 \\
\hline C128 & Relative Density (SSD) & 168.5 & 162.4 \\
\hline $\mathrm{C} 29$ & $\begin{array}{c}\text { Bulk Density (Unit Weight) by Rodding } \\
\text { in PCF }\end{array}$ & 105 & 110 \\
\hline $\mathrm{C} 29$ & Voids in Aggregate by Rodding, $\%$ & 39 & - \\
\hline C131 & L.A. Abrasion, Grading (Meth. B), $\%$ loss & 25 & - \\
\hline $\mathrm{C} 88$ & $\begin{array}{c}\text { Soundness of Aggregate by use of } \\
\text { Magnesium Sulfate, } \%\end{array}$ & 0.6 & 1.5 \\
\hline D4791 & Flat and Elongated (3:1), \% & 1.2 & - \\
\hline C142 & $\begin{array}{c}\text { Clay Lumps \& Friable Particles in } \\
\text { Aggregate }\end{array}$ & 0.1 & 0.0 \\
\hline C117 & $\begin{array}{c}\text { Material finer than } 75 \mu \mathrm{m} \text { (No.200) } \\
\text { Sieve, } \%\end{array}$ & 0.3 & 0.4 \\
\hline $\mathrm{C} 123$ & Lightweight Particles in Aggregate, \% & 0.03 & 0.0 \\
\hline $\mathrm{C} 123$ & Chert (less than 2.4 sp. Gr. SSD), $\%$ & 0.0 & - \\
\hline D123 & $\begin{array}{l}\text { Coal and lignite (less than } 2.0 \mathrm{sp} . \mathrm{Gr} . \\
\text { SSD), \% }\end{array}$ & 0.1 & 0.01 \\
\hline $\mathrm{C} 33$ & $\begin{array}{c}\text { Sum of clay lumps, Friable Particles, and } \\
\text { Chert (less than } 2.4 \text { sp. Gr. SSD), \% }\end{array}$ & 0.1 & - \\
\hline $\mathrm{C} 40$ & Organic Impurities & - & $<$ plate No. 1 \\
\hline $\mathrm{C} 33$ & Fineness modulus & - & 2.85 \\
\hline D3042 & Acid Insoluble Residue by Wt, \% & - & 98 \\
\hline D2419 & Sand Equivalent Value, \% & - & 94 \\
\hline
\end{tabular}




\subsubsection{Cement}

Commercially available Type I \& II Portland cement (I-II Low Alkalie) was utilized for all mixtures used in this study. Tables 4.2 and 4.3 provide a summary of the cement composition and its properties, as supplied by the manufacturer and specified by ASTM C150/C150M (2012).

Table 4.2 Chemical composition of cement

\begin{tabular}{|c|c|c|}
\hline Standard Chemical Requirements & Specifications Limit & Test Results \\
\hline $\mathrm{SiO}_{2}$ & $\mathrm{~N} / \mathrm{A}$ & $19.9 \%$ \\
\hline $\mathrm{Al}_{2} \mathrm{O}_{3}$ & $6.0 \max$ & $4.6 \%$ \\
\hline $\mathrm{Fe}_{2} \mathrm{O}_{3}$ & $6.0 \max$ & $3.7 \%$ \\
\hline $\mathrm{CaO}$ & $\mathrm{N} / \mathrm{A}$ & $63.6 \%$ \\
\hline $\mathrm{MgO}$ & $6.0 \max$ & $1.9 \%$ \\
\hline $\mathrm{SO}_{3}$ & $3.0 \max$ & $2.80 \%$ \\
\hline Loss on ignition & $3.0 \max$ & $0.35 \%$ \\
\hline Insoluble residue & $0.75 \max$ & $1.48 \%$ \\
\hline $\mathrm{CO}_{2}$ & $\mathrm{~N} / \mathrm{A}$ & $3.57 \%$ \\
\hline Limestone content & $5.0 \max$ & $2.94 \%$ \\
\hline Corrected limestone & $5.0 \max$ & $94.0 \%$ \\
\hline CaCO ${ }_{3}$ in limestone & $70.0 \min$ & $23 \%$ \\
\hline $\mathrm{C}_{4} \mathrm{AF}+2\left(\mathrm{C}_{3} \mathrm{~A}\right)$ or $\mathrm{C}_{4} \mathrm{AF}+\mathrm{C}_{2} \mathrm{~F}$ & $\mathrm{~N} / \mathrm{A}$ & $0.55 \%$ \\
\hline $\mathrm{Alkalies}^{*}$ & $0.60 \max$ & \\
\hline & & \\
\hline
\end{tabular}

N/A Not applicable

*Optional (Sodium Oxide Equivalent) min. 0.55\% and max. 0.59\%

Table 4.3 Potential compound composition of cement

\begin{tabular}{|c|c|c|c|}
\hline $\mathrm{C} 3 \mathrm{~S}$ & $\mathrm{C} 2 \mathrm{~S}$ & $\mathrm{C} 3 \mathrm{~A}$ & $\mathrm{C} 4 \mathrm{AF}$ \\
\hline $56 \%$ & $15 \%$ & $6 \%$ & $11 \%$ \\
\hline
\end{tabular}




\subsubsection{Fibers}

The commercially available fiber that was used in this study was fibrillated polypropylene micro-synthetic fiber (FPF), produced by the Euclid Chemical Company. FPF is manufactured from $100 \%$ homopolymer virgin polypropylene, containing no recycled materials. FPF provides optimum strength, reduces cracking and increases long-term durability. FPF fiber products are typically used at dosage rates of $0.6-0.9 \mathrm{~kg} / \mathrm{m}^{3}\left(1.0-1.5 \mathrm{lbs} / \mathrm{yd}^{3}\right)$. Table 4.4 shows the properties of the FPF fiber.

Table 4.4 Properties of FPF fiber

\begin{tabular}{|c|c|}
\hline Material & Fibrillated polypropylene \\
\hline Specific gravity & 0.91 \\
\hline Typical dosage rate & $0.9 \mathrm{~kg} / \mathrm{m}^{3}\left(1.5 \mathrm{lbs} / \mathrm{yd}^{3}\right)$ \\
\hline Available lengths & 19,39 and $51 \mathrm{~mm}(3 / 4,1 \mathrm{~m} / 2$ and $2 \mathrm{in})$. \\
\hline Used Length & $660 \mathrm{Mpa}(97 \mathrm{kn})$. \\
\hline Tensile strength & $4.0 \mathrm{GPa}(580 \mathrm{ksi})$ \\
\hline Modulus of elasticity & $165^{\circ} \mathrm{C}\left(330{ }^{\circ} \mathrm{F}\right)$ \\
\hline Melt point & Low \\
\hline Electrical Conductivity & Negligible \\
\hline Water absorption & Excellent \\
\hline Acid and alkali resistance & Approximately 31 million/ kg $(14 \mathrm{~m} / \mathrm{lb})$ \\
\hline Fiber count & \\
\hline
\end{tabular}

\subsection{WATER-CEMENT RATIOS}

The water-cement ratios were selected to be $0.5,0.55$ and 0.60 . These ratios are the most common ones for normal construction (e.g. residential, pavement, and light commercial building projects) and produce concrete with good workability in hot and dry regions, such as West Texas. In addition, according to ACI 305R-1999 (ACI 1999) the bleeding water of concrete made with these water-cement ratios is about the same as the water that evaporates, thus maintaining the surface of the concrete wet during the set time of concrete. The compressive 
strengths of the concrete made with these water-cement ratios range from 17 to $34 \mathrm{Mpa}$ (2500 to 5000 psi).

\subsection{PREPARATION OF SPECIMENS}

\subsubsection{Mixture Proportions}

Normal strength concrete with compressive strength ranging from 17 to $34 \mathrm{Mpa}$ (2500 to $5000 \mathrm{psi}$ ) and density ranging from 2240 to $2800 \mathrm{~kg} / \mathrm{m}^{3}$ (140 to $\left.175 \mathrm{lb} / \mathrm{ft}^{3}\right)$, was produced using Type I \& II Portland cement, fine aggregate (C-33), and coarse aggregate (19 mm, 3/4 in). The proportions of the concrete mixtures used in this study are shown in Table 4.5. These proportions are the ones used by the concrete supplier. Also, the fibered concrete mixtures were produced by adding FPF fibers to concrete coming from the same batch. The proportion of FPF fibers in the mixture was $0.9 \mathrm{~kg} / \mathrm{m}^{3}\left(1.5 \mathrm{lbs} / \mathrm{yd}^{3}\right)$, as specified by Euclid Chemical Company. (www.euclidchemical.com).

Table 4.5: Mixture proportion for normal strength concrete

\begin{tabular}{|c|c|c|c|c|}
\hline $\begin{array}{c}\text { Water-cement } \\
\text { ratio }\end{array}$ & $\begin{array}{c}\text { Cement kg/m } \\
\left(\mathrm{lb} / \mathrm{Yd}^{3}\right)\end{array}$ & $\begin{array}{c}\text { Water } \mathrm{kg} / \mathrm{m}^{3} \\
\left(\mathrm{lb} / \mathrm{Yd}^{3}\right)\end{array}$ & $\begin{array}{c}\text { Coarse aggregate } \\
\mathrm{kg} / \mathrm{m}^{3}\left(\mathrm{lb} / \mathrm{Yd}^{3}\right)\end{array}$ & $\begin{array}{c}\text { Fine aggregate } \\
\mathrm{kg} / \mathrm{m}^{3}\left(\mathrm{lb} / \mathrm{Yd}^{3}\right)\end{array}$ \\
\hline 0.50 & $279(470)$ & $139.4(235)$ & $1067.9(1800)$ & $947.5(1597)$ \\
\hline 0.55 & $279(470)$ & $153.7(259)$ & $1048.3(1767)$ & $929.7(1567)$ \\
\hline 0.60 & $279(470)$ & $167.3(282)$ & $1048.9(1768)$ & $893.5(1506)$ \\
\hline
\end{tabular}

\subsubsection{Mixing}

ASTM C1579 specifies that evaporation rates should be the same for all specimens with a tolerance of $\pm 5 \%$. In this work, all samples for a given water-cement ratio were cast at the same time, using the same batch of concrete. Therefore, all samples were subjected to the same weather conditions and were assumed to have the same evaporation rates. To control the quality of the mix, mixing was done in the concrete batching plant of the concrete supplier in accordance with ACI and ASTM standards. Three batches of concrete (one for each water-cement ratio) 
were delivered from the concrete batching plant to the laboratory to conduct the experiments. For each water-cement ratio, about $3 / 4$ cubic meters (one cubic yard) of the concrete mixture was brought to the laboratory by a truck mixer and poured into the tested specimens. To prepare the specimens with fibered concrete, fibers were added to the mixtures and mixed by hand.

\subsubsection{Molds}

\subsubsection{PSC Molds}

To evaluate the plastic shrinkage cracking, of the re-vibrated and fibered concrete, plywood-restrained slab molds (as shown in Figure 4.4) were utilized in accordance with ASTM C1579 (ASTM 2013). The stress riser, shown in Figure 4.4, was then inserted in the molds. The molds received a light oil coating to facilitate removal of the specimen.

\subsubsection{Compressive Strength Molds}

Standard cylindrical molds $(15 \times 30 \mathrm{~cm}$ or $6 \times 12$ in) were used to cast the specimens and determine the compressive strengths of concrete, as specified by ASTM C39/C39M (ASTM 2012) and shown in Figure 4.5.
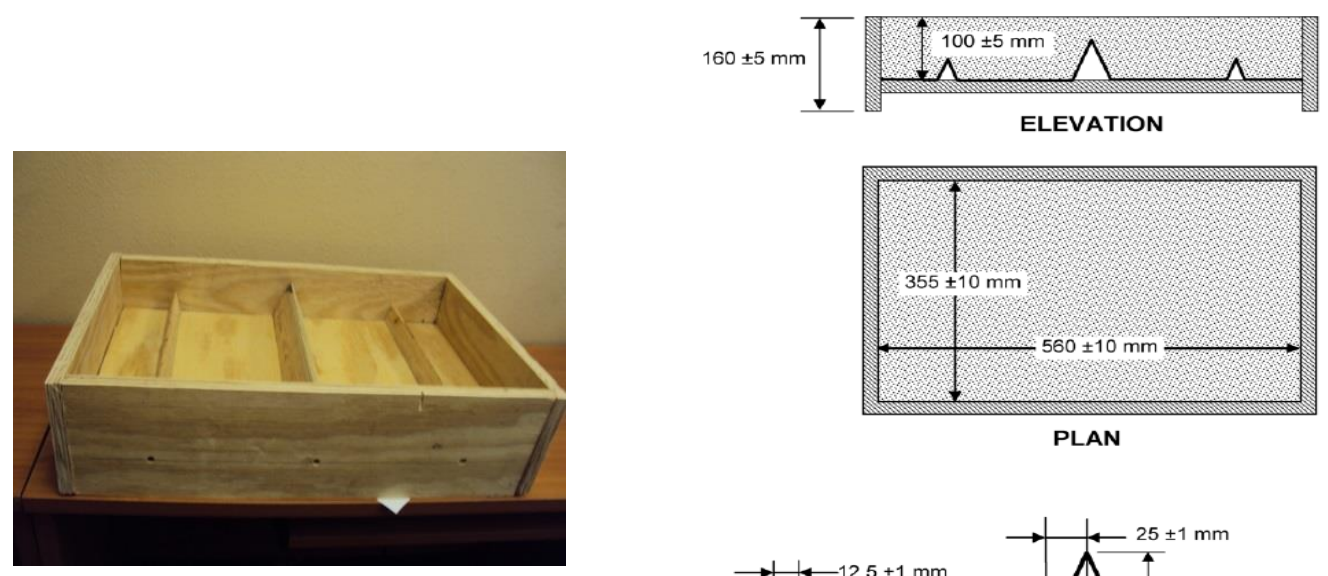

Slab mold fabricated from Plywood

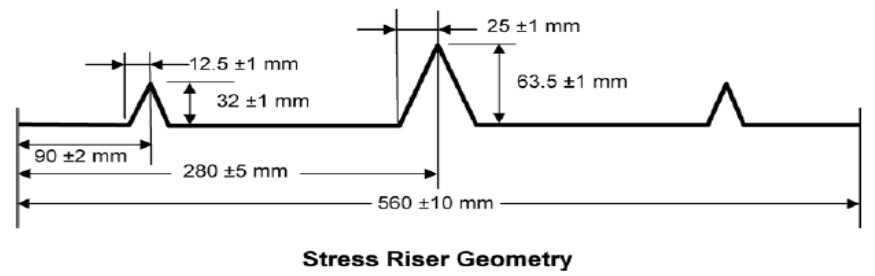

Figure 4.4: Restrained slab mold dimensions (after ASTM C1579-2013) 


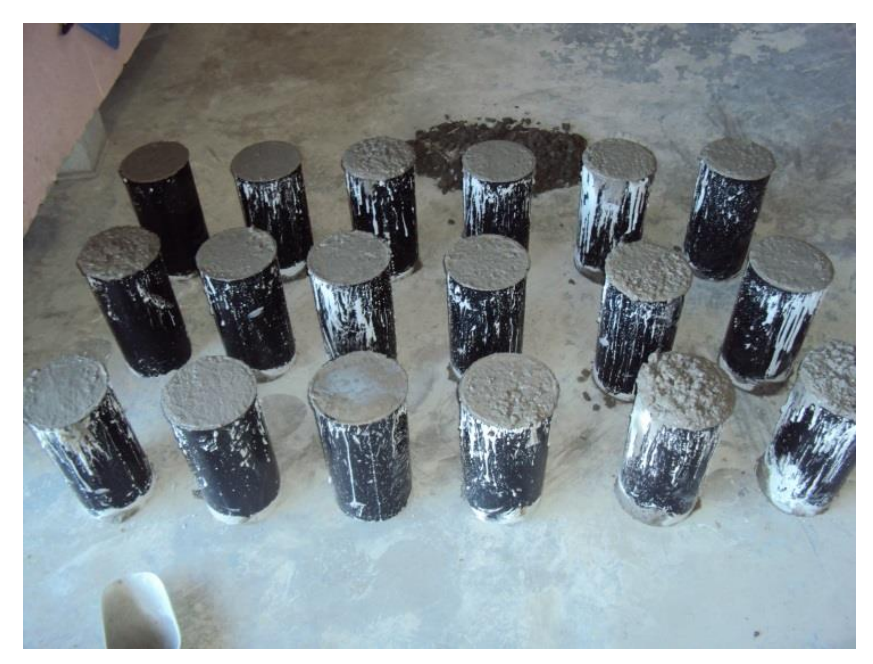

Figure 4.5: Standard cylindrical molds filled with concrete

\subsubsection{Placing}

Slab and cylindrical specimens were cast inside the lab but outside of the control room. After casting the concrete into the slab and cylindrical molds, an internal vibration was initially applied to the mix for approximately 3-5 seconds. After this first vibration, concrete slabs were moved to a controlled room, where they set for one and half hours. During this time the concrete began to harden and water continued to bleed to the surface of the slabs. After one and a half hours of the hardening process, a second vibration was applied to the specimens. Three vibration times for the second vibration were used: 15, 30 and 45 seconds. An explanation of why these second vibration time lengths were chosen is provided in the section 4.7. After the second vibration, the concrete slabs were screeded perpendicular to the stress risers. Concrete surface was finished using a smooth steel trowel. The slabs that did not have a second vibration and the fibered concrete slabs were finished outside of the control room before they were moved inside.

\subsection{EnVironmental Conditions}

The concrete slabs were prepared and moved to the control room in order to expose them to controlled drying weather conditions for the first six hours. Drying weather conditions are the conditions that promote the development of plastic shrinkage cracks and are achieved through a combination of air temperature, humidity, concrete temperature and wind speed values. There 
are multiple combinations of these parameters that create a dry weather condition. The air temperature, relative humidity, and wind speed values inside the control room were recorded every hour. The concrete temperature was measured directly after casting. Figure 4.6 and 4.7 show the variation of the air temperature and relative humidity inside the control room respectively. They also show the upper and lower bounds for the variation of the air temperature and relative humidity from the respective average values. The author used a variation of $\pm 3{ }^{\circ} \mathrm{C}$ $\left( \pm 5.5^{\circ} \mathrm{F}\right.$ ) to set the bounds for the air temperature and a variation of $\pm 10 \%$ to set the bounds for the relative humidity. These bounds are similar to those specified by the ASTM C1579. The figures show that for the three tests (one for each mixture) conducted the air temperature and relative humidity stayed within bounds. Table 4.6 summarizes the average values of the air temperature, relative humidity, wind speed and concrete temperature. The table also shows the computed evaporation rates using equation 2.1. According to the NRMCA (1960) these values indicate the concrete slabs are prone to show PSCs. 

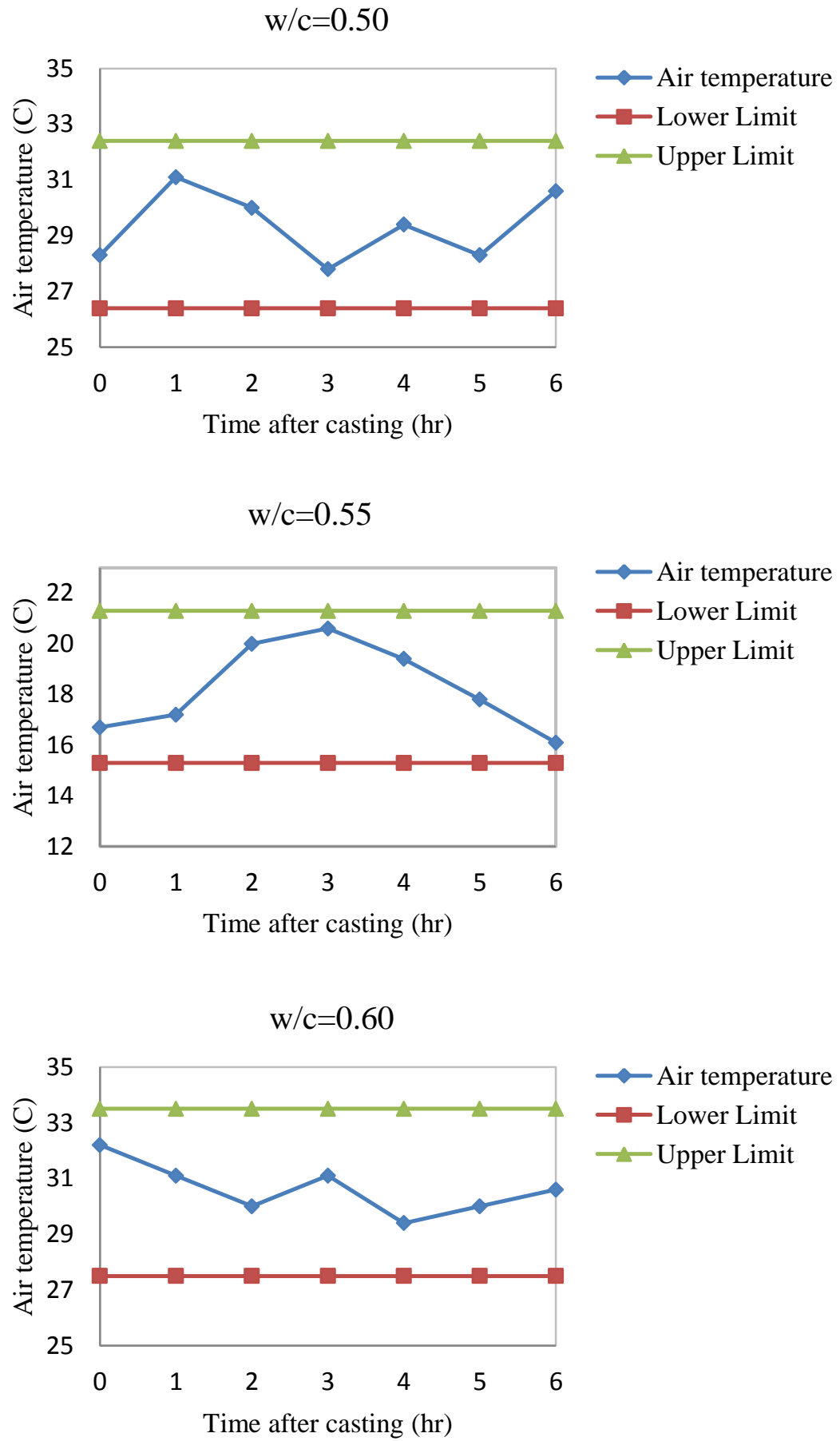

Figure 4.6: Variation of the air temperatures inside the control room. 

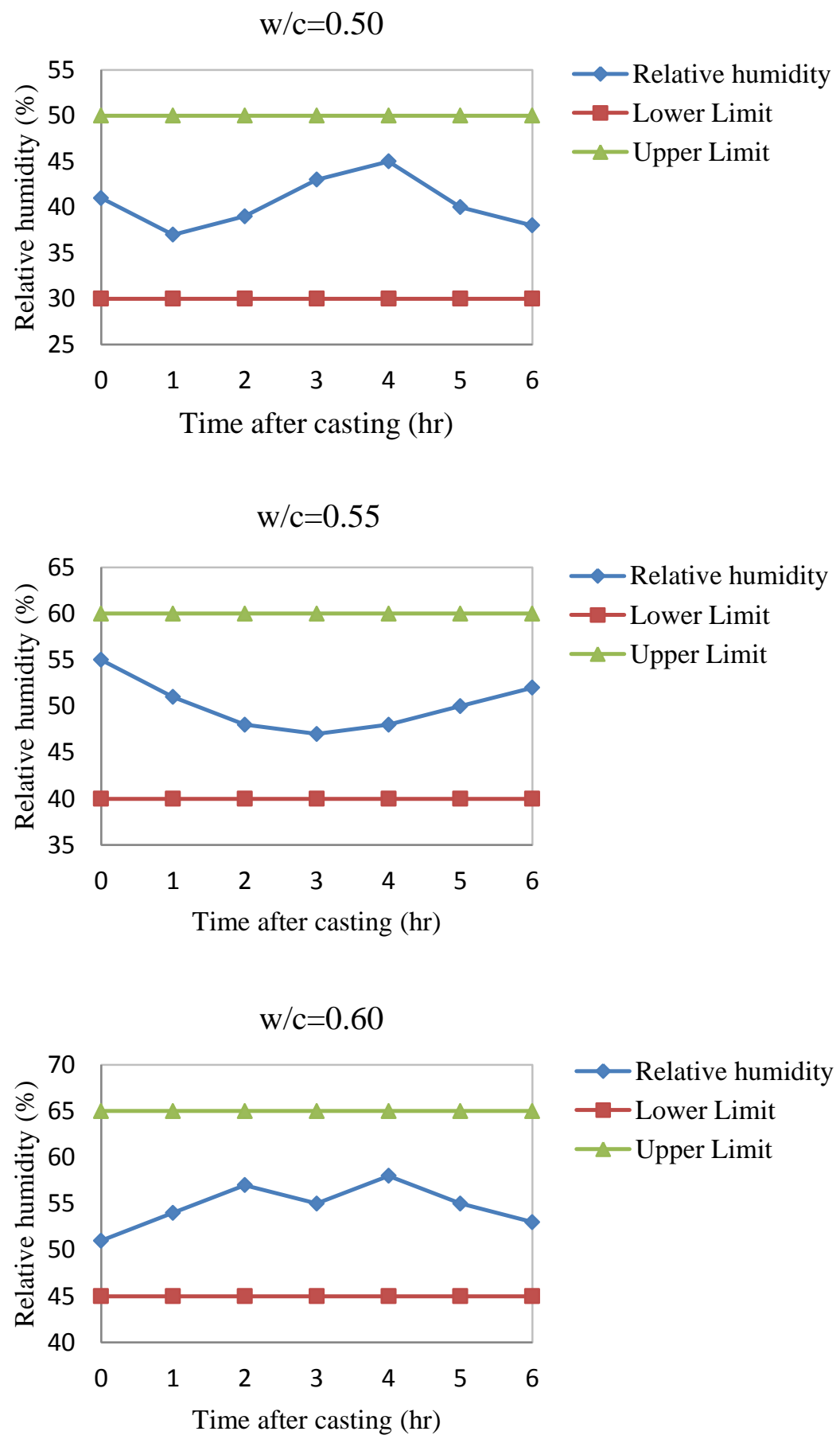

Figure 4.7: Variation of the relative humidity inside the control room. 
Table 4.6: Designated drying weather conditions and computed evaporation rates

\begin{tabular}{|c|c|c|c|c|c|}
\hline $\begin{array}{c}\text { Water- } \\
\text { cement } \\
\text { ratio }\end{array}$ & $\begin{array}{c}\text { Air temperature, } \\
(\mathrm{Ta}),{ }^{\circ} \mathrm{C}\left({ }^{\circ} \mathrm{F}\right)\end{array}$ & $\begin{array}{c}\text { Relative } \\
\text { Humidity }(\mathrm{r}), \\
\%\end{array}$ & $\begin{array}{c}\text { Wind speed } \\
(\mathrm{V}), \mathrm{kg} / \mathrm{hr} \\
(\mathrm{mph})\end{array}$ & $\begin{array}{c}\text { Concrete } \\
\text { temperature } \\
(\mathrm{Tc}),{ }^{\circ} \mathrm{C}\left({ }^{\circ} \mathrm{F}\right)\end{array}$ & $\begin{array}{c}\text { Evaporation rate } \\
(\mathrm{E}) \text { from equation } \\
(2.1), \mathrm{kg} / \mathrm{m}^{2} / \mathrm{hr} \\
\left(\mathrm{lb} / \mathrm{ft}^{2} / \mathrm{hr}\right)\end{array}$ \\
\hline 0.50 & $29.4(85)$ & 40 & $13(8)$ & $26.7(80)$ & $0.61(0.128)$ \\
\hline 0.55 & $18.3(65)$ & 50 & $13(8)$ & $21.7(71)$ & $0.51(0.107)$ \\
\hline 0.60 & $30.5(87)$ & 55 & $13(8)$ & $29.4(85)$ & $0.55(0.109)$ \\
\hline
\end{tabular}

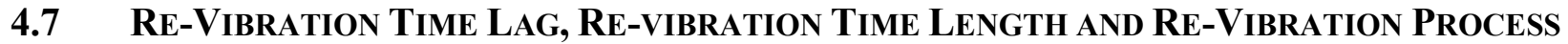

In this study, the waiting time after specimen casting and before a second vibration (revibration time lag) was selected as one and a half hours, based on the findings of Vollick (1958), Aldalinsi et al. (2003) and Krishna et al. (2008), which were discussed in chapter 3. To assess the effect of the length of the second vibration, three lengths of re-vibration times were selected: 15 , 30 and 45 seconds. These re-vibration time lengths produced good vibration of the mixtures, as shown by the uniformity of the mix and the visual sign of good compaction. The author also tried a re-vibration time of 60 seconds. However, the mixtures showed signs of over-vibration and concrete cylinders made with these mixtures showed a decrease in the 7-day compressive strength of concrete. Therefore this re-vibration time length was discarded.

Selection of the internal vibrator was based on the guidelines provided by CVH (2003), CCANZ (2006) and CCAA (2006). According to those guidelines a flexible shaft vibrator is the most adequate for experimental specimens. The author used a $3 / 4$ HP concrete vibrator that has frequency of 13,000 vibrations per minute (vpm), a head diameter and length of 1-3/8" and 15$1 / 8$ " respectively, and a flexible shaft diameter and length of 1-7/32" and 20-3/16"respectively. A $3 / 4$ HP concrete vibrator is shown in Figure 4.8 . 


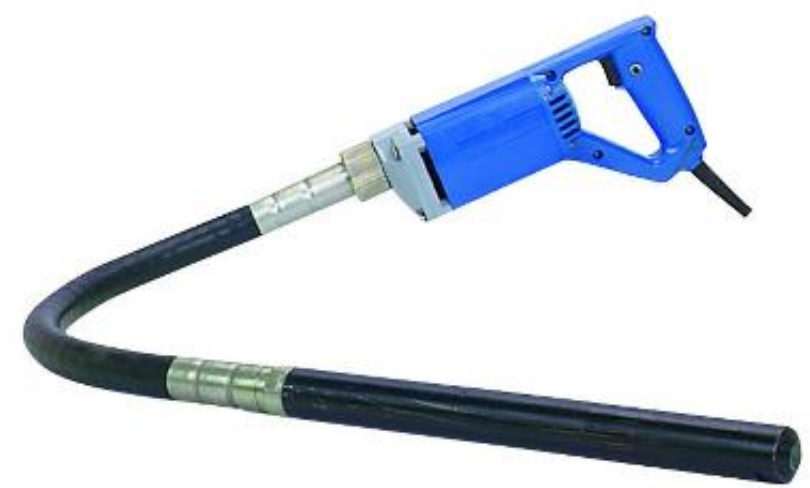

Figure 4.8: A 3/4 HP Flexible shaft (needle) concrete internal vibrator

\subsection{NUMBER OF SPECIMENS}

ASTM requires casting at least two concrete specimens when evaluating the plastic shrinkage cracking or calculating the compressive strength of concrete. In this study, three concrete specimens were chosen for each length of re-vibration time and water-cement ratio combination, and for the fibered concrete, as recommended by Qi et al. (2005). The selection of the three water-cement ratios was discussed in section 4.4 and the selection of the three lengths of re-vibration was discussed in section 4.7. 15 slab specimens were cast to evaluate the plastic shrinkage cracking for each water-cement ratio. The casted slabs for each water-cement ratio were as follows: 1) 3 slab specimens were cast and were only subject to initial vibration (no revibration was applied), 2) 3 slab specimens were cast using the fibered concrete mixture and were not re-vibrated, 3) 3 slab specimens were cast and were subjected to 15 seconds of revibration time, 4) 3 slab specimens were cast and were subjected to 30 seconds of re-vibration time, and 5) 3 slab specimens were cast and were subjected to 45 seconds of re-vibration time. Similarly, 15 cylindrical specimens were cast to calculate the compressive strengths of concrete for each water-cement ratio. Table 4.7 shows the total number of cast specimens that were used in the experimental program. 
Table 4.7: Experimental matrix

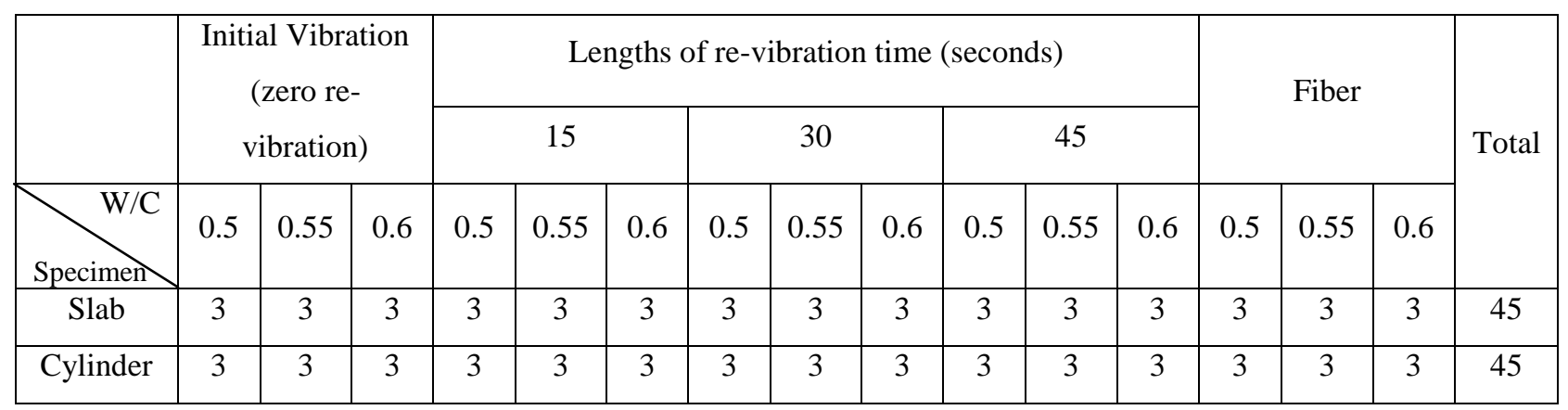

\subsection{Experimental Procedures}

\subsubsection{Slump Test}

The slump test, according to ASTM C143/C143M (2012), was used to describe the workability of all the mixtures investigated in this study. Typically, measuring the slump is very useful in detecting variations in the uniformity (consistency) of a mix, which may provide useful information within a range of variation in workability. The slump test is also very useful in checking the variation of the materials among batches. For example, an increase in slump may mean that the moisture content of aggregate has unexpectedly increased or a change in the grading of the aggregate has occurred. Too high or too low of a slump gives immediate warning and enable the mixer operator to fix the problem (Neville 2011). Mixtures that are re-vibrated have to have a slump of more than $15 \mathrm{~mm}$.

The mold for the slump test is shown in Figure 4.9. It was filled by the concrete in three layers, each layer approximately one third the volume of the mold. Each layer was compacted by $16 \mathrm{~mm}$ rounded end rod (5/8 in) for 25 times uniformly over the cross section. After the top layer was compacted, the surface of concrete was stricken off by means of a screeding and rolling motion of tamping rod. The mold was removed carefully in a vertical direction and immediately the slump was measured by determining the vertical difference between the top of the mold and the displaced original center of the top surface of specimen. 
The workability results were reported as the slump ( $\mathrm{mm}$ or in). Table 4.8 shows the slump measurements and the description of workability of the mixtures investigated in this study. From this table, the workability descriptions of the used concrete mixtures used in this research were of medium to high workability as defined by Neville (2011); therefore, they were able to receive a second vibration.
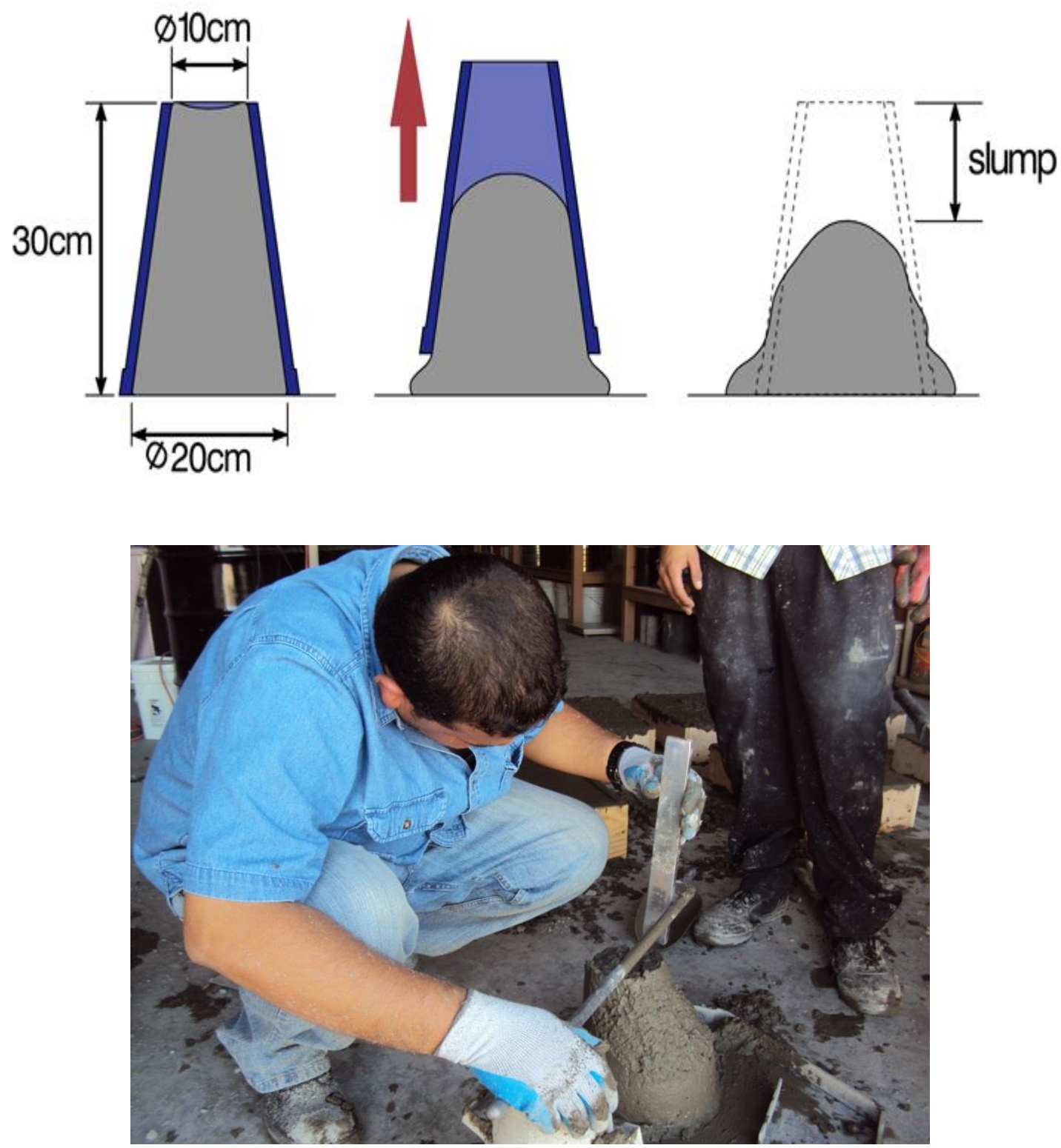

Figure 4.9: Slump test mold and slump measurement 
Table 4.8: Slump magnitude and description of workability of the concrete mixtures

\begin{tabular}{|c|c|c|}
\hline Water-cement ratio & Slump, $\mathrm{mm}$ (in) & Description of workability \\
\hline 0.5 & $68(2.7)$ & Medium \\
\hline 0.55 & $85(3.3)$ & High \\
\hline 0.6 & $102(4)$ & High \\
\hline
\end{tabular}

\subsubsection{Compressive Strength Test}

Compression tests were conducted to confirm that the compressive strength of concrete increases when the cylindrical concrete specimens are exposed to re-vibration after a certain time of delay (time lag of re-vibration) as observed by Sawyer \& Lee (1956), Vollick (1958), Maclnnis \& Kosteniuk (1979), Aldalinsi at el (2003), and Krishna et al. (2008). The compressive strength test method was conducted according to ASTM C39/C39M (ASTM 2012). The test method consists of applying a compressive load to molded concrete cylinders $(15 \times 30 \mathrm{~cm}$ or $6 \mathrm{x}$ $12 \mathrm{in})$ at a certain loading rate $(0.25 \mathrm{Mpa} / \mathrm{sec}$ or $35 \mathrm{psi} / \mathrm{sec})$ until failure occurs. The compressive strength of the specimen is calculated by dividing maximum load attained during the test by the cross-sectional area of the specimen. Figure 4.10 shows the compression testing machine MN-F$30 \mathrm{EX}$, with a load capacity of $1330 \mathrm{KN}(300,000 \mathrm{lb}$.) and the cylindrical concrete specimens used in this study. 


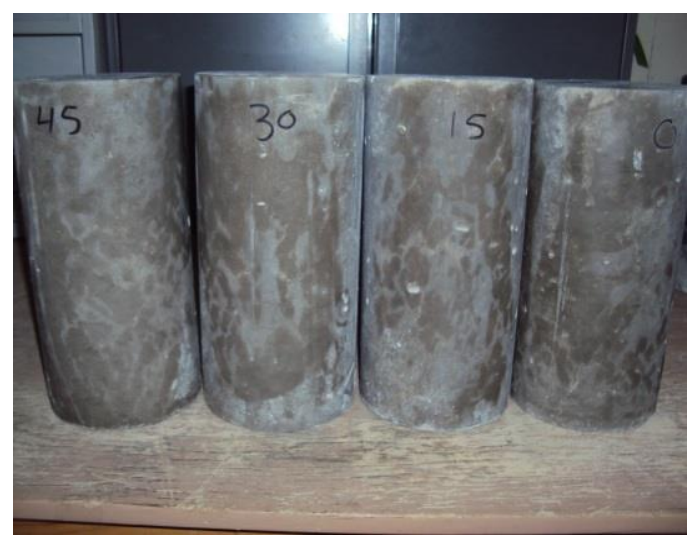

Cylindrical concrete specimens

(a)

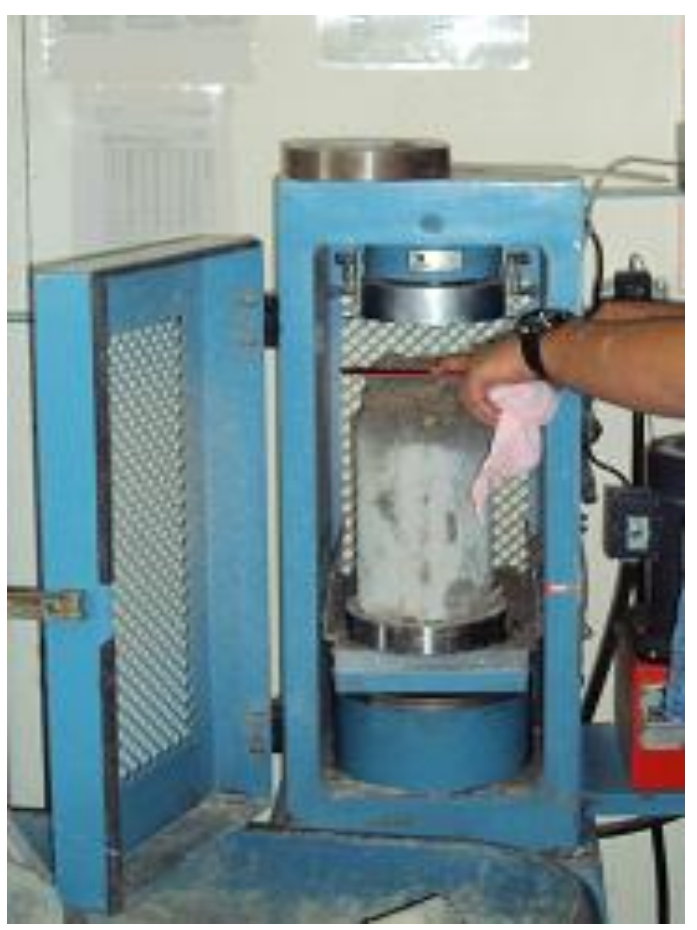

Compression testing machine MN-F-30 EX (b)

Figure 4.10: Testing compressive strength of concrete (a) cylindrical concrete specimens and (b) compression testing machine.

The 28 day-compressive strengths of concrete for all the cylinders tested are shown in Table 4.8 and plotted in Figure 4.11. The general observations from this table are: 1) the compressive strengths were increased up to $7 \%$ when the water-cement ratio was decreased and the concrete was not re-vibrated, as expected; 2) for a given water-cement ratio, the compressive strengths were increased up to $20 \%$ when the concrete specimens were re-vibrated; 3) adding fibers did not show significant impacts on the compressive strengths.

The average compressive strengths versus the lengths of re-vibration time for concretes with different water-cement ratios are plotted in Figure 4.12. The figure shows that the compressive strength of re-vibrated concrete depends on the water-cement ratios and the length of the re-vibration time. 
For water-cement ratio equal to 0.60 , the highest compressive strength was obtained after the mixture was re-vibrated 15 seconds. Longer re-vibration times produced mixtures with significantly lower compressive strengths than the one corresponding to 15 seconds but still higher than the compressive strength of the mixtures that were not re-vibrated. For this watercement ratio, mixtures that experienced a re-vibration for 30 and 45 seconds showed signs of having been over-vibrated, such as an excessive thickness of mortar at the surface of the specimens.

Concretes made with a mixture containing a water-cement ratio of 0.55 also increased their compressive strength after re-vibration. For this mixture the highest increase in compressive strength was obtained when the concrete was re-vibrated for 30 seconds. When the concrete was re-vibrated for 45 seconds it began to show signs of over-vibration, as reflected in a lower compressive strength than that was re-vibrated 30 seconds. The concrete that was re-vibrated for 15 seconds produced concrete with a lower compressive strength. These concrete showed signs of under-vibration such as the appearance of air bubbles on the surface of the specimens.

Concretes made with a mixture containing a water-cement ratio of 0.50 showed an improvement in the compressive strength, as a function of the re-vibration time. In this case the cylinders that were re-vibrated for 45 seconds had an average compressive strength $20 \%$ greater than the cylinders that were not re-vibrated. Cylinders that were re-vibrated 15 and 30 seconds show signs of under-vibration as shown in Figure 4.13.

Concrete mixtures containing fibers did not show a significant improvement in the 28day compressive strength of the concrete, fc' independently of the water-cement ratio used. Figure 4.14 shows the variation of the average fc' for all the mixtures and re-vibration times considered in this research. 
Table 4.8: Compressive strengths of concrete for initial vibrated, re-vibrated and fibered cylindrical concrete specimens

\begin{tabular}{|c|c|c|c|c|c|c|}
\hline \multicolumn{7}{|c|}{28 days compressive strength (fc'), Mpa (psi) } \\
\hline \multirow{2}{*}{$\mathrm{w} / \mathrm{c}$ ratio } & \multirow{2}{*}{ Samples } & \multirow{2}{*}{ Initial vibration } & \multicolumn{3}{|c|}{ Lengths of re-vibration time (seconds) } & \multirow{2}{*}{ Fiber } \\
\hline & & & 15 & 30 & 45 & \\
\hline \multirow{4}{*}{0.50} & 1 & $22.8(3310)$ & $23.6(3420)$ & $27.3(3960)$ & $29(4212)$ & $23.5(3405)$ \\
\hline & 2 & $22.2(3217)$ & $24.5(3556)$ & $26.6(3858)$ & $28.3(4107)$ & $23(3339)$ \\
\hline & 3 & $22.1(3200)$ & $23.2(3365)$ & $24.3(3524)$ & $26.8(3892)$ & $22(3202)$ \\
\hline & Average & 22.37 & 23.77 & 26.07 & 28.03 & 22.83 \\
\hline \multirow{4}{*}{0.55} & 1 & $22.3(3240)$ & $25.5(3700)$ & $28.3(4101)$ & $27.3(3960)$ & $22.5(3270)$ \\
\hline & 2 & $20.8(3018)$ & $24.5(3553)$ & $27.4(3976)$ & $25.6(3713)$ & $21.2(3077)$ \\
\hline & 3 & $21.9(3170)$ & $24.6(3570)$ & $25.5(3695)$ & $24.9(3611)$ & $21.5(3112)$ \\
\hline & Average & 21.67 & 24.87 & 27.07 & 25.93 & 21.73 \\
\hline \multirow{4}{*}{0.60} & 1 & 20.4 (2959) & $26(3771)$ & $22.6(3278)$ & $21.7(3147)$ & 20.8 (3016) \\
\hline & 2 & $21.2(3078)$ & $24.3(3524)$ & 24.1(3495) & $21.4(3104)$ & $21.5(3118)$ \\
\hline & 3 & $20.9(3033)$ & $25.8(3742)$ & $21.9(3176)$ & $21.5(3118)$ & $21.2(3075)$ \\
\hline & Average & 20.83 & 25.37 & 22.87 & 21.53 & 21.17 \\
\hline
\end{tabular}

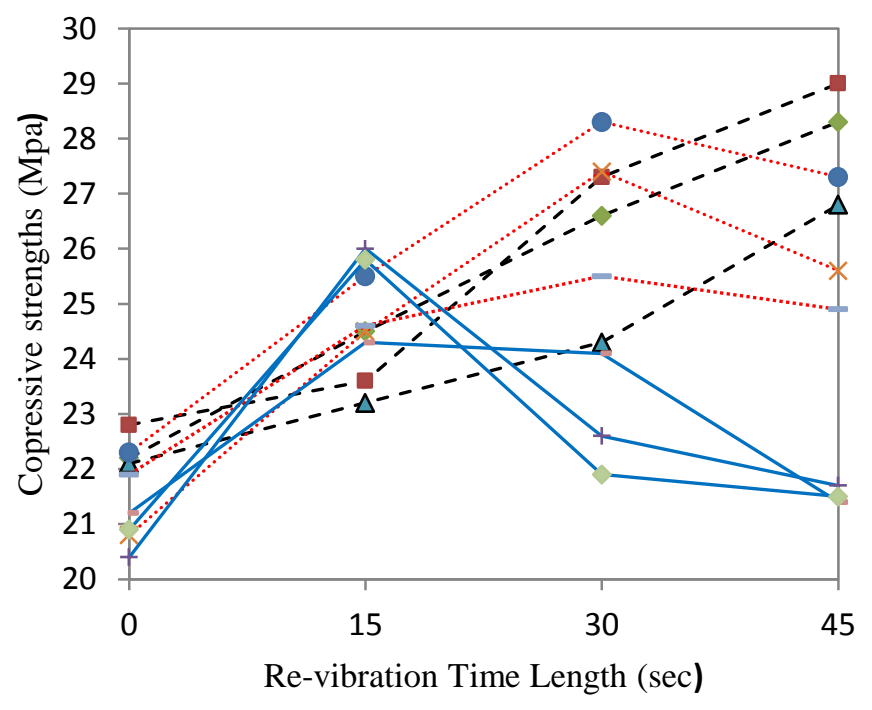

$--m-w / c=0.5(1)$

$--w / c=0.5(2)$

$--\Delta-w / c=0.5(3)$

.........w/c=0.55(1)

.............w/c=0.55(2)

$\cdots \cdot \cdots \cdot \cdots \cdot \mathrm{w} / \mathrm{c}=0.55(3)$

$\longrightarrow w / c=0.6(1)$

$w / c=0.6(2)$

$-w / c=0.6(3)$

Figure 4.11: 28 day-compressive strengths of concrete for all the cylinders tested versus revibration time lengths 


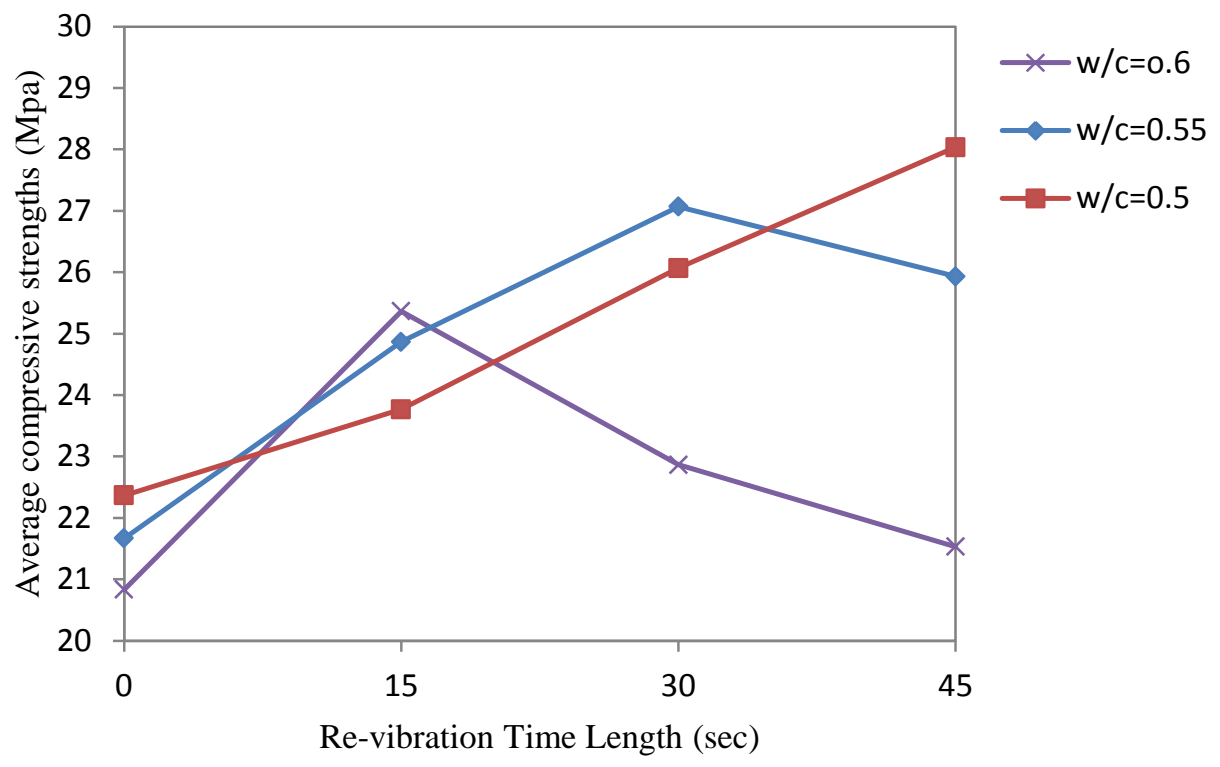

Figure 4.12: Average of 28 day-compressive strength versus re-vibration time lengths

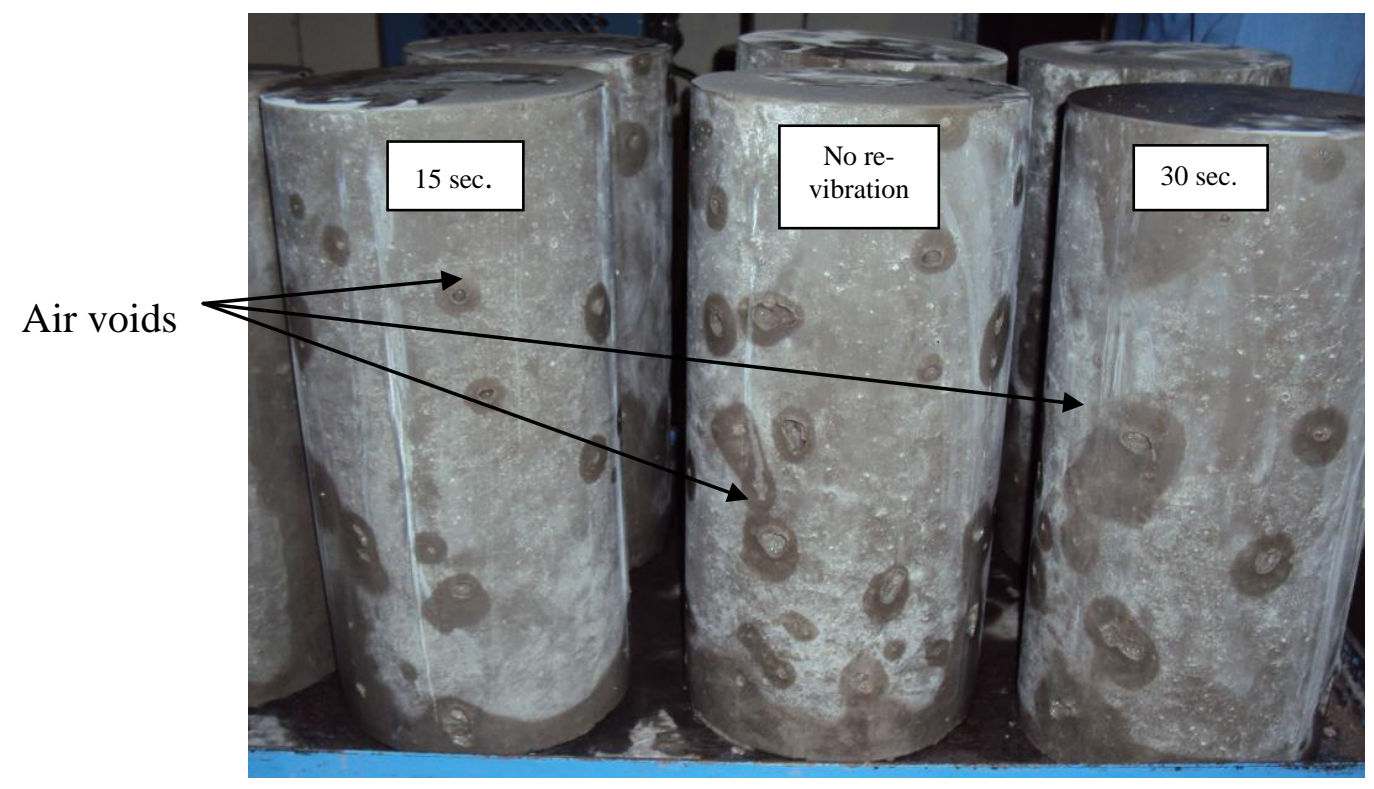

Figure 4.13: Air voids due to under-vibration of cylindrical specimens that were not-re-vibrated, re-vibrated for $15 \mathrm{sec}$. and re-vibrated for $30 \mathrm{sec}$. 


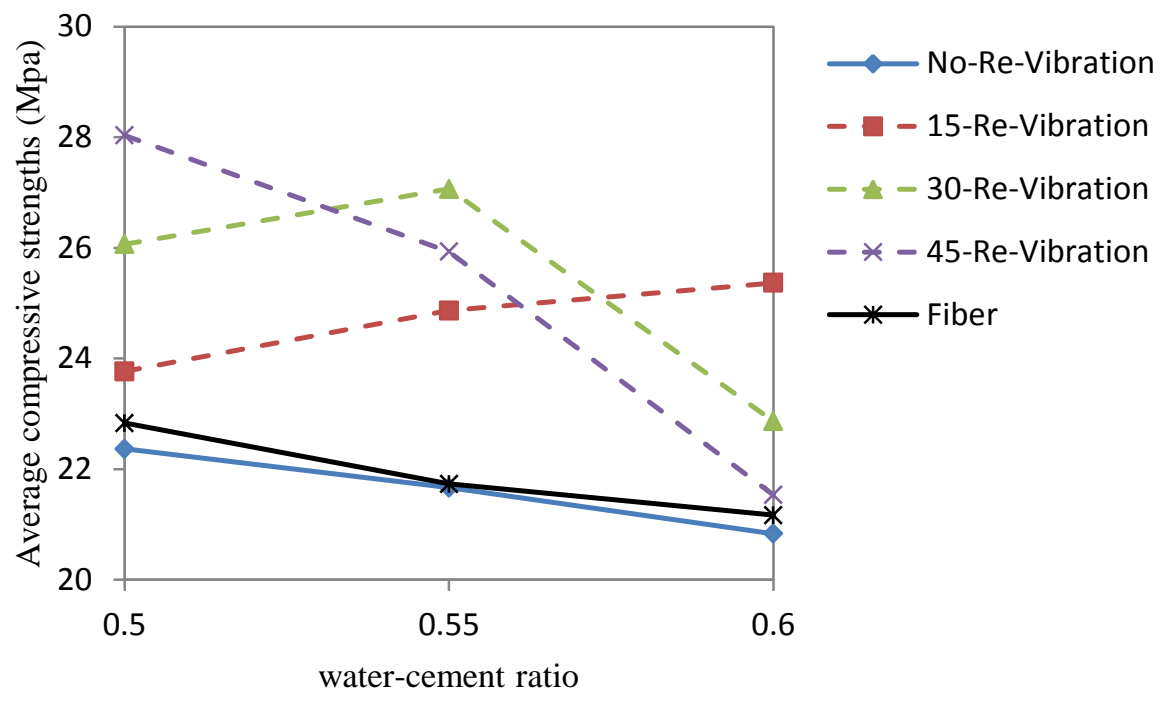

Figure 4.14: Compressive strength versus water-cement ratios

\subsubsection{Plastic Shrinkage Cracking}

One and half hours after concrete casting, the restrained slab specimens were re-vibrated and refinished inside the control room. Plastic shrinkage cracking was monitored continuously for the first 6 hours. After 6 hours, the specimens were kept in the control room at normal environmental conditions for an additional 18 hours. Between 6 and 24 hours, it was noted that the cracking did not change considerably. Therefore, at the time the plastic stage ended $(24 \pm 2$ hours after casting) the specimens were ready to perform the crack measurements.

The time of crack initiation was observed during testing. For non-re-vibrated concrete slabs, approximately 30 minutes after the concrete was cast, fine hairline cracks could be seen above the stress riser in some specimens, independently of the water-cement ratio of the mixture. These very fine cracks, shown in Figure 4.15, were primarily due to plastic settlement. The settlement cracks grew bigger with the time the specimens remained under drying conditions. For re-vibrated concrete slabs, approximately 30 minutes after the concrete was re-vibrated and refinished (two hours after concrete was cast), fine hairline cracks could also be observed above the stress riser in some specimens, independent of the water-cement ratio of the mixture or the time the specimens were re-vibrated. For the fiber reinforced concrete slabs, the surface of fiber 
reinforced concrete appeared to be free of cracking for a longer time. In all cases, the cracks developed along the length of the stress riser. Detailed information about the development of cracks will be presented and discussed in the next chapter.
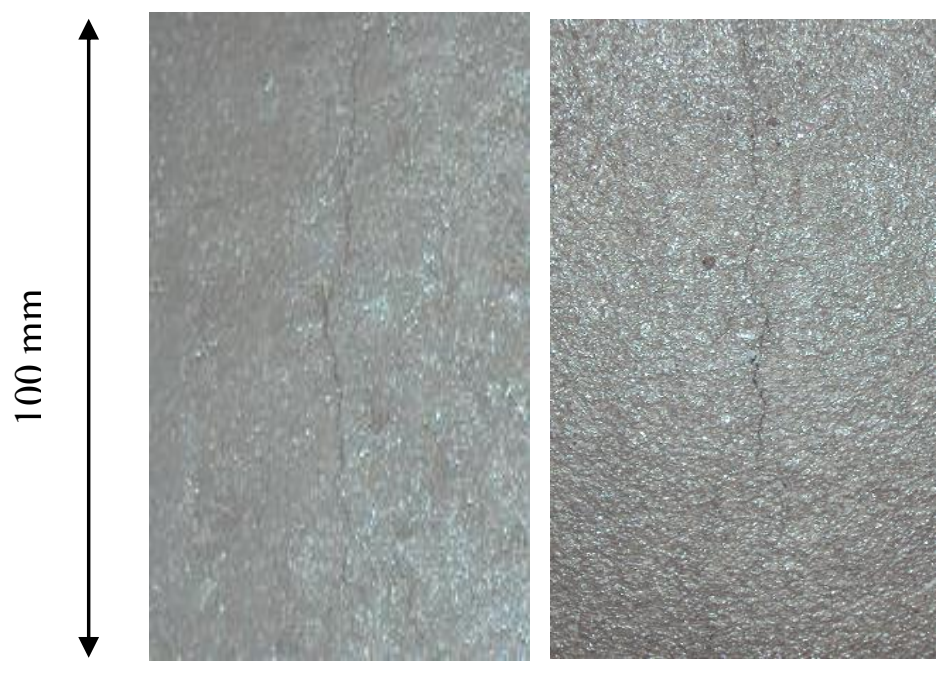

Figure 4.15: Hairline cracks observed after 30 minutes from casting in some slab specimens

\subsection{SUMMARY AND CONCLUSIONS}

This chapter provides information regarding the modifications made to the standard test method for evaluating plastic shrinkage cracking, materials used, specimen preparation, environmental conditions, as well as the re-vibration procedures utilized in this study. The slump test for fresh concrete and the standard compression test for hardened concrete were conducted. Finally, the development of plastic shrinkage cracking was monitored and recorded. The conclusions from this chapter can be summarized as follows:

1. The workability description of the concrete mixtures used in this study was classified as medium to high; therefore, the application of the second vibration was beneficial due to the ability of the mixtures to be re-vibrated without causing segregation.

2. Improvement of the 28-days cylindrical compressive strengths of re-vibrated concrete was observed to be up to $25 \%$ from original concrete cylindrical specimens 
3. The crack initiation time in re-vibrated specimens was random for each of the specimens. Observed crack initiation times vary from $1 / 2$ to 5 hours. More discussion may be found in Chapter 5. Crack initiation times in fibered concrete specimens took about 30 minutes more than the non-re-vibrated specimens. 


\section{Chapter 5: Crack Assessment}

\section{$5.1 \quad$ INTRODUCTION}

Durability may be defined as the ability of concrete to resist weathering action, chemical attack, and abrasion while maintaining its desired engineering properties. The appearance of plastic cracks in concrete reduces its durability because the crack increases water permeability and absorption which allow the water to seep through the concrete structure and cause further problems, such as the corrosion of the embedded reinforcing steel. The occurrence of cracking also provides a direct route for deleterious substances to penetrate the concrete, negatively affecting the concrete's durability. The importance of crack width on long-term durability has been recognized by ACI 224R (ACI 2001) by specifying acceptable crack widths for various exposure conditions for durability design, as shown in Table 5.1. If plastic shrinkage cracking has occurred, the surface of the concrete may require a sealant to enhance durability of concrete structures. It is also important to limit crack width so as to ensure adequate shear behavior in a concrete structure. As crack widths increase, the ability of a structure to transfer shear stresses by collective interlock decreases.

Table 5.1: Acceptable crack widths (ACI 2001)

\begin{tabular}{|c|c|}
\hline Exposure condition & $\begin{array}{c}\text { Acceptable crack width, } \\
\mathrm{mm}(\mathrm{in})\end{array}$ \\
\hline Dry air protective membrane & $0.40(0.016)$ \\
\hline Humidity, moist air, soil & $0.30(0.012)$ \\
\hline Deicing chemicals & $0.18(0.007)$ \\
\hline $\begin{array}{c}\text { Seawater and seawater spray; } \\
\text { wetting and drying }\end{array}$ & $0.15(0.006)$ \\
\hline Water retaining structures & $0.10(0.004)$ \\
\hline
\end{tabular}

Recent research for evaluating the plastic shrinkage cracking in early age concrete used a number of different techniques to measure and characterize the developed cracks. Haavik (1990) 
used a crack comparator to measure the crack width; Soroushia et al. (1995) used optical lenses; Banthia and Yan (2000) and Qi et al. (2003, 2005) used an optical hand-held microscope; and Wang, et al. (2001), Qi et al. (2003, 2005) and Pelisser, et al. (2010) measured crack widths with the help of an automated image analysis system. The measurement accuracy of these techniques was up to $0.01 \mathrm{~mm}$.

In this research, an image analysis approach was followed to characterize the plastic shrinkage cracks. Modifications to the automated image analysis techniques were adopted due to the time required to monitor the growth of the crack width along its length using optical lenses and the unavailability of laboratory equipment for the automated image analysis. In addition, the advantage of the used image analysis approach was that it facilitated the measurement of parallel cracks in the concrete surface when they occurred. More details about this approach are discussed later on in this chapter.

In this chapter, crack widths along the length of the cracks were measured and characterized by their probability density from which statistical parameters, such as the average crack width and its variability (measured as the standard deviation or alternatively by its coefficient of variation) can be computed. The total length of the crack was characterized by the sum of the lengths of all the cracks that appeared. Also, to estimate crack growth, measurements were taken at several time intervals to show how the width and the length of plastic shrinkage cracks change with time during the plastic stage. The chapter describes the crack measurement process and quantifies how applying concrete re-vibration or adding fibers to a concrete mix reduces the development and growth of plastic shrinkage cracks and discusses which solution is more effective.

\subsection{Image AnAlysis}

\subsubsection{Background}

Image analysis is used to automatically extract features of interest from a digital image and to provide rapid and accurate interpretation of the image contents. When a gray scale digital 
image is acquired, the information enabling the reconstruction of the image is stored in a matrix of pixels, which contains information about light intensity (I) and corresponding position (coordinates $\mathrm{x}, \mathrm{y}$ ) of the pixel. The values of light intensity are ranged between black and white. The image processing approach applies a mathematical algorithm to the stored digital image in order to interpret the image contents.

In the past 30 years, image analysis has been used to better understand crack development in concrete structures. For example, Mindess \& Diamond (1980) used a scanning electron microscope (SEM) imaging to assess the crack extension in mortar specimens. They found that SEM imaging helped to characterize the crack widths and figure out that some small bits of material in cracking were fragmented. Diamond \& Bonen (1995) used a backscattered electron imaging of polished cement paste specimens to re-evaluate structure details of hydrated cement paste. They found that the image analysis helped to figure out that the microstructural units contain a highly porous groundmass and large distinct grains set in it. The groundmass is composed of several kinds of fine particles, with a significant content of easily detected gross pores. Ammouche et al. (2001) used a tri-CCD (Charge-coupled device) camera linked to a personal computer for image analysis to assess microcracks in cement-based materials. They found that maps of the sample crack network over an area of several tens of square centimeters were drawn to determine the crack pattern characteristics. Qi et al. (2003) used a Cambridge Instruments Quantiment $570 \mathrm{TM}$ system connected to CCD camera for the image analysis to assess fibered concrete specimens. They found that the fine cracks were easily identified in contrast of optical measurement. The following sections describe the image analysis procedure followed in this study to process digital images of the cracks.

\subsubsection{Image Analysis Approach to Quantify Surface Plastic Shrinkage Cracking}

An image analysis approach, which is capable of extracting only the relevant features of a crack (crack widths and total crack length) and rapidly providing objective results, was used to quantitatively characterize plastic shrinkage cracking patterns. Figures 5.1 and 5.2 provide an 
overview of the image processing and analysis procedure that was used. From Figure 5.1, it can be seen that the process involves: (a) image acquisition and (b) image processing. Figure 5.2 shows the crack measurement. Detailed information on each step is provided in following section.

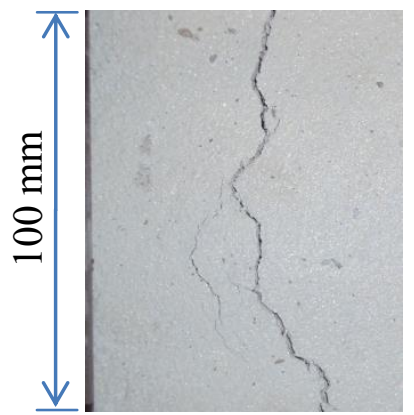

(A)

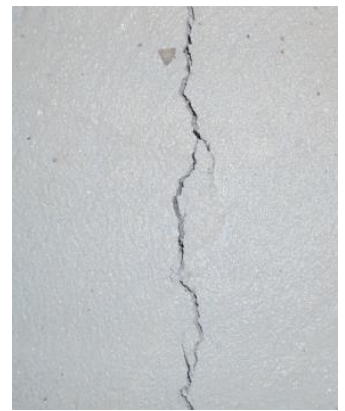

(B)

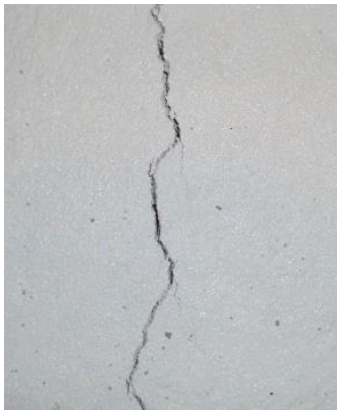

(C)

Original crack images

(a)

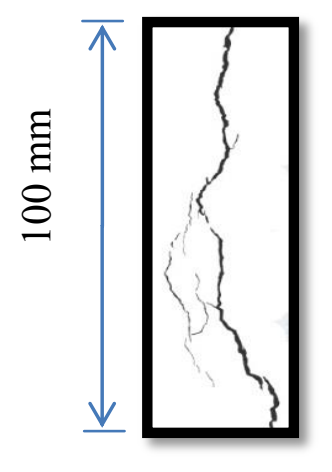

(A)

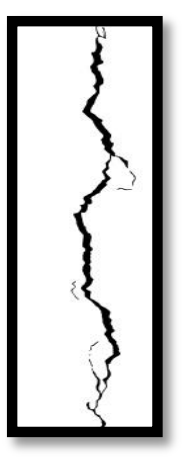

(B)

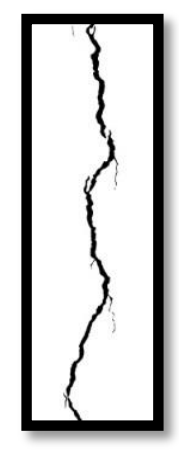

(C)

Cleaned crack images

(b)

Figure 5.1: image analysis procedure, (a) image acquisition and (b) image processing 

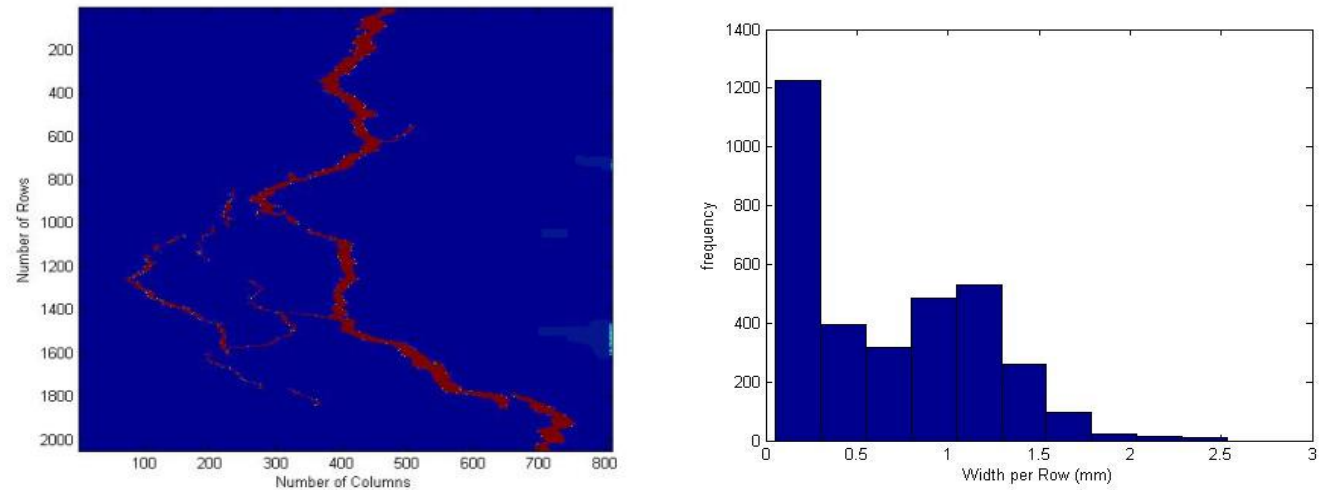

Crack measurement of crack (A)
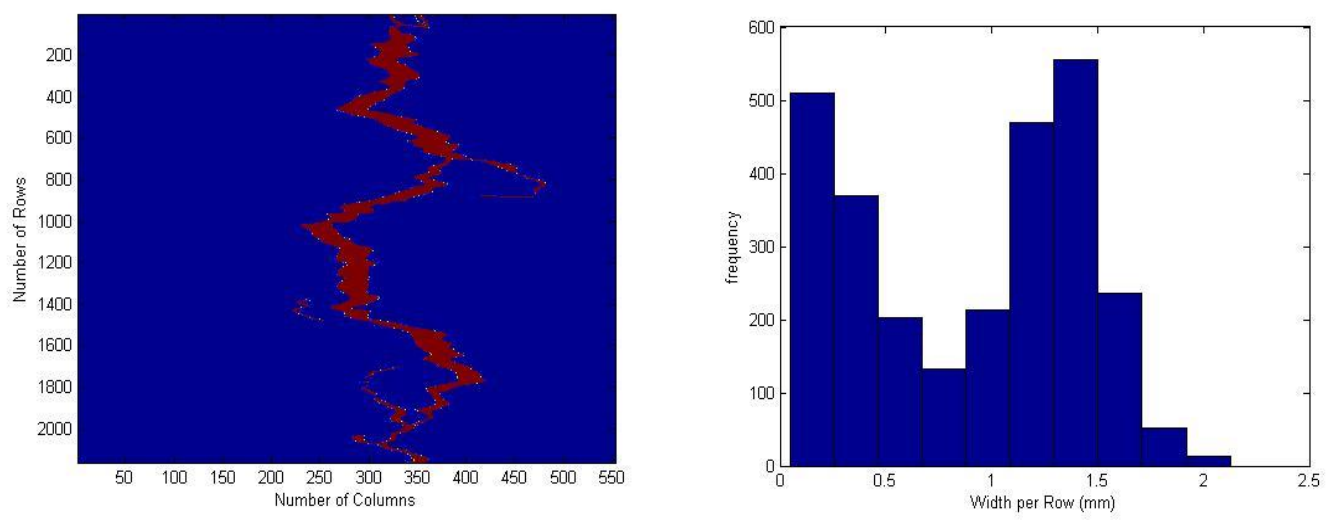

Crack measurement of crack (B)
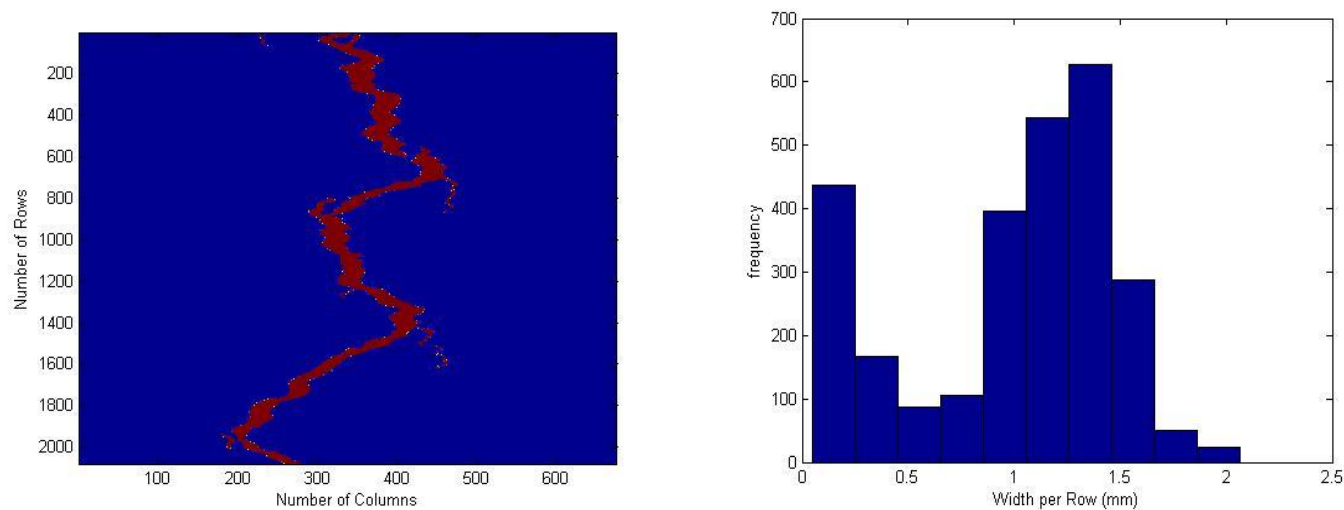

Crack measurement of crack (C)

Figure 5.2: Image analysis procedure for crack measurement 


\subsubsection{Image Acquisition}

As described in chapter 4, plastic shrinkage cracks started to develop as early as approximately 30 minutes after concrete was casted in some concrete slabs and as late as five hours after casting in others. Once they were visible, cracks continued to grow with time. Image acquisition was performed at every 60 minutes during the first 6 hours after concrete casting in order to gather information to evaluate the cracks' growth. A crack is considered a plastic crack if it develops before 24 hours ( \pm 2 ) after casting (ASTM 2013). Therefore, image acquisition was performed for all concrete specimens up to an age of 24 hours, which was considered to be the end of the plastic stage of the concrete. Digital pictures of the surface of the concrete slab were taken above the stress riser, which is the location where the cracks appeared. To minimize human error, the cracked specimens were kept in the control room during image acquisition. To eliminate the influence of the boundaries of the specimens, no information was recorded within $25 \mathrm{~mm}(1 \mathrm{in})$ from outer edges of the specimen. The images were acquired along the remaining $300 \mathrm{~mm}$ (11.9 in) of the crack path as recommended by Qi et al. (2003) and ASTM (2013). The images in Figure 5.1 (a) were captured with a Sony Cyber-shot DSC-H55 14.1 MP digital camera, digitized as gray level images and saved for subsequent interpretation. In this figure, the crack was divided into three sections and close up pictures were taken of each of them to increase the resolution of the crack image. The crack features are clearer in the close up pictures.

The size of each image that was used for the image analysis was represented as an M-by$\mathrm{N}$ matrix. Table 5.2 shows the sizes of the three closed up images (A), (B) and (C) shown in Figure 5.3. The sizes are different because each of these images was extracted from a larger picture as shown in Figure 5.3. Because the sizes are different, there was a need to determine the length that each pixel in the image represented. A scale of $100 \mathrm{~mm}$ was inserted in the picture to compute the scale factor that converts the number of pixels to length in $\mathrm{mm}$. Scale factor obtained for the images in Figure 5.3 are also shown in Table 5.2. 
Table 5.2: Image size and scale factor

\begin{tabular}{|c|c|c|c|}
\hline \multirow{2}{*}{ Image } & \multicolumn{2}{|c|}{ Image size } & \multirow{2}{*}{ Scale factor } \\
\cline { 2 - 3 } & Rows & Columns & \\
\hline $\mathrm{A}$ & 2050 & 810 & 20.5 \\
\hline $\mathrm{B}$ & 2163 & 553 & 21.63 \\
\hline $\mathrm{C}$ & 2080 & 676 & 20.8 \\
\hline
\end{tabular}
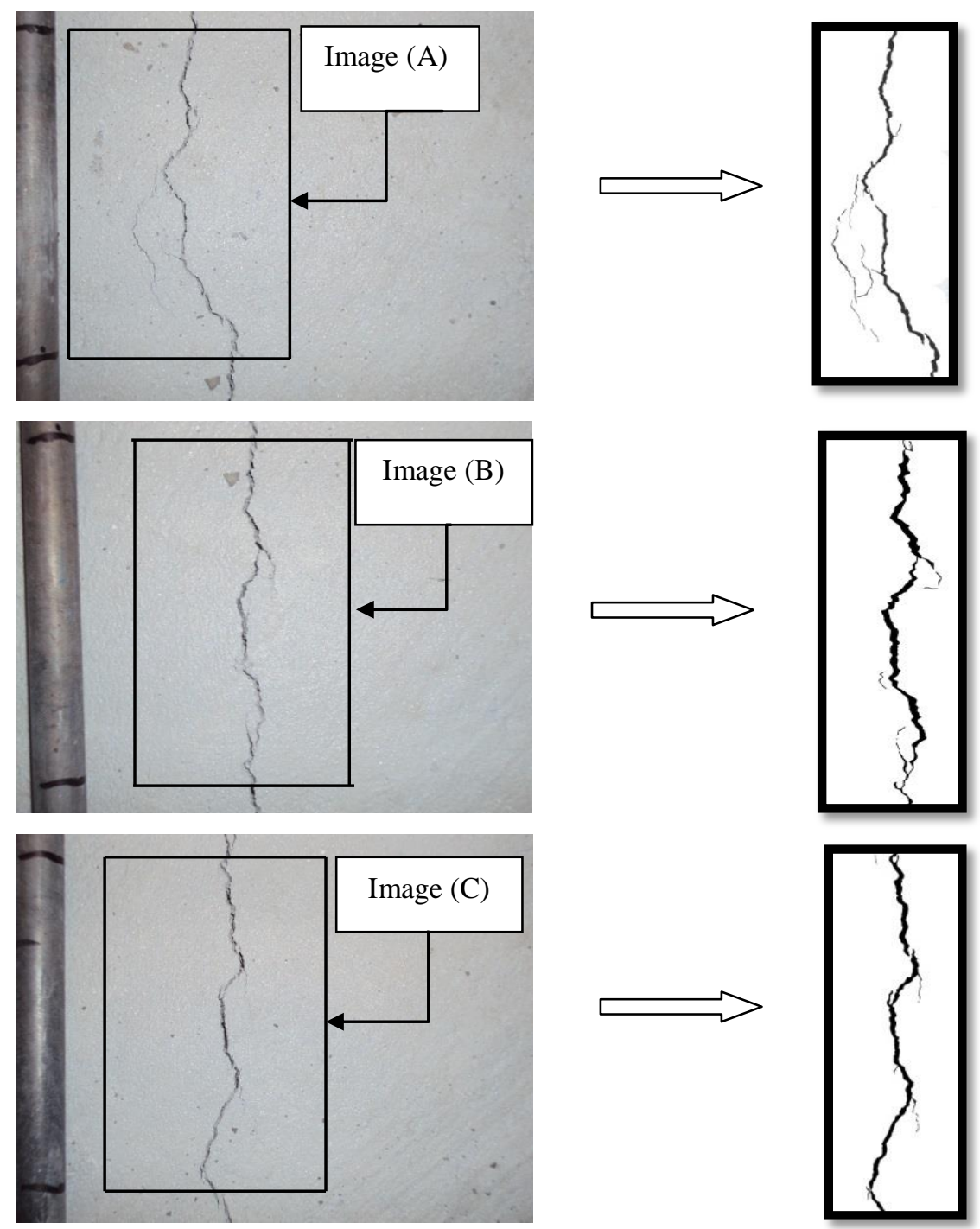

Original crack images

Cleaned crack images

Figure 5.3: Extraction of the cleaned crack images from original crack images 


\subsubsection{Image Processing and Crack Measurement}

The acquired digital images were converted to binary (black and white) images and cleaned to remove surface imperfections using Photoshop as shown in Figure 5.1 (b). This figure shows the cleaned pictures, where the crack is shown in black. The cleaned images of the crack were image processed to quantify the crack width at set points along the crack and the total crack length. Crack widths were measured at every pixel row. Figure 5.2 shows the histogram of the crack widths measured in each close up image. The following process was followed to perform the numerical analysis and programmed using Matlab:

1. The developed Matlab code Shown in Appendix $\mathrm{C}$ reads the cleaned images as black and white images of pixels and stores these pixel images as M-by-N matrixes.

2. In each matrix, the program finds the beginning, the center and the ending pixels of a crack in each row.

3. The crack width was determined in pixels by subtracting the ending and beginning pixels.

4. The total crack length was determined in pixels by adding the center pixels in each row.

5. The average crack width in pixels was found by dividing the sum of the crack widths on the inclined crack length not on the number of rows. This was considered because the cracks were following inclining paths, so the average crack width is more accurate in such a case, as shown in Figure 5.4 .

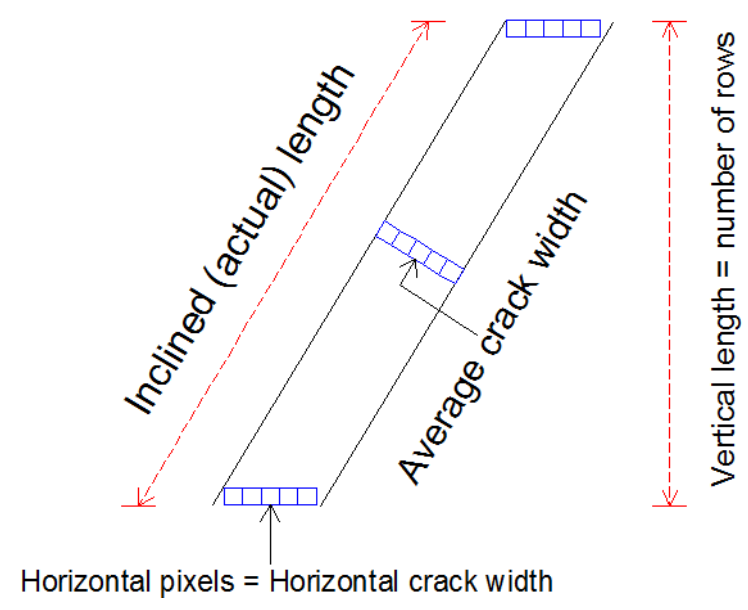

Figure 5.4: How the average crack width was measured. 
6. Finally, the average crack width and the total crack length were calculated in mm using the scale factors shown in Table 5.2. Table 5.3 shows the average cracks widths and the total cracks lengths for the three close up pictures of the cracks, shown in Figure 5.1. This process was applied to the all of the images taken.

Table 5.3: Crack measurement of the cleaned crack images

\begin{tabular}{|c|c|c|c|c|c|}
\hline Image & $\begin{array}{c}\text { Scale } \\
\text { factor }\end{array}$ & $\begin{array}{c}\text { Avg. width } \\
(\mathrm{px})\end{array}$ & $\begin{array}{c}\text { Total length } \\
(\mathrm{px})\end{array}$ & $\begin{array}{c}\text { Avg. Width } \\
(\mathrm{mm})\end{array}$ & $\begin{array}{c}\text { Total length } \\
(\mathrm{mm})\end{array}$ \\
\hline (A) & 20.5 & 10.8318 & 4310.3 & 0.5238 & 210.2858 \\
\hline (B) & 21.63 & 16.2915 & 3322.8 & 0.7532 & 153.62 \\
\hline (C) & 20.80 & 17.5439 & 3239 & 0.8435 & 155.4279 \\
\hline
\end{tabular}

\subsection{Determination of Cracks' Dimensions}

Cracks are usually characterized by their width and length because the crack may become wider and longer during the life time of a structure due to the sustainable loads. This may significantly reduce the serviceability and the durability of the structure (Soroushian et al. 1995 and Banthia \& Yan 2000). In this thesis, the growth evolution of the crack was also monitored to help understand its evolution from nucleation to the end of the plastic state of the concrete.

During the experimental testing some cracks were short and discontinuous, while other cracks would appear as long and continuous as shown in Figure 5.4. To measure the total crack length, all the discontinue sections and parallel cracks lengths were added. 


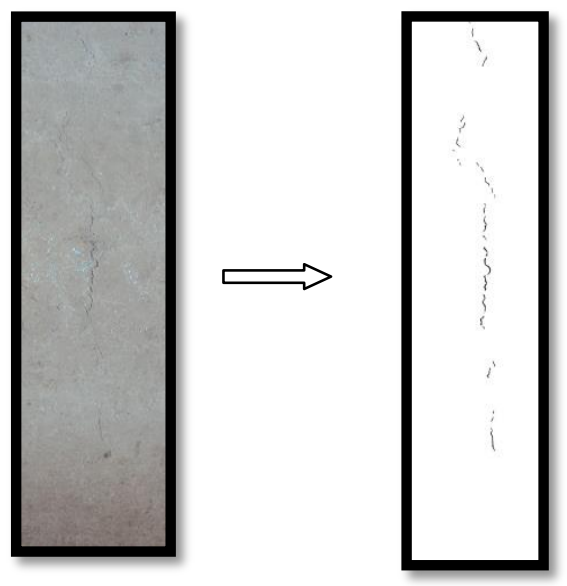

(a)

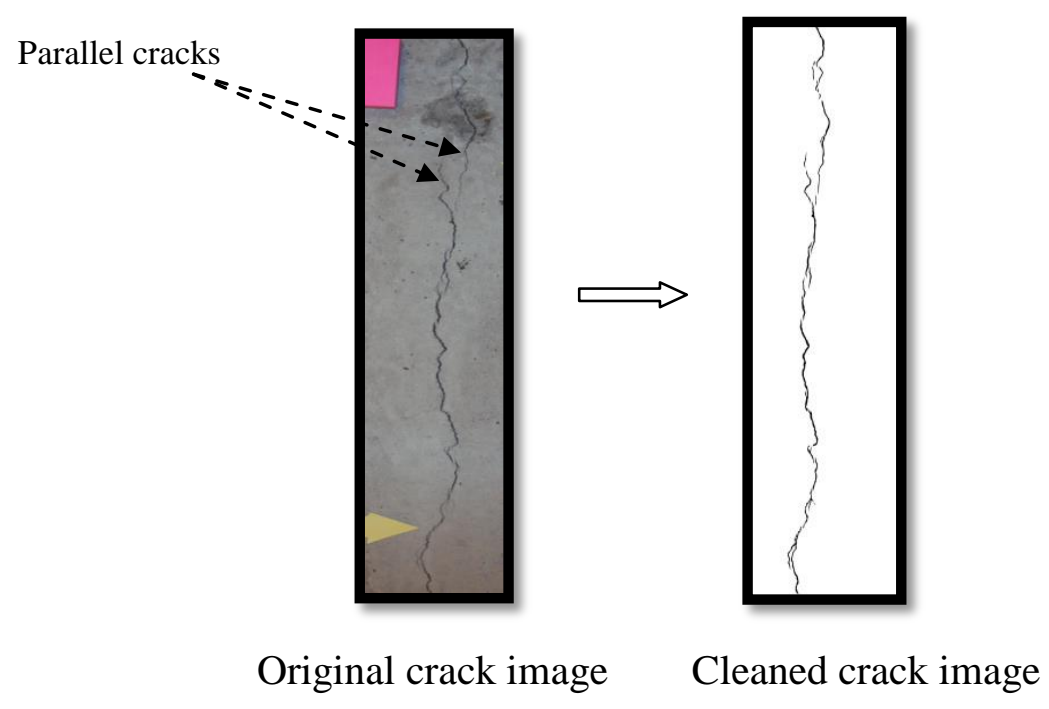

(b)

Figure 5.4: Different appearances of the developed cracks: a) Short and discontinued crack, b) Long and continued crack.

To determine the widths and lengths of the developed cracks above the stress riser, the image processing was applied to the images taken from all cracked slabs listed in Table 4.7. In total there were 45 slabs. Figure 5.5 shows the images of the developed cracks in five concrete specimens built with a water-cement ratio of 0.6. Figure 5.5(a) shows a concrete specimen that was not re-vibrated (only initial vibration was applied), (b) a concrete specimen that was fibered, (c) a specimen that was re-vibrated for 15 seconds, (d) a specimen that was re-vibrated for 30 seconds, and (e) a concrete specimen that was re-vibrated for 45 seconds. Visually specimens 
that were re-vibrated show different reductions on crack width and length. The specimen that was re-vibrated for 15 seconds shows the most significant reduction. The figure also show that the fibered concrete develop smaller plastic cracks than the non-fibered concrete. The following section analyzes the images in more detailed and discusses the variability in cracks widths for all tested slabs.

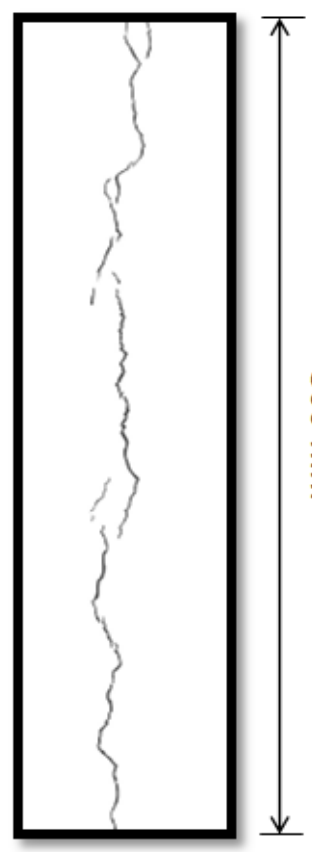

(a)

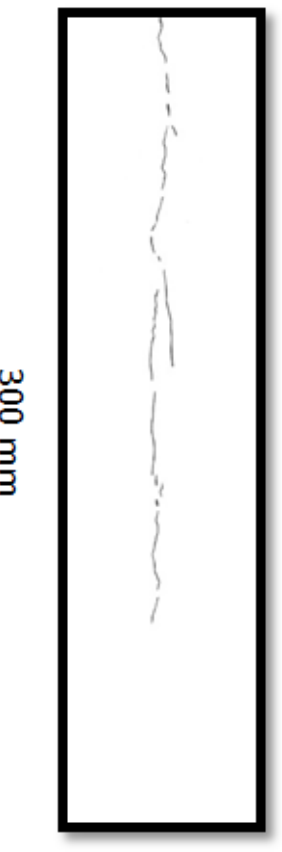

(b)

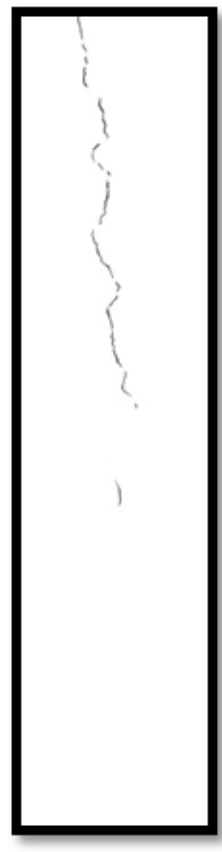

(c)

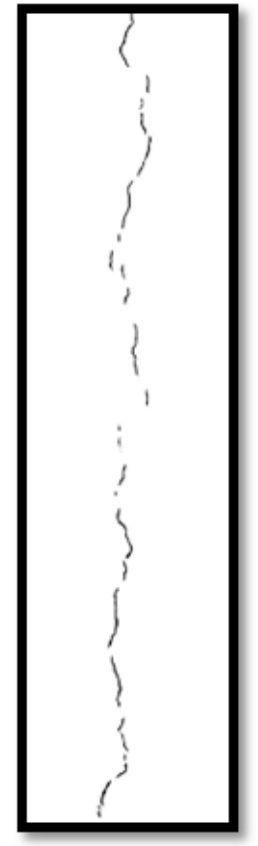

(d)

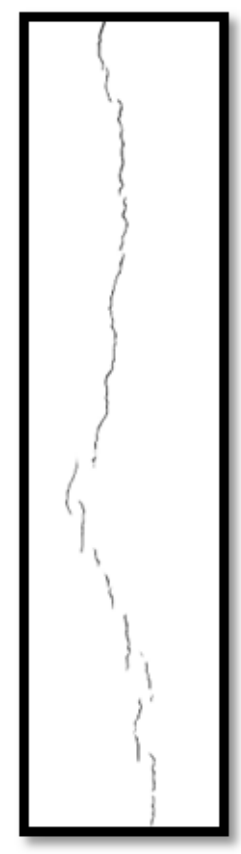

(e)

Figure 5.5: Typical crack patterns for concrete specimens made with a water-cement ratio of 0.6: a) non-re-vibrated, b) fibered, c) re-vibrated $15 \mathrm{~s}$, d) re-vibrated $30 \mathrm{~s}$, and e) revibrated $45 \mathrm{~s}$.

\subsubsection{Analysis of Crack Width}

As already mentioned earlier, crack widths were measured at every pixel row. The measured width varies from row to row, thus making the width of the crack a random variable that depends on where along the crack it is measured. To understand the variability of the measured crack widths, the information of the three images $(\mathrm{A}, \mathrm{B}$ and $\mathrm{C})$ that define the crack was pooled together. Using this larger data set of crack widths the histograms and the 
corresponding cumulative distribution functions were plotted. The same data set was used to compute the mean value, standard deviation, and coefficient of variation of the cracks widths in each slab specimen. Figure 5.6 shows the cleaned crack images for the specimens corresponding to non-re-vibrated concrete made with a water-cement ratio of 0.6. The crack images show the existence of parallel cracks. When quantifying the crack widths in rows where parallel cracks exists, the widths of all the cracks were added and recorded as the width value for that row.

For these cracks images, histograms of cracks widths and the corresponding cumulative plots were constructed, as shown in Figure 5.7. The histograms in Figure 5.7 show the high variability of the data and they also show that cracks widths data seem to be skewed to the right. Also, the cumulative distribution functions are very similar to each other; however, there is still variability from sample data to sample data as read in the table of statistical data. To determine the probability distribution model that best fit the cracks widths data sets, several candidate distributions were fitted to the data. A model with skewed distribution pattern appeared reasonable. Even though several statistical distribution functions were used to fit the data sets, it was determined that the Weibull distribution made it an appropriate function to best fit the crack widths data sets of high variability because it was flexible enough to model the variety of the data sets. The Weibull distribution model was also used by other researchers to be the best fit distribution when they assessed widths of plastic shrinkage cracking (Qi et al. 2003). Figure 5.7 shows the typical histograms and cumulative distribution functions of the specimens corresponding to non-re-vibrated concrete made with water-cement ratio of 0.6 with Weibull distribution and computed statistical information. This figure shows the cracks widths (mm) in $\mathrm{x}-$ axes, the frequencies of cracks in left y-axes and cumulative percentages in right y-axes.

Appendix D shows typical histograms, cumulative distribution functions, Weibull distribution and statistical information of the cracks widths for the five slab conditions (non-revibrated, fibered, 15 sec. re-vibrated, $30 \mathrm{sec}$. re-vibrated, and $45 \mathrm{sec}$. re-vibrated slabs) and for the three water-cement ratios $(0.6,0.55$ and 0.5$)$ being dealt with in this thesis. In general, the histograms show the high variability of the data and they also show that crack widths data seem 
to be skewed to the right. The cumulative distribution plots of the crack widths measured in each of the sample slabs, given a set of conditions, are very similar to each other. The values of the means and standard deviations for each data sample were shown as well. The fit cumulative distribution curves can be observed to provide a reasonable representation of the actual data for all slab conditions and water-cement ratios.

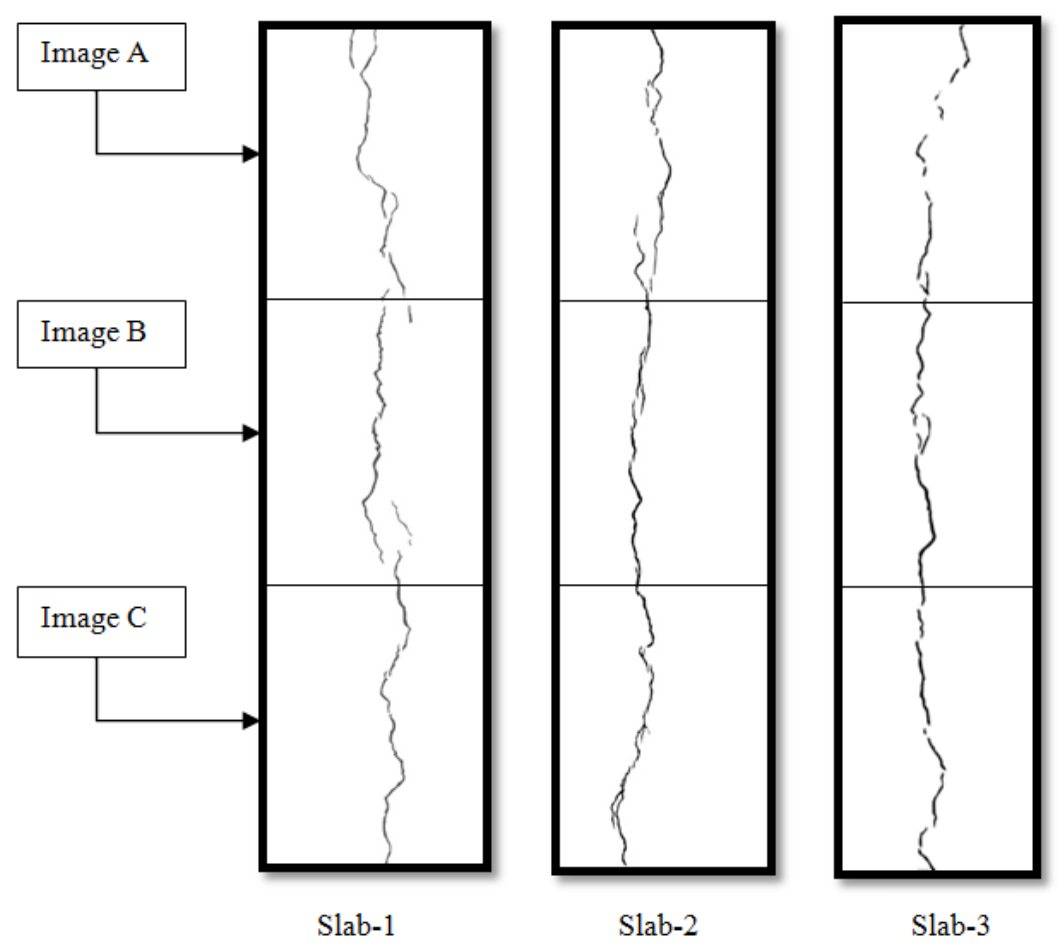

Figure 5.6: Cleaned crack images for the specimens corresponding to non-re-vibrated concrete slabs made with a water-cement ratio of 0.6 . 

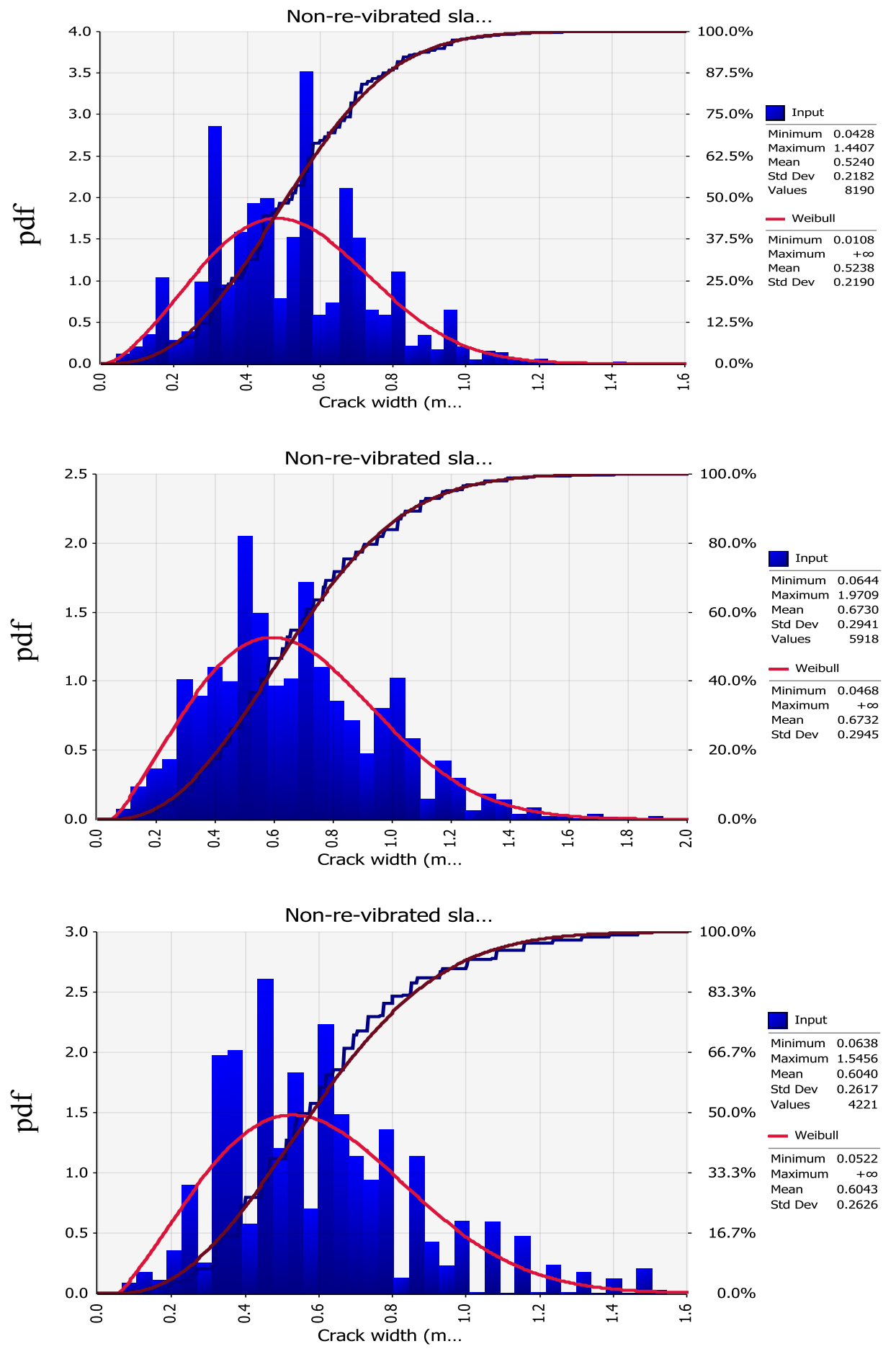

Figure 5.7: Histograms, cumulative distribution, fitting function, and statistical data of cracks widths for non-re-vibrated concrete slabs made with a water-cement ratio of 0.6. 
Table 5.4 summarizes the average values of the mean, the standard deviation, and coefficient of variation of the crack widths. Each of these values was computed by averaging the results of three specimens corresponding to set conditions. From the table it is observed that, in general, the smaller the water-cement ratio the smaller the average crack width, which is in agreement with common knowledge. It is also observed, by comparing the coefficients of variation, that the water-cement ratio does not influence the variability of the data, which is of, more or less, the same magnitude for all data samples. Results also show that for a given watercement ratio, there is a vibration time that provides average crack widths similar to the average crack widths measured in specimens made with fibered concretes. For example, the average crack width for the specimens made with a water-cement ratio of 0.6 and fibered concrete, the average crack width is $0.39 \mathrm{~mm}$ and the corresponding coefficient of variation is 0.38 ; while the average crack width of the specimens that were re-vibrated 15 second is 0.34 and the corresponding coefficient of variation is 0.47 . In this case re-vibration provided a similar average crack width but it introduced more variability of the crack width along the path of the crack. Figure 5.8 graphically shows the variation of the average crack width as a function of the watercement ratios and the re-vibration time length.

Table 5.4: The average crack widths measured from the image analysis procedure.

\begin{tabular}{|c|c|c|c|c|}
\hline Slabs & $\begin{array}{c}\text { Number of } \\
\text { slabs }\end{array}$ & $\begin{array}{c}\text { Avg. Crack } \\
\text { width (mm) }\end{array}$ & $\begin{array}{c}\text { Crack width standard } \\
\text { deviation (mm) }\end{array}$ & $\begin{array}{c}\text { Coefficient of } \\
\text { variation (\%) }\end{array}$ \\
\hline \multicolumn{7}{|c|}{ Water-cement =0.60 } \\
\hline Non-re-vibrated & 3 & 0.6 & 0.26 & 0.43 \\
\hline Fibered & 3 & 0.39 & 0.15 & 0.38 \\
\hline Re-vibrated 15sec. & 3 & 0.34 & 0.16 & 0.44 \\
\hline Re-vibrated 30sec. & 3 & 0.52 & 0.23 & 0.37 \\
\hline Re-vibrated 45sec. & 3 & 0.51 & 0.19 & 0.42 \\
\hline
\end{tabular}




\begin{tabular}{|c|c|c|c|c|}
\hline Fibered & 3 & 0.29 & 0.12 & 0.41 \\
\hline Re-vibrated 15sec. & 3 & 0.39 & 0.17 & 0.44 \\
\hline Re-vibrated 30sec. & 3 & 0.38 & 0.16 & 0.42 \\
\hline Re-vibrated 45sec. & 3 & 0.24 & 0.11 & 0.46 \\
\hline \multicolumn{5}{|c|}{ Water-cement $=0.50$} \\
\hline Non-re-vibrated & 3 & 0.26 & 0.11 & 0.42 \\
\hline Fibered & 3 & 0.11 & 0.05 & 0.45 \\
\hline Re-vibrated 15sec. & 3 & 0.19 & 0.08 & 0.42 \\
\hline Re-vibrated 30sec. & 3 & 0.16 & 0.07 & 0.44 \\
\hline Re-vibrated 45sec. & 3 & 0.09 & 0.04 & 0.44 \\
\hline
\end{tabular}

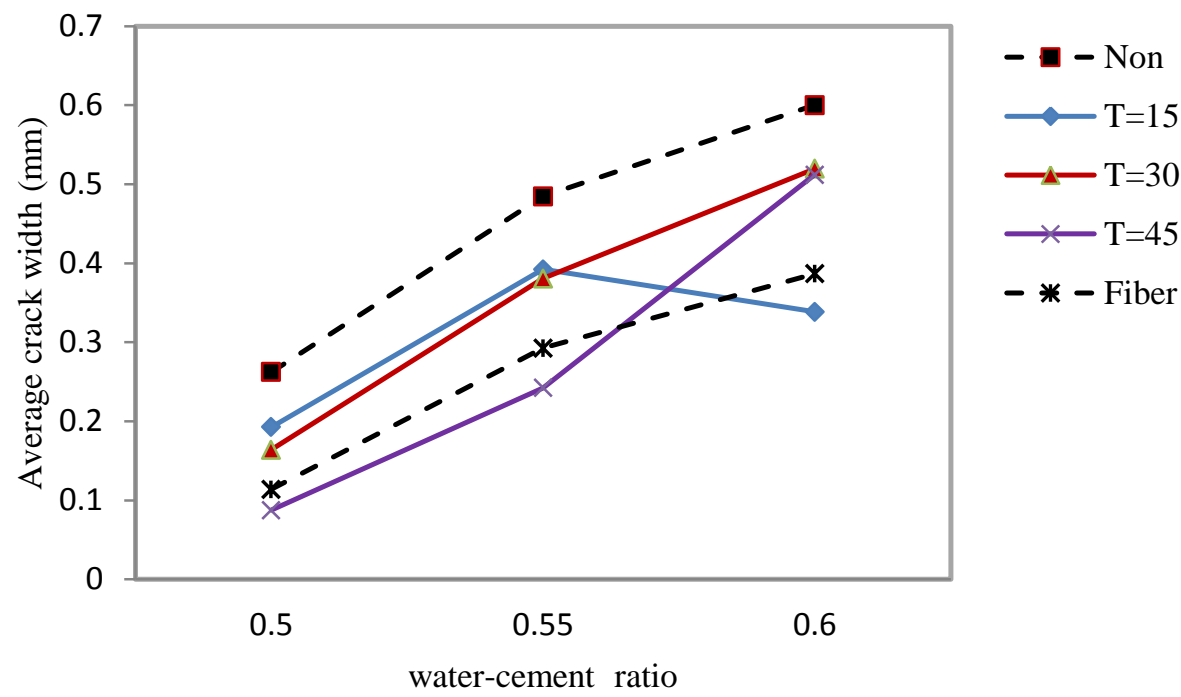

Figure 5.8: Average values of the cracks' width for all slabs versus the water-cement ratios

\subsubsection{A Model to Predict the Time Length of Re-vibration}

As mentioned early in this chapter, the crack width has a significant influence on structure durability. Therefore, ACI has specified acceptable crack widths for several exposure conditions for durability design, as shown in Table 5.1. In this study, three water-cement ratios $(0.5,0.55$ and 0.6$)$, four re-vibration time lengths $(0,15,30$, and 45 seconds) and one revibration time lag $(1.5 \mathrm{hr}$.) were tested to figure out their impacts on the average crack width of 
slab specimens. Since the maximum crack width and water-cement ratio should be specified by the structural designers, an empirical equation to compute the optimal time length of revibration, as shown in Equation 5.1, was developed. This model is useful for water-cement ratios greater than or equal $0.45(\mathrm{w} / \mathrm{c} \geq 0.45)$, which meets the fact that for a water-cement ratio of 0.4 , the application of second vibration after 1.5 hours from casting was not acceptable as has been shown in this study; also the plastic shrinkage cracking was not form when water-cement ratio of 0.4 was used. Furthermore, the model is also useful for time lengths of re-vibration less than 60 seconds, which meets the fact that when re-vibration time length of 60 seconds was applied on cylindrical specimens, the 7 days-compressive strengths of concrete were reduced when compared with non-re-vibrated specimens.

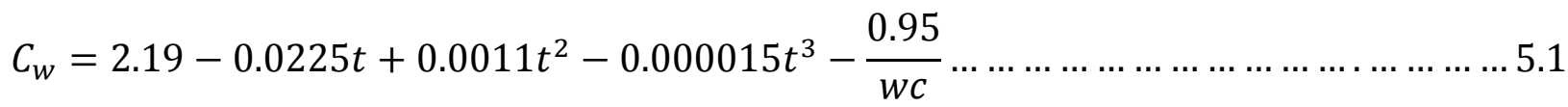

Where: $t$ is re-vibration time length, $C_{w}$ is crack width, and $w c$ is water-cement ratio.

Figure 5.9 shows the data set that represents the experimental data points of average cracks widths of slab specimens obtained in this study and equation 5.1. For example, if a structural designer wishes to specify the re-vibration time length for concrete after 1.5 hours from casting to assure that average crack widths are less than $0.5 \mathrm{~mm}$ when using a water-cement ratio of 0.6 , he should specify a re-vibration time length of 7 seconds. 


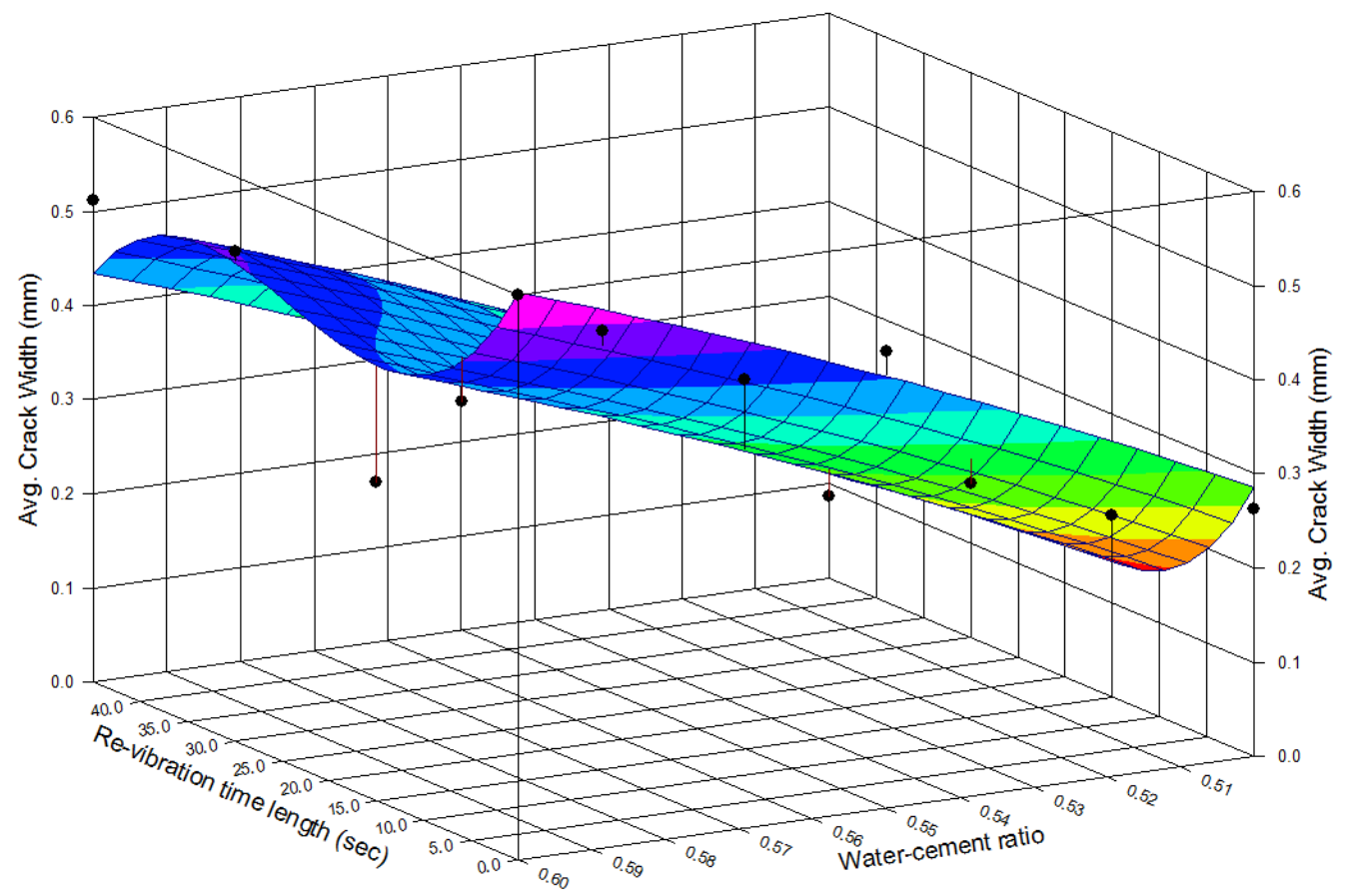

Figure 5.9: Relationship among average cracks widths, water-cement ratios and re-vibration time lengths of tested slab specimens and the best fit model, using 3-D plot.

\subsubsection{Total Crack Length}

The average values of the total cracks lengths for all tested concrete slabs are shown in Table 5.5 and plotted in Figure 5.10. The total cracks lengths were obviously shortened when the second vibration or fiber addition were applied to the concrete slabs for all the water-cement ratios. However the re-vibration time lengths that generated the shortest crack length for each water-cement ratio was different. For a water-cement ratio of 0.6 , the shortest cracks were achieved when the mixed was re-vibrated for 15 seconds. When this mixed was re-vibrated for longer times it showed signs of over-vibration. For water-cement ratios of 0.55 and 0.5 , the shorter cracks appeared when the mixed were re-vibrated for 30 and 45 seconds respectively. When this mixes were re-vibrated for smaller times they showed signs of under-vibration. 
Table 5.5: Average values of the total cracks lengths (mm)

\begin{tabular}{|c|c|c|c|c|c|}
\hline $\begin{array}{c}\text { Water-cement } \\
\text { ratio }\end{array}$ & $\begin{array}{c}\text { Non-re- } \\
\text { vibrated } \\
\text { specimens }\end{array}$ & $\begin{array}{c}15 \text { second re- } \\
\text { vibrated } \\
\text { specimens }\end{array}$ & $\begin{array}{c}30 \text { second re- } \\
\text { vibrated } \\
\text { specimens }\end{array}$ & $\begin{array}{c}45 \text { second re- } \\
\text { vibrated } \\
\text { specimens }\end{array}$ & $\begin{array}{c}\text { Fibered } \\
\text { specimens }\end{array}$ \\
\hline 0.5 & 232.5 & 184.7 & 153.4 & 104.7 & 138.4 \\
\hline 0.55 & 338.3 & 289.2 & 166.2 & 256.2 & 179.5 \\
\hline 0.6 & 428.1 & 181 & 312.1 & 336.6 & 192.5 \\
\hline
\end{tabular}

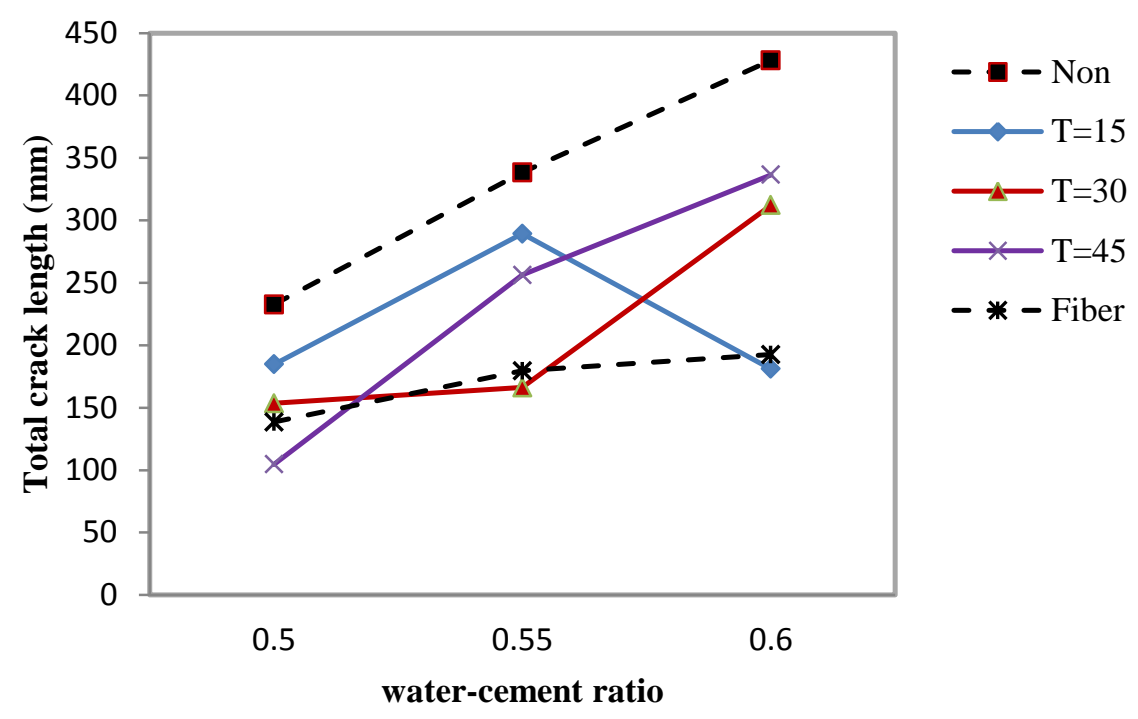

Figure 5.10: Average values of the total cracks lengths for all slabs versus water-cement ratios

\subsection{CRACK Reduction Ratio (CRR)}

To quantify the influences of adding fiber and application of the second vibration on the crack reduction, ASTM (ASTM 2013) recommends an index called crack reduction ratio (CRR). The calculation of CRR is done using the following equations for both crack dimensions (average crack length calculated using equation 5.2 and total crack length calculated using equation 5.3). 


$$
\begin{aligned}
& C R R=\left[\begin{array}{c}
\text { Avg.crack width } \\
1-\frac{\text { of re - vibrated slabs }}{\text { Avg.crack width }}
\end{array}\right] \times 100 \% \\
& C R R=\left[\begin{array}{c}
\text { Avg.crack width } \\
\text { of fibered slabs } \\
1-\frac{\text { Avg.crack width }}{\text { of non }- \text { re }- \text { vibrated slabs }}
\end{array}\right] \times 100 \% \\
& C R R=\left[\begin{array}{c}
\text { Total crack length } \\
1-\frac{\text { of re }- \text { vibrated slabs }}{\text { Total crack length }} \\
\text { of non }- \text { re }- \text { vibrated slabs }
\end{array}\right] \times 100 \% \\
& C R R=\left[\begin{array}{c}
\text { Total crack length } \\
\text { of fibered slabs }
\end{array}\right] \times 100 \%
\end{aligned}
$$

\subsubsection{CRR of Average Crack Width}

CRR of the average crack widths for all the water-cement ratios are plotted in Figure 5.11. Figure 5.11 (a) shows the CRR of the average crack widths when the water-cement ratio is 0.6. In this figure, the best CRR is when the slabs were re-vibrated for 15 seconds. Figure 5.11 (b) shows the CRR of the average crack widths when the water-cement ratio is 0.55 . In this figure, the best CRR is obtained when the slabs were re-vibrated for 45 seconds. Figure 5.11 (c) shows the CRR of the average crack widths when the water-cement ratio is 0.5 . In this figure, the best CRR is obtained when the slabs were re-vibrated for 45 seconds. 


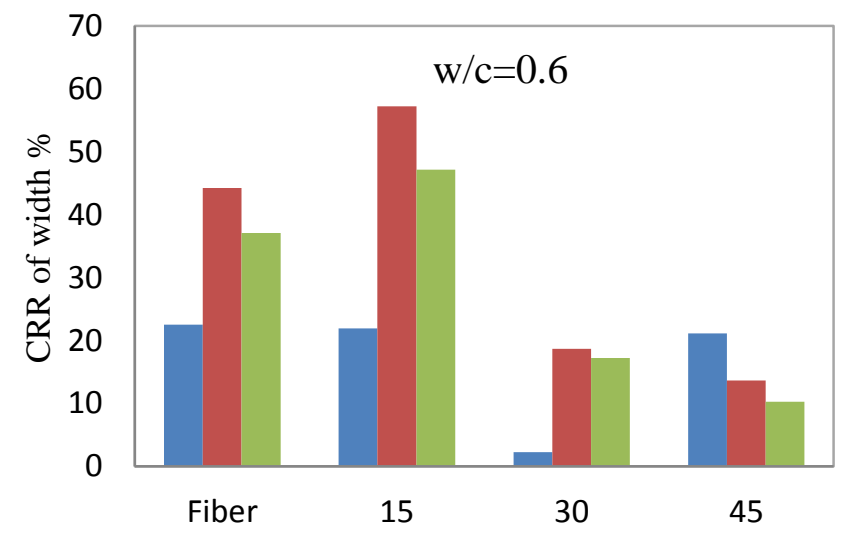

Fibered and Re-vibreated specimens

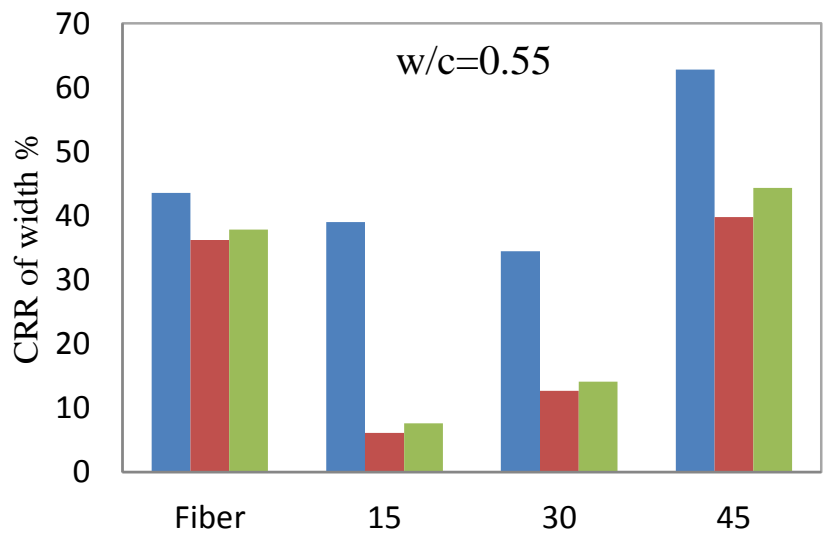

Fibered and Re-vibreated specimens

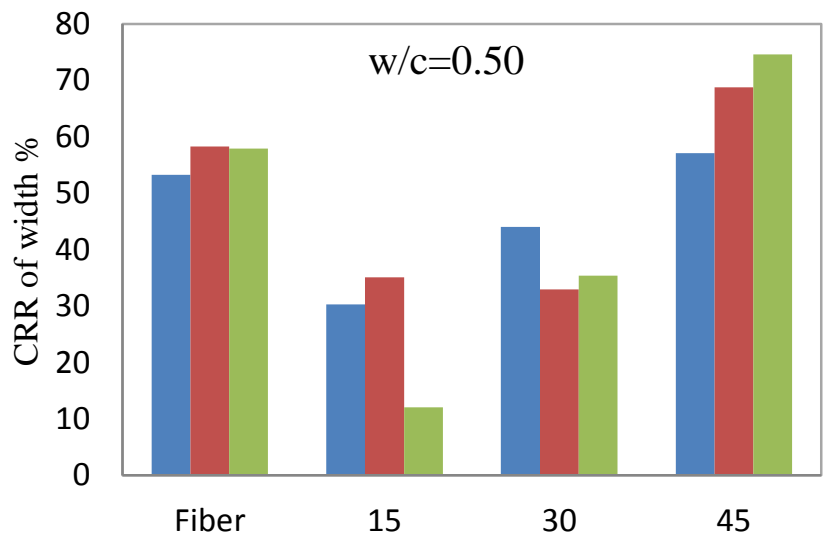

Fibered and Re-vibreated specimens

Figure 5.11: Crack reduction ratios (CRR) of the average crack widths for fibered and revibrated specimens 


\subsubsection{CRR of Total Crack Length}

CRR of the total crack lengths for all the water-cement ratios are plotted in Figure 5.12. Figure 5.12 (a) shows the CRR of the total crack lengths when the water-cement ratio is 0.6. In this figure, the best CRR is obtained when the slabs were re-vibrated for 15 seconds. Figure 5.12 (b) shows the CRR of the total crack lengths when the water-cement ratio is 0.55 . In this figure, the best CRR occurred when the slabs were re-vibrated for 30 seconds. Figure 5.12 (c) shows the CRR of the total crack lengths when the water-cement ratio is 0.5 . In this figure, the best CRR is obtained when the slabs were re-vibrated for 45 seconds. 

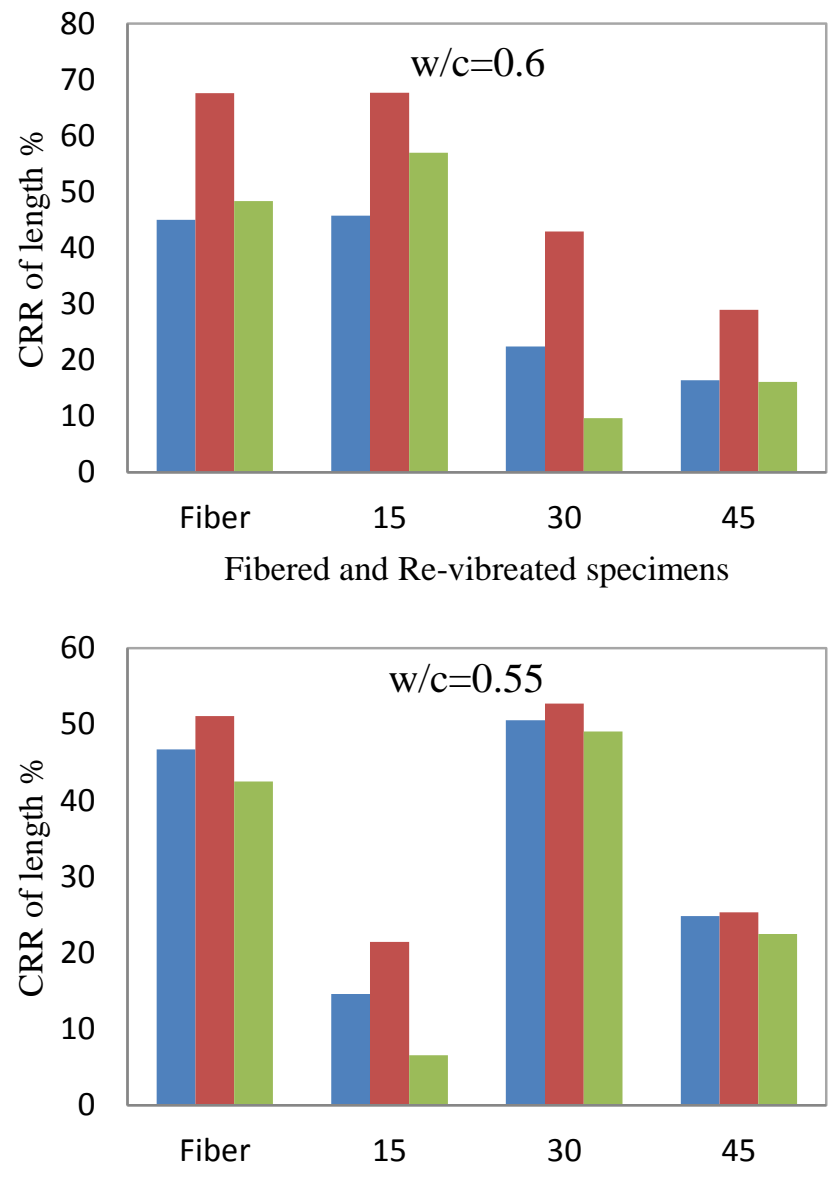

Fibered and Re-vibreated specimens

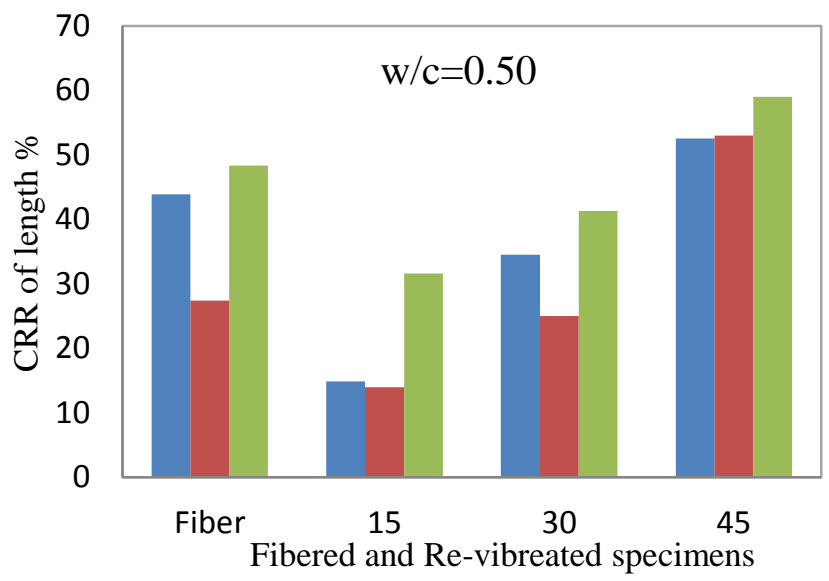

Figure 5.12: Crack reduction ratios (CRR) of the total crack lengths for fibered and re-vibrated slabs 


\subsection{Growth OF CRacks' WIDTh AND LeNGTH}

The developed cracks were monitored continuously for the first six hours from concrete cast until the end of plastic stage ( $24 \pm 2$ hours). The average cracks widths and the total cracks lengths with respect of the water-cement ratios are shown in Table 5.6. This table is divided into three tables ( $a, b$ and $c$ ) each one corresponding to a water-cement ratio. The first column in the table (measurement time) shows the times at which the measurement was made for each one of the three specimens that were tested for a given condition. Measurement times were: 1, 2, 3, 4, 5,6 , and 24 hours after concrete re-vibration. For specimens that were not re-vibrated, the measurement times correspond to the times after casting. The columns 2, 8, 11 and 14 identified the test specimen. The first number refers to the length of re-vibration time that was applied on the specimen and the number in parenthesis refers to the specimen number (e.g. 15(3) means, specimen number 3 that was re-vibrated for 15 seconds). The column 5 identified the test specimens that were fibered. The rest of the table shows the average cracks widths and the total cracks lengths for each measurement time and specimen number.

The growth of the average crack width for non-re-vibrated, fibered and re-vibrated slabs for each water-cement ratio $(0.6,0.55$ and 0.5$)$ is plotted in Figures 5.13, 5.14 and 5.15, respectively. In these plots, the horizontal axes, which represents the measurement times, are in logarithmic scale and the vertical axis that represent the average crack width is in normal scale. In all plots, it is observed that the average crack width grows very fast during the first six hours and then it became asymptotic in the time range from 6 to 24 hours. The plots for a given set of conditions show variability in the crack growth curves from specimen to another. It is clear in these plots that the average crack widths were smaller in specimens which were made with fibered concrete and those who were re-vibrated. The growth of the average crack widths seems to follow an S-shape tendency in all cases.

For the specimens made with a concrete with a water-cement ratio of 0.6 , the cracks appeared before one hour after re-vibration or casting (in the case of non-re-vibrated and fibered mixes). Exemptions were specimen 3, made with the fibered concrete, which showed no cracks 
after one hour and specimens 2 and 3 in the concrete that was re-vibrated for 15 seconds, which showed no cracks after 1 and 2 hours, respectively. For the specimens made with concrete with a water-cement ratio of 0.55 and were not re-vibrated, cracks appeared before one hour. In the case of specimens made with fibered concrete, cracks appeared at different time that range from less than one hour to more than two hours. For concretes that were re-vibrated 15 seconds, the cracks in two specimens appeared after one hour and after two hours in the third specimen. For specimens that were re-vibrated 30 seconds, cracks in two of the specimens appeared after one hour. The third specimen showed cracks before one hour. Two specimens made with concrete that was re-vibrated for 45 seconds showed crack initiation times greater than two hours. The third specimen showed cracks after three hours. All specimens made with a water-cement ratio of 0.5 showed cracks after two hours. In the case of specimens made with concrete that was revibrated 45 seconds, crack initiation times were greater than 4,5 and 6 hours. These specimens also show the smallest average crack widths after 24 hours.

The growth of total crack length for non-re-vibrated, fibered and re-vibrated specimens with respect of each water-cement ratio $(0.6,0.55$ and 0.5) is plotted in Figures 5.16, 5.17 and 5.18 , respectively. The growth of the total cracks lengths was similar to the average cracks width. The only exception was the measured crack lengths on the specimens made with a watercement ratio of 0.55 . In this case the specimens that were re-vibrated for 30 seconds showed the shortest total crack lengths. Remember that for these specimens the smallest crack average crack widths were observed in specimens re-vibrated 45 seconds. 
Table 5.6 a: Cracks widths and lengths for non-re-vibrated, fibered and re-vibrated slabs (when water-cement $=0.60$ )

\begin{tabular}{|c|c|c|c|c|c|c|c|c|c|c|c|c|c|c|c|}
\hline $\begin{array}{l}\text { Measurement } \\
\text { Time (hr) } \\
\end{array}$ & $\begin{array}{c}\text { slab } \\
\# \\
\end{array}$ & $\begin{array}{l}\text { width } \\
(\mathrm{mm})\end{array}$ & $\begin{array}{l}\text { Length } \\
(\mathrm{mm})\end{array}$ & $\begin{array}{c}\text { slab } \\
\# \\
\end{array}$ & $\begin{array}{l}\text { width } \\
(\mathrm{mm})\end{array}$ & $\begin{array}{l}\text { Length } \\
(\mathrm{mm})\end{array}$ & slab\# & $\begin{array}{l}\text { width } \\
(\mathrm{mm})\end{array}$ & $\begin{array}{l}\text { Length } \\
(\mathrm{mm})\end{array}$ & slab\# & $\begin{array}{l}\text { width } \\
(\mathrm{mm})\end{array}$ & $\begin{array}{l}\text { Length } \\
(\mathrm{mm})\end{array}$ & slab\# & $\begin{array}{l}\text { width } \\
(\mathrm{mm})\end{array}$ & $\begin{array}{l}\text { Length } \\
(\mathrm{mm})\end{array}$ \\
\hline 1 & $0(1)$ & 0.07 & 65.742 & $\mathrm{f}(1)$ & 0.088 & 37.889 & $15(1)$ & 0.121 & 57.661 & $30(1)$ & 0.122 & 79.253 & $45(1)$ & 0.11 & 69.121 \\
\hline 2 & $0(1)$ & 0.112 & 198.636 & $\mathrm{f}(1)$ & 0.121 & 85.621 & $15(1)$ & 0.189 & 91.542 & $30(1)$ & 0.166 & 106.189 & $45(1)$ & 0.167 & 98.881 \\
\hline 3 & $0(1)$ & 0.197 & 234.874 & $\mathrm{f}(1)$ & 0.189 & 117.387 & $15(1)$ & 0.229 & 121.339 & $30(1)$ & 0.204 & 184.218 & $45(1)$ & 0.236 & 149.662 \\
\hline 4 & $0(1)$ & 0.276 & 277.432 & $\mathrm{f}(1)$ & 0.259 & 153.223 & $15(1)$ & 0.282 & 149.258 & $30(1)$ & 0.291 & 229.114 & $45(1)$ & 0.289 & 199.972 \\
\hline 5 & $0(1)$ & 0.323 & 303.561 & $\mathrm{f}(1)$ & 0.301 & 188.021 & $15(1)$ & 0.319 & 172.338 & $30(1)$ & 0.352 & 266.667 & $45(1)$ & 0.321 & 251.333 \\
\hline 6 & $0(1)$ & 0.346 & 337.913 & $\mathrm{f}(1)$ & 0.376 & 202.116 & $15(1)$ & 0.374 & 191.644 & $30(1)$ & 0.449 & 293.448 & $45(1)$ & 0.376 & 304.051 \\
\hline 24 & $0(1)$ & 0.524 & 407.626 & $\mathrm{f}(1)$ & 0.406 & 224.125 & $15(1)$ & 0.409 & 221.066 & $30(1)$ & 0.512 & 316.126 & $45(1)$ & 0.413 & 340.621 \\
\hline 1 & $0(2)$ & 0.136 & 109.567 & $\mathrm{f}(2)$ & 0.078 & 33.564 & $15(2)$ & 0 & 0 & $30(2)$ & 0.134 & 88.552 & $45(2)$ & 0.128 & 79.264 \\
\hline 2 & $0(2)$ & 0.214 & 184.332 & $f(2)$ & 0.109 & 69.984 & $15(2)$ & 0 & 0 & $30(2)$ & 0.198 & 125.285 & $45(2)$ & 0.199 & 126.555 \\
\hline 3 & $0(2)$ & 0.287 & 269.775 & $\mathrm{f}(2)$ & 0.159 & 98.778 & $15(2)$ & 0.109 & 61.555 & $30(2)$ & 0.267 & 168.747 & $45(2)$ & 0.284 & 197.887 \\
\hline 4 & $0(2)$ & 0.394 & 318.411 & $f(2)$ & 0.213 & 122.465 & $15(2)$ & 0.176 & 95.878 & $30(2)$ & 0.361 & 192.336 & $45(2)$ & 0.363 & 245.215 \\
\hline 5 & $0(2)$ & 0.482 & 384.745 & $\mathrm{f}(2)$ & 0.282 & 136.158 & $15(2)$ & 0.212 & 117.542 & $30(2)$ & 0.402 & 206.879 & $45(2)$ & 0.425 & 295.784 \\
\hline 6 & $0(2)$ & 0.564 & 467.419 & $f(2)$ & 0.324 & 153.227 & $15(2)$ & 0.247 & 139.538 & $30(2)$ & 0.489 & 266.563 & $45(2)$ & 0.512 & 312.251 \\
\hline 24 & $0(2)$ & 0.673 & 515.612 & $\mathrm{f}(2)$ & 0.375 & 166.842 & $15(2)$ & 0.288 & 166.639 & $30(2)$ & 0.547 & 294.125 & $45(2)$ & 0.581 & 366.087 \\
\hline 1 & $0(3)$ & 0.132 & 112.687 & $f(3)$ & 0 & 0 & $15(3)$ & 0 & 0 & $30(3)$ & 0.113 & 72.258 & $45(3)$ & 0.132 & 88.225 \\
\hline 2 & $0(3)$ & 0.201 & 168.514 & $\mathrm{f}(3)$ & 0.084 & 35.258 & $15(3)$ & 0.104 & 54.919 & $30(3)$ & 0.178 & 116.539 & $45(3)$ & 0.187 & 127.778 \\
\hline 3 & $0(3)$ & 0.274 & 202.125 & $f(3)$ & 0.115 & 79.145 & $15(3)$ & 0.169 & 87.688 & $30(3)$ & 0.265 & 188.336 & $45(3)$ & 0.244 & 185.258 \\
\hline 4 & $0(3)$ & 0.364 & 231.487 & $\mathrm{f}(3)$ & 0.164 & 112.543 & $15(3)$ & 0.213 & 100.152 & $30(3)$ & 0.312 & 226.747 & $45(3)$ & 0.297 & 226.987 \\
\hline 5 & $0(3)$ & 0.451 & 288.224 & $\mathrm{f}(3)$ &. .221 & 134.226 & $15(3)$ & 0.267 & 117.845 & $30(3)$ & 0.393 & 285.198 & $45(3)$ & 0.391 & 269.254 \\
\hline 6 & $0(3)$ & 0.551 & 314.268 & $f(3)$ & 0.305 & 168.664 & $15(3)$ & 0.292 & 137.883 & $30(3)$ & 0.468 & 303.538 & $45(3)$ & 0.488 & 287.146 \\
\hline 24 & $0(3)$ & 0.604 & 361.211 & $\mathrm{f}(3)$ & 0.38 & 186.512 & $15(3)$ & 0.319 & 155.244 & $30(3)$ & 0.5 & 326.125 & $45(3)$ & 0.542 & 302.961 \\
\hline
\end{tabular}


Table 5.6 b: Cracks widths and lengths for non-re-vibrated, fibered and re-vibrated slabs (when water-cement $=0.55$ )

\begin{tabular}{|c|c|c|c|c|c|c|c|c|c|c|c|c|c|c|c|}
\hline $\begin{array}{c}\text { Measurement } \\
\text { Time (hr) }\end{array}$ & $\begin{array}{c}\text { slab } \\
\#\end{array}$ & $\begin{array}{l}\text { width } \\
(\mathrm{mm})\end{array}$ & $\begin{array}{l}\text { Length } \\
(\mathrm{mm})\end{array}$ & $\begin{array}{c}\text { slab } \\
\# \\
\end{array}$ & $\begin{array}{l}\text { width } \\
(\mathrm{mm})\end{array}$ & $\begin{array}{l}\text { Length } \\
(\mathrm{mm})\end{array}$ & slab\# & $\begin{array}{l}\text { width } \\
(\mathrm{mm})\end{array}$ & $\begin{array}{l}\text { Length } \\
(\mathrm{mm})\end{array}$ & slab\# & $\begin{array}{l}\text { width } \\
(\mathrm{mm})\end{array}$ & $\begin{array}{l}\text { Length } \\
(\mathrm{mm})\end{array}$ & slab\# & $\begin{array}{l}\text { width } \\
(\mathrm{mm})\end{array}$ & $\begin{array}{l}\text { Length } \\
(\mathrm{mm})\end{array}$ \\
\hline 1 & $0(1)$ & 0.104 & 102.354 & $f(1)$ & 0.082 & 62.531 & $15(1)$ & 0 & 0 & $30(1)$ & 0.075 & 33.245 & $45(1)$ & 0 & 0 \\
\hline 2 & $0(1)$ & 0.178 & 131.562 & $\mathrm{f}(1)$ & 0.108 & 79.514 & $15(1)$ & 0 & 0 & $30(1)$ & 0.102 & 84.111 & $45(1)$ & 0 & 0 \\
\hline 3 & $0(1)$ & 0.237 & 188.415 & $\mathrm{f}(1)$ & 0.152 & 109.548 & $15(1)$ & 0.128 & 88.051 & $30(1)$ & 0.169 & 97.528 & $45(1)$ & 0 & 0 \\
\hline 4 & $0(1)$ & 0.298 & 245.954 & $\mathrm{f}(1)$ & 0.189 & 129.054 & $15(1)$ & 0.196 & 106.095 & $30(1)$ & 0.236 & 117.458 & $45(1)$ & 0.101 & 89.255 \\
\hline 5 & $0(1)$ & 0.387 & 289.547 & $\mathrm{f}(1)$ & 0.225 & 147.428 & $15(1)$ & 0.259 & 183.756 & $30(1)$ & 0.292 & 129.895 & $45(1)$ & 0.156 & 176.558 \\
\hline 6 & $0(1)$ & 0.478 & 311.017 & $f(1)$ & 0.288 & 166.145 & $15(1)$ & 0.301 & 237.457 & $30(1)$ & 0.324 & 157.445 & $45(1)$ & 0.187 & 216.487 \\
\hline 24 & $0(1)$ & 0.551 & 342.127 & $f(1)$ & 0.311 & 182.402 & $15(1)$ & 0.336 & 292.188 & $30(1)$ & 0.361 & 169.201 & $45(1)$ & 0.205 & 257.223 \\
\hline 1 & $0(2)$ & 0.072 & 54.832 & $f(2)$ & 0 & 0 & $15(2)$ & 0 & 0 & $30(2)$ & 0 & 0 & $45(2)$ & 0 & 0 \\
\hline 2 & $0(2)$ & 0.103 & 111.412 & $f(2)$ & 0.077 & 33.124 & $15(2)$ & 0.101 & 43.258 & $30(2)$ & 0.095 & 29.951 & $45(2)$ & 0 & 0 \\
\hline 3 & $0(2)$ & 0.172 & 178.846 & $f(2)$ & 0.095 & 61.245 & $15(2)$ & 0.179 & 91.369 & $30(2)$ & 0.142 & 66.765 & $45(2)$ & 0.099 & 61.885 \\
\hline 4 & $0(2)$ & 0.212 & 202.354 & $f(2)$ & 0.125 & 89.135 & $15(2)$ & 0.223 & 144.098 & $30(2)$ & 0.192 & 91.548 & $45(2)$ & 0.143 & 105.566 \\
\hline 5 & $0(2)$ & 0.277 & 248.846 & $f(2)$ & 0.187 & 101.624 & $15(2)$ & 0.299 & 189.258 & $30(2)$ & 0.256 & 113.087 & $45(2)$ & 0.195 & 173.442 \\
\hline 6 & $0(2)$ & 0.355 & 299.789 & $f(2)$ & 0.226 & 152.358 & $15(2)$ & 0.368 & 235.087 & $30(2)$ & 0.322 & 142.056 & $45(2)$ & 0.219 & 212.633 \\
\hline 24 & $0(2)$ & 0.442 & 356.414 & $f(2)$ & 0.282 & 174.241 & $15(2)$ & 0.415 & 280.016 & $30(2)$ & 0.386 & 168.413 & $45(2)$ & 0.266 & 266.215 \\
\hline 1 & $0(3)$ & 0.105 & 77.648 & $f(3)$ & 0 & 0 & $15(3)$ & 0 & 0 & $30(3)$ & 0 & 0 & $45(3)$ & 0 & 0 \\
\hline 2 & $0(3)$ & 0.182 & 103.258 & $f(3)$ & 0 & 0 & $15(3)$ & 0.11 & 45.321 & $30(3)$ & 0.097 & 35.145 & $45(3)$ & 0 & 0 \\
\hline 3 & $0(3)$ & 0.254 & 176.843 & $f(3)$ & 0.088 & 39.568 & $15(3)$ & 0.187 & 84.654 & $30(3)$ & 0.149 & 72.894 & $45(3)$ & 0.088 & 52.093 \\
\hline 4 & $0(3)$ & 0.321 & 207.548 & $f(3)$ & 0.105 & 69.587 & $15(3)$ & 0.213 & 122.015 & $30(3)$ & 0.201 & 101.444 & $45(3)$ & 0.112 & 99.658 \\
\hline 5 & $0(3)$ & 0.378 & 236.412 & $f(3)$ & 0.158 & 99.396 & $15(3)$ & 0.295 & 191.095 & $30(3)$ & 0.266 & 128.622 & $45(3)$ & 0.164 & 162.545 \\
\hline 6 & $0(3)$ & 0.399 & 292.146 & $f(3)$ & 0.214 & 137.154 & $15(3)$ & 0.387 & 244.355 & $30(3)$ & 0.337 & 150.458 & $45(3)$ & 0.203 & 202.354 \\
\hline 24 & $0(3)$ & 0.46 & 316.259 & $f(3)$ & 0.286 & 181.775 & $15(3)$ & 0.425 & 295.413 & $30(3)$ & 0.395 & 161.055 & $45(3)$ & 0.256 & 245.115 \\
\hline
\end{tabular}


Table 5.6 c: Cracks widths and lengths for non-re-vibrated, fibered and re-vibrated slabs (when water-cement $=0.5$ )

\begin{tabular}{|c|c|c|c|c|c|c|c|c|c|c|c|c|c|c|c|}
\hline $\begin{array}{c}\text { Measurement } \\
\text { Time (hr) }\end{array}$ & $\begin{array}{c}\text { slab } \\
\# \\
\end{array}$ & $\begin{array}{l}\text { width } \\
(\mathrm{mm})\end{array}$ & $\begin{array}{l}\text { Length } \\
(\mathrm{mm})\end{array}$ & slab\# & $\begin{array}{l}\text { width } \\
(\mathrm{mm})\end{array}$ & $\begin{array}{l}\text { Length } \\
(\mathrm{mm})\end{array}$ & slab\# & $\begin{array}{l}\text { width } \\
(\mathrm{mm})\end{array}$ & $\begin{array}{l}\text { Length } \\
(\mathrm{mm})\end{array}$ & slab\# & $\begin{array}{l}\text { width } \\
(\mathrm{mm})\end{array}$ & $\begin{array}{l}\text { Length } \\
(\mathrm{mm})\end{array}$ & slab\# & $\begin{array}{l}\text { width } \\
(\mathrm{mm})\end{array}$ & $\begin{array}{c}\text { Length } \\
(\mathrm{mm})\end{array}$ \\
\hline 1 & $0(1)$ & 0 & 0 & $\mathrm{f}(1)$ & 0 & 0 & $15(1)$ & 0 & 0 & $30(1)$ & 0 & 0 & $45(1)$ & 0 & 0 \\
\hline 2 & $0(1)$ & 0 & 0 & $f(1)$ & 0 & 0 & $15(1)$ & 0 & 0 & $30(1)$ & 0 & 0 & $45(1)$ & 0 & 0 \\
\hline 3 & $0(1)$ & 0.08 & 34.258 & $\mathrm{f}(1)$ & 0 & 0 & $15(1)$ & 0 & 0 & $30(1)$ & 0 & 0 & $45(1)$ & 0 & 0 \\
\hline 4 & $0(1)$ & 0.114 & 92.264 & $f(1)$ & 0.077 & 46.253 & $15(1)$ & 0.101 & 77.966 & $30(1)$ & 0.086 & 57.254 & $45(1)$ & 0 & 0 \\
\hline 5 & $0(1)$ & 0.166 & 153.914 & $\mathrm{f}(1)$ & 0.093 & 89.748 & $15(1)$ & 0.125 & 114.338 & $30(1)$ & 0.106 & 94.113 & $45(1)$ & 0.072 & 31.144 \\
\hline 6 & $0(1)$ & 0.216 & 206.215 & $f(1)$ & 0.106 & 112.333 & $15(1)$ & 0.149 & 181.956 & $30(1)$ & 0.14 & 129.012 & $45(1)$ & 0.097 & 79.336 \\
\hline 24 & $0(1)$ & 0.261 & 237.256 & $f(1)$ & 0.122 & 133.113 & $15(1)$ & 0.182 & 201.88 & $30(1)$ & 0.146 & 155.426 & $45(1)$ & 0.112 & 112.549 \\
\hline 1 & $0(2)$ & 0 & 0 & $f(2)$ & 0 & 0 & $15(2)$ & 0 & 0 & $30(2)$ & 0 & 0 & $45(2)$ & 0 & 0 \\
\hline 2 & $0(2)$ & 0 & 0 & $f(2)$ & 0 & 0 & $15(2)$ & 0 & 0 & $30(2)$ & 0 & 0 & $45(2)$ & 0 & 0 \\
\hline 3 & $0(2)$ & 0.081 & 30.667 & $f(2)$ & 0 & 0 & $15(2)$ & 0 & 0 & $30(2)$ & 0.077 & 31.998 & $45(2)$ & 0 & 0 \\
\hline 4 & $0(2)$ & 0.111 & 93.215 & $f(2)$ & 0.073 & 56.987 & $15(2)$ & 0.076 & 49.852 & $30(2)$ & 0.099 & 79.751 & $45(2)$ & 0 & 0 \\
\hline 5 & $0(2)$ & 0.161 & 154.147 & $f(2)$ & 0.089 & 109.123 & $15(2)$ & 0.101 & 92.111 & $30(2)$ & 0.129 & 101.548 & $45(2)$ & 0 & 0 \\
\hline 6 & $0(2)$ & 0.223 & 189.258 & $f(2)$ & 0.1 & 127.846 & $15(2)$ & 0.146 & 161.224 & $30(2)$ & 0.169 & 137.125 & $45(2)$ & 0.072 & 47.512 \\
\hline 24 & $0(2)$ & 0.285 & 212.565 & $f(2)$ & 0.119 & 154.258 & $15(2)$ & 0.185 & 182.875 & $30(2)$ & 0.191 & 159.423 & $45(2)$ & 0.089 & 99.9 \\
\hline 1 & $0(3)$ & 0 & 0 & $\mathrm{f}(3)$ & 0 & 0 & $15(3)$ & 0 & 0 & $30(3)$ & 0 & 0 & $45(3)$ & 0 & 0 \\
\hline 2 & $0(3)$ & 0 & 0 & $f(3)$ & 0 & 0 & $15(3)$ & 0 & 0 & $30(3)$ & 0 & 0 & $45(3)$ & 0 & 0 \\
\hline 3 & $0(3)$ & 0.072 & 29.285 & $\mathrm{f}(3)$ & 0 & 0 & $15(3)$ & 0.098 & 72.127 & $30(3)$ & 0 & 0 & $45(3)$ & 0 & 0 \\
\hline 4 & $0(3)$ & 0.104 & 81.187 & $\mathrm{f}(3)$ & 0.072 & 35.258 & $15(3)$ & 0.112 & 94.446 & $30(3)$ & 0.075 & 33.122 & $45(3)$ & 0 & 0 \\
\hline 5 & $0(3)$ & 0.156 & 134.082 & $f(3)$ & 0.091 & 77.121 & $15(3)$ & 0.132 & 110.925 & $30(3)$ & 0.099 & 81.419 & $45(3)$ & 0 & 0 \\
\hline 6 & $0(3)$ & 0.201 & 181.448 & $f(3)$ & 0.096 & 101.122 & $15(3)$ & 0.187 & 148.887 & $30(3)$ & 0.126 & 121.217 & $45(3)$ & 0 & 0 \\
\hline 24 & $0(3)$ & 0.24 & 247.652 & $f(3)$ & 0.101 & 127.856 & $15(3)$ & 0.211 & 169.37 & $30(3)$ & 0.155 & 145.337 & $45(3)$ & 0.061 & 101.548 \\
\hline
\end{tabular}



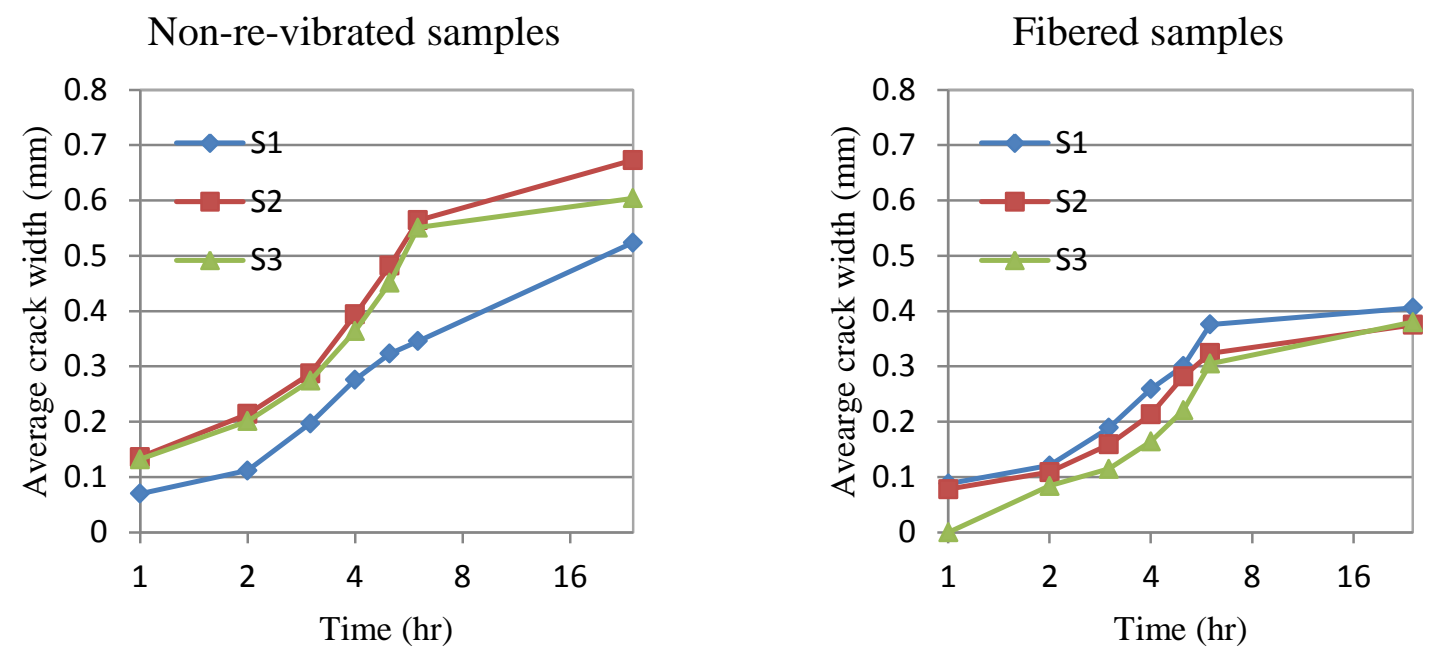

$15 \mathrm{sec}$. re-vibrated samples

30 sec. re-vibrated samples

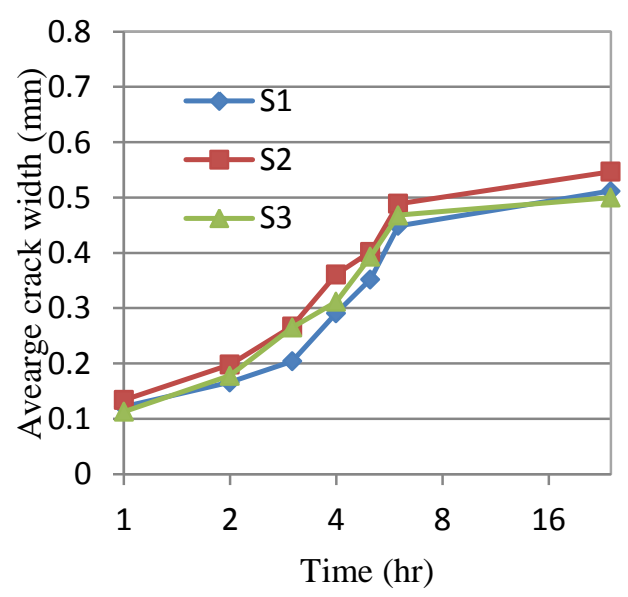

$45 \mathrm{sec}$. re-vibrated samples
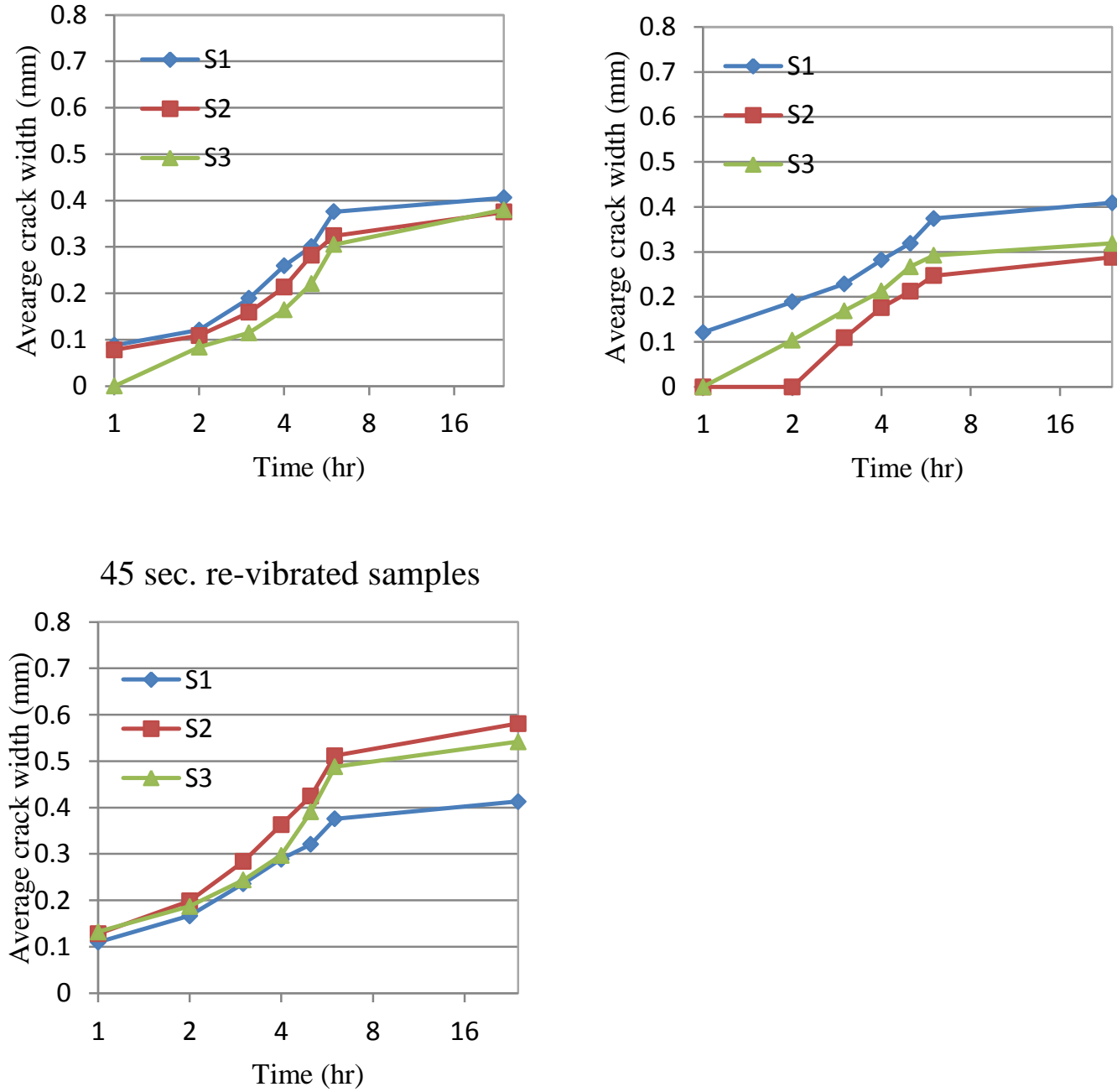

Figure 5.13: Average cracks widths vs. time for a water-cement ratio of 0.60 

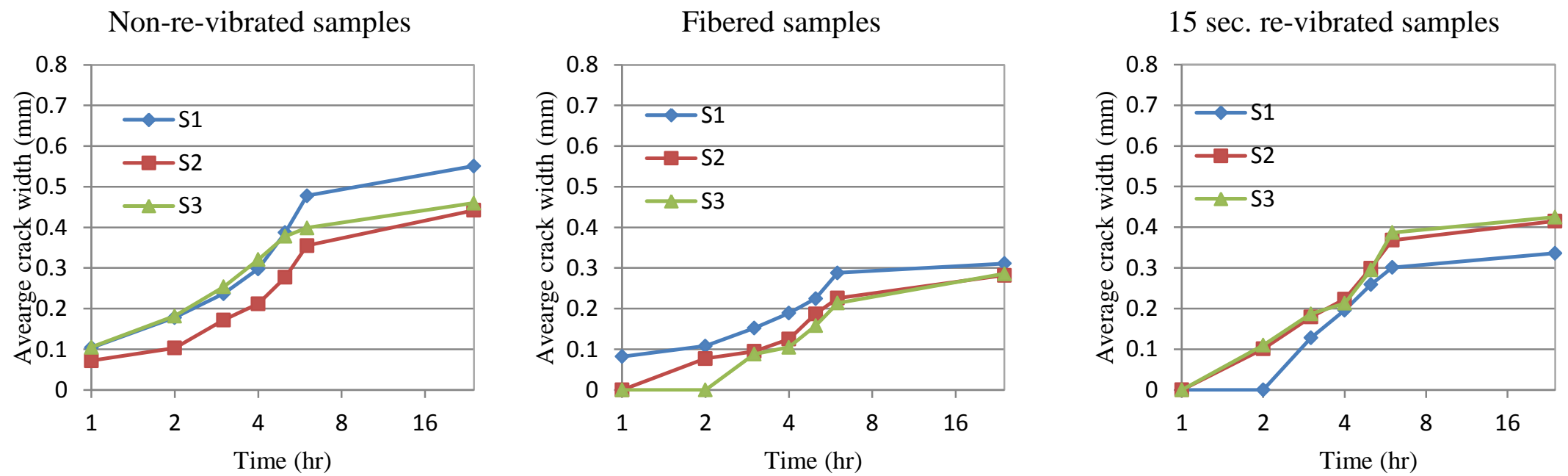

$30 \mathrm{sec}$. re-vibrated samples

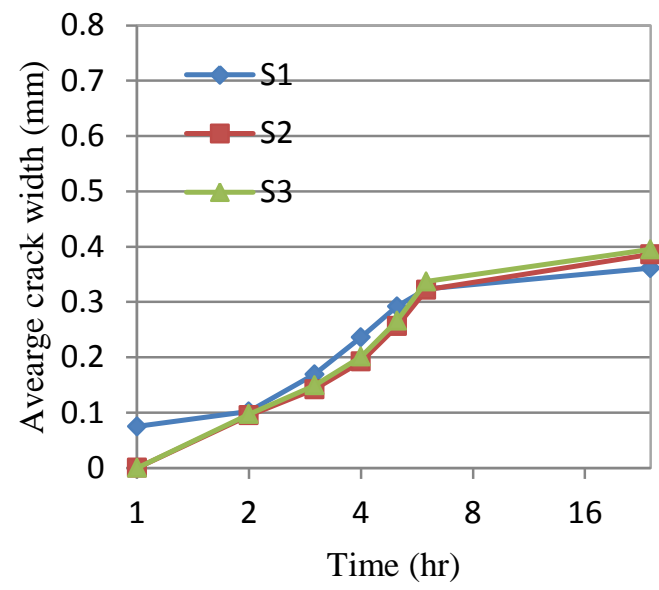

$45 \mathrm{sec}$. re-vibrated samples

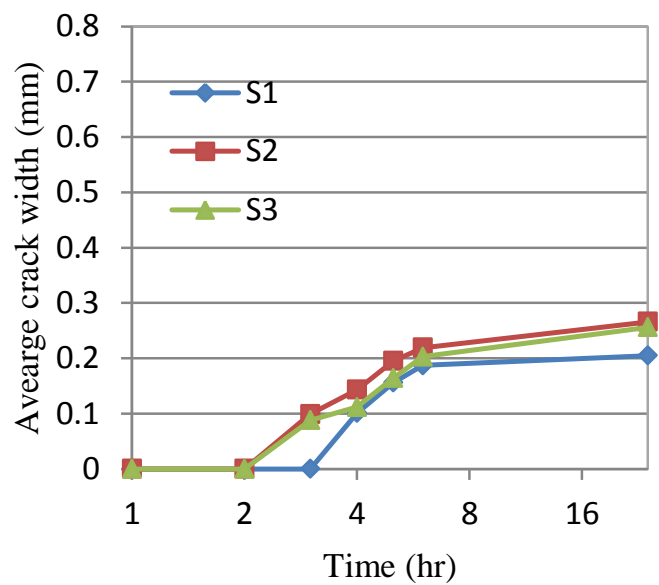

Figure 5.14: Average cracks widths vs. time for a water-cement ratio of 0.55 

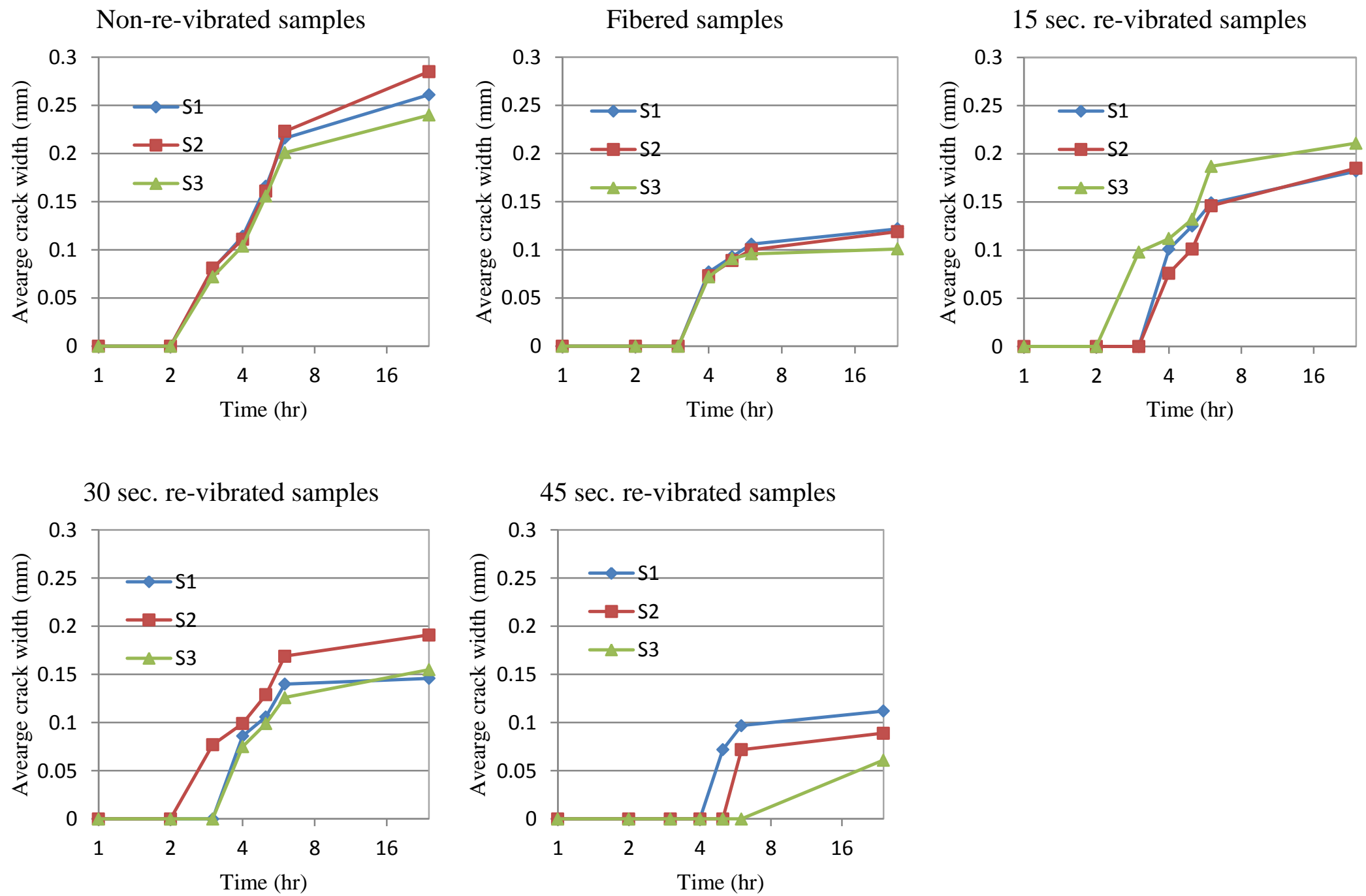

Figure 5.15: Average cracks widths vs. time for a water-cement ratio of 0.5 

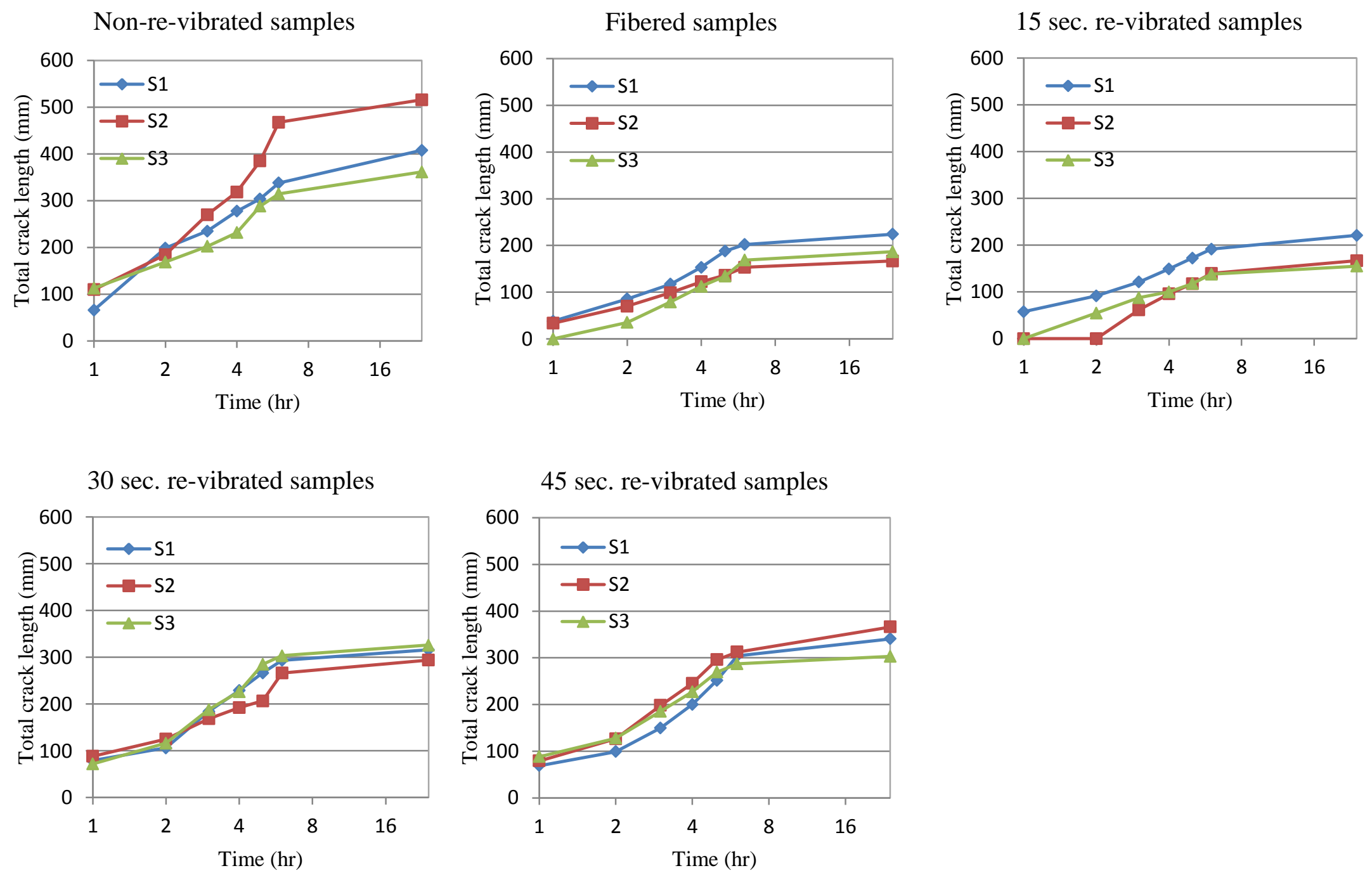

Figure 5.16: Total cracks length vs. time for a water-cement ratio of 0.60 

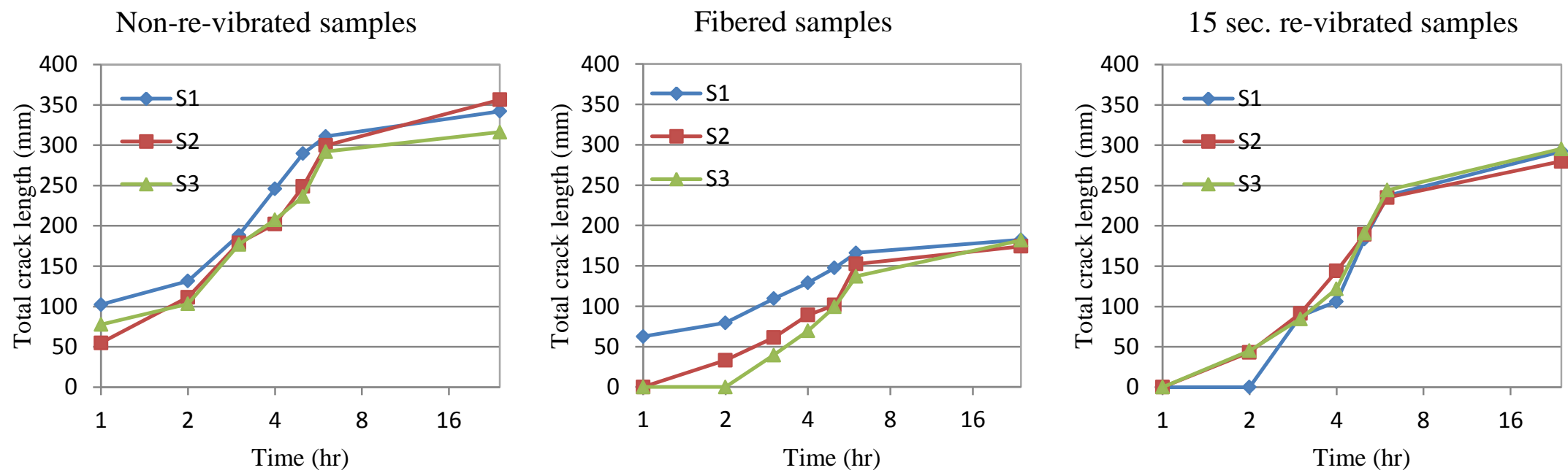

30 sec. re-vibrated samples

45 sec. re-vibrated samples
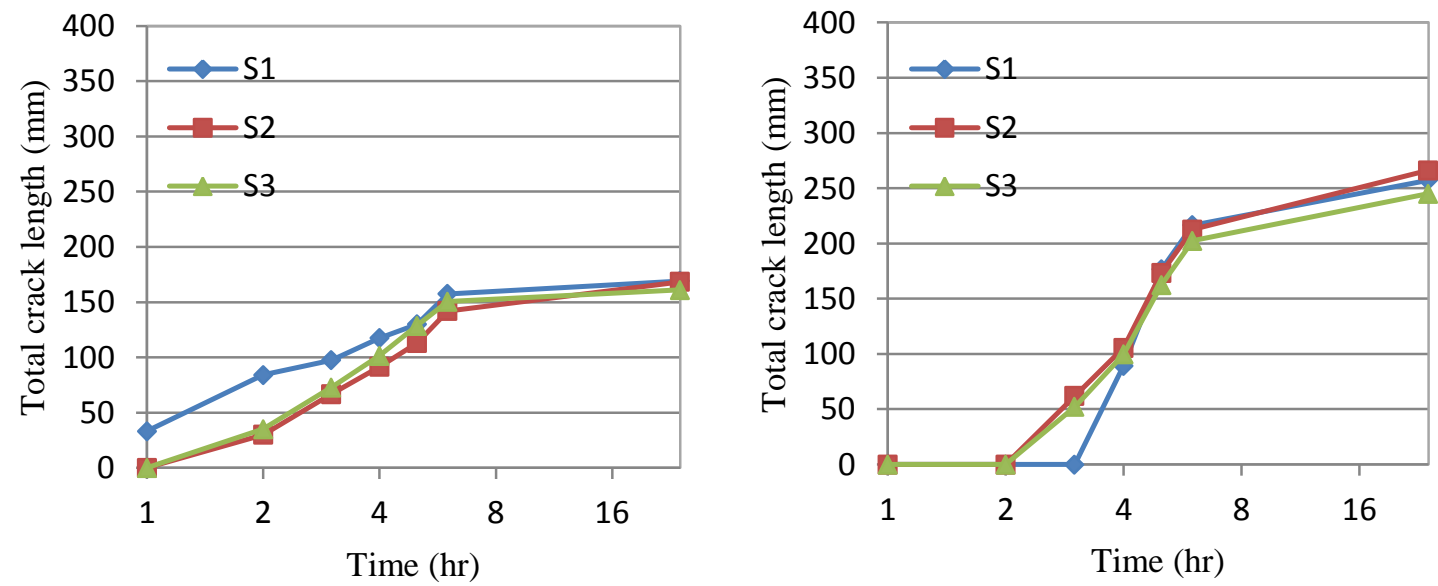

Figure 5.17: Total cracks length vs. time for a water-cement ratio of 0.55 

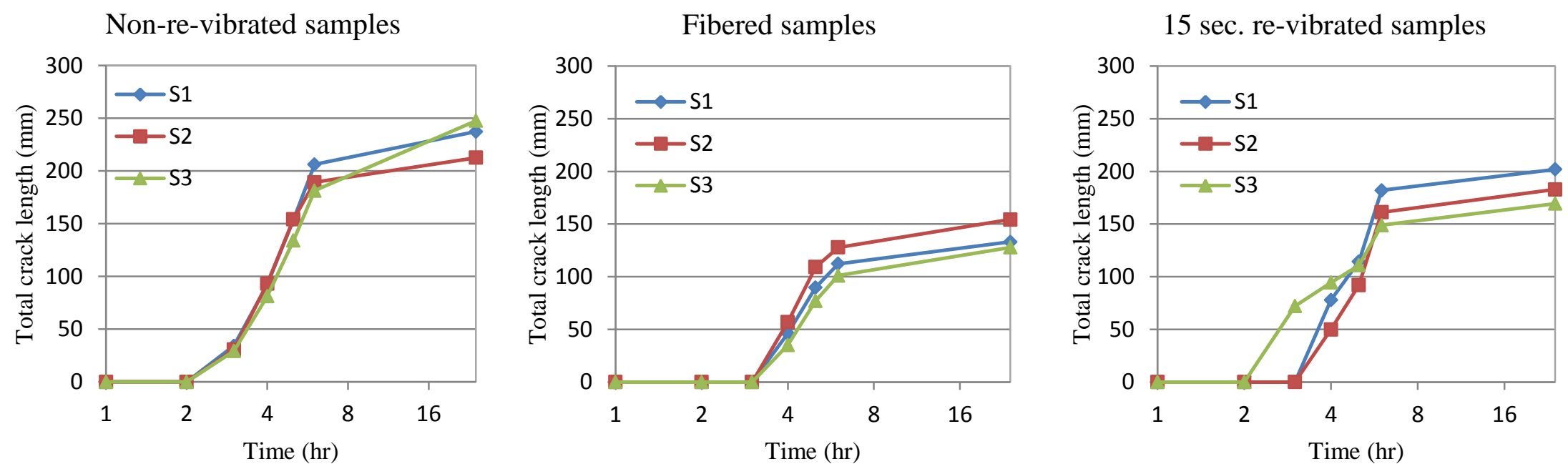

30 sec. re-vibrated samples

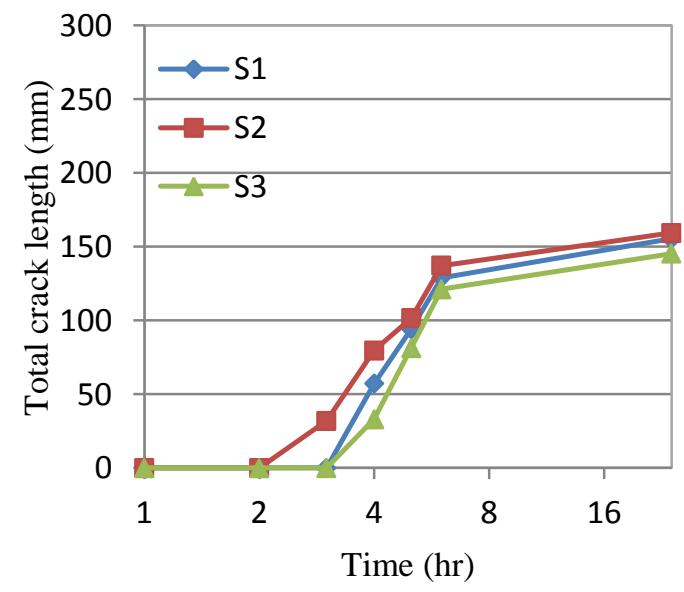

45 sec. re-vibrated samples

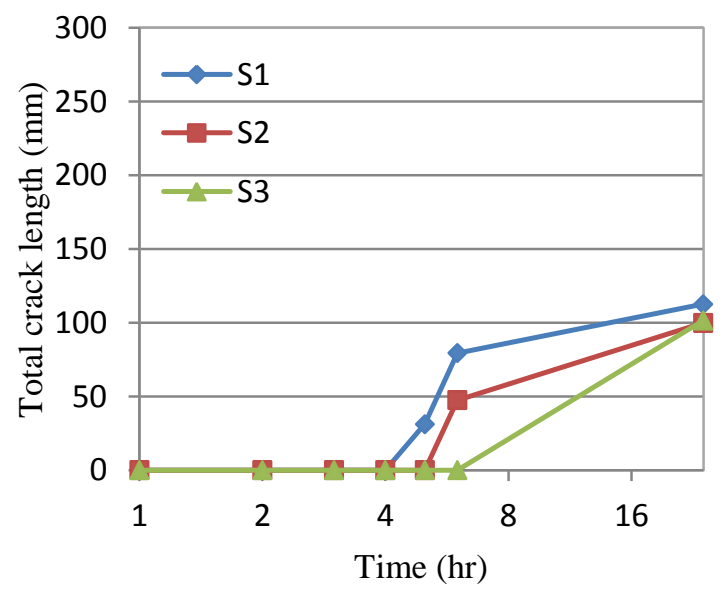

Figure 5.18: Total cracks length vs. time for a water-cement ratio of 0.5 


\subsubsection{Correlation between the Total Crack Length and Average Crack Width}

Correlation between crack length and crack width was analyzed. The analysis shows how two variables are related. The total crack lengths and the average crack widths of all tested slabs at different time intervals ( 1 to 6 , and 24 hours) are shown in table 5.6 (a, b and c). In these tables, it is clear that the average crack widths and the total crack lengths were reduced in all tested slabs when the fiber was added to the concrete mixes. In addition, when different times of re-vibration were applied, the average crack widths and the total crack lengths were reduced in all tested slabs.

Figures 5.19 (a) to 5.19(c) show the total crack length and the average crack width for the cracks in the slabs made with each water-cement ratio. The plots in each figure also show the regression lines and the regression coefficient $\left(\mathrm{R}^{2}\right)$ values. For analysis of the figures it can be concluded that there is almost a perfect correlation between crack length and crack width.

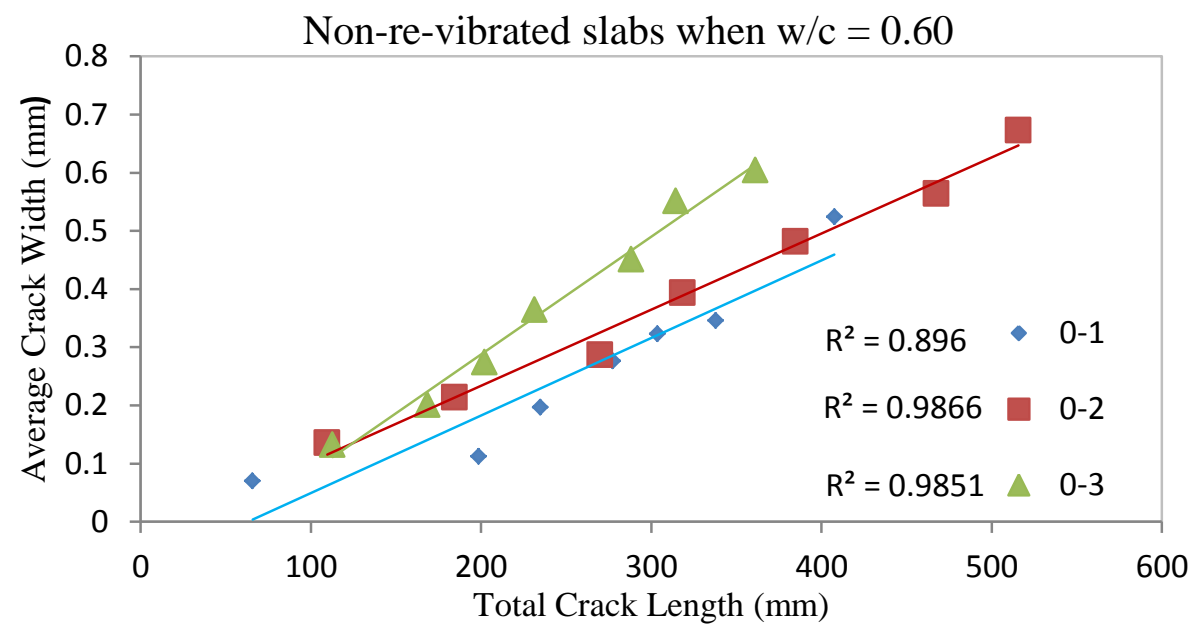



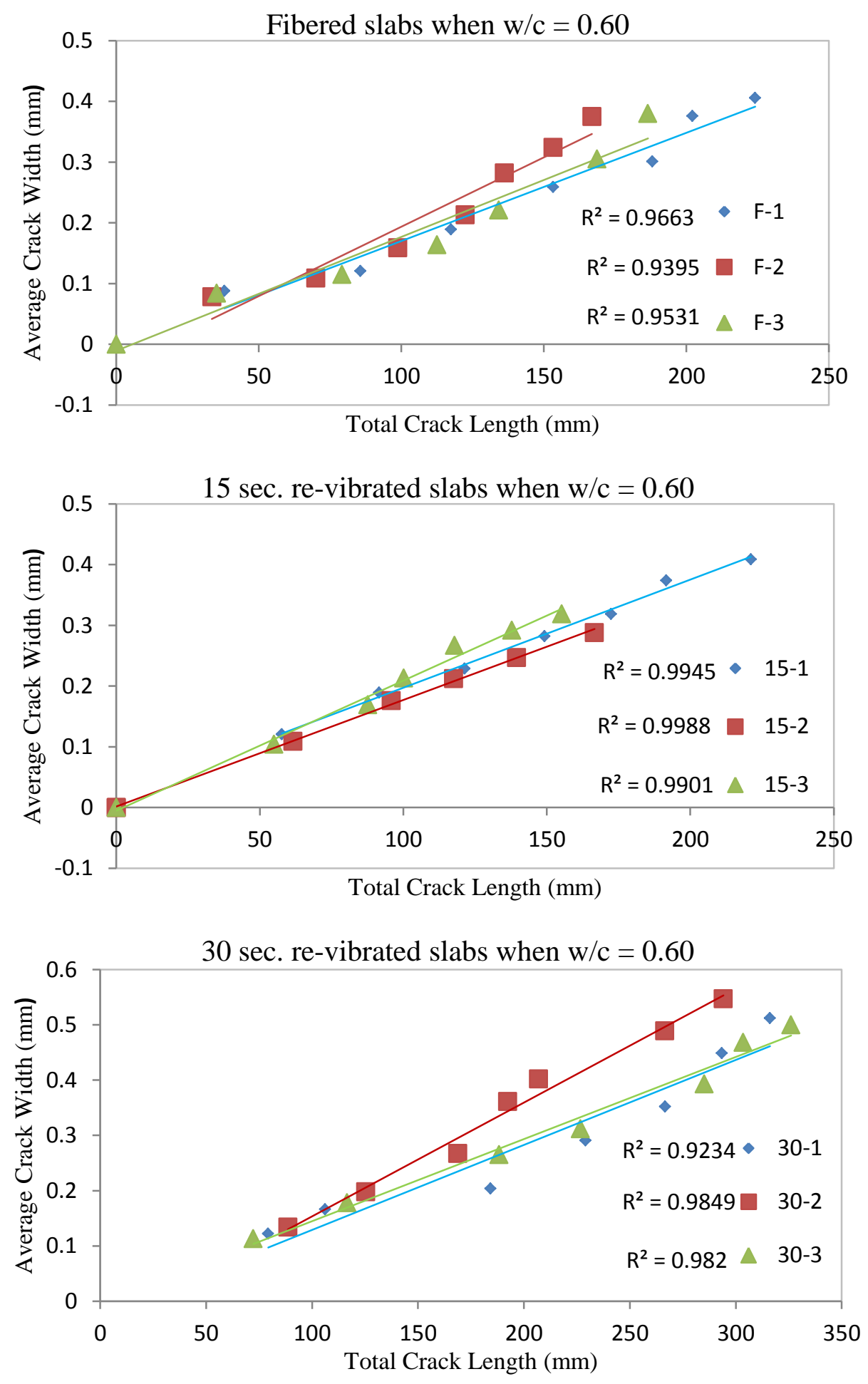


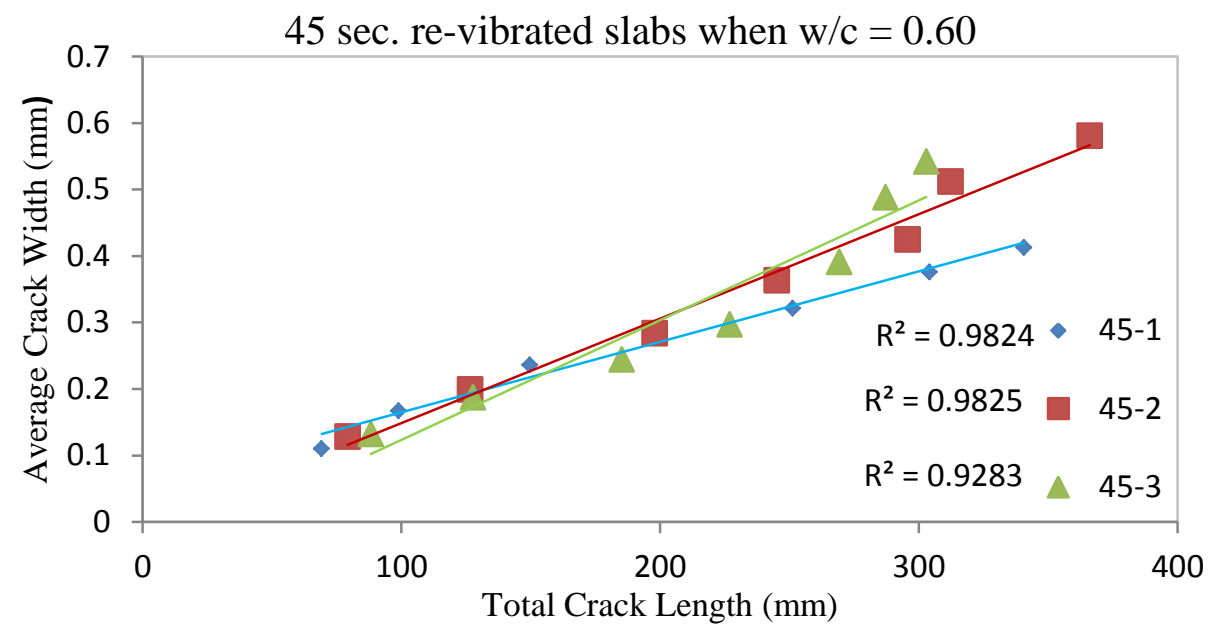

(a)
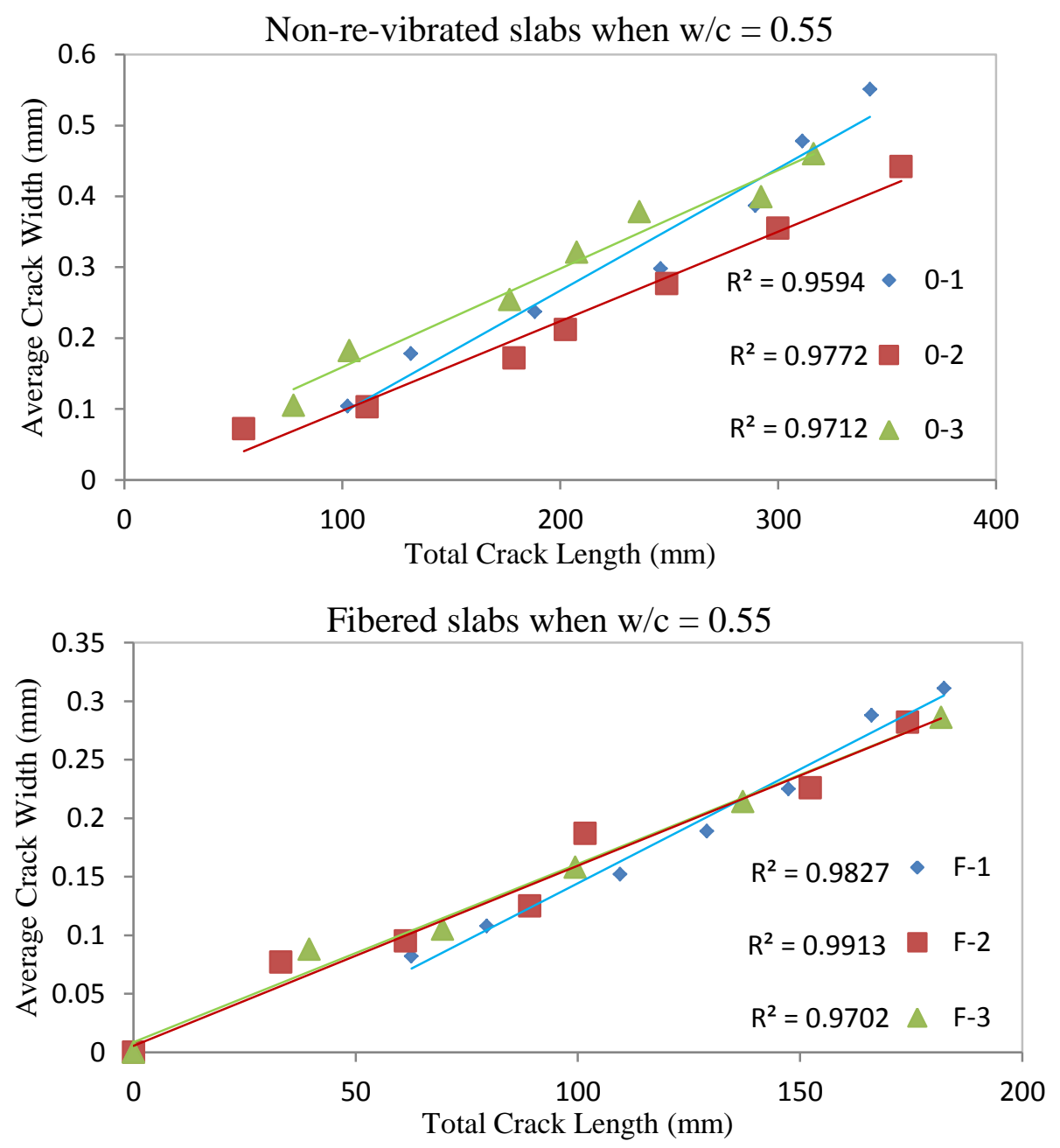

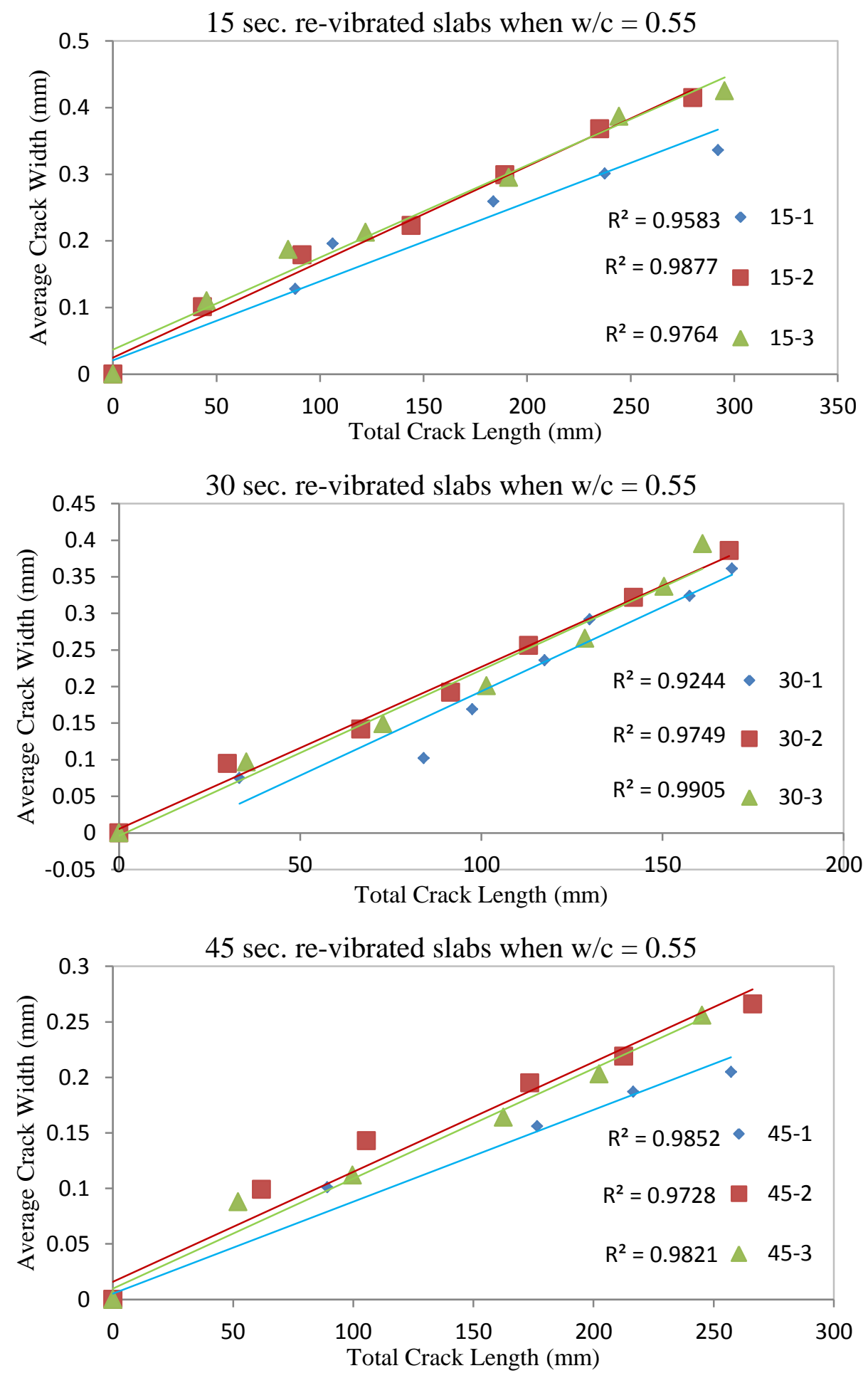

(b) 

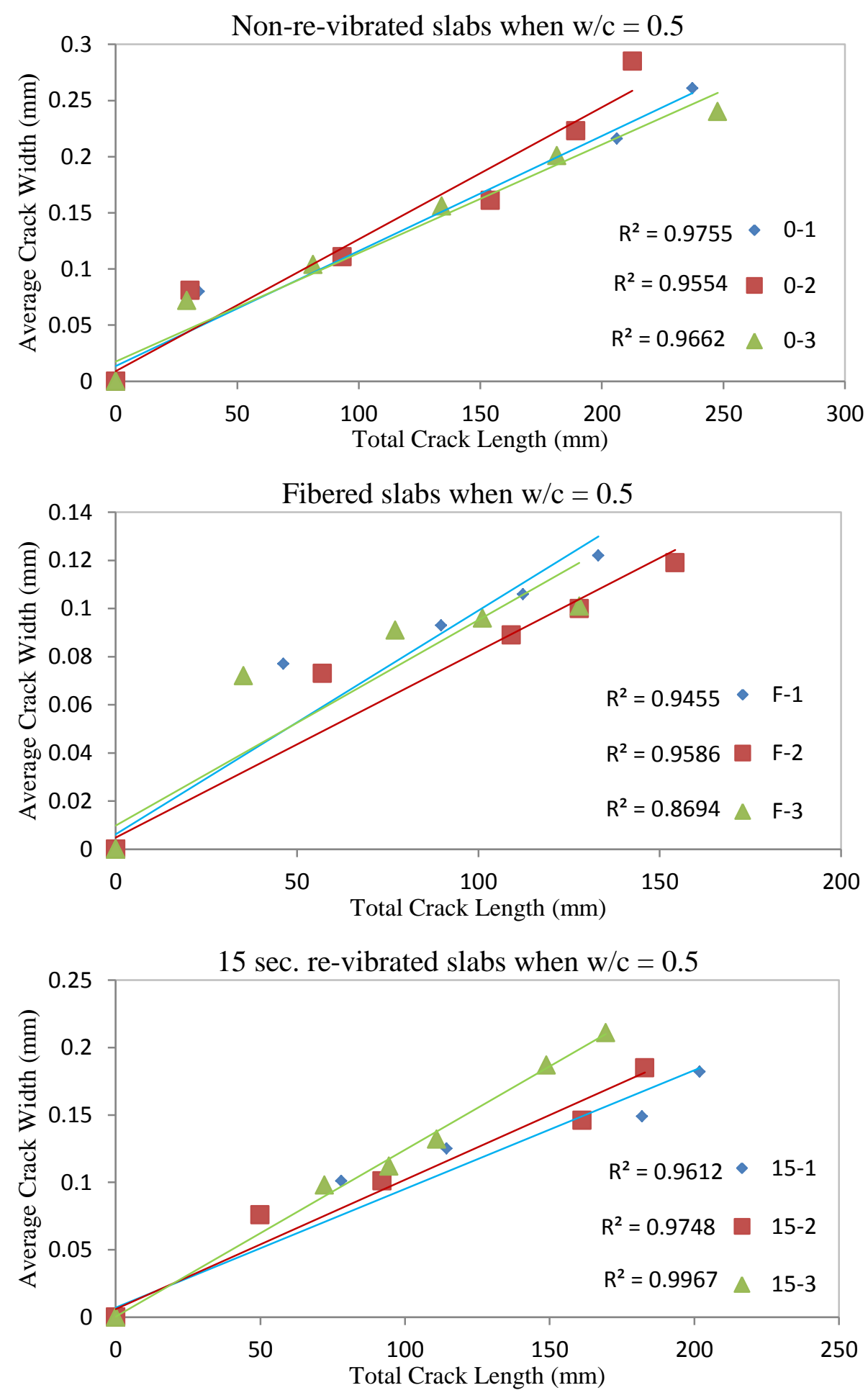

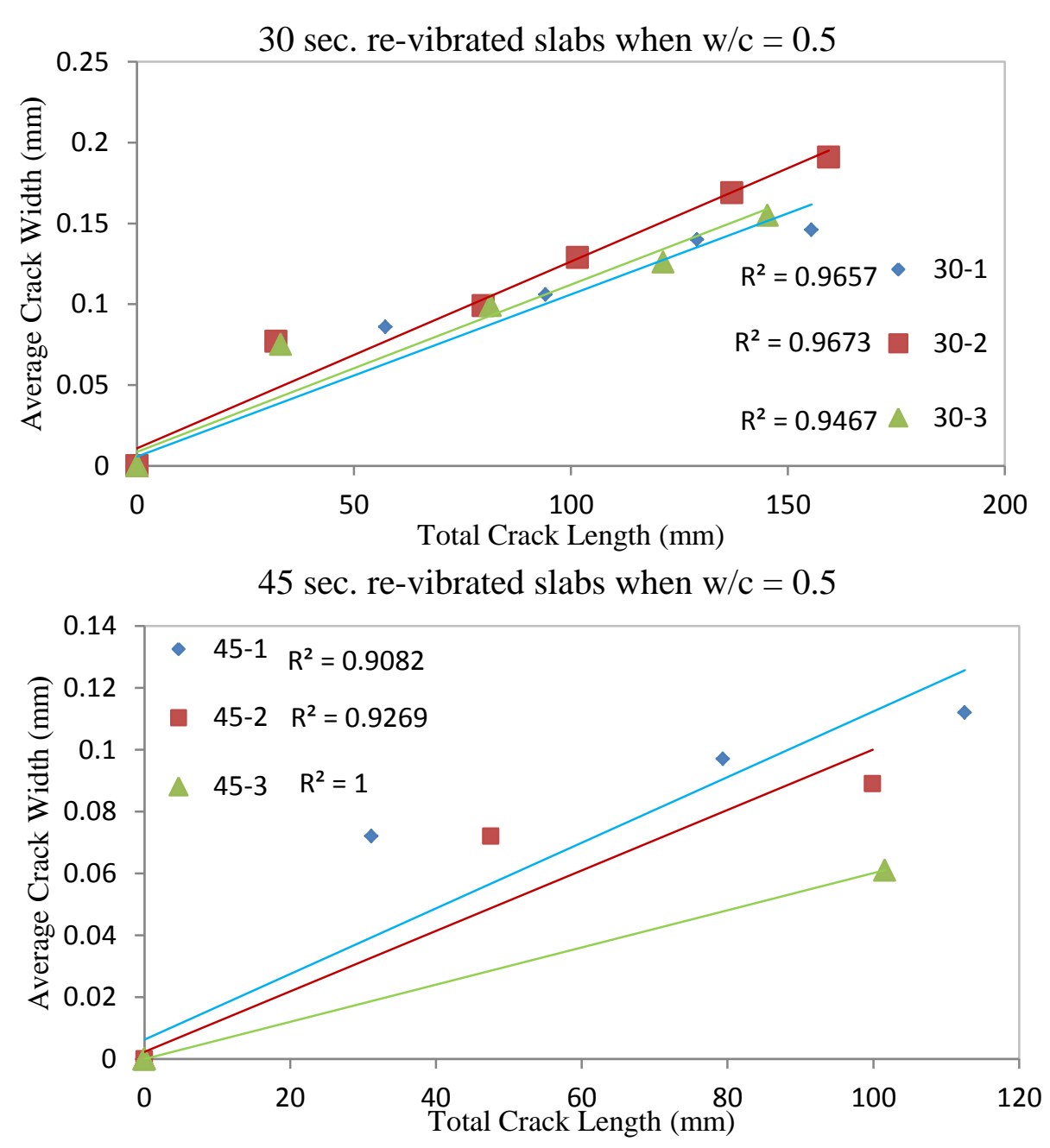

(c)

Figure 5.19: Correlation between the total cracks lengths and the average crack widths: a) watercement ratio of $0.6, b)$ water-cement ratio of 0.55 , and c) water-cement ratio of 0.5

\subsection{ConCLUSION}

In this chapter an image analysis approach was used to assess the effectiveness of applying a second vibration to reduce the development of plastic shrinkage cracking. Several concrete mixes were tried. These included: plain concrete mix, fibered concrete mix and plain concrete mixes that exposed to a second vibration for different time lengths. The results presented in this chapter allow for the following conclusions: 
1. Application of the second vibration on the tested concrete specimens made with different water-cement ratios reduced the average crack width and the total crack length because the second vibration encouraged the top layers of the concrete specimens to release the extra water that was entrapped between aggregate particles and relieve the tensile forces that happened due to rising of bleeding water and caused plastic shrinkage cracking to occur.

2. Addition of FPF fiber to the used concrete mixes reduced the average crack width and the total crack length because the FPF fiber provided reinforcement in the top layers where tensile forces that cause the PSCs to occur were very low.

3. Crack Reduction Ratio (CRR), which was used as an indicator of how concrete revibration or adding FPF fiber reduces plastic shrinkage cracking, showed that average cracks widths and total cracks lengths were reduced when the second vibrations were applied on the tested concrete specimens or the fibers were added to the concrete mixes.

4. The growth of average cracks widths and total cracks lengths was very fast for all tested concrete specimens during the first six hours and then it became asymptotic in the time range from 6 to 24 hours.

5. The total cracks lengths and the average cracks widths were positively correlated.

6. Weibull distribution function provides a reasonable representation of the actual data for all slab conditions (non-re-vibrated, fibered and re-vibrated slabs) and the water-cement ratios $(0.6,0.55$ and 0.5$)$ used in the experimental program. 


\section{Chapter 6: Summary and Conclusion}

The significance of early-age cracking control in concrete structures should be highlighted since the durability performance of concrete is frequently associated with cracking. The development of plastic shrinkage cracks may reduce the service life of structures and require the need for premature repair or replacement of structural components which can be costly. There are significant efforts that have been done to prevent or reduce early age cracking in concrete structures. However, research is still needed in field of early age cracking to predict performance of concrete structures. This thesis introduced an alternative method, called concrete re-vibration method, to reduce the development of plastic shrinkage cracking especially in arid regions worldwide. The concrete re-vibration method was considered because the existing methods are time consuming and significantly add to the costs of construction. For example, one of the available methods is to add a certain volume of fiber to a concrete mix to control plastic shrinkage cracking; volume of fiber needs to be investigated for every concrete mix before it is added.

The concrete re-vibration method also provides good concrete workability, reduces concrete cost due to the ability to use high water-cement ratios, and improves some concrete properties such as compressive strength. In addition, limited availability of fibers, which are traditionally used to control plastic shrinkage cracking, in some developing countries makes the re-vibration method more appealing. Since adding fibers to a concrete mix is a suggested solution to reduce plastic shrinkage cracking, fibrillated polypropylene fiber (FPF) was added to some of the concrete mixes to compare the influence of adding FPF fiber with the influence of applying the concrete re-vibration method on crack reduction. An explanation about how the application of concrete re-vibration on concrete mixes reduces the plastic shrinkage cracking was provided. It was observed that by using the right re-vibration time lengths the cracks widths and lengths are reduced in a manner comparable to the addition of FPF fiber. 
An image analysis approach that characterizes plastic shrinkage cracking patterns was used to measure the crack widths and lengths. Furthermore, the image analysis approach was utilized to understand the variability of the measured crack widths. Histograms and their corresponding cumulative distribution functions for the crack widths data sets were constructed. A Weibull distribution, which is a model with skewed distribution pattern, was selected to be an appropriate function to best fit the crack widths data sets of high variability because it was flexible enough to model the variety of the data sets. Crack reduction ratios (CRR) of average cracks widths and total cracks lengths were calculated and used as indicators to compare the effectiveness of applying a second vibration on some of the tested concrete specimens or adding FPF fiber to some of the tested concrete specimens on crack reduction. The growth of the developed cracks was monitored for the first six hours after casting and until the end of the plastic stage ( $24 \pm 2$ hours). It was found that the growth of average cracks widths and total cracks lengths was faster in the first six hours than the time range from 6 to 24 hours. To understand how crack width and length related, the thesis showed graphically the correlation between the average cracks widths and the total cracks lengths. It showed that average cracks widths and total cracks lengths were positively correlated.

The main conclusions from the research work indicate the following:

1. The concrete mixtures made with the different water-cement ratios $(0.6,0.55$ and 0.5$)$ showed that the compressive strengths of concrete were increased up to $25 \%$ when the application of a second vibration was applied. However, adding fibers to the same concrete mixtures showed no influence on the compressive strengths of concrete.

2. The application of the second vibration on the tested concrete specimens reduced the average cracks widths as following: $43 \%$ for the specimens made with concrete with water-cement ratio of 0.6 and exposed to 15 seconds re-vibration time, $50 \%$ for the specimens made with concrete with water-cement ratio of 0.55 and exposed to 45 seconds re-vibration time, and $65 \%$ for the specimens made with concrete with water- 
cement ratio of 0.5 and exposed to 45 seconds re-vibration time. Thus optimal revibration time was found to be a function of the water-cement ratio.

3. Addition of FPF fiber to the tested concrete mixes reduced the average cracks widths as following: $35 \%$ for the specimens made with concrete with water-cement ratio of 0.6 , $40 \%$ for the specimens made with concrete with water-cement ratio of 0.55 , and $57 \%$ for the specimens made with concrete with water-cement ratio of 0.5 . Thus the proposed revibration method seems to be more efficient than adding fibers to concrete mix.

4. The application of the second vibration on the tested concrete specimens reduced the total cracks lengths as following: 58\% for the specimens made with concrete with watercement ratio of 0.6 and exposed to 15 seconds re-vibration time, $51 \%$ for the specimens made with concrete with water-cement ratio of 0.55 and exposed to 30 seconds revibration time, and $55 \%$ for the specimens made with concrete with water-cement ratio of 0.5 and exposed to 45 seconds re-vibration time.

5. Addition of FPF fiber to the tested concrete mixes reduced the total cracks lengths as following: $55 \%$ for the specimens made with concrete with water-cement ratio of 0.6 , $47 \%$ for the specimens made with concrete with water-cement ratio of 0.55 , and $40 \%$ for the specimens made with concrete with water-cement ratio of 0.5 .

6. The re-vibration time lengths that give the maximum crack reduction were: 15 seconds for the concrete specimens made with water-cement ratio of 0.6 and 45 seconds for the concrete specimens made with water-cement ratios of 0.55 and 0.5 .

7. Although the CRRs of the average cracks widths and the total cracks lengths were very close when concrete mixes were re-vibrated and fibered, the re-vibrated concrete mixers showed better compressive strengths of concrete than the fibered concrete mixes, as it stated in chapter 4. Therefore, the proposed method can be considered as better alternative than the addition of fiber to concrete mixtures in order to control plastic shrinkage cracking, especially in arid regions worldwide. 


\subsection{SUgGESTIONS FOR FUTURE WORK}

While satisfactory work has been made herein towards the quantitative assessment of plastic shrinkage cracking for fibered and re-vibrated concrete specimens, the author recommends further investigations to be considered in future. First, using a different vibration method, such as vibration table, should be considered to guaranty the uniformity of vibration distribution on the concrete specimens which is hard to be achieved by the method used in this study (needle vibrator). Second, a different re-vibration time lag, such as 2 or 3 hours after concrete casting, should be considered to assess the impact of this time on the development of plastic shrinkage cracking. Third, as it is well known, the tensile strength of concrete is much lower than the compressive strength; therefore, most concrete studies consider testing only the compressive strength of concrete. However, an early tensile strength is an important factor in the field of early aging cracking, as explained in chapter 2; therefore, the influence of adding fiber to concrete mixes or applying a second vibration on concrete mixes should be investigated for the tensile strength. Fourth, using a scanning electron microscope (SEM) imaging should be considered to figure out the influence of the second vibration on the microstructure of the developed cracks. 


\section{References}

ACI 116R, 2000, "Cement and Concrete Technology."

ACI 224R, 2001, "Control of Cracking in Concrete Structures."

ACI 234, 1996, "Guide for use of silica fume in concrete", American Concrete Institute, Farmington Hill, Michigan, 51 pages.

ACI 308, 2001, "Guide to Curing Concrete".

ACI 309.1R, 1993, "Behavior of Fresh Concrete during Vibration."

ACI 309R, 1996, "Guide for Consolidation of Concrete."

Aldalinsi, M. A., Al-Zahra, S. M., and Hana, S. Y., 2003, "Re-vibration of Concrete." Bachelors thesis, Higher Institute of Engineering at Hoon, Libya.

Al-Fadhala, M., and Hover, K. C., 2001, "Rapid Evaporation from Freshly Cast Concrete and the Gulf Environment," Construction and Building Materials, V. 15, No. 1, Jan., pp. 1-7.

Almussalam, A. A., Maslehuddin, M., Abdul-Waris, M., and Khan, M. M., 1998, "Effect of Mix Proportions on Plastic Shrinkage Cracking of Concrete in Hot Environments", Construction and Building Materials, No. 12, pp. 353-358.

Ammouche, A., Riss, J., Breysse, D., and Marchand, J., 2001, "Image Analysis for the Automated Study of Micro-cracks in Concrete," Cement \& Concrete Composites, Vol. 23, pp. 267-278.

ASTM C-127, 2007, "Standard Test Method for Density, Relative Density (Specific Gravity), and Absorption of Coarse Aggregate,"

ASTM C-128, 2007, "Standard Test Method for Density, Relative Density (Specific Gravity), and Absorption of Fine Aggregate."

ASTM C143/C143M., 2012, "Standard Test Method for Slump of Hydraulic-Cement concrete,"

ASTM C150/C150M., 2012, "Standard Specification for Portland Cement."

ASTM C-1579, 2013, "Standard test method for Evaluating Plastic Shrinkage Cracking of Restrained Fiber Reinforced Concrete."

ASTM C192/C192M, 2012, "Standard Practice for Making and Curing Concrete Test specimens in the Laboratory."

ASTM C33/C33M., 2013, "Standard Specification for Concrete Aggregates."

ASTM C39/C39M., 2012, "Standard Test Method for Compressive Strength of Cylindrical Concrete Specimens."

ASTM C403/C403M., 2008, "Standard Test Method for Time of Setting of Concrete Mixtures by Penetration Resistance."

ASTM C827/C827M, 2010, "Standard Test Method for Change in Height at Early Ages of Cylindrical Specimens of Cementitious Mixtures,"

Balaguru, P., 1994, "Contribution of Fibers to Crack Reduction of Cement Composites during the Initial and Final Setting Period," ACI Material Journal, May-June, pp. 280-288. 
Banthia, N., and Yan, C., 2000, "Shrinkage cracking in polyolefin fiber-reinforced concrete," ACI Materials Journal, July-Aug., pp. 432-437.

Banthia, N., Azzabi, M., and Pigeon, M., 1993, "Restrained Shrinkage Cracking in Fiberreinforced Cementitious composites," Materials and Structures, Vol. 26, Aug-Sep., pp. 405-413.

Banthia, N., Azzabi, M., and Pigeon, M., 1994, "Restrained Shrinkage Test on Fiber Reinforced Cementitious Composites," ACI SP-155-7, Testing of Fiber Reinforced Concrete, pp. 137-152.

Banthia, N., Yan, C., and Mindess, S., 1996, "Restrained Shrinkage Cracking in Fiber Reinforced Concrete: a novel test technique," Cement and Concrete Research, Vol. 26, Jan., pp. 9-14.

Berke, N. S., and Dalliare, M. P., 1994, "The Effect of Low Addition Rate of Polypropylene Fibers on Plastic Shrinkage Cracking and Mechanical Properties of Concrete," Fiber Reinforced Concrete: development and innovations, ACI SP-142-2, pp. 19-41.

Bhattacharjee, B., 2005, “Compaction of Concrete," Department of Civil Engineering, IIT, Delhi, India.

Bloem, D. L., 1960, "Plastic cracking of concrete," National Ready Mixed Concrete Association (NRMCA), Engineering information, July.

Bloom, R., and Bentur, A., 1995, "Free and restrained shrinkage for normal and high strength concretes," ACI Material Journal, Vol. 92, No. 2, pp. 211-217.

Cement \& Concrete Association of New Zealand (CCANZ), 2006, "Vibration of Concrete," Information Bulletin: IB 46.

Cement Concrete \& Aggregates Australia (CCAA), 2005, "Plastic Settlement Cracking," Data Sheet, June 2005.

Cement Concrete \& Aggregates Australia (CCAA), 2006, "Compaction of Concrete," Data Sheet, June 2006.

Cohen, M. D., Olek, J., and Dolch, W. L., 1990, "Mechanism of plastic shrinkage cracking in Portland-cement and Portland cement-silica fume paste and mortar," Cement and Concrete Research, Vol. 20, pp. 103-119.

Diamond, S., and Bonen, D., 1995, “A Re-evaluation of Hardened Cement Paste Microstructure based on Backscattered SEM Investigations," Materials Research Society, symposium proceedings, Vol. 370, pp. 13-22.

Euclid Chemical Company: http://www.euclidchemical.com/

GCC Rio Grande Company: http://www.GCCusa.com/

Haavik, D., J., 1990, "Evaluating Concrete Cracking by Measuring Crack Width," Publication\# C900553

Handheld Weather Station., http://www.kestrelmeters.com/products/kestrel-3500-weather-meter

Holt, E. E., 2000, “Where did these cracks come from?” Concrete International, Sept., pp. 57-60.

http://www.aboutcivil.org/Properties-of-concrete-factors-affecting-them.html\#bl 
http://www.fhwa.dot.gov/publications/research/infrastructure/pavements/pccp/05038/005.cfm

Ismail, A. M., 2009, "Vibration \& Re-vibration." Benha Higher Institute of Technology, 3rd Civil Engineering DEP.

Kelly, J. W., 1981, “Cracks in Concrete: Kinds of Cracks and Causes of Cracking,” Publication \# C810725

Kraai, P. P., 1985, "Proposed Test to Determine the Cracking Potential Due to Drying Shrinkage of Concrete," Concrete Construction, Vol. 30, Sept., pp. 775-778.

Krishna, M. V., Kumar, P. R., \& Bhaskar, B. N., 2008, "Effect of Re-vibration on Compressive Strength of Concrete." Asian Journal of Civil Engineering (Building and Housing), Vol. 9, No. 3, pp. 291-301.

Lane, S., Scott, M. L., and Weyers, R. E., 1997 "Relationship between capillary pore pressure and early shrinkage cracking of concrete" VTRC report No. 97-R12, Virginia Transportation Research Council, Copyrighted of the Commonwealth of Virginia.

Maclnnis, C., and Kosteniuk, P. W., 1979, "Effectiveness of Re-vibration and High-Speed Slurry Mixing for producing High-Strength Concrete,” ACI Journal, No. 76, pp. 1255-1265.

Mangat, P. S., and Azari, M. M., 1990, "Plastic Shrinkage of Steel Fiber Reinforced Concrete", Materials and Structures, Vol. 23, pp. 186-195.

Menzel, C., 1954, "Cause and Prevention of Cracks Developing in Plastic Concrete,"

Mindess, S., and Diamond, S., 1980, "A Preliminary SEM Study of Crack-Propagation in Mortar." Cement and Concrete Research, Vol. 10, pp. 509-519.

Multiquip Inc., (CVH) 2003, “Concrete Vibration Handbook,” www.multiquip.com

National Ready Mixed Concrete Association (NRMCA), 1960, "Plastic Cracking of Concrete." Engineering information, July, Soroka I, Concrete in hot environments, London: Chapman and Hall, 1992:13-24.

Neville, A. M., 2011, "Properties of Concrete," Fifth Edition.

Pelisser, F., Santos Neto, A. B., La Rovere, H. L., and Pinto, R. C. A., 2010, "Effect of the Addition of Synthetic Fibers to Concrete Thin Slabs on Plastic Shrinkage Cracking." Construction and Building Materials, No. 24, pp. 2171-2176.

Portland Cement Association (PCA) webinar, 2010, "Fly ash, Slag, Silica fume, and Natural Pozzolans", Thursday, March 11.

Portland Cement Association (PCA), 2003, "Design and Control of Concrete Mixtures." 14th edition, Engineering Bulletin 001.

Powers, T. C., 1968, “The Properties of Fresh Concrete”, John Wiley \& Sons, Inc. New York, $664 \mathrm{pp}$.

Qi, C., Weiss, J., \& Olek, J., 2003, “Characterization of Plastic Shrinkage Cracking in FiberReinforced Concrete Using Semi-Automated Image Analysis." RILEM Materials and Structures, Vol. 36, No. 260, July 2003, pp. 386-395. 
Qi, C., Weiss, J., \& Olek, J., 2005,"Statistical Significance of the Restrained Slab Test for Quantifying Plastic Cracking in Fiber Reinforced Concrete." Journal of ASTM International, July/August., Vol. 2, No. 7, Paper ID JAI12242.

Radocea, A., 1992, “A New Method for Studying Bleeding of Cement Paste”, Cement and Concrete Research, Vol. 22, No. 5, pp.855-865.

Ravina and Shalon, 1968, "Plastic Shrinkage Cracking", Journal of the American Concrete Institute, vol. 65, No. 22, April. 1968, pp. 282-291.

Ritchie, Alistair G.B., 1968, "The Rheology of Fresh Concrete," Proceedings, ASCE, V. 94, C01, Jan., pp. 55-74.

Sanjuan, M. A., and Moragues, A., 1997, "Polypropylene fiber reinforced Mortar Mixes: Optimization to Control Plastic Shrinkage," Composite Science and Technology, Vol. 57, pp. 665-660.

Sawaide, M. and Iketani. J., 1992, "Rheological Analysis of the Behaviour of Bleed Water from Freshly Cast Mortar or Concrete," ACI Materials Journal, V. 4, No. 89, July, pp. 323327.

Sawyer, D. H., and Lee, S. F., 1956, "The Effect of Re-vibration on Properties of Portland Cement Concrete," presented at the 1956 annual meeting of the American Society for Testing and Materials.

Schaeles, C. A., and Hover, K. C., 1988, "Influence of Mix Proportions and Construction Operations on Plastic Shrinkage Cracking in Thin Slab", ACI Material Journal, Vol. 85, No. 6, pp. 495-504.

Schaeles, C. A., Hover, K. C., 1988, "Influence of Nix Proportions and Construction Operations on Plastic Shrinkage Cracking in thin Slabs," ACI Material Journal, Vol. 85, No. 6, pp. 495-504.

Snell, L. M., 2008, "How to prevent plastic shrinkage cracks" Del E. Webb School of Construction Arizona State University, Tempe, Arizona

Soroka, I., and Ravina, D., 1998, "Hot Weather Concreting with Admixtures". Cement and Concrete Research, Vol. 20, pp. 129-136.

Soroushian, P., Mirza, F., and Alhozaimy, A., 1995, "Plastic Shrinkage Cracking of Polypropylene Fiber-reinforced Concrete", ACI Materials Journal, Vol. 92, Sep.-Oct., pp. 553-560.

Transportation Research Circular, 2006, "Control of Cracking in Concrete," Number E-C107, October.

Tuthil, L., H., and Davis, H., E., 1938, “Over-vibration and Re-vibration of Concrete,” Journal of the American Concrete Institute, Proceedings of the American Concrete Institute, Vol. 35, September.

Tuthill, L. H., 1977, “Re-vibration Reexamined,” Publication \# C770537

Uno, P. J., 1998, "Plastic Shrinkage Cracking and Evaporation Formulas," ACI Materials Journal, V. 95, No. 4, pp. 365-375.

Vollickt, C. A., 1958, “Effects of Re-vibrating Concrete,” ACI Journal, No. 54, pp. 721-732. 
Wang, K., Shah, S. P. \& Phuaksuk, P., 2001, "Plastic Shrinkage Cracking in Concrete Materials - Influence of Fly Ash and Fibers," ACI Materials Journal, Vol. 98, No. 6, pp. 458-464.

Weyers, R. E., Conway, J. C., and Cady, P. D., 1982, "Photoelastic Analysis of Rigid Inclusions in Fresh Concrete", Cement and Concrete Research, Vol. 12, pp. 475-484.

Wittmann, F. H., 1976, "On the Action of Capillary Pressure in Fresh Concrete", Cement and Concrete research, Vol. 6, Jan. 1976, pp.49-56. 


\section{Appendix A}

\section{Standard Test Method for Evaluating Plastic Shrinkage Cracking of Restrained Fiber Reinforced Concrete (Using a Steel Form Insert) ${ }^{1}$}

This standard is issued under the fixed designation C1579; the number immediately following the designation indicates the year of original adoption or, in the case of revision, the year of last revision. A number in parentheses indicates the year of last reapproval. $\mathrm{A}$ superseript epsilon ( $s$ ) indicales an editorial change since the last revision or reapproval.

\section{Scope*}

1.1 This test method compares the surface cracking of fiber reinforced concrete panels with the surface cracking of control concrete panels subjected to prescribed conditions of restraint and moisture loss that are severe enough to produce cracking before final setting of the concrete.

1.2 This test method can be used to compare the plastic shrinkage cracking behavior of different concrete mixtures containing fiber reinforcement.

1.3 The values stated in SI units are to be regarded as standard. No other units of measurement are included in this standard.

1.4 This standard does not purport to address all of the safety concerns, if any, associated with its use. It is the responsibility of the user of this standard to establish appropriate safety and health practices and determine the applicability of regulatory limitations prior to use. (Warning - fresh hydraulic cementitious mixtures are caustic and may cause chemical burns to skin and tissue upon prolonged exposure. $)^{2}$

\section{Referenced Documents}

2.1 ASTM Standards: ${ }^{3}$

C125 Terminology Relating to Concrete and Concrete Aggregates

C143/C143M Test Method for Slump of Hydraulic-Cement Concrete

C192/C192M Practice for Making and Curing Concrete Test Specimens in the Laboratory

C403/C403M Test Method for Time of Setting of Concrete Mixtures by Penetration Resistance

"This test method is under the jurisdiction of ASTM Committer $\mathrm{CO9}$ an Concrete and Concrete Aggregates and is the direct responsibility of Subcommittee C09.42 an Fiber-Reinforved Concrete.

Current edition approved April 1, 2013. Published May 2013. Originally published in 2006. Last previous edition approved in 2012 as C1579-06(2012). DOI: 10.1520151579-13.

Section on Safety Precautions, Manual of Aggregate and Concrete Testing. Anenual Book of ASTM Stondanit, Vol. 04.02.

${ }^{3}$ For referenced ASTM standards, visit the ASTM website, www.astmorg, of contact ASTM Custnmer Service at service astm.org. For Anevual Book of ASTM Standards volume information, refer to the standard's Document Summary page on the ASTM website.
C670 Practice for Preparing Precision and Bias Statements for Test Methods for Construction Materials

\section{Summary of Test Method}

3.1 Panels of control concrete and fiber reinforced concrete are prepared in a prescribed manner and are exposed to controlled drying conditions after finishing. The drying conditions (See Note 1) are intended to be severe enough to induce plastic shrinkage cracking in test panels made of control concrete. The evaporation rate from a free water surface is monitored by pans placed next to the panels in the environmental chamber.

Non: 1-An important parameter in this method is the rate of evaporative water loss, which is controlled by the atmospheric conditions surrounding the test specimens. Since the concrete specimens will not always have the same rate of water evaporation as the pan of water (due to evaporative and bleeding effects), the rate of evaporation of $1.0 \mathrm{~kg} / \mathrm{m}^{2}-\mathrm{h}$ from the pan of water represents the minimum evaporation rate that mus be attained for this test (1). ${ }^{4}$ The moisture loss from the concrete test panels can also be monitored and reported, however, the rate of evaporation from the free surface of the water in the pan is the parameter that should be used to quantify the drying eavironment.

3.2 The test is terminated at the time of final setting of the concrete determined in accordance with Test Method C403/ C403M. At $24 \mathrm{~h}$ from initial mixing, the average crack width is determined.

3.3 A cracking reduction ratio (CRR) is computed from the average crack width for the fiber-reinforced concrete panels and the average crack width for the control concrete panels.

\section{Significance and Use}

4.1 The test method is intended to evaluate the effects of evaporation, settlement, and early autogenous shrinkage on the plastic shrinkage cracking performance of fiber reinforced concrete up to and for some hours beyond the time of final setting (See Terminology C125).

4.2 The measured values obtained from this test may be used to compare the performance of concretes with different mixture proportions, concretes with and without fibers, concretes containing various amounts of different types of fibers,

t The boldface numbers in parentheses refer to the list of references at the end of this standard.

-A Summary of Changes section appears at the end of this standard

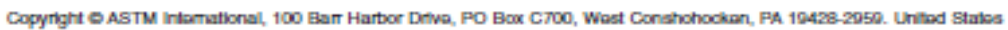

Copyright by ASTM Int1 (all rights reserved): Tmu Jun 20 15:07:47 EDT 2013 ,

Downloaded printed by

University of Texas El Paso purvant to License Agreament. No further reproductions autborized. 
and concretes containing various amounts and types of admixtures. For mearingful comparisons, the evaporative conditions during test shall be sufficient to produce an average crack width of at least $0.5 \mathrm{~mm}$ in the control specimens $(2,5)$ (See Note 2). In adilion, the evaporation rate from a free surface of water shall be within $\pm 5 \%$ for each test.

More 2-To achieve evapontion rates that result in a crack of at last os rom in the control specimens, it ney be frecessary b use an evaporation rate higher than that discused in Note 1.

4.3 This method attempts to control atmospheric variables to quantify the relative performance of a given fresh concrete mix ture. Since many other variables such as cement finenes, aggregate gradation, aggregate volume, mixing procedures, slump, air content, concrete temperature and surface finish can also influence potential cracking, attention shall be paid to keep these as corsistent as possible from mixture to mixture.

\section{Apparatus}

5.1 Holds:
5.1.1 For maximum coarse aggregate size equal to or less than $19 \mathrm{~mm}$, use a mold with a depth of $100 \pm 5 \mathrm{~mm}$ and rectangular dimensions of $355 \pm 10 \mathrm{~mm}$ by $560 \pm 15 \mathrm{mom}$ (See Fig. 1). The mold can be fabricated from metal, plastic, or plywood.

Nork 3-If plywood is used for molds, the phywood should have low moisture absomption. The mold should be constre ted $b$ be lightweight and stiff. The molds, when properly constructed, should last for approximately 50 ues.

5.1.2 This test method is designed for aggregate less than or equal to $19 \mathrm{~mm}$. For coarse aggregate geater than $19 \mathrm{~mm}$, the depth of the mold shall be at least $65 \mathrm{~mm}$ plus at least 2 times the maximum coarse aggegate size.

5.2 Stress Riser and Internal Restraints-The internal restraints and stress riser shall be bent from one piece of sheet metal, as illustrated in Fig. 1, or made from a solid piece of steel. The sheet metal shall have a thickress of $1.2 \pm 0.05 \mathrm{~mm}$ (18 gauge) (See Fig. 1 and Ref 2). Two $32 \pm 1 \mathrm{~mm}$ high
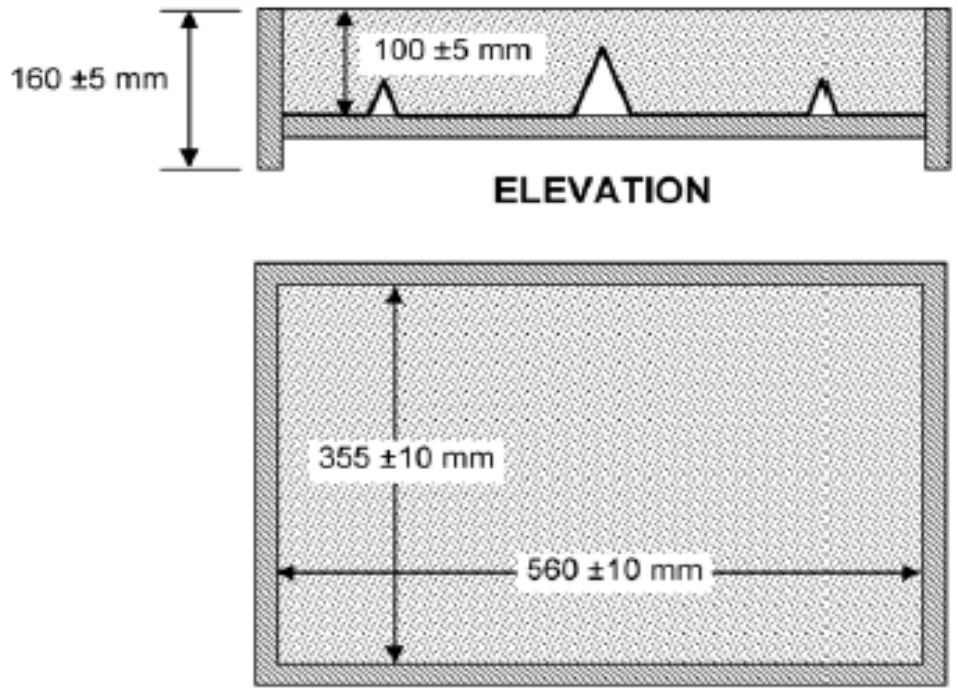

PLAN

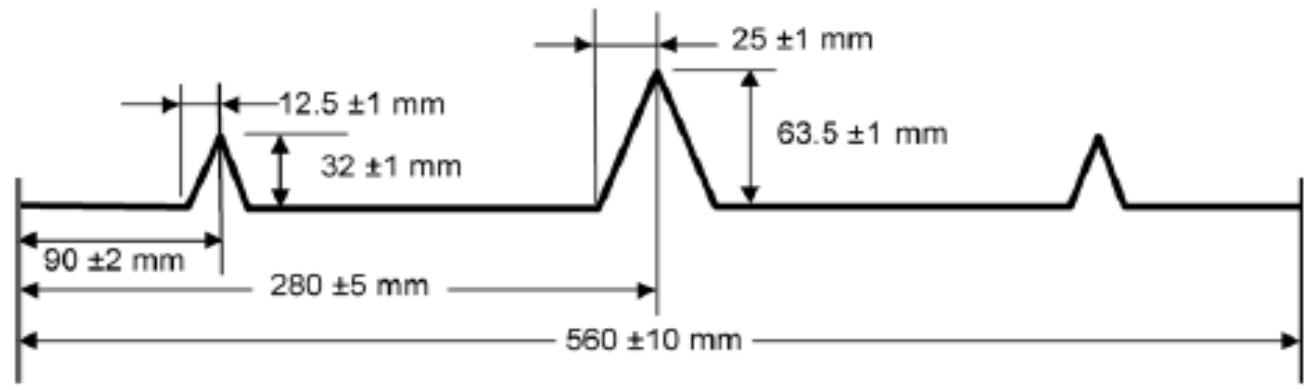

Stress Riser Geometry

FIG. 1 Specimen and Stress Riser Geomet ny (4, 5) 
restraints are placed $90 \pm 2 \mathrm{~mm}$ irward from each end of the mold. The central stress riser is $64 \pm 2 \mathrm{~mm}$ high and serps as an iritiation point for cracking. This sheet metal stres riser with internal restraints shall fit at the bottom of the mold

5.2.1 Use form release oil to coat the metal irsert and mold sides to reduce bond with concrete. The insert and mold are considered to be properly oiled when the entire surface is coated and excess oil has been removed with a clean, dry rag.

5.3 Wriablespeed Fan(s) - The fan(s) used shall becapable of achieving a wind speed of more than $4.7 \mathrm{~m} / \mathrm{s}$ over the entire test parel surface area.

5.4 Environmenal Chamber-The use of a fan box in an environmental chamber is a method for producing a uniform airflow over the panel surface (See Fig. 2). A clear cover over the panels will aid in obtaining uniform aifflow and allow for observation of cacking. Another method of protucing uniform airflow is to use aspecifically designed environmental chamber as shown in Fig. 3. A commercially available heater, humidifier, and dehumidifier can be used to maintain the specified environmental condition. This test is conducted using either apparatus shom in Fig 2 or Fig. 3 by exposing the panels to an evaporation rate of at least $1.0 \mathrm{~kg}^{2} \mathrm{~m}^{2}$.h (See Note 1). For the standard test, the temperature must be maintained at $36 \pm 3^{\circ} \mathrm{C}$, the relative humidity must be $30 \pm 10 \%$, and the wind velocity must be sufficient to maintain the minimum evaporation rate during the test.

Nore 4-Before casting the concrete panels, amospleric variables in the enviromorental focility should be checked to deternine that the necessary evaporative conditions can be achieved. A wind velocity of 4.7 $\mathrm{mos}$ should be sufficient to achieve the minimum specified evaporation rat, but a higher wind velocity may be nesded to obsir sufficient average crack width in some control panels.

5.5 Sensors-Use temperature, humidity, and wind velocity sersors to measure ambient air and concrete surface temperature to the nearest $0.5^{\circ} \mathrm{C}$, relative humidity to the nearest $1 \%$, and air speed to the rearst $0.1 \mathrm{~m} / \mathrm{s}$.

56 Thbating Platfom-Any device that can fully consolidate the test parel that meets minimum frequency requirements as stated in Practice C192/C192M for an extemal vibrator is suitable.

5.7 Surface Finishing Equipment-An angle iron screed shall be ued for the concrete after vibration. A magresium, steel, or wood trowel shall be used for firishing the surface of the specimen after screeding.

5.8 Monitoring Pan-A pan suitable for exposing water to the air stream for each concre te test panel is required. The sides of the pan shall be vertical. The pan shall be of sufficient size to expose at least $0.1 \pm 0.01 \mathrm{~m}^{2}$ of water to the air stream. The expoeed lip of the pan shall not extend more than 5 mm above the water level at the start of the test.

Nowe 5-The test panels and monitoring pans can be placed in an ervirorrmentel chamber designed for this est method (See Fig. 3) or the pans can be placed donnstream from panels in a fan box (See Fig. 2).

59 Scale-If the rate of moisture loss from test panels is required by the specifier of tests, weigh test panels with a scale having a capacity of at least $100 \mathrm{~kg}$ and accurate to within $0.1 \%$ of the test load. Weigh the evaporation rate monitoring pans with a balance or scale having a capacity of at least $3 \mathrm{~kg}$ and accurate to within $5 \mathrm{~g}$.

5.10 Crack Measurement Tool-Optical hand-held microscope, crack comparator, or image analysis system can be used. The measurement tool should be capable of measuring crack width to at least the nearest $0.05 \mathrm{~mm}$. If an automated image analysis system is used, it should be demorstrated to provide an accurate measurement. To demonstrate the accuracy of the measurement, the system shall be used to measure a 0.5 mm notch that is machired into a piece of steel and the reported notch width shall be within $\pm 005 \mathrm{~mm}$ of the machined witth

\section{Sampling, Test Specimens, and Test Units}

6.1 Test Panels-Cast test parels in accordance with the applicable provisions of Practice $\mathrm{C} 192 \mathrm{C} 192 \mathrm{M}$, wing the same source of materials, preparation, mixing and finishing procedures.

6.2 Test Unit-A test unit is comprised of at least two control specimers and at least two fiber reinforced concrete specimers with the same mix ture proportions. A group of two control specimens has to be tested each time in order to determine the plastic shrirkage crack reduction of fiber reinforced concrete.

\section{Procedure}

7.1 Detemine the slump of each mixture in accordance with Test Method C143/C143M.

7.2 Fabricate specimens for setting time determination in accordance with Test Method C403/C403M. If fiber reinforced concrete cannot be wet sieved readily, we the control concrete specimen to measure time of final setting of both the control and the fiber-reinforced mixtures. Place the time of setting specimers in the air stream so that they are exposed to the same environmental conditions as the plastic shrinkage panels.

7.3 Fill the parel molds using one layer. Consolidate the concrete with external vibration until the concrete is approximately level with the top of the mold. Screed each specimen perpendicular to the stress riser three times.

7.4 After screeding, trowel specimens using a predetermined number of passes. If moisture los from the parel is to be determined, remove any waste concrete adhering to the outside of the mold and weigh each panel while in the mold.

7.5 Place a fiber reinforced concrete mixture parel and control mixture parel in the envimnmental chamber downstream from the fan(s) (See arrangements in Figs. 2 and 3).

76 Turn on the fan(s), which have been preset to achieve the air speed to obtain the required evaporative conditions (See Note 4). The evaluation of cracling commences at this time.

7.7 At the start of the test and at 30-min intervals, record air temperature, relative humidity, and air flow speed at a location $100 \pm 5 \mathrm{~mm}$ above each panel surface. If required by the specifier of tests, record the time at which cracking is first obeerved for each panel surface. Perform penetration tests at 

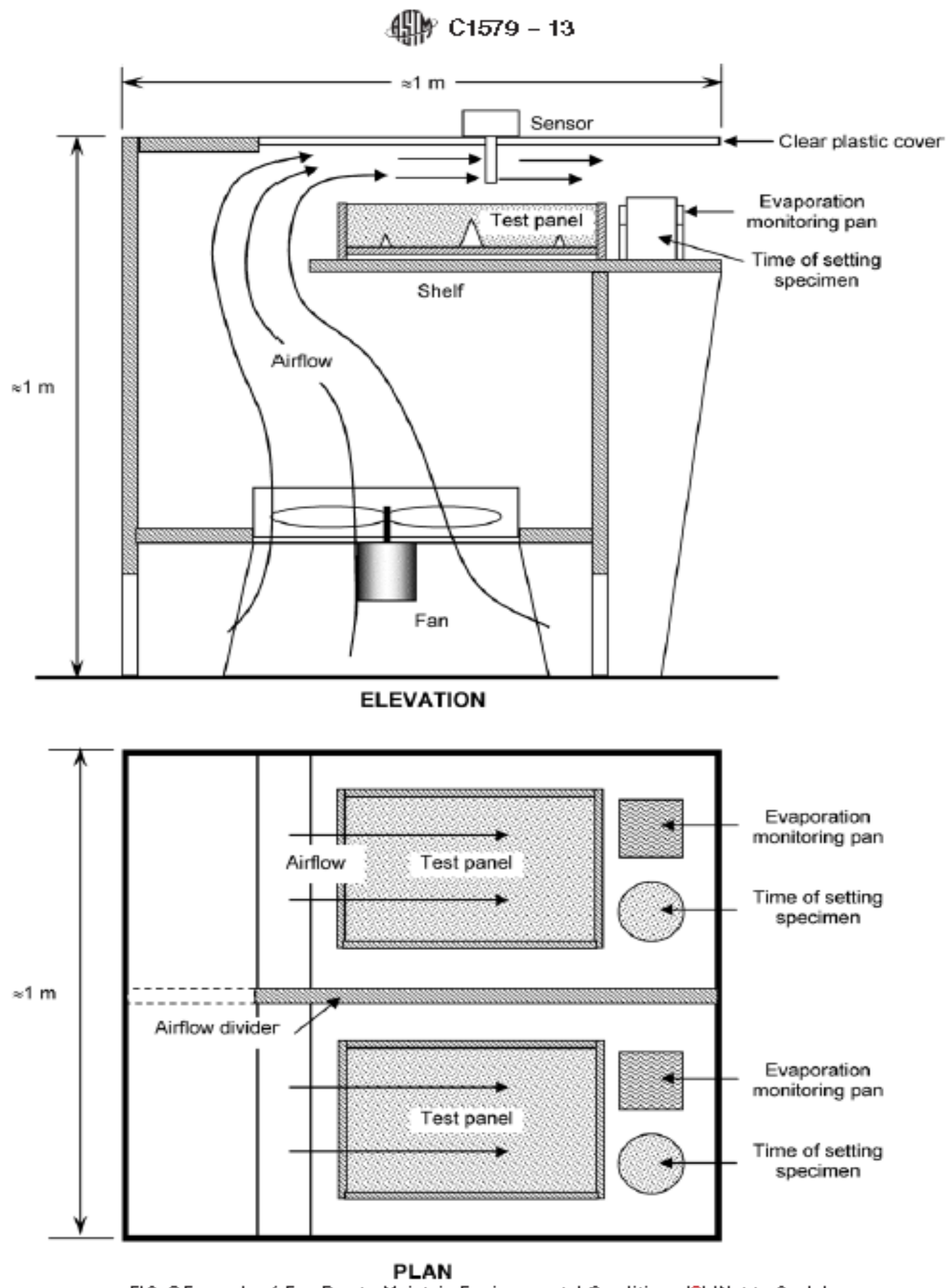

FIG. 2 Example of Fan Box to Mainta in Environmental Conditions (2) (Not to Scale) 


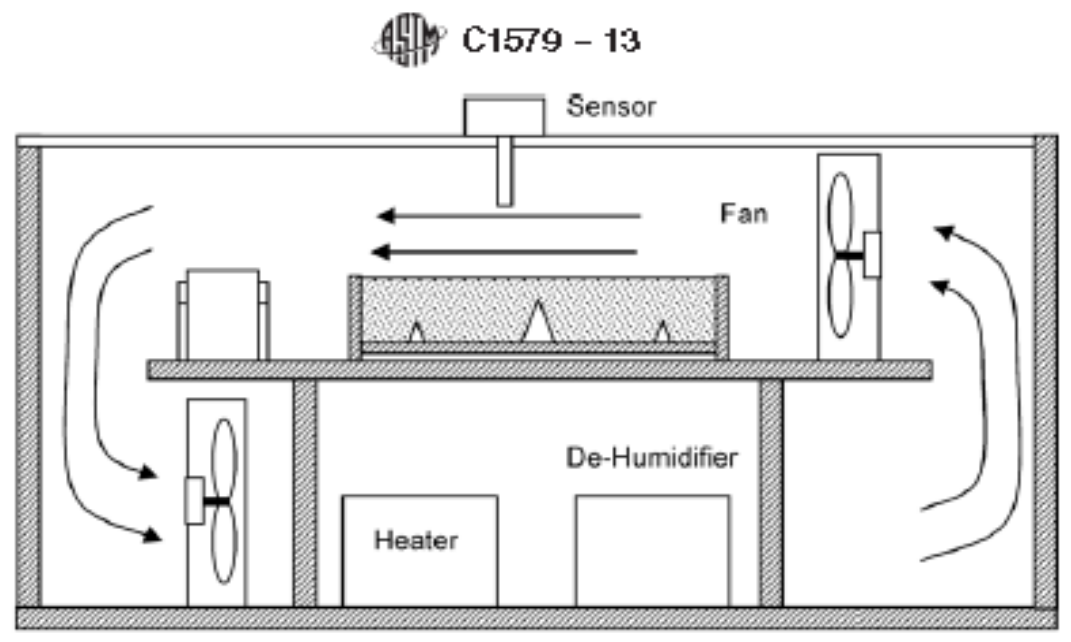

ELEVATION

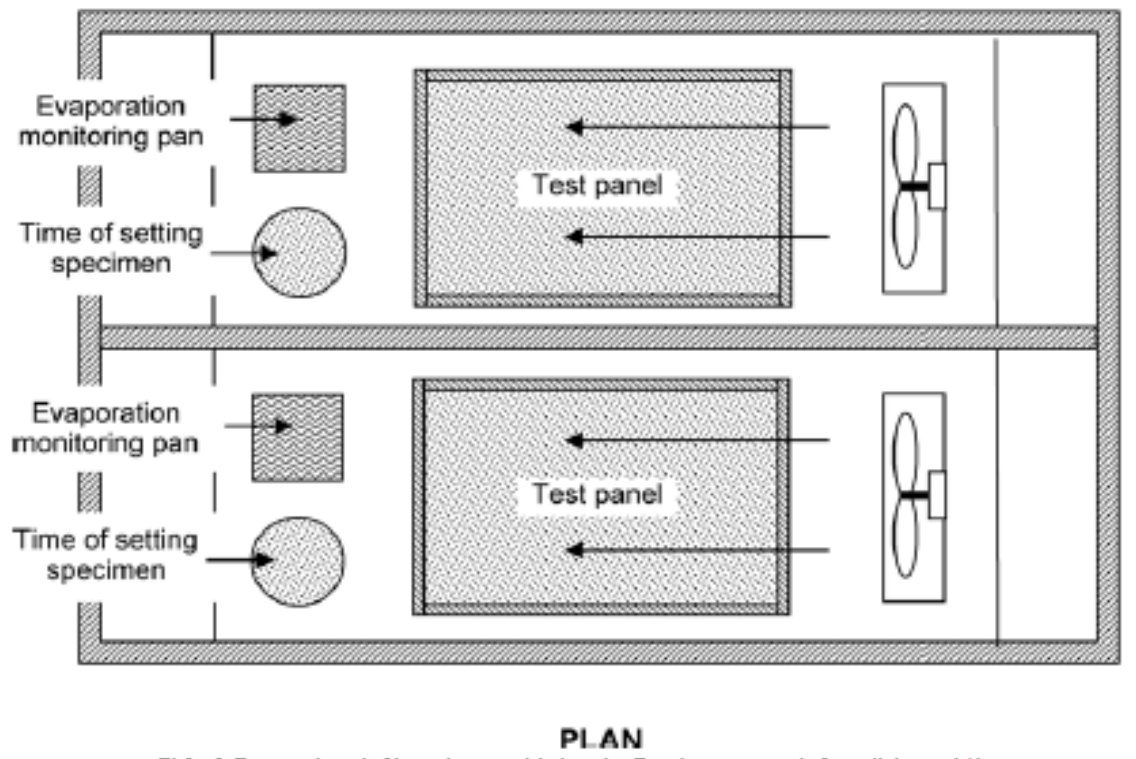

FIG. 3 Example of Chamber to Maintain Environmental Conditions (4)

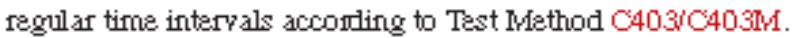
Continue recording the envimonental variables until the time of final setting.

7.8 The evaporation rate is determined by iritially weighing the full monitoring pans at the start of the test and at 30-min intervals thereafter (3). Recond the mass loss to the nearest $5 \mathrm{~g}$ at each weighing. To determine the evaporation rate during each time interval, divide the mass loss between successive weighings by the surface area of the water in the weighing pan and the time interpal between successive weighings (See Note 6). The test is rot valid if the average evaponation rate is less than $1.0 \mathrm{~kg} / \mathrm{m}^{2} \cdot \mathrm{h}$.

Now 6 -Adjustments to wind velocily should be mede if necessany to maintain the evaponation rate at the required level It is suggesed that the monitorify pans be placed on scales in the air stream for continuous monitoring without periodic removal during testing. If this is not possible, the monibring pan should be removed from the air strearn, weighed, and re turned $b$ the air stram within 15 seconds.

79 After final setting occurs (use the later of the measured time of setting in the two specimens), record the atmospheric variables, stop the fans, recond the time, and determine the total water loss from the moritoring pans. If panel moisture loss is to be determined, weigh the test panels in their molds. Store the panels in the laboratory at $23 \pm 2^{\circ} \mathrm{C}$ and under plastic sheets to minimize evaporation until time of crack width measurement. 


\section{Quantification of Cracking}

8.1 Quantify the amount of cracking by measuring crack widths at the surface of the panels $24 \pm 2 \mathrm{~h}$ after mixing.

Note 7-Studies have shown that, when ponels ane covered with plastic, there is so apprecible change in average crok widt froma time of six hours to $24 \mathrm{~h}$ after mixing (S).

8.2 To avoid possible effects of panel boundaries on crack width, do not measure crack widths within $25 \mathrm{~mm}$ of test panel boundaries.

8.3 Measure the width of each crack along the cracking path over the stres riser in a progressive order from ore side of the panel to the other. If a marual cack witth measuring procedure is used, use a crack companator or crack micmscope to measure crack widths. Measure crack width to the nearest 0.1 $\mathrm{mm}$ at $10 \pm 1 \mathrm{~mm}$ interyals along the length of the crack. Repeat the above procedure until all cracks have been measured. If an imaging analysis procedure is used for crack width measurement, recorl crack widths over the same measuring distance (See Note 8). Orerlap between adjacent images shall be cut off to aroid duplicated measurements (4). Recoml all crack widths to calculate average crack with.

Hote 8-A grid resk can be used b sample crack width at prede errivied locations (4).

8.4 Calculate the areage crack width to the nearest 0.05 $\mathrm{mm}$. If an average crack width of at least $0.5 \mathrm{~mm}$ is not observed on the control parels (average of at least two panels), with no single control panel under $0.4 \mathrm{~mm}$ average crack width, the test is not valid. Increase the evaporation rate to achieve this minimal average crack width, and repeat the test (See Note 10).

Note 9-Requiring a minimum crack width of the control panel will help to grevent rearginal modifications to the concrebe rodx ture from showing a statis lically sigrificant perfornerce improvernent, which ney sot be sufficient to control cracking under field conditions.

TABLE 1 Single-Operator Average Crack Width Repea tability

(22 Crack Width Measurements per Panel Using Manual Measurement Procedure)

Nort 1-The results in this table conrespond with the behavion of a mix ture using a single type of fiber as described in Ref 5 .

\begin{tabular}{|c|c|c|c|c|}
\hline $\begin{array}{c}\text { Mixture } \\
\text { identitication }\end{array}$ & $\begin{array}{l}\text { Fber } \\
\text { volume }\end{array}$ & $\begin{array}{l}\text { Number } \\
\text { of Pant } \\
\text { els }\end{array}$ & $\begin{array}{c}\text { Anerage } \\
\text { Crack Widt } \\
\text { ('mm) }\end{array}$ & $\begin{array}{c}\text { Standard Devalon } \\
\text { of } \\
\text { Average Crack Widh } \\
\text { (m m) }\end{array}$ \\
\hline $\mathrm{A}$ & 0 \% Fber & 6 & 0.67 & 004 \\
\hline B & $0.05 \%$ Fber & 4 & 0.44 & 005 \\
\hline $\mathrm{c}$ & $0.10 \%$ Fber & 4 & 0.33 & 005 \\
\hline D & $0.15 \%$ Fber & 4 & 008 & 0.04 \\
\hline E & $020 \%$ Fber & 2 & 0.03 & 002 \\
\hline
\end{tabular}

NowE 10 -Refer to ACI $305 \mathrm{R}$ ( 1 ) for guidance on how wind speed affects evaporation rabe.

8.5 Calculate the crack reauction ratio (CRR) using the following equation:

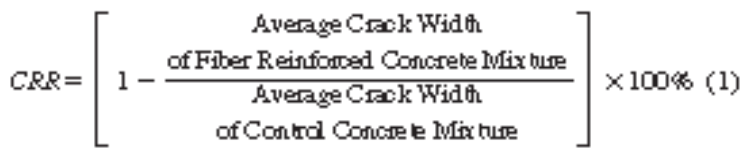

\section{Report}

9.1 Report the following for each mix ture tested:

9.1.1 The mix ture proportions in $\mathrm{kg} / \mathrm{m}^{3}$ of water, cement (or cementitious materials): aggregates; admixtures in $\mathrm{L}^{\mathrm{m}} \mathrm{m}^{3}$; water-cement ratio (wic) to the nearest 0.01 ; and slump in mm.

9.1.2 The fiber characteristics (if avalable) including fiber material, length, cross-sectional are a, fiber shape, and addition rate in $\mathrm{kg} / \mathrm{m}^{3}$.

9.1.3 Length, depth, and width of panels in mm.

9.1.4 Cracking value of each panel as the areage crack width to the nearest $0.05 \mathrm{~mm}$.

9.1.5 The temperature, relative humidity, wind velocity, and measured evaporation rate during the test.

9.1.6 If required, the moisture loss of each panel in kilograms of water per square meter of surface ( $\left.\mathrm{gog}^{2} \mathrm{~m}^{2}\right)$. Report the time interval between parel weighings.

9.1.7 The cracking reduction ratio (CRR) to the nearest percent $(\%)$.

\section{Precision and $B$ ias}

10.1 Precision-A multi-laboratory study of precision has not been completed. Information on repeatability of this test method was derived from within-laboratory testing using a single operator and replicate panels (5) (See Practices C670). Table 1 shows the number of replicate panels, average of the average crack width, and standand deviation of the average crack width for control panels and panels made with concretes having different amounts of fiber. The standard deviation appears to be constant and is used as the measure of repeatability. When three panels were used to determine the Crack Reauction Ratio (CRR), the value of the single operator standard deviation was $4.6 \%$.

10.2 Bias-The procedure for measuring the cracking value has no bias because the cracking value is defined only in terms of this test method.

\section{Keywords}

11.1 crack width; evaporation; fiber-reinforced concrete; plastic shrinkage cracking, restrained shrinkage cracking 


\section{A然 $\mathrm{C} 1579-13$ \\ REFERENCES}

(1) "Hot Weather Concre ling" ACI 305.R-99, ACI Mwnsud of Concrete Practice American Concrete Isstibute Famisiston Hills MII 2004.

(2) Berke, N. S., and Delliane, M. P, "The Effect of Low dddition Rate of Poly propylese Fibers on Plastic Slarinkage Croching and Mechandcal Properties of Concre e," Fiber Reinfoned Concrete: Development and hnovations, ACI SP-142, American Concrete Institute, Famaingtor Hills, MIL 1994, pp.19-41.

(3) Nandi, A., Ludwig D. A, and Mogillis, M. T, "Plastic Shrinkage Crocling of Restrined Fiber-Reinfonced Concrete." Transportation ReseWdi Reoow 1382,1993 , pp. $69-72$.
(4) Qi, C, Weis, J., and Olek, J, "Charcenization of Phatic Shrirkage Croling in Fiber-Reinfonced Concrete Using Sern-Aubmated Image

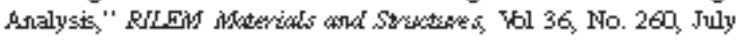
2003 , pp. 386 -395.

(5) Qi, $C_{3}$ Mriss, $J_{3}$ and Olek, $J$ "Statistical Sinfificance of the Restrined Slab with a Stress Rier for Quantifying Plastic Cracking in Fiber Reinforoed Concrete," ASTM Josknal of Testing and Exalsuation, July 2005

\section{SUMIMARY OF CHANGES}

Committee $\mathrm{COP}$ has identified the location of selected changes to this specification since the last issue, C1579-06 (2012), that may impact the use of this specification. (Approved April 1, 2013)

(1) Removed reference to ASTM C995 from Sections $2.1,7.1$, and 9.1.1.

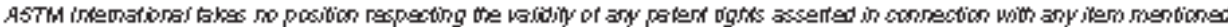

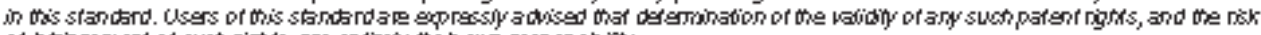

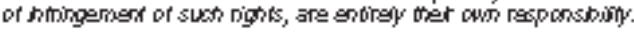

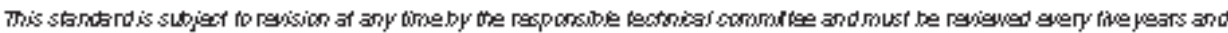

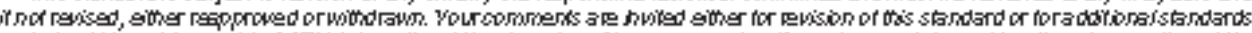

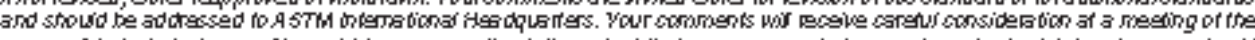

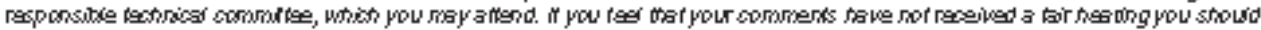

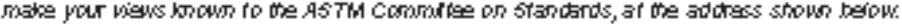

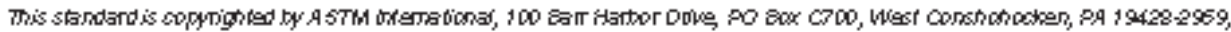

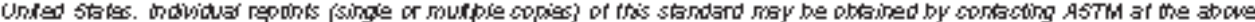

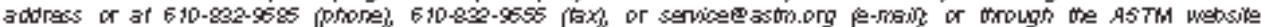

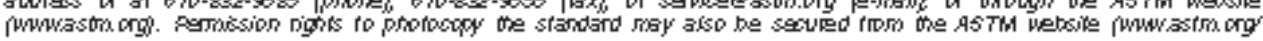
COPYRIGHT) 


\section{Appendix B}

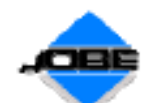

Jobe Materials, L.P.

1150 Southuiem, Dr. EI Paso, Texas 79928

Office: (915)298-9900, F ax: (915)298-9990

\begin{tabular}{|c|c|c|c|c|c|c|c|}
\hline \multicolumn{8}{|c|}{ - } \\
\hline \multicolumn{8}{|c|}{-OPTIMIZEDAGgREGATEGRADATION. } \\
\hline $\begin{array}{l}\text { Plient: } \\
\text { Projed: }\end{array}$ & \multicolumn{5}{|c|}{$\begin{array}{l}\text { Mustafa Aldalinsi, PhD Candidate } \\
\text { A Method to Reduce Plastic Shrinkage Cracking Using Re-Vibration Technic }\end{array}$} & \multicolumn{2}{|c|}{$\begin{array}{l}\text { Submittal Date: } 05 / 20 / 13 \\
\text { Report Date: } 05 / 20 / 13\end{array}$} \\
\hline Address: & \multicolumn{5}{|c|}{ UTEP } & \multicolumn{2}{|c|}{ Spesified $\left(f^{\prime} \circ\right): 3,000$} \\
\hline Use: & \multicolumn{5}{|c|}{ Research Project } & \multicolumn{2}{|c|}{ Required ( $f \circ r$ ): 4,200 } \\
\hline Mix ID: & \multicolumn{4}{|c|}{4402} & \multicolumn{3}{|c|}{ Coarseness Factor: 60} \\
\hline Description: & \multicolumn{4}{|c|}{$3,000 \mathrm{PSI} 34$ " 5 SK } & \multicolumn{3}{|c|}{ Workability Factor: 37} \\
\hline \multicolumn{8}{|c|}{ Nominal Maxi mum Size Sieves wth Square Openings [ $3 / 4$ in.]: Size Number 67 [ $7 / 4$ in. to No. 4] } \\
\hline Sieve Size & $\begin{array}{c}\text { Coarse } \\
\text { Aggregate } \\
\text { \& Passing }\end{array}$ & $\begin{array}{c}\text { Coarse } \\
\text { Aggregate } \\
\text { \& Passing }\end{array}$ & \multicolumn{2}{|c|}{$\begin{array}{c}\text { Coarse } \\
\text { Aggregate } \\
\text { \& Passing }\end{array}$} & $\begin{array}{l}\text { Fine Aggregate \#1 } \\
\text { \% Passing }\end{array}$ & Combined & Indiuidual \\
\hline 2 in. & & 100 & & & 100 & 100.0 & \\
\hline $11 / 2$ in. & & 100 & & & 100 & 100.0 & \\
\hline 1in. & & 100 & & & 100 & 100.0 & \\
\hline $3 / 4$ in. & & 96 & & & 100 & 97.8 & 2 \\
\hline $1 / 2$ in. & & 71 & & & 99 & 83.9 & 14 \\
\hline $3 / \%$ in. & & $\$$ & & & 97 & 63.5 & 20 \\
\hline No.4 & & 6 & & & 92 & 45.6 & 18 \\
\hline No.8 & & 1 & & & 84 & 39.2 & 6 \\
\hline No.16 & & & & & 67 & 30.8 & 8 \\
\hline No.30 & & & & & 49 & 22.5 & 8 \\
\hline No.50 & & & & & 24 & 11.0 & 12 \\
\hline No.100 & & & & & 2 & 0.9 & 10 \\
\hline No.200 & & & & & & & 1 \\
\hline Percent: & & 54.0 & & & 460 & & \\
\hline Wieight: & & 1783 & & & 1519 & & \\
\hline Sp. Gr. & & 2.701 & & & 2.602 & & \\
\hline C ummulative: & 2.60 & Material & Wheight & Vol. & Coarseness Factor: & 60 & 45.75 \\
\hline Slump: & & Cement: & 470 & 2.4 & codseness ractor. & 00 & 40.70 \\
\hline $\begin{array}{l}\text { Wh: } \\
\text { U nit Wu eight: }\end{array}$ & $\begin{array}{c}0.55 \\
149.3\end{array}$ & Fly Ash: & & & Workability Factor: & 37 & $28-44.5$ \\
\hline $\begin{array}{l}\text { Aggregate Wi eight: } \\
\text { Coarse Aggregate: }\end{array}$ & $\begin{array}{l}3302 \\
1783\end{array}$ & $\begin{array}{l}\text { Mixing Wiater: } \\
\text { Air, \&: }\end{array}$ & $\begin{array}{c}259 \\
1.5\end{array}$ & $\begin{array}{l}4.1 \\
0.5\end{array}$ & $\begin{array}{r}\text { Nomin al Maximum Coars } \\
3 / 4 \mathrm{i}\end{array}$ & $\begin{array}{l}\text { irse Aggregate } \\
\text { in. }\end{array}$ & Size [in]: \\
\hline Inter me diate: & & Paste: & & 7.1 & Theor etic al U nit W' eight ( & $(\mathrm{PCF})$ & 149.3 \\
\hline F ine Aggregate: & 1519 & Aggregate: & & 199 & Design Absolute Volume. &, $\mathrm{tt}^{3}$ & 270 \\
\hline & & $\begin{array}{l}\text { Agg. Correctio } \\
\text { AGG1:Total C } \\
\text { AGG2:Total C } \\
\text { AGG3:Total C }\end{array}$ & $\begin{array}{l}\text { Ar: } \\
\text { Aggregate: } \\
\text { Aggregate: } \\
\text { Aggregate: }\end{array}$ & $\begin{array}{l}0.40 \\
1.00\end{array}$ & $\begin{array}{r}\text { Mor } \\
\mathrm{P} \\
\text { Sand/Aggreg } \\
\text { Rock/Aggreg }\end{array}$ & $\begin{array}{l}\text { rtar Factor: } \\
\text { aste Ratio: } \\
\text { gate Ratio: } \\
\text { gate Ratio: }\end{array}$ & $\begin{array}{l}52.6 \% \\
24.2 \% \\
45.0 \% \\
54.0 \% \\
\end{array}$ \\
\hline
\end{tabular}

\section{Remarks:}

The aggregate proportions may be adjusted during concrete production.

if necessany, to keep the coarseness factor and workability factor plotted within

the workability box on the Coarseness Factor Chart. 
Jobe Materials, L.P.

1150 Southuien, Dr. EI Paso, Texas 79928

Otfice: (915)298-g900, Fax: (915)298-g9g0

- OPTIMIZEDAGgREgATE GRADATION.

Client: Mustafa Aldalirsi, PhD Candidate

Project: A Method to Reduce Plastic Shrinkage Cracking Using Re-Vibration Technic

Address: UTEP

Use: Research Project

Mix ID: $\quad 4402$

Description: $\quad 3,000$ PSI $3 / 4 " 5 \mathrm{SK}$
Submittal Dat: $05 / 20 / 13$

Report Date: $05 / 20 / 3$

Specified (f'c): 3,000

Required (f'cr): 4,200

Coarseness Factor: 60

Workability Factor: 37
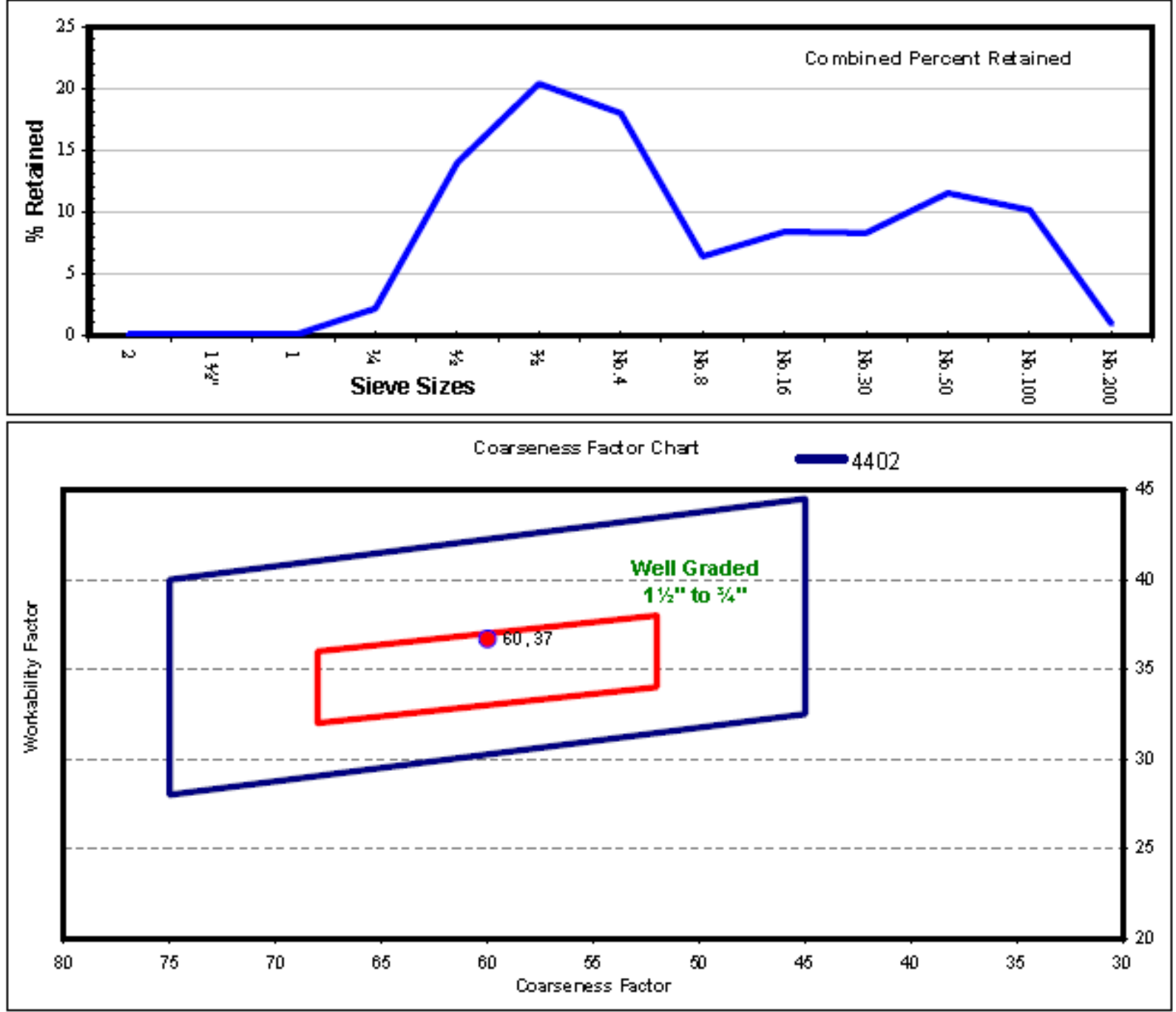
Jobe Materials, L.P.

1150 Southwiew, Dr. EI Paso, Texas 79928

Otfice: (915)298-9900, F ax: (915)298-9990

\section{-OPTIMIZED AGgREGATE GRADATION.}

Client: Mustafa Aldalirsi, PhD Candidate

Projed:

Address:

A Method to R educe Plastic Shrinkage Cracking Using Re-Vibration Technic UTEP

Use:

Research Project

Mix ID:

4402

Description: $\quad 3,000 \mathrm{PSI}^{3 / 4}$ " $5 \mathrm{SK}$

Submittal Date: $05 / 20 / 3$

Report Date: 05/20/13

Specified (f'c): 3,000

Required (f'or): 4,200

Coarseness Factor: 60

Workability Factor: 37

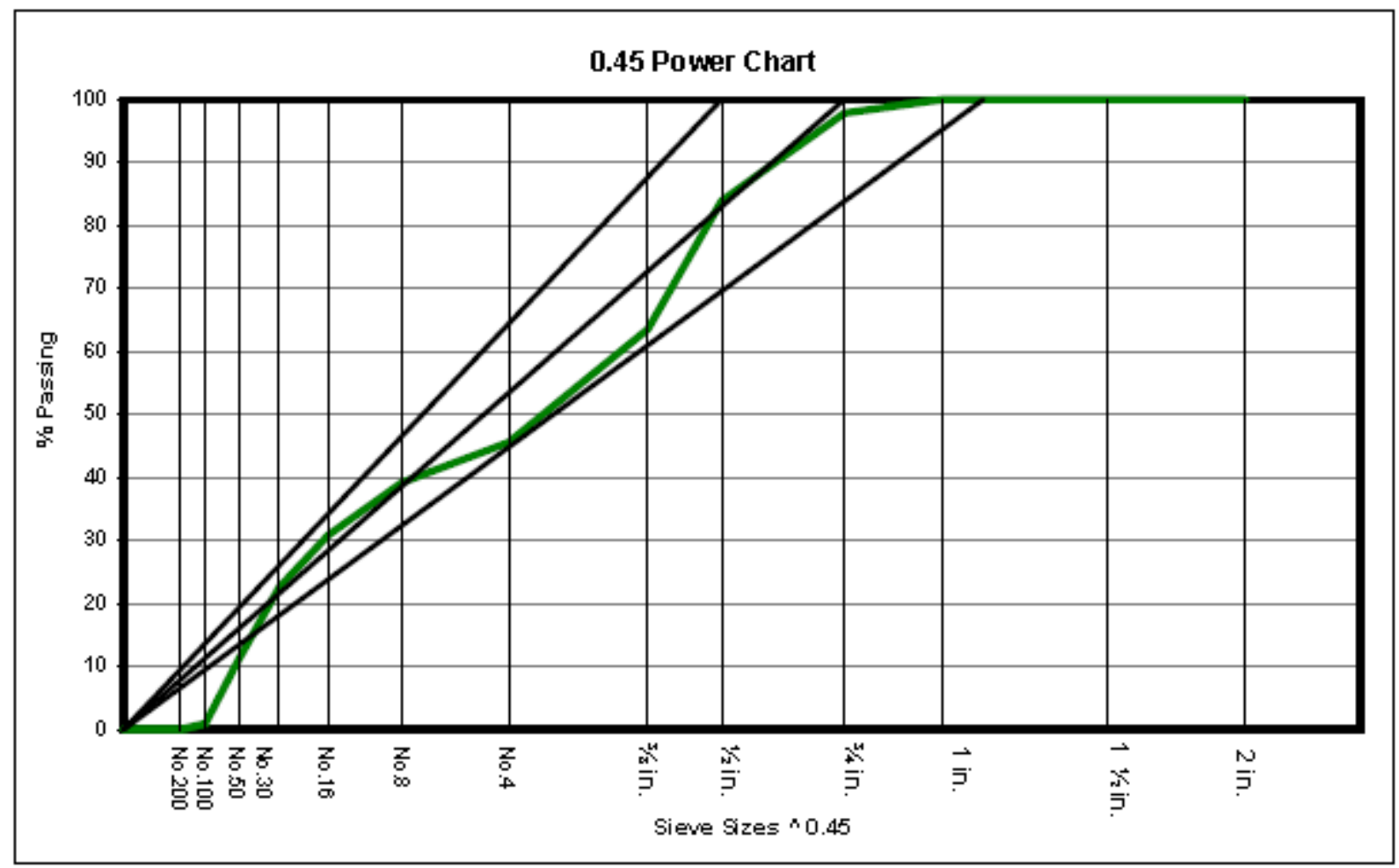

Remarks:

The aggregate proportions may be adjusted during concrete production,

if necesary, to keep the coarseness factor and workability factor plotted within

the workability box on the Coarseness Factor Chart. 


\section{Appendix C}

\section{Matlab Code Used in the Image Analysis}

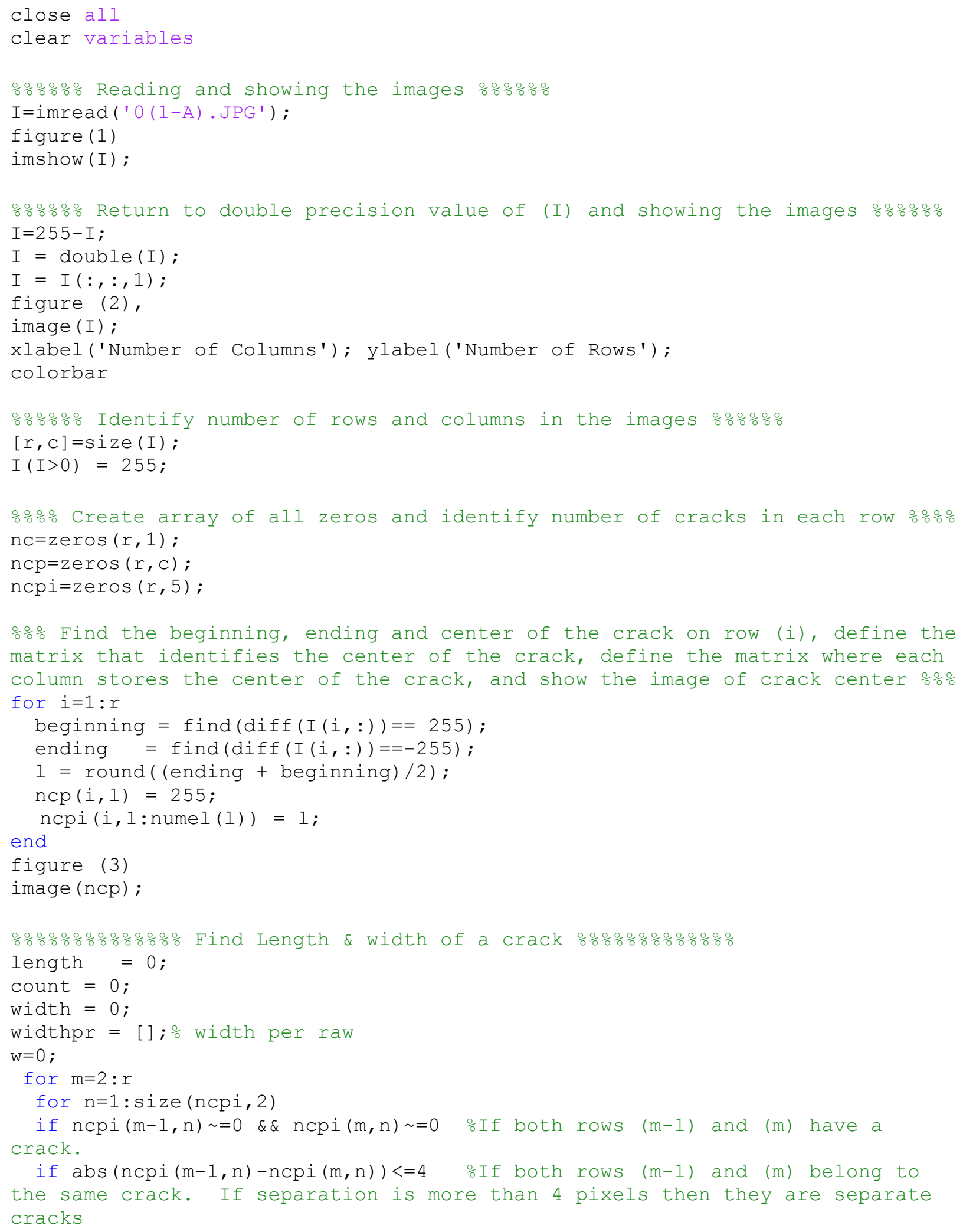




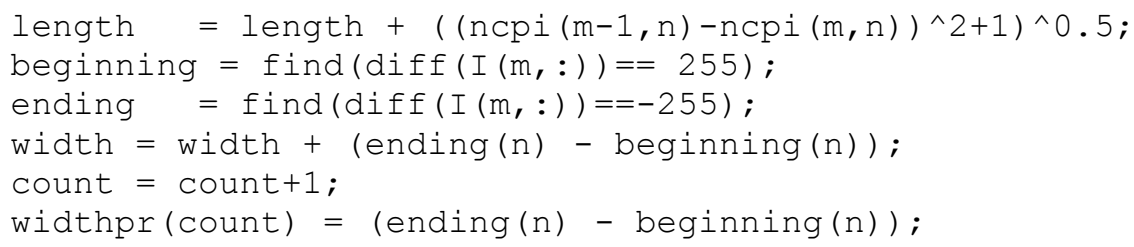




\section{Appendix D}

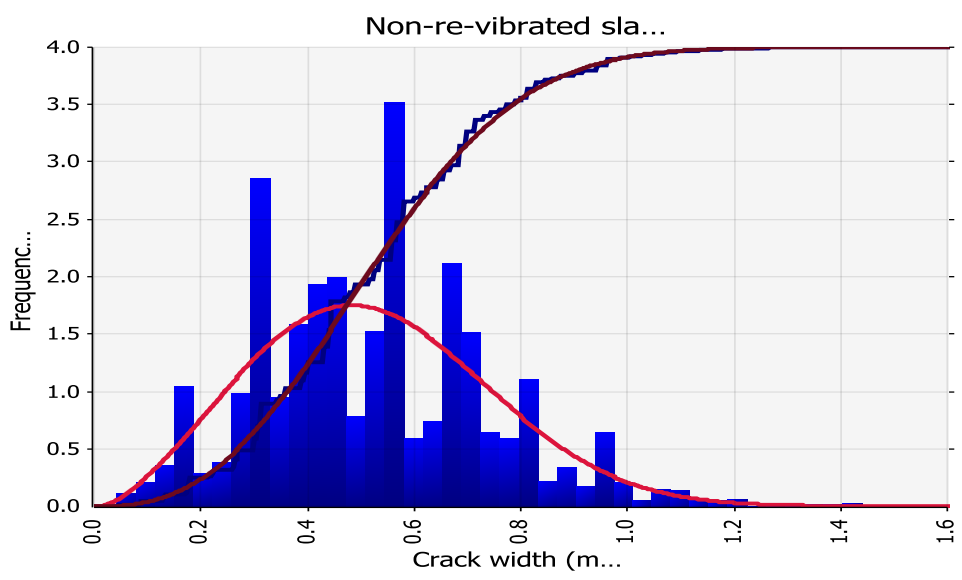

$100.0 \%$

$87.5 \%$

$75.0 \% \square$ Input

Minimum 0.0428

Maximum 1.0407

$62.5 \%$ Mean 0.5240

Std Dev $\quad 0.2182$

$50.0 \%$

$37.5 \%$ Minimum 0.0108

Maximum $+\infty$

Mean 0.5238

$25.0 \%$ Std Dev 0.2190

$12.5 \%$

$0.0 \%$

Non-re-vibrated sla...

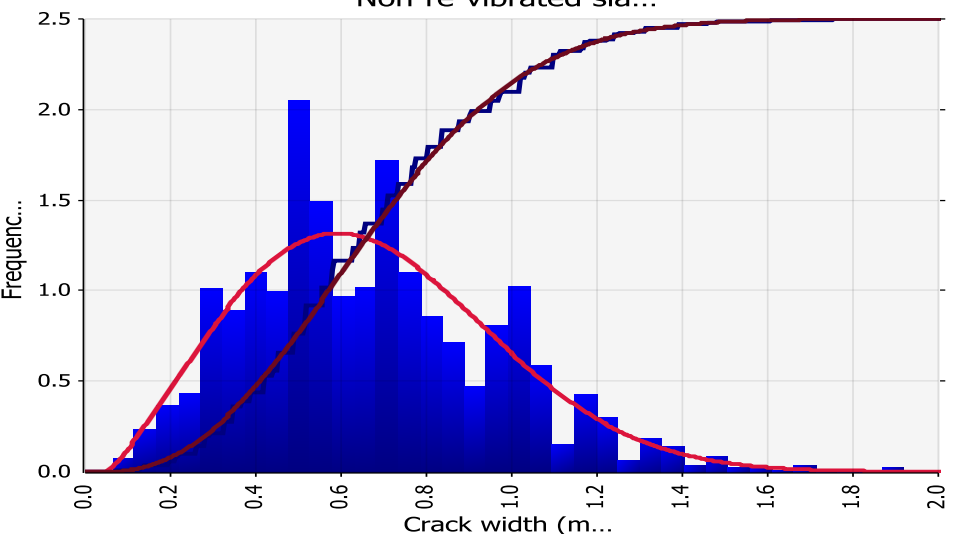

$100.0 \%$

$80.0 \%$

Input

Minimum 0.0644

Maximum 1.9709

$60.0 \%$

Mean 0.6730

Values $\quad 5918$

40.0\% $\frac{\text { Theibull }}{\text { Minimum } 0.0468}$

Maximum $+\infty$

Mean 0.6732

$20.0 \%$

$0.0 \%$
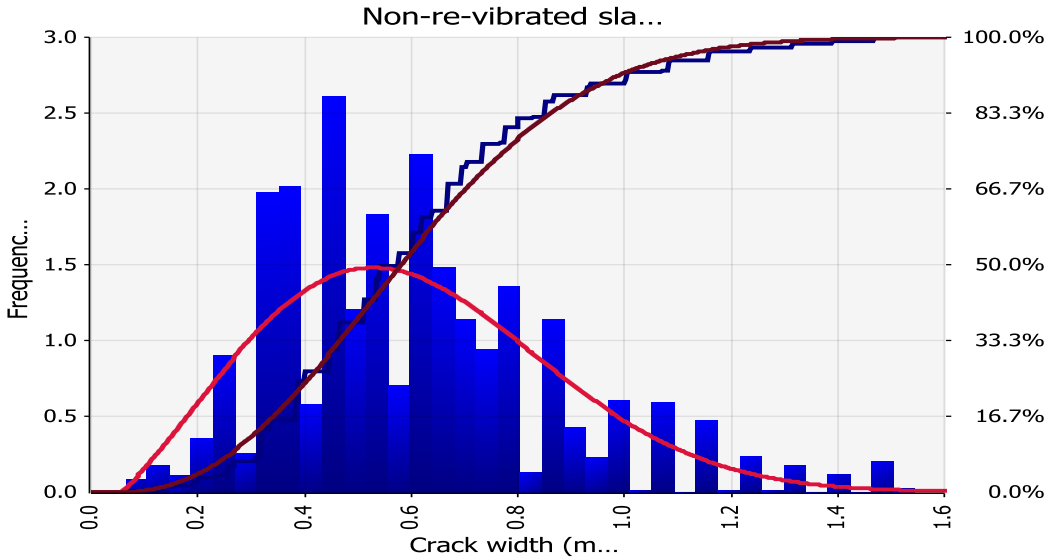

Figure D1-a: Histograms, cumulative distribution curves and corresponding Weibull distribution fitting of cracks widths for non-re-vibrated slabs made with w/c of 0.6 

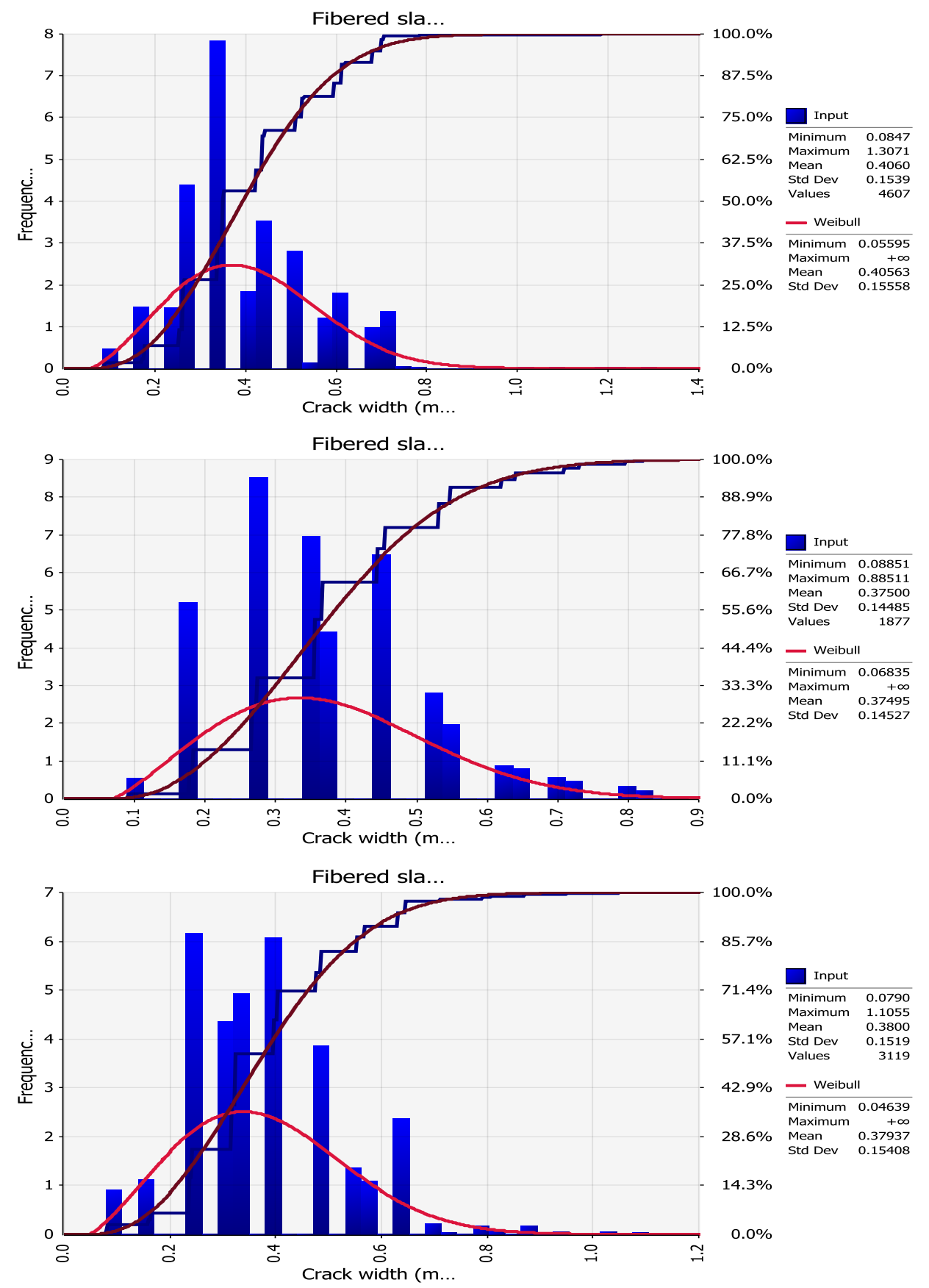

Figure D1-b: Histograms, cumulative distribution curves and corresponding Weibull distribution fitting of cracks widths for fibered slabs made with w/c of 0.6 

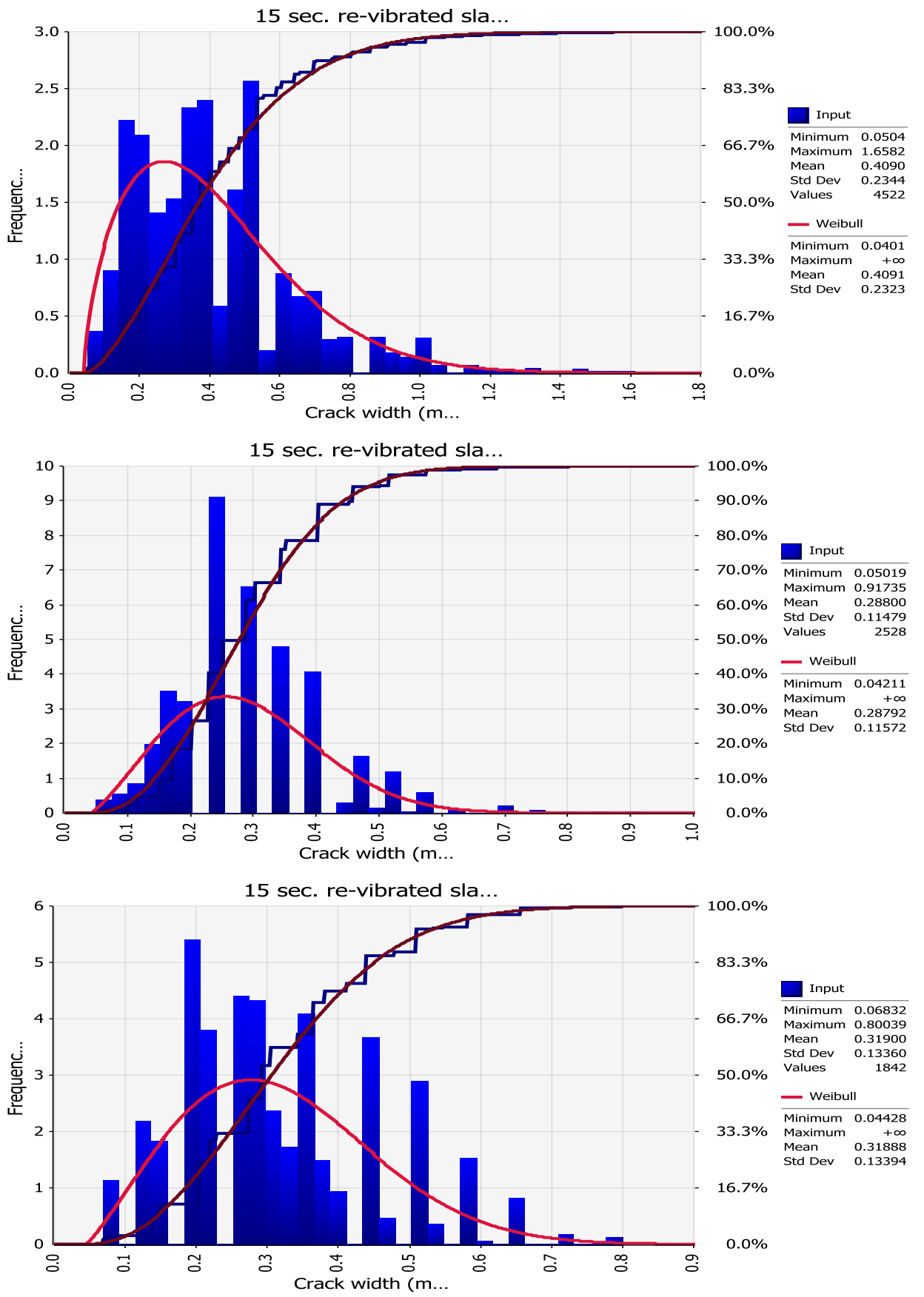

Figure D1-c: Histograms, cumulative distribution curves and corresponding Weibull distribution fitting of cracks widths for $15 \mathrm{sec}$. re-vibrated slabs made with w/c of 0.6 

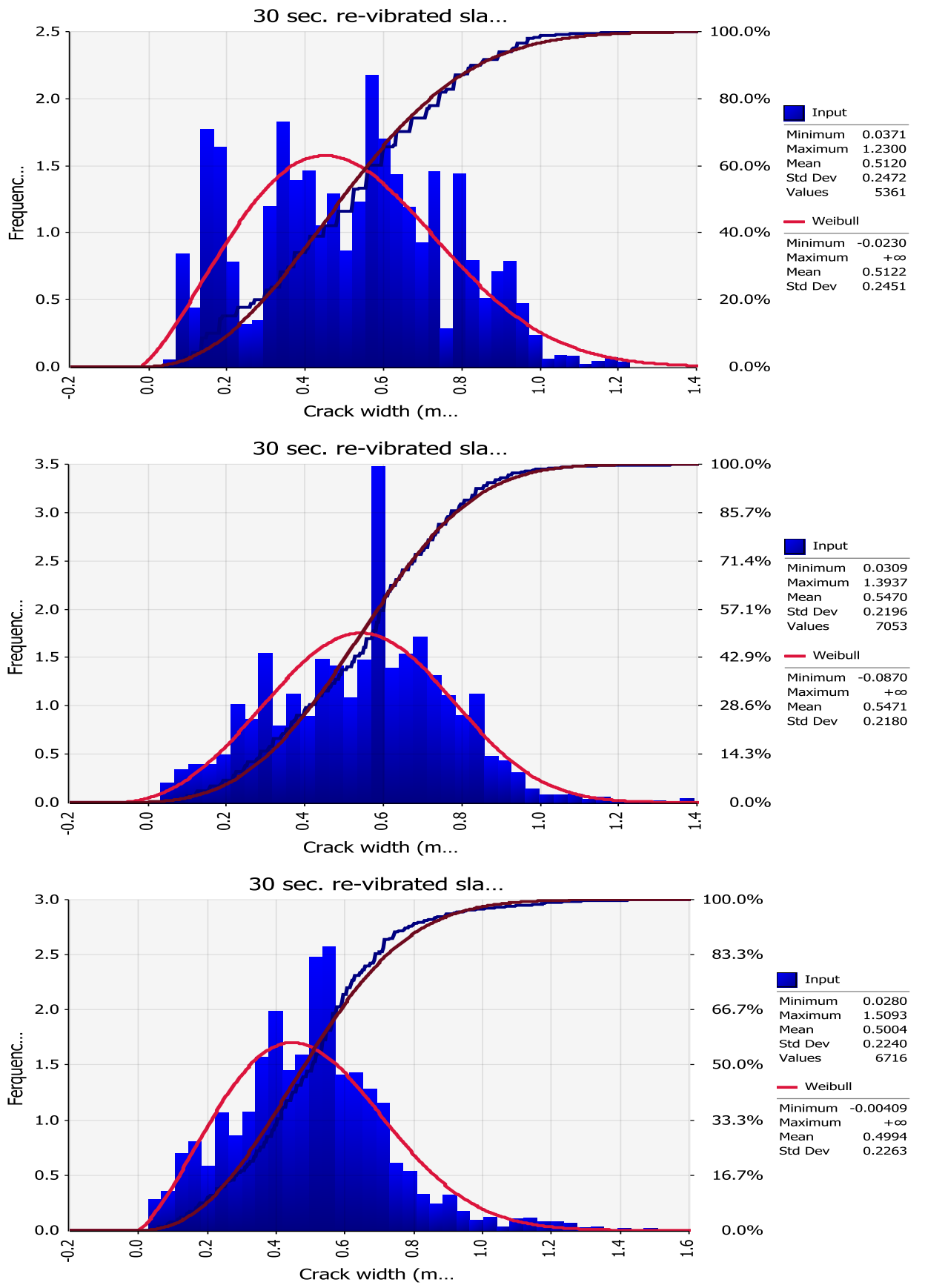

Figure D1-d: Histograms, cumulative distribution curves and corresponding Weibull distribution fitting of cracks widths for $30 \mathrm{sec}$. re-vibrated slabs made with w/c of 0.6 

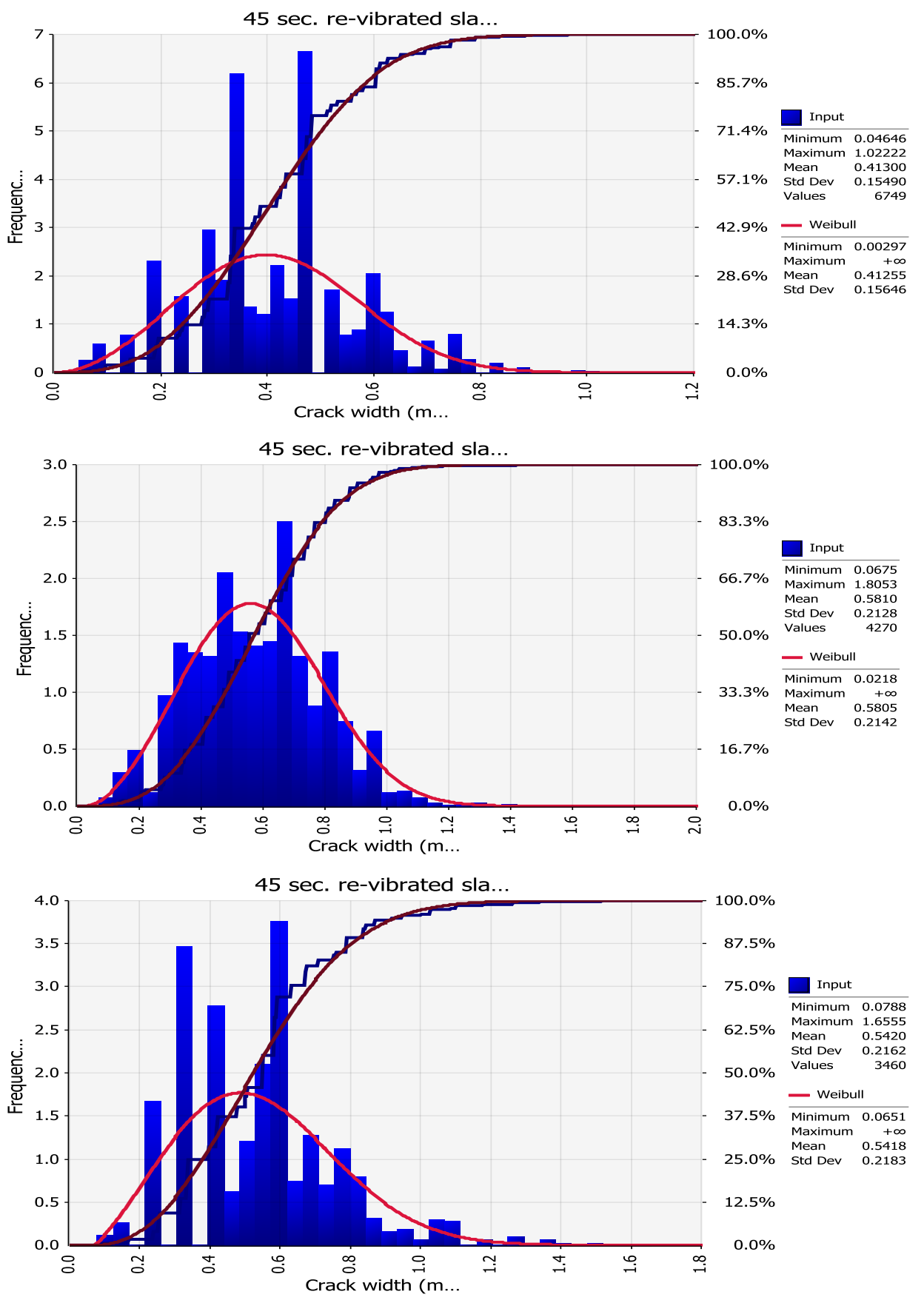

Figure D1-e: Histograms, cumulative distribution curves and corresponding Weibull distribution fitting of cracks widths for $45 \mathrm{sec}$. re-vibrated slabs made with w/c of 0.6 

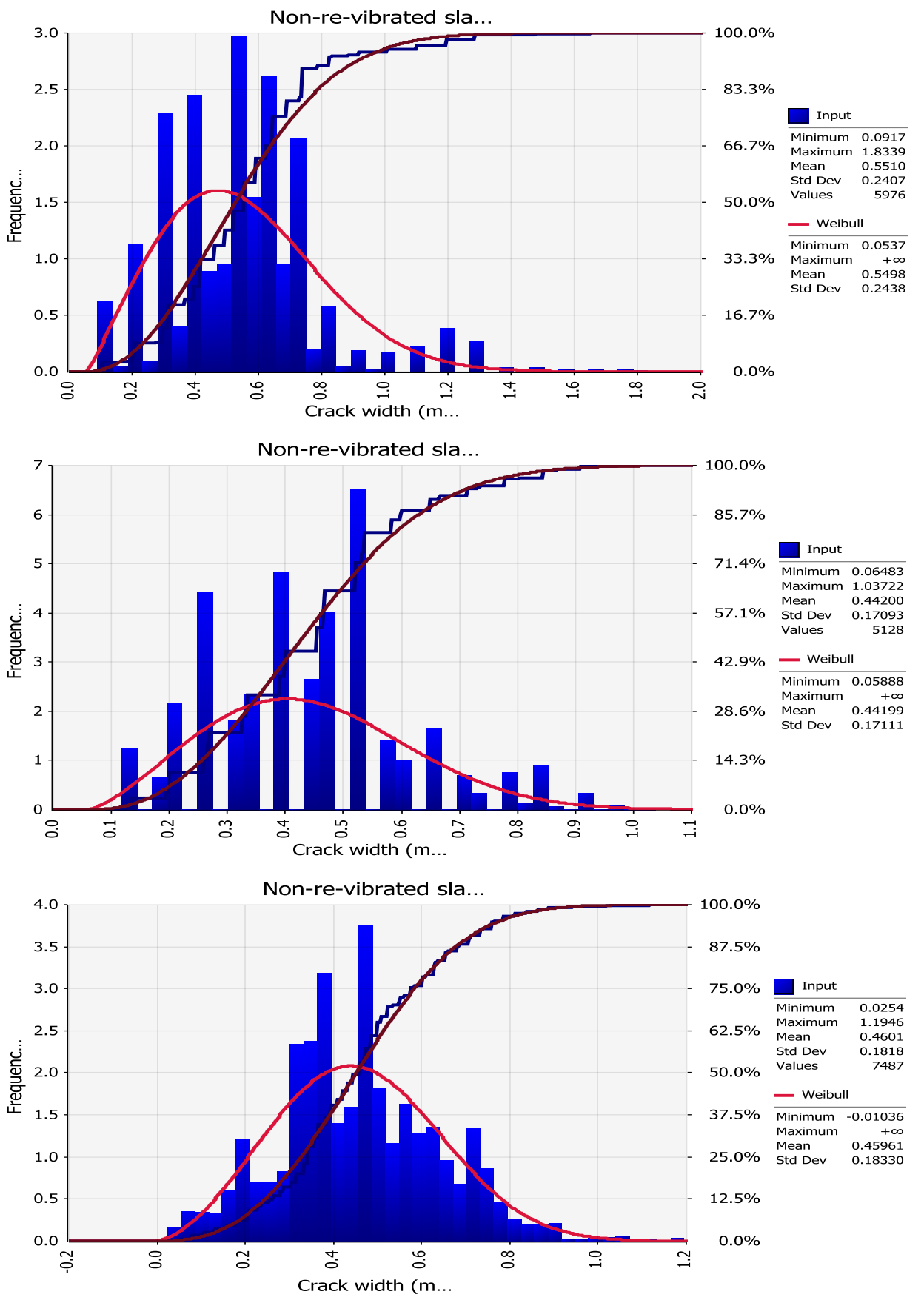

Figure D2-a: Histograms, cumulative distribution curves and corresponding Weibull distribution fitting of cracks widths for non-re-vibrated slabs made with w/c of 0.55 

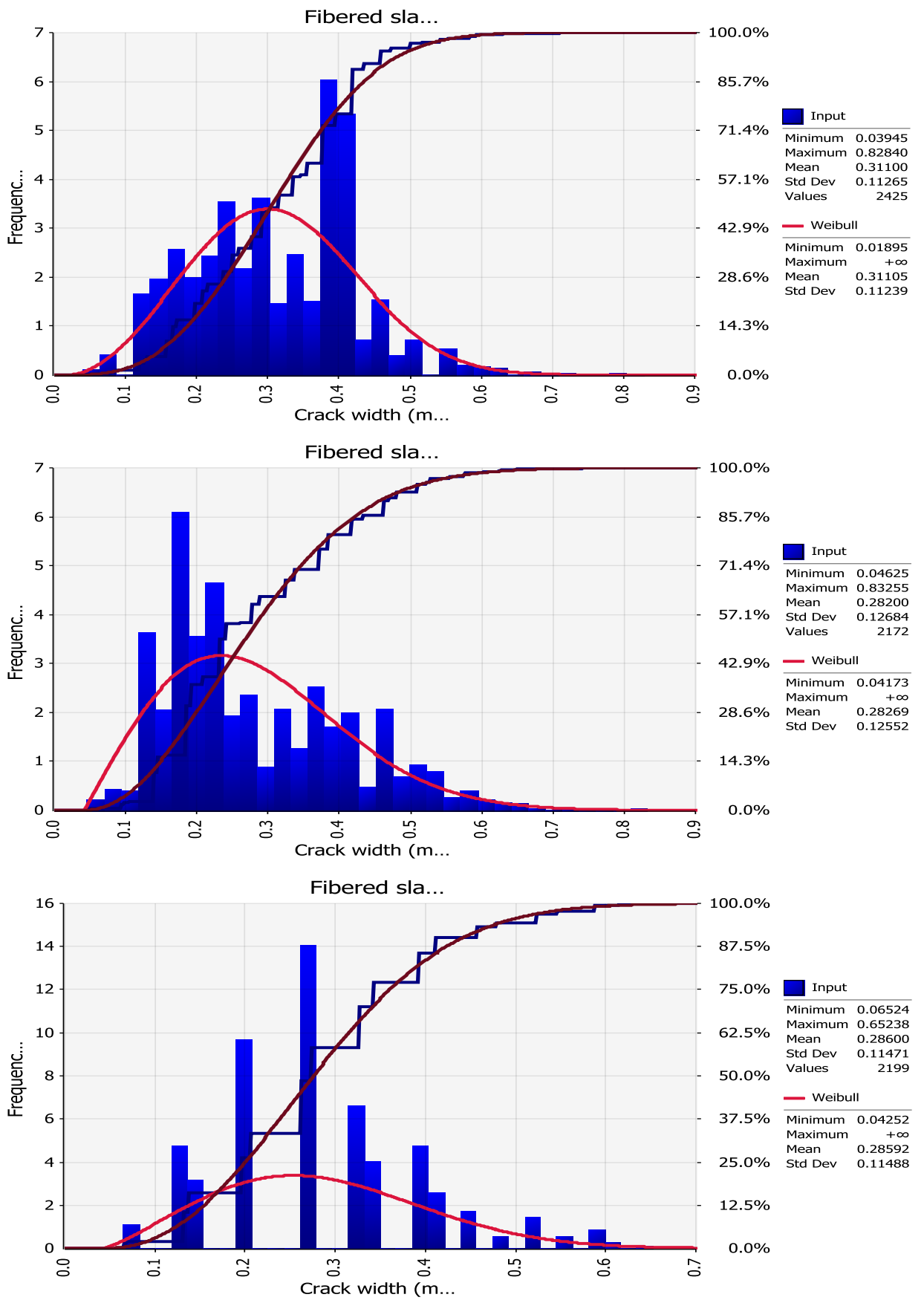

Figure D2-b: Histograms, cumulative distribution curves and corresponding Weibull distribution fitting of cracks widths for fibered slabs made with w/c of 0.55 

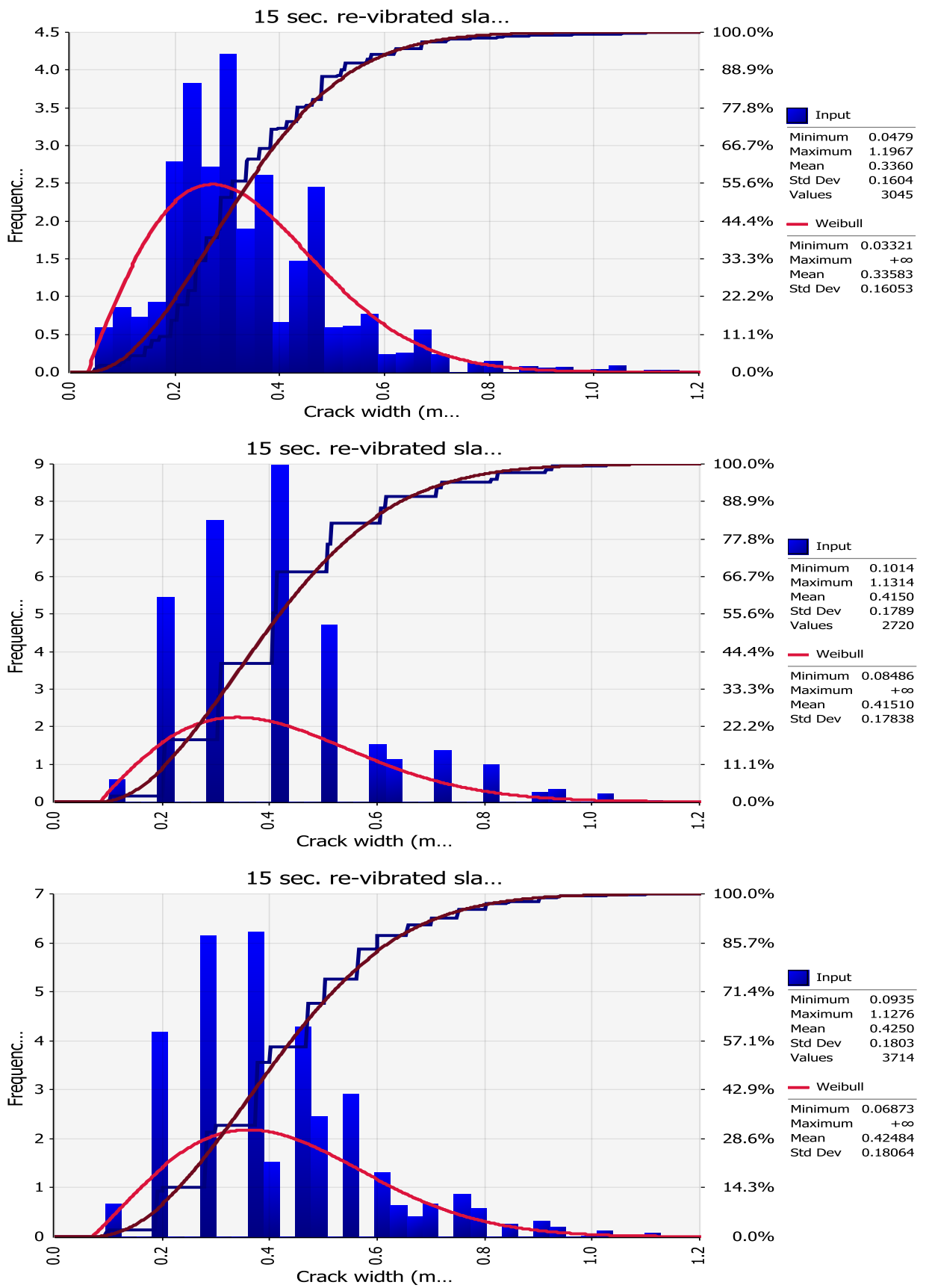

Figure D2-c: Histograms, cumulative distribution curves and corresponding Weibull distribution fitting of cracks widths for $15 \mathrm{sec}$. re-vibrated slabs made with w/c of 0.55 

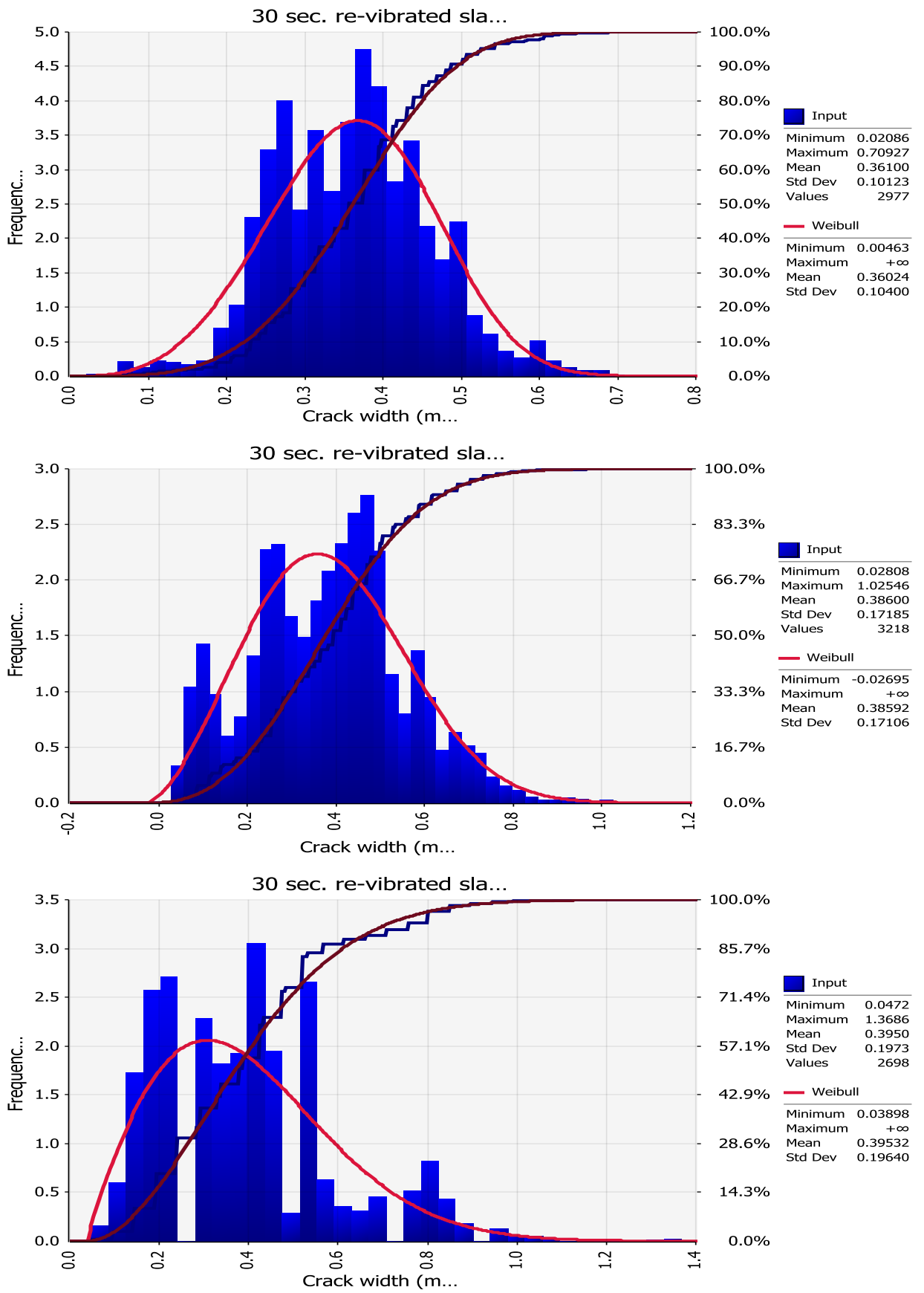

Figure D2-d: Histograms, cumulative distribution curves and corresponding Weibull distribution fitting of cracks widths for $30 \mathrm{sec}$. re-vibrated slabs made with w/c of 0.55 

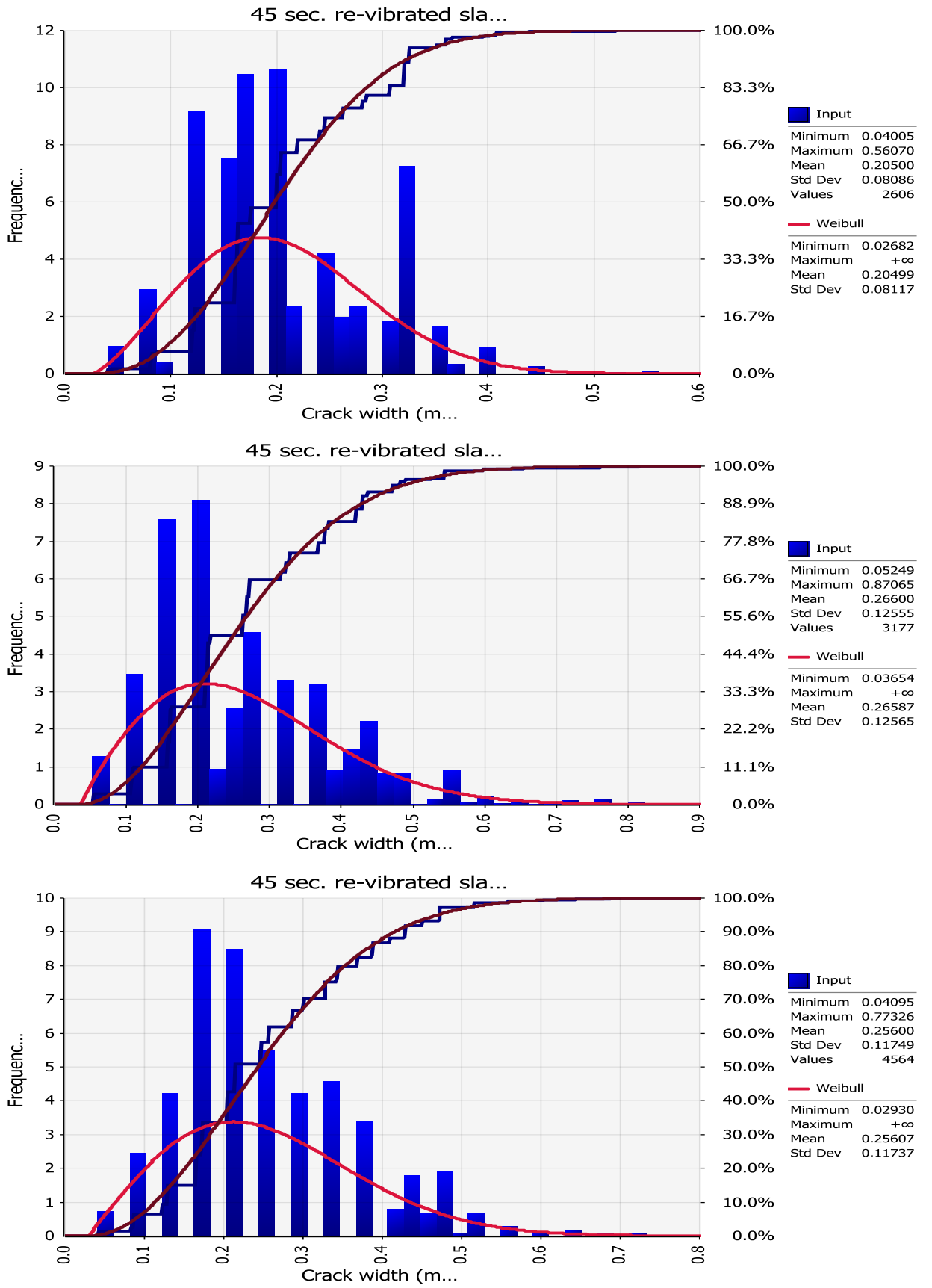

Figure D2-e: Histograms, cumulative distribution curves and corresponding Weibull distribution fitting of cracks widths for $45 \mathrm{sec}$. re-vibrated slabs made with w/c of 0.55 

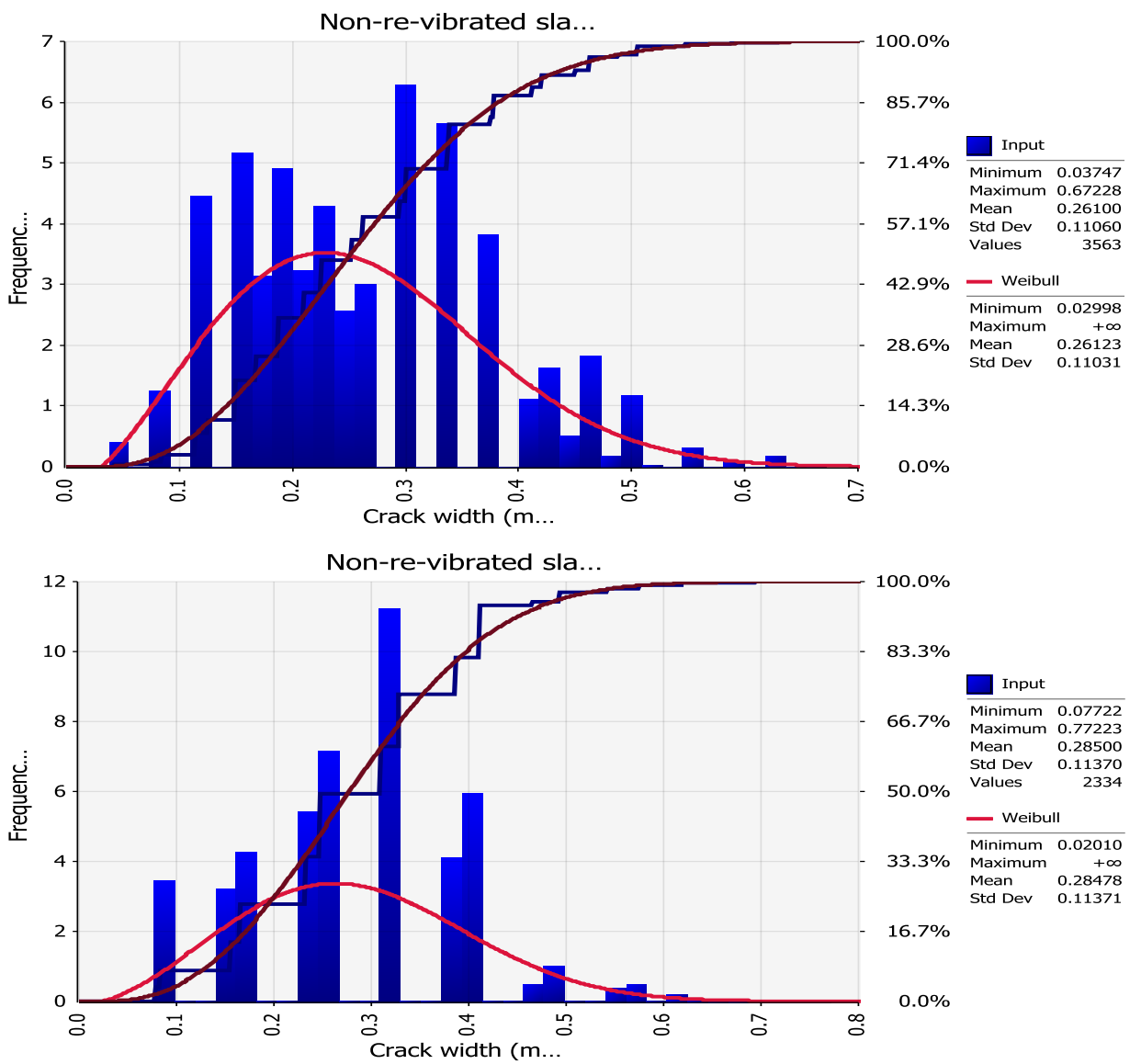

$100.0 \%$

$83.3 \%$

$66.7 \%$ Minimum 0.07722

Maximum 0.77223

Mean 0.28500

$\begin{array}{ll}50.0 \% & \text { Values } \\ & 2334\end{array}$

- Weibull

Minimum 0.02010

$33.3 \%$ Maximum $+\infty$

$\begin{array}{ll}\text { Mean } & 0.28478\end{array}$

$16.7 \%$

$0.0 \%$

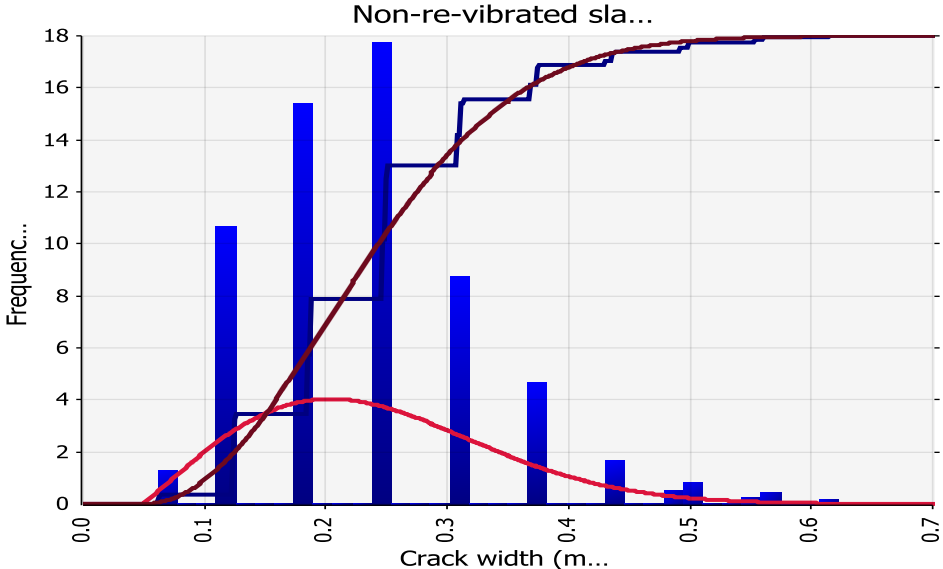

$100.0 \%$

$88.9 \%$

$77.8 \%$

$66.7 \%$ Minimum 0.06149

Maximum 0.62276

Mean $\quad 0.24010$

$\begin{array}{llr}55.6 \% & \text { Std Dev } & 0.09785 \\ & \text { Values } & 3266\end{array}$

$44.4 \%$ - Weibull

33.3\% Minimum 0.04953

Maximum $\quad+\infty$

Mean 0.24003

$22.2 \%$ Std Dev 0.09804

$11.1 \%$

$0.0 \%$

Figure D3-a: Histograms, cumulative distribution curves and corresponding Weibull distribution fitting of cracks widths for non-re-vibrated slabs made with w/c of 0.5 

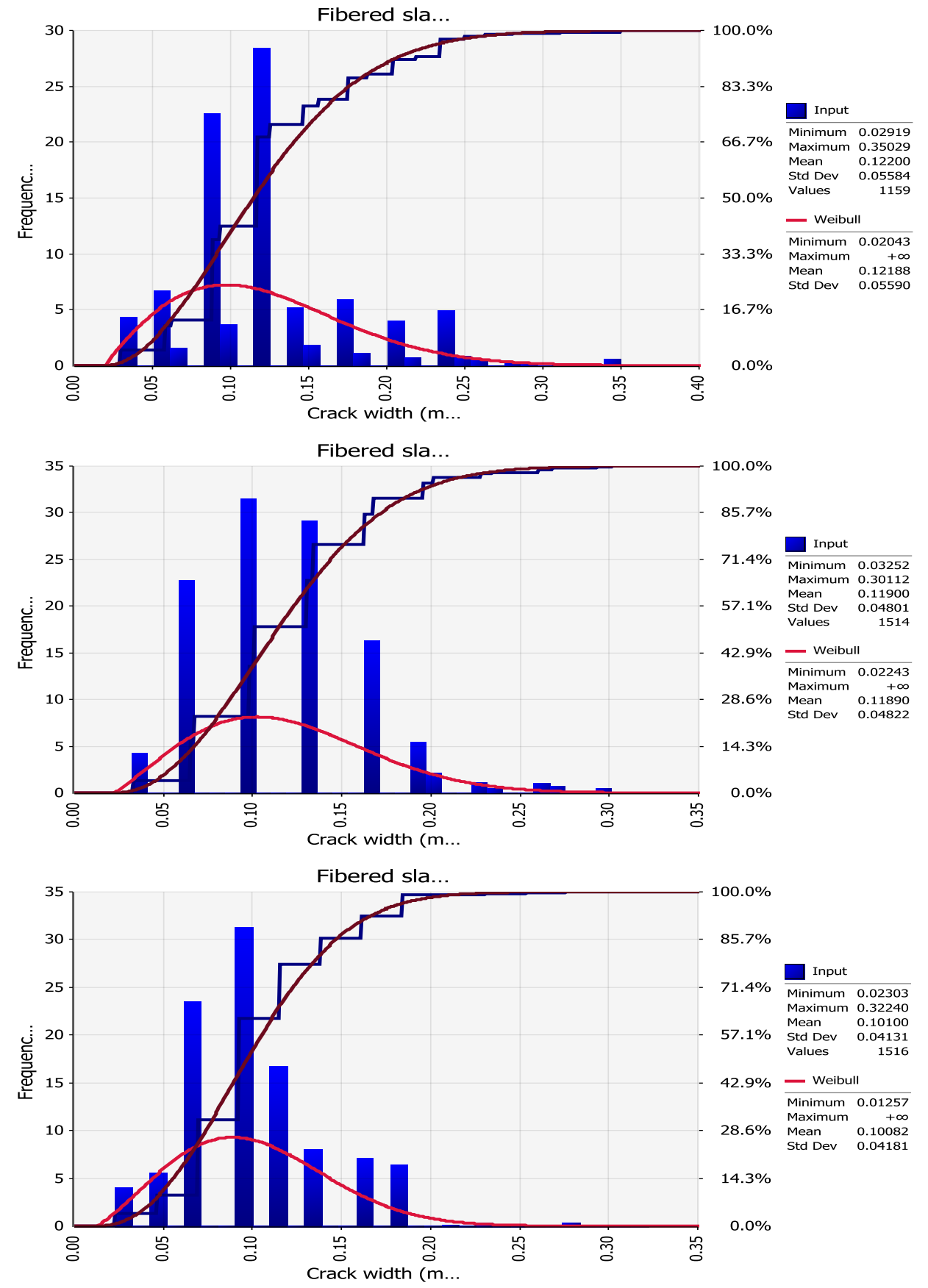

Figure D3-b: Histograms, cumulative distribution curves and corresponding Weibull distribution fitting of cracks widths for fibered slabs made with w/c of 0.5 

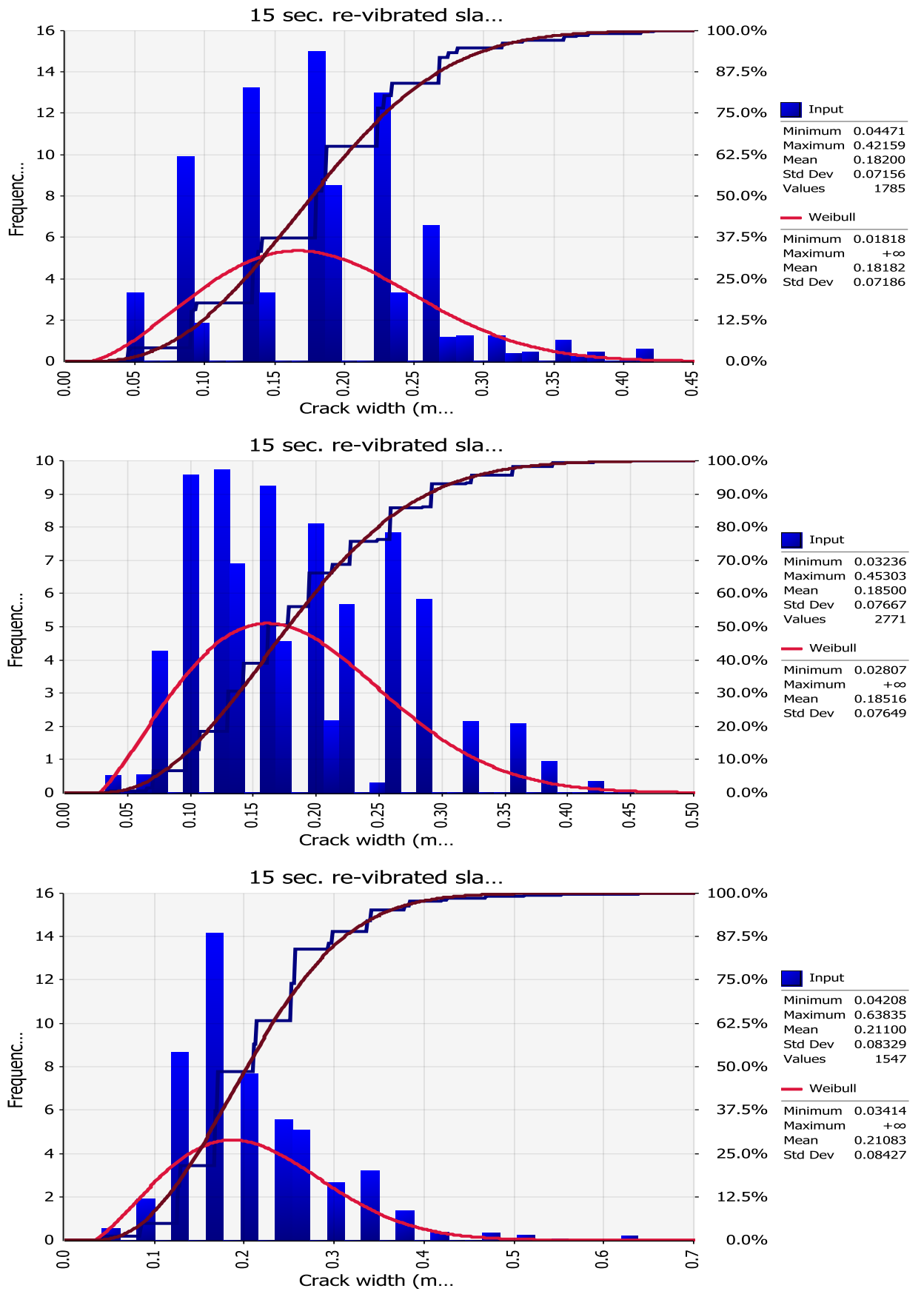

Figure D3-c: Histograms, cumulative distribution curves and corresponding Weibull distribution fitting of cracks widths for $15 \mathrm{sec}$. re-vibrated slabs made with w/c of 0.5 

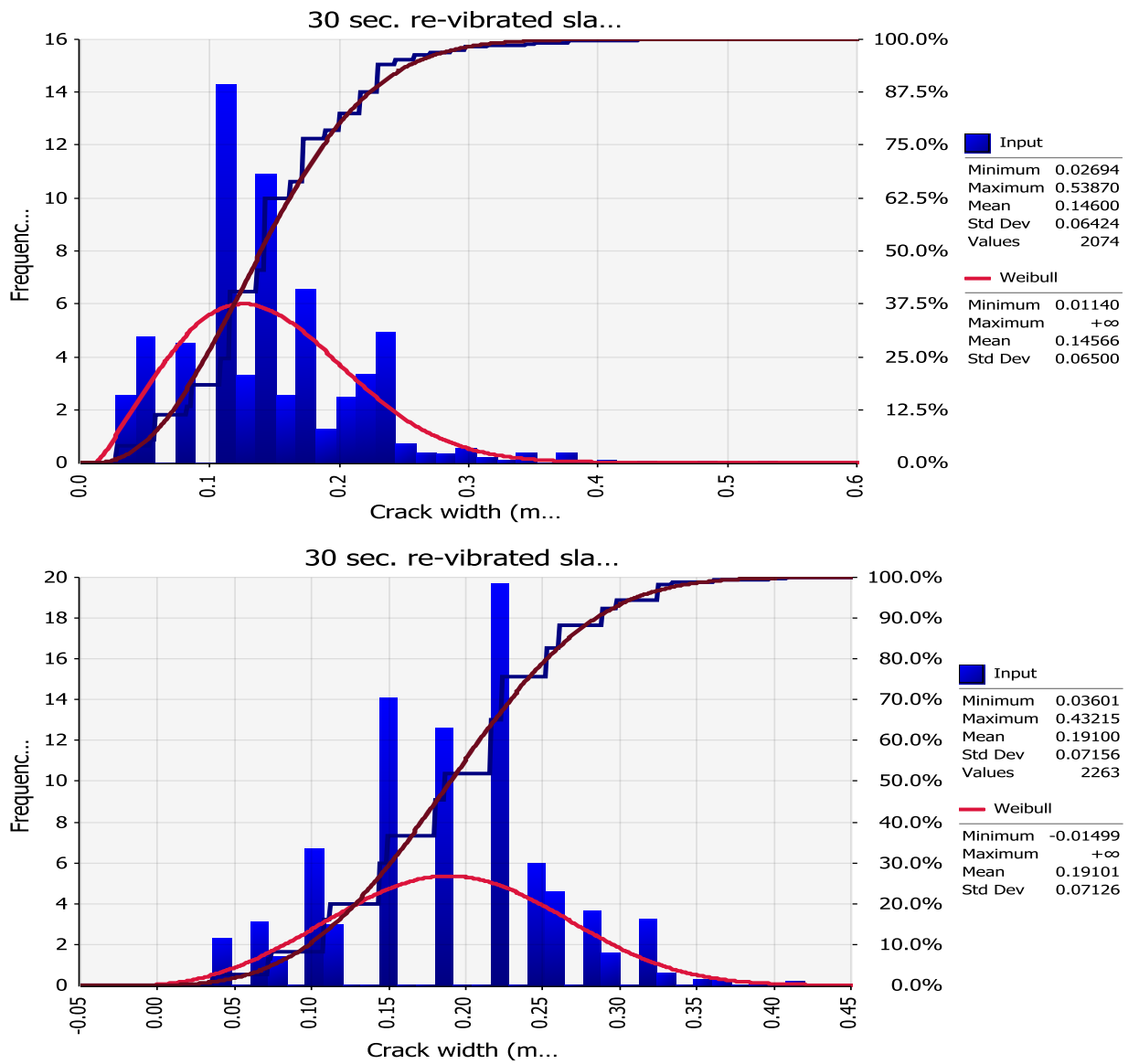

$100.0 \%$

$90.0 \%$

$80.0 \%$

$70.0 \% \quad$ Minimum 0.03601

$60.0 \%$ Maximum 0.43215

$\begin{array}{ll} & \text { Mean Dev } 0.07156\end{array}$

$50.0 \%$

$40.0 \%$

— Weibull

Minimum -0.01499

$\begin{array}{llr}30.0 \% & \text { Maximum } & +\infty \\ & \text { Mean } & 0.19101\end{array}$

$20.0 \%$

Maxt Dev 0.19712

$10.0 \%$

$0.0 \%$

30 sec. re-vibrated sla...

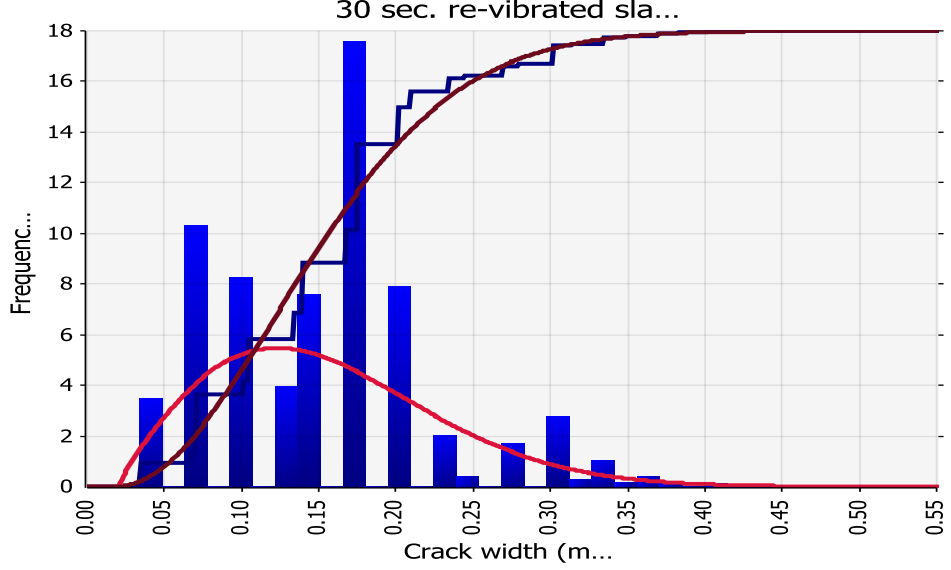

$100.0 \%$

$88.9 \%$

$77.8 \%$

$66.7 \%$ Minimum 0.03348

Maximum 0.50224

Mean 0.15500

$\begin{array}{llr}55.6 \% & \text { Std Dev } & 0.07301 \\ & \text { Values } & 1869\end{array}$

44.4\% — Weibull

Minimum 0.01968

$33.3 \%$ Maximum $+\infty$

Mean 0.15475

$22.2 \%$ Std Dev 0.07351

$11.1 \%$

$0.0 \%$

Figure D3-d: Histograms, cumulative distribution curves and corresponding Weibull distribution fitting of cracks widths for $30 \mathrm{sec}$. re-vibrated slabs made with w/c of 0.5 

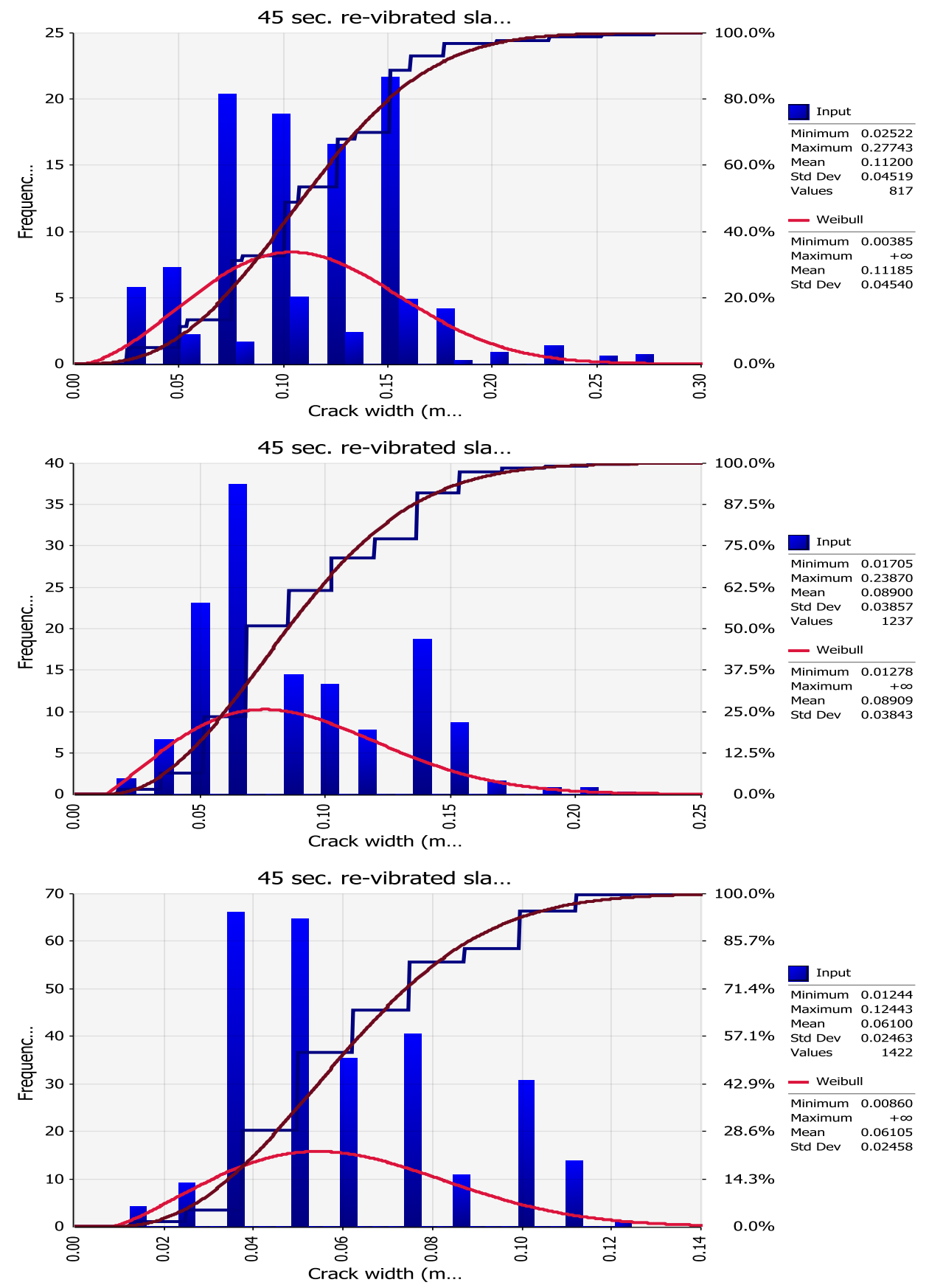

Figure D3-e: Histograms, cumulative distribution curves and corresponding Weibull distribution fitting of cracks widths for $45 \mathrm{sec}$. re-vibrated slabs made with w/c of 0.5 


\section{Vita}

Mustafa A. Aldalinsi earned his Bachelor Degree B.Sc. in Civil Engineering, Structural Engineering from Higher Institute of Engineering at Hoon, Libya in July 2003. In addition he got his Master degree M.Sc. in Civil Engineering from the University of Texas at El Paso in May 2010. His thesis in masters is "Probability Analysis of Concrete Fracture".

Mr. Mustafa A Aldalinsi has a wide experience in different disciplines of Civil Engineering in public and private sectors. He has an experience of 10 years. He worked as: Structure Engineer, Surveyor, Teaching Assistant at Misurata University, Libya and UTEP, USA.

Mr. Mustafa A Aldalinsi is currently pursuing doctoral (Ph.D.) in Civil Engineering at UTEP. His Dissertation topic is "A Method to Reduce Plastic shrinkage Cracking of Concrete Using Re-vibration Technique" under the supervision of Dr. Carlos Ferregut.

Mr. Mustafa A. Aldalinsi is planning to return back to his country after he earns his Ph.D. as a faculty member in Misurata University, Libya.

Permanent address: 21 Tripoli Street Bld. 206

Misurata, Libya 521

This dissertation was typed by Mustafa Abushaala Aldalinsi 